Universidade de São Paulo - USP

Escola de Engenharia de São Carlos - EESC

Departamento de Engenharia Elétrica

\title{
Alocação de Recursos e Roteamento de Tráfego em Telecomunicações por Meio de Algoritmo Genético: Rede Óptica WDM e Rede de Comunicação Móvel Celular
}

Autor: Marcos Antônio Cardoso de Lima

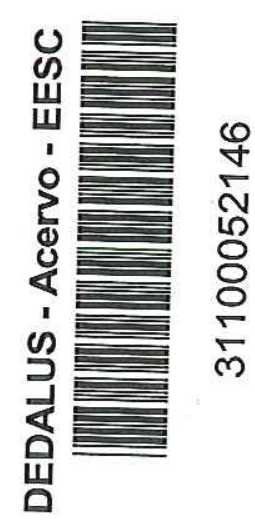

\begin{abstract}
Tese de doutorado apresentada à Escola de Engenharia de São Carlos da Universidade de São Paulo, como parte dos requisitos para obtenção do título de Doutor em Engenharia Elétrica
\end{abstract}

Orientador: Prof. Dr. Amílcar Careli César Co-orientador: Prof. Dr. Aluizio Fausto Ribeiro Araújo 
FOLHA DE JULGAMENTO

Candidato: Engenheiro MARCOS ANTÔNIO CARDOSO DE LIMA

Tese defendida e julgada em 04-03-2005 perante a Comissão Julgadora:

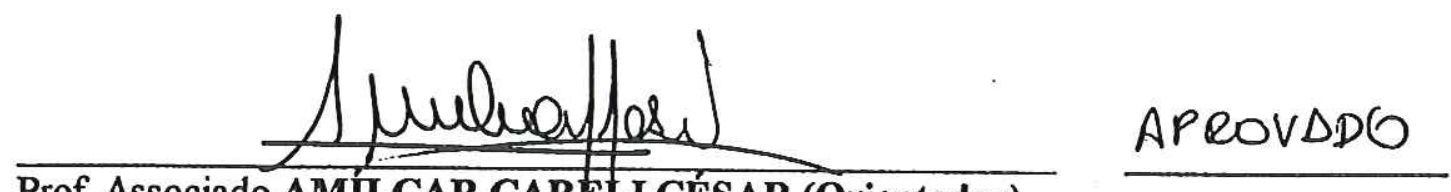

Prof. Associado AMĹLAR CARELI CÉSAR (Orientador)

(Escola de Engenharia de São Carlos/USP)

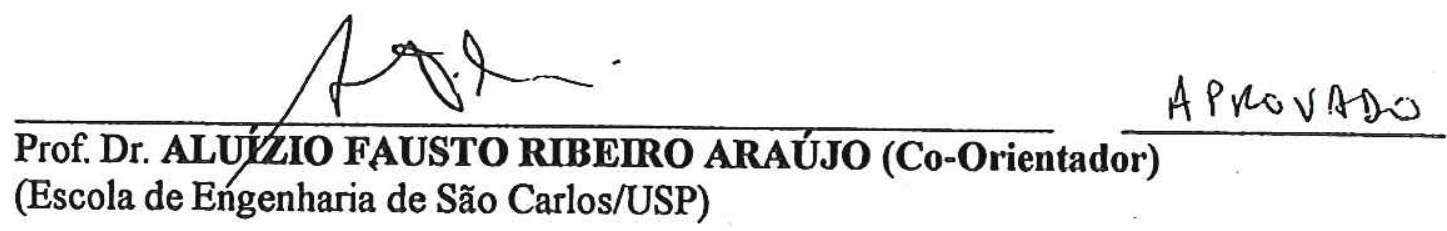

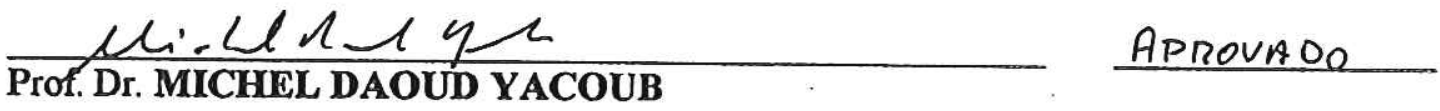

(Universidade Estadual de Campinas/UNICAMP)

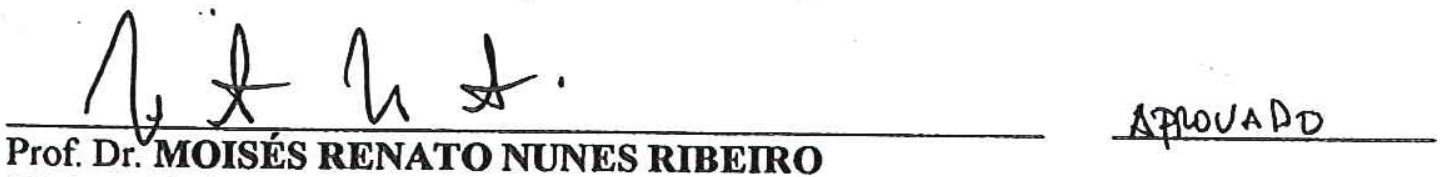

(Universidade Federal do Espírito Santo/UFES)

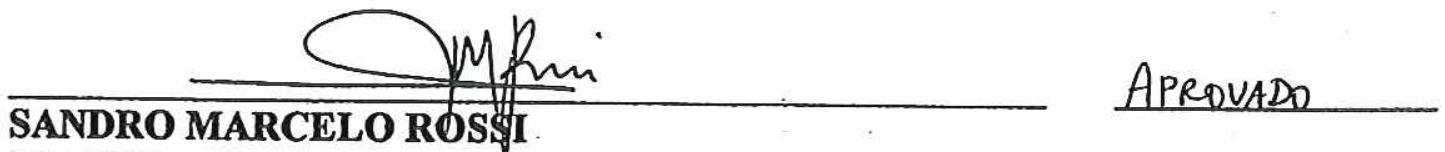

(CPqD/Campinas)

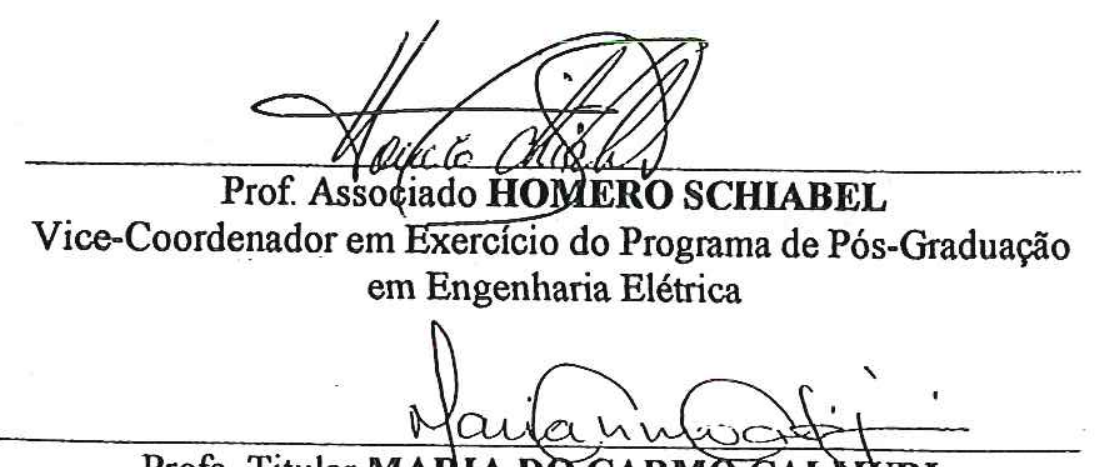

Profa. Titular MARIA DO CARMO CAL NATRI

Presidente da Comissão de Pós-Graduação 
Lima, Marcos Antônio Cardoso de

Alocação de recursos e roteamento de tráfego em telecomunicações por meio de algoritmo genético : rede óptica WDM e rede de comunicação móvel celular / Marcos Antônio Cardoso de Lima. -- São Carlos, 2005.

Tese (Doutorado) -- Escola de Engenharia de São Carlos-Universidade de São Paulo, 2005.

Área: Engenharia Elétrica.

Orientador: Prof. Dr. Amílcar Careli César.

Co-orientador : Prof. Dr. Aluizio Fausto Ribeiro Araújo.

1. RWA. 2. CAP. 3. Algoritmos genéticos. 4. Otimização. 5. Rede óptica WDM. 6. Rede de comunicação móvel celular. 7. Rede de comunicação via satélite. 8. Restrições da camada física. 9. Restrições eletromagnéticas. 10. Agregação dinâmica de tráfego. 11. Alocação de recursos em telecomunicações. I. Título. 
Kelles

A tua beleza...

A tua inteligência...

A tua transparência...

A tua alegria...

E sobretudo à tua perseverança...

Dedico! 


\section{Agradecimentos}

A Deus, pela oportunidade de viver.

Aos meus pais, Maria Madalena e José Sinésio, por tudo o que eles representam e por tudo que fizeram por mim.

A Kelles Cristina de Castro Dutra, pelo apoio, incentivo, compreensão e carinho.

Às minhas irmãs, Edel, Ellen, Elisângela e Juliana, e familiares pelo incentivo, apoio e amizade.

Ao Professor Doutor Amílcar Careli César, pela orientação, instrução, dedicação e paciência, sem os quais este trabalho não se concretizaria.

Ao Professor Doutor Aluizio Fausto Ribeiro Araújo pela co-orientação, incentivo e conhecimentos.

Aos professores Ben-Hur Viana Borges, José Carlos Sartori e Murilo Araujo Romero, pelos conhecimentos transmitidos.

Aos professores e funcionários do Departamento de Engenharia Elétrica da EESCUSP, pelo conhecimento, amizade e colaboração.

A Fundação de Amparo à Pesquisa do Estado de São Paulo - FAPESP - pelo suporte financeiro.

Aos amigos de laboratório Belini, Betiol, Carlos, Evandro, Fábio, Fernanda, Fernando, Helvécio, João Marcelo, Juliano, Licinius, Liliane, Pizolato, Raiciano, Regiane, Reinaldo, Rivail, Spadoti e Valtemir.

Aos grandes companheiros de alojamento Bruno, Robson e Cristina e amigos Gilberto, Diego, Júnior, Daniel, Carlos e tantos outros.

Aos amigos de Florianópolis Roberto, Cláudio, Jamal, Elton e Zanches pelo incentivo a este trabalho.

A todos os que contribuíram direta ou indiretamente para o sucesso desta Tese. 


\section{Resumo}

A crescente demanda por largura de faixa e o aumento exponencial do número de usuários têm exercido enorme pressão sobre as redes de telecomunicações, exigindo constante melhoria de desempenho. A tecnologia fotônica tem sido capaz de atender a boa parte desta demanda, sendo a principal alternativa para transportar quantidades elevadas de tráfego. Por outro lado, tem havido um impressionante avanço tecnológico no setor de comunicação móvel celular, com destaque para os sistemas que utilizam o esquema de reuso de freqüências como principal tecnologia.

Diante da demanda elevada, a alternativa usual de expandir os recursos proporcionalmente tem se mostrado inviável por causa do custo elevado. Assim, soluções eficientes para o problema de alocação de recursos e roteamento de tráfego (PARRT) tornaram-se uma necessidade imperiosa no projeto, expansão e gerenciamento de redes de telecomunicações. O PARRT pode ser modelado como um problema de otimização, geralmente não-polinomial, e as abordagens baseadas em algoritmo genético (AG) têm sido empregadas para solucionar esta classe de problemas para os quais as soluções heurísticas não são possíveis ou freqüentemente conduzem a resultados insatisfatórios.

Nesta pesquisa, a abordagem escolhida para resolver o PARRT em redes ópticas e de comunicação móvel celular é baseada em AG. Estratégias adicionais foram incorporadas aos algoritmos propostos para aumentar a eficiência do correspondente AG canônico e proporcionar adaptação às mudanças ocorridas no ambiente investigado. A meta principal é a redução da probabilidade de bloqueio de solicitação de conexão.

Em redes ópticas, o modelo proposto resolve o roteamento e a alocação de comprimentos de onda, determina a localização esparsa de conversores de comprimento de onda, limita o número de amplificadores em cascata, proporciona agregação dinâmica de tráfego e imparcialidade de capacidade de largura de faixa por meio de controle de admissão de conexão. Restrições da camada física como emissão espontânea amplificada e dispersão por modo de polarização são incluídas nos algoritmos.

Em redes de comunicação móvel celular, os modelos propostos resolvem o problema de alocação de canais proporcionando baixos valores de probabilidade de bloqueio de novas chamadas e de handoff. Os algoritmos incluem o efeito simultâneo de três restrições eletromagnéticas: co-canal, canal-adjacente e co-site.

Uma rede híbrida óptica e via satélite é também simulada para constatar a versatilidade dos algoritmos em gerenciar de forma integrada redes de naturezas distintas.

Resultados numéricos apresentados demonstram a potencialidade dos algoritmos propostos para gerenciar recursos e rotear tráfego em redes de telecomunicações. 


\begin{abstract}
The growing demand for bandwidth together with the exponential increase in the number of users have exerted huge pressure on the telecommunication networks, requiring constant performance improvement. Photonic technology has been capable of attending a large amount of this demand, which makes it the main alternative in high traffic transport networks. On the other hand, a remarkable technological progress has occurred in the mobile cellular communications field, which employs frequency reuse as its key technology. The usual alternative of expanding the resources proportionally to the traffic demand has proved to be impractical due to the high cost involved. Thus, efficient solutions to traffic routing and resource allocation problem (TRRAP) became an imperative requirement in design, expansion and management of telecommunication networks. The TRRAP is an optimization problem, generally non-polynomial (NP), that can be successfully modeled with genetic algorithm (GA) as opposed to heuristic solutions, since the later is either not applied or frequently lead to unsatisfactory results. In this research, the elected approach to solve the TRRAP in both optical and cellular mobile communication networks is based on GA. Complementary strategies were incorporated to the algorithms to increase the efficiency of the corresponding canonical GA. Additionally, the strategies adopted provide robustness to the GA adaptation against the changes in the investigated environment. The main goal of the proposed GA is the reduction of request-connection blocking probability.

The proposed approach is capable of handling the following tasks in WDM optical networks: routing and wavelength assignment (RWA) optimization, sparse wavelength converters arrangement, limitation of the number of cascade amplifiers, dynamic traffic grooming, and bandwidth capacity fairness through connection admission control (CAC) procedure. Physical layer constraints such as amplified spontaneous emission (ASE) and polarization mode dispersion (PMD) are also taken into account.

Two algorithms are proposed to solve the channel assignment problem (CAP) in cellular mobile communication networks, providing low values of blocking probability for new calls and handoff. The algorithms include the simultaneous effect of three electromagnetic constraints: cochannel, adjacent channel and cosite.

A hybrid optical and wireless network is also simulated to evidence the versatility of the proposed algorithm in managing integrated networks from distinct natures.

The numerical results presented throughout this work demonstrate the potentiality of the proposed algorithms in managing resources and providing traffic routing in telecommunication networks.
\end{abstract}




\section{Sumário}

1 Panorama das Redes Ópticas WDM e das Redes de Comunicação Móvel Celular 1

1.1 Introdução. . . . . . . . . . . . . . . . . . . . . 1

1.2 Rede Óptica WDM . . . . . . . . . . . . . . . . . . . . . . 2

1.2.1 Problema de Roteamento e Alocação de Comprimento de Onda

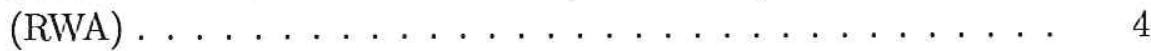

1.2 .2 Soluções para o RWA . . . . . . . . . . . . . . . 5

1.2 .3 Restrições da Camada Física . . . . . . . . . . . . . . . . . . . 10

1.3 Rede de Comunicação Móvel Celular . . . . . . . . . . . . . . . . . . . 11

1.3.1 Problema de Alocação de Canais (CAP) . . . . . . . . . . . . . 11

1.3.2 Restrições Eletromagnéticas (EMC) . . . . . . . . . . . . 12

1.3 .3 Soluções para o CAP . . . . . . . . . . . . . . . . . . . . . 12

1.4 Escopo da Pesquisa . . . . . . . . . . . . . . . . . . 15

1.4 .1 Redes Ópticas . . . . . . . . . . . . . . . . . . . . 15

1.4.2 Rede de Comunicação Móvel Celular . . . . . . . . . . . . . . . 16

1.4.3 Rede Híbrida Brasileira de Comunicação Óptica e Via Satélite 17

1.5 Artigos Publicados sobre Resultados desta Pesquisa . . . . . . . . . 17

1.6 Organização do Texto . . . . . . . . . . . . . . . . . . . . . . . . 19

2 Características das Redes Óptica e de Comunicação Móvel Celular 20

2.1 Introdução . . . . . . . . . . . . . . . . . . . . . . 20

2.2 Características das Redes . . . . . . . . . . . . . . . 21

2.2.1 Classificação das Redes de Acordo com a Dimensão Territorial 21

2.2.2 Características de Tráfego e Probabilidade de Bloqueio . . . . . 22

2.3 Redes Ópticas WDM . . . . . . . . . . . . . . . . . . . . . . . . . 23

2.3 .1 Introdução . . . . . . . . . . . . . . . . . . . . 23

2.3.2 Dispositivos Ópticos . . . . . . . . . . . . . . . . . . . . . . . . 24

2.3.3 Topologia de Rede Óptica e RWA . . . . . . . . . . . . 30

2.3.4 Restrições da Camada Física . . . . . . . . . . . . . . . . . . . 32

2.3.5 Agregação de Tráfego e Imparcialidade de Capacidade de Largura de Faixa . . . . . . . . . . . . . . . . 35

2.3 .6 Alocação de Recursos . . . . . . . . . . . . . . . . . . . . . 38

2.4 Redes de Comunicação Móvel Celular . . . . . . . . . . . . . . . . . 39

2.4 .1 Introdução . . . . . . . . . . . . . . . . . . . . . . . . 39

2.4 .2 Sistema Celular . . . . . . . . . . . . . . . . . . . 40 
2.4 .3 Handoff . . . . . . . . . . . . . . . . . . . . . . . . . . 41

2.4 .4 Restrições Eletromagnéticas . . . . . . . . . . . . . . . . . . 42

2.4.5 Esquemas Propostos de Alocação de Canais . . . . . . . . . . . 43

3 Formulação de Problema de Otimização com Algoritmos Genéticos 45

3.1 Introdução . . . . . . . . . . . . . . . . . . . 45

3.2 Formulação de Problema de Otimização . . . . . . . . . . . . . . . . 46

3.3 Descrição do Algoritmo Genético . . . . . . . . . . . . . . . . . . 47

3.3 .1 Fundamentos . . . . . . . . . . . . . . . . . . . . . . . 48

3.3.2 Componentes do Algoritmo Genético . . . . . . . . . . . . . . . 49

3.3.3 Algoritmos Genéticos Adaptáveis . . . . . . . . . . . . . . . 54

3.4 Algoritmos Genéticos Propostos . . . . . . . . . . . . . . . . . 57

3.4 .1 Rede Óptica . . . . . . . . . . . . . . . . . . . . . 57

3.4 .2 Rede de Comunicação Móvel Celular . . . . . . . . . . . . 58

3.4.3 Rede Híbrida Óptica e Via Satélite . . . . . . . . . . . . . . . 58

4 Formulação do Problema de Otimização de Recursos 59

4.1 Introdução . . . . . . . . . . . . . . . . . . . . . 59

4.2 Redes Ópticas WDM . . . . . . . . . . . . . . . . . . . . . 60

4.2.1 Modelagem de Redes e Probabilidade de Bloqueio de Conexão 60

4.2.2 Redes WDM com Conversão de Comprimentos de Onda Utilizando Algoritmos Genéticos . . . . . . . . . . . . 76

4.2 .3 Parâmetros de Simulação . . . . . . . . . . . . . . . 78

4.2.4 Inclusão das Restrições da Camada Física . . . . . . . . . . . 79

4.2 .5 Agregação Dinâmica de Tráfego . . . . . . . . . . . . . . . . . 81

4.2.6 Imparcialidade de Capacidade de Largura de Faixa e Controle de Admissão de Conexão . . . . . . . . . . . . . . . . . . . 84

4.3 Redes de Comunicação Móvel Celular . . . . . . . . . . . . . . . . 86

4.3.1 Alocação de Canais . . . . . . . . . . . . . . . . . . 87

4.3.2 Algoritmo Genético Adaptativo . . . . . . . . . . . . . . . . . 90

5 Resultados Numéricos 101

5.1 Rede Óptica . . . . . . . . . . . . . . . . . . . . . . . . . . . 102

5.1.1 Roteamento e Alocação de Comprimentos de Onda em Rede em Anel . . . . . . . . . . . . . . . . . . . . 102

5.1.2 Roteamento e Alocação de Comprimentos de Onda na Rede NSFnet . . . . . . . . . . . . . . . . 107

5.1 .3 Falhas em Equipamentos . . . . . . . . . . . . . . . 115

5.1.4 Aplicabilidade do Algorimo Genético Proposto . . . . . . . . . 117

5.1.5 Roteamento e Alocação de Comprimentos de Onda na Rede Italiana de Faixa Larga . . . . . . . . . . . . . . . . . . . . 118

5.1.6 Impacto da Inclusão das Restrições da Camada Física Sobre a Probabilidade de Bloqueio . . . . . . . . . . . . . . . . . 122

5.1 .7 Agregação Dinâmica de Tráfego . . . . . . . . . . . . . . . . . . 129

5.2 Rede de Comunicação Móvel Celular . . . . . . . . . . . . . . . . . . . 142 
5.2.1 Alocação de Canais e Comparação com Esquemas de Outros Autores . . . . . . . . . . . . . . . . . . . . . . . 142

5.2.2 Alocação Dinâmica de Canais em Sistemas com Handoff . . . . 144

5.2.3 Demanda de Tráfego com Variação Temporal . . . . . . . . . . 152

5.2 .4 Restrições Eletromagnéticas . . . . . . . . . . . . . . . . . . . 154

5.2 .5 Restrições Eletromagnéticas e Handoff . . . . . . . . . . . . . . 164

5.2 .6 Falhas em Equipamentos . . . . . . . . . . . . . . 165

5.3 Rede Híbrida Brasileira Óptica e Via Satélite . . . . . . . . . . . . . 175

5.3 .1 Requisitos da Rede Híbrida . . . . . . . . . . . . . . . 176

5.3 .2 Resultados Numéricos . . . . . . . . . . . . . . . . . 177

6 Conclusões 193

6.1 Problema . . . . . . . . . . . . . . . . . . . . . 193

6.2 Abordagem . . . . . . . . . . . . . . . . . . . . . . . 194

6.2 .1 Rede Óptica . . . . . . . . . . . . . . . . . . . . . . . . . 194

6.2 .2 Rede Móvel Celular . . . . . . . . . . . . . . . . . . . . 195

6.2 .3 Rede Híbrida . . . . . . . . . . . . . . . . . . . . . . . . 195

6.3 Resultados . . . . . . . . . . . . . . . . . . . . . . 195

6.3 .1 Rede Óptica . . . . . . . . . . . . . . . . . . . . . . . . . . 195

6.3 .2 Rede Móvel Celular . . . . . . . . . . . . . . . . . . . . . . . 196

6.3 .3 Rede Híbrida . . . . . . . . . . . . . . . . . . . . . . . . . . . . 197

6.4 Propostas para Trabalhos Futuros . . . . . . . . . . . . . . . . . 198

A Algoritmos para Coordenação de Roteamento em Redes Ópticas 214

B Problema de Estabelecimento Estático de Caminhos Ópticos 215

C Problema de Alocação de Comprimentos de Onda em Redes com Conversores 


\section{Lista de Figuras}

2.1 Conversão utilizando modulação cruzada de ganho (XGM- cross-gain modulation) em SOA nas configurações: a) co-propagante; e b) contrapropagante. Curva de resposta óptica em função da frequiência [9], [118]. TOBPF: tunable optical band pass filter. . . . . . . . . . . . . . . .

2.2 Conversão baseada em modulação cruzada de fase (XPM - cross-phase modulation), ou interferometria, empregando os arranjos: a) MachZehnder assimétrico; b) Mach-Zehnder simétrico com acoplamento assimétrico; c) Michelson; e d) NOLM (nonlinear optical loop mirror) utilizando um SOA como meio não-linear [9], [118]. . . . . . . . . . . .

2.3 Espectro do sinal na saída de amplificador óptico semicondutor (SOA) operando como conversor de comprimento de onda com técnica de mistura de quatro ondas $(\mathrm{FWM}) \ldots \ldots \ldots \ldots \ldots \ldots$

2.4 Arquitetura genérica de um roteador. Cada fibra óptica comporta $W$ comprimentos de onda. OXC: optical crossconnect. . . . . . . . . .

2.5 Arquiteturas de roteadores [17], [66]: a) share-per-node; e b) share-perlink. No estágio add-drop local os roteadores podem dispor de transceptores no domínio elétrico para realizar agregação de tráfego em taxas baixas. . . . . . . . . . . . . . . . . . .

2.6 Rede óptica roteada por comprimento de onda. Os nós de roteamento são representados por $\mathrm{S}_{1}$ e $\mathrm{S}_{2}$, e as estações ou módulos de acesso por A-E. Três caminhos são apontados neste exemplo: as interligações entre $\mathrm{D}$ e $\mathrm{A}$; entre $\mathrm{D}$ e $\mathrm{E}$; e entre $\mathrm{C}$ e $\mathrm{B}$. As rotas entre $\mathrm{D}$ e $\mathrm{E}$ e C e B são estabelecidas por meio do comprimento de onda $\lambda_{1}$, enquanto que a rota entre $\mathrm{D}$ e $\mathrm{A}$ é realizada por meio de $\lambda_{2} \ldots \ldots \ldots \ldots \ldots$

2.7 Remoção de bloqueio pelo uso de nó com conversor de comprimento de onda. O caminho entre os nós 1 e 2 é estabelecido por meio de $\lambda_{2}$, enquanto que entre 2 e 3 a conexão é feita por meio de $\lambda_{1} \ldots \ldots$. . .

2.8 Sistema de transmissão WDM e distorções introduzidas no sinal óptico.

2.9 Arquitetura genérica de um nó roteador com capacidade de agregação [77]. Cada fibra óptica comporta $W$ comprimentos de onda. OXC: $o p$ tical crossconnect. T: transmissor. R: receptor. . . . . . . . . . . . .

2.10 Modelo de rede com agregação WSXC para as seguintes requisições: 1) $\mathrm{B} \rightarrow \mathrm{E}$; 2) $\mathrm{A} \rightarrow \mathrm{F}$; 3) $\mathrm{A} \rightarrow \mathrm{G}$, necessita de um comprimento de onda diferente; e 4) $\mathrm{C} \rightarrow \mathrm{D}$, possível se forem utilizados OADMs e OXCs com reconfiguração rápida. Todas as requisições exigem capacidade $C / 4$ [79]. 
2.11 Cluster formado por $N=7 \ldots \ldots \ldots \ldots \ldots$

2.12 As três restrições eletromagnéticas consideradas na alocação de canais: co-canal, co-site e canal adjacente, para três condições particulares. As fileiras representam a vizinhança em relação a uma célula de referência. Distância co-canal $D=\sqrt{21} R . \ldots \ldots \ldots \ldots \ldots$

3.1 Algoritmo genético canônico [48]. . . . . . . . . . . . . . . . . . . . 53

3.2 Classificação dos ajustes dos parâmetros [149]. . . . . . . . . . . . 55

4.1 Probabilidade de bloqueio em função do número de enlaces de uma rota, com e sem conversores. O número de comprimentos de onda $(W)$ e a carga em cada enlace são, respectivamente: (a) $W=5$ e 1 erlang; e (b) $W=100$ e 80 erlangs [24]. . . . . . . . . . . . . . . . .

4.2 Probabilidade de bloqueio em função do número de enlaces e probabilidade de ocupação dos enlaces utilizando 8 comprimentos de onda: (a) sem conversores de comprimento de onda; e (b) após a inclusão dos conversores [61]. . . . . . . . . . . . . . . . . .

4.3 Alocação dos comprimentos de onda nos enlaces utilizando roteamento fixo com rota única para cada par origem-destino. B indica requisição bloqueada. $W=4 \ldots \ldots \ldots \ldots \ldots \ldots \ldots$

4.4 Alocação dos comprimentos de onda nos enlaces utilizando roteamento fixo com dois percursos distintos para cada par origem-destino. $W=4$.

4.5 Probabilidade de bloqueio em função do tráfego oferecido de uma rede hipotética utilizando roteamento fixo com rota única para cada par origem-destino. $W=4 \ldots \ldots \ldots \ldots \ldots$

4.6 Probabilidade de bloqueio em função do tráfego oferecido para uma rede hipotética utilizando roteamento fixo com dois percursos distintos para cada par origem-destino. $W=4 \ldots \ldots \ldots \ldots \ldots$

4.7 Algoritmo genético proposto para o RWA . . . . . . . . . . . . . .

4.8 Ambiente celular padrão hexagonal $7 \times 7$. Célula $j$ e suas correspondentes células de interferência. $R$ é o raio médio da célula e $D$ a distância de reuso co-canal. . . . . . . . . . . . . . . . . . .

4.9 (a) Número de gerações (média e desvio padrão) e tempo de simulação em função do número de indivíduos considerando $0 \%$ de aumento de tráfego para os modelos propostos GALC e GASC; e (b) Probabilidade de bloqueio em função do tempo de operação do sistema. . . . . . . . .

4.10 (a) Número de gerações (média e desvio padrão) e tempo de simulação em função do número de indivíduos considerando $20 \%$ de aumento de tráfego para os modelos propostos GALC e GASC; e (b) Probabilidade de bloqueio em função do tempo de operação do sistema. . . . . . . . .

4.11 (a) Número de gerações (média e desvio padrão) e tempo de simulação em função do número de indivíduos considerando $40 \%$ de aumento de tráfego para os modelos propostos GALC e GASC; e (b) Probabilidade de bloqueio em função do tempo de operação do sistema. . . . . . . . 
4.12 (a) Número de gerações (média e desvio padrão) e tempo de simulação em função do número de indivíduos considerando $60 \%$ de aumento de tráfego para os modelos propostos GALC e GASC; (b) Probabilidade de bloqueio em função do tempo de operação do sistema. . . . . . . . .

4.13 (a) Número de gerações (média e desvio padrão) e tempo de simulação em função do número de indivíduos considerando $80 \%$ de aumento de tráfego para os modelos propostos GALC e GASC; e (b) Probabilidade de bloqueio em função do tempo de operação do sistema. . . . . . . . .

4.14 (a) Número de gerações (média e desvio padrão) e tempo de simulação em função do número de indivíduos, considerando $100 \%$ de aumento de tráfego para os modelos propostos GALC e GASC; e (b) Probabilidade de bloqueio em função do tempo de operação do sistema. . . . . . . . . .

4.15 (a) Número de novas requisições por segundo (média e desvio padrão); e (b) Tempo de simulação por requisição em função do aumento de tráfego, parametrizada pelo número de indivíduos. Distribuição heterogênea de tráfego com média 91,83 chamadas por hora. . . . . . . . .

4.16 Desempenho do AG proposto considerando $n$-pontos para o operador cruzamento. . . . . . . . . . . . . . . . . .

4.17 Variação dos operadores genéticos cruzamento $\left(\rho_{c}\right)$, reprodução $\left(\rho_{r}\right)$ e percentual de indivíduos que sofrem mutação $\left(\eta_{m}\right)$, em função da diversidade dos pais, $P_{\text {div }} \ldots \ldots \ldots \ldots \ldots \ldots \ldots$

4.18 Melhoria do desempenho do sistema no transitório inicial e em regime estacionário com a inclusão do controle adaptativo sigmoidal. . . . . . .

4.19 Melhoria do desempenho do sistema sob variações na dinâmica do ambiente com a inclusão do controle adaptativo sigmoidal. . . . . . . . .

5.1 Rede em anel constituída por 12 nós e 12 enlaces bidirecionais [61]. . .

5.2 Probabilidade de bloqueio em função do tráfego oferecido para a rede em anel com 8 comprimentos de onda por enlace. Resultados obtidos por Vijayanand et al. [61] são mostrados para efeito de comparação. .

5.3 Ocupação média dos enlaces em função do tráfego oferecido para a rede em anel com 8 comprimentos de onda por enlace. Resultados obtidos por Vijayanand et al. [61] são mostrados para efeito de comparação. .

5.4 Comprimento médio das rotas em função do tráfego oferecido para a rede em anel com 8 comprimentos de onda por enlace. Resultados obtidos por Vijayanand et al. [61] são mostrados para efeito de comparação. 106

5.5 Rede norte-americana NSFnet constituída por 14 nós e 21 enlaces bidirecionais [22], [60], [61]. Distâncias em km. . . . . . . . . . . . . . 109

5.6 Probabilidade de bloqueio em função da demanda de tráfego oferecido para a rede NSFnet com 8 comprimentos de onda por enlace. A parametrização é feita pelo número de rotas alternativas para cada par origemdestino. Rede sem conversão (linha tracejada); e rede com conversão completa (linha contínua). . . . . . . . . . . . . . . . . . 
5.7 Probabilidade de bloqueio em função do tráfego oferecido para a rede NSFnet considerando roteamento fixo alternativo com 5 rotas possíveis e 8 comprimentos de onda por enlace. Resultados obtidos por Vijayanand [61] são mostrados para efeito de comparação. . . . . . . . . . . . . . .

5.8 Probabilidade de bloqueio em função do tráfego oferecido para a rede NSFnet considerando roteamento fixo alternativo com 5 rotas possíveis e roteamento dinâmico. Há 8 comprimentos de onda por enlace. . . . .

5.9 Ocupação média dos enlaces (\%) em função do tráfego oferecido para a rede NSFnet utilizando conversão plena, esparsa e rede sem conversão. Há 8 comprimentos de onda por enlace. . . . . . . . . . . . .

5.10 Comprimento médio das rotas (número de enlaces) em função do tráfego oferecido para a rede NSFnet utilizando conversão plena, esparsa e rede sem conversão. Há 8 comprimentos de onda por enlace. . . . . . . . .

5.11 Probabilidade de bloqueio para os algoritmos: (a) Fixo alternativo; e (b) dinâmico. Falha ocorrida no enlace entre os nós 6 e 7 durante o período das 10 às $15 \mathrm{~h}$. Tráfego homogêneo, média 70 erlangs e 8 comprimentos de onda. . . . . . . . . . . . . . . . . .

5.12 Probabilidade de bloqueio para os algoritmos (a) Fixo alternativo; e (b) dinâmico. Falha ocorrida no enlace entre os nós 6 e 7 durante o período das 10 às $15 \mathrm{~h}$. Tráfego homogêneo, média 100 erlangs e 8 comprimentos de onda. . . . . . . . . . . . . . . . . . .

5.13 Topologia da rede italiana de faixa larga constituída de 21 nós e 36 enlaces bidirecionais [69]. Distâncias em km. . . . . . . . . . . . .

5.14 Nós da rede italiana de faixa larga que devem ser equipados com conversores e o percentual de conversões realizadas. 12 comprimentos de onda por enlace e 5 rotas alternativas. (a) $\min ($ probabilidade de bloqueio); e

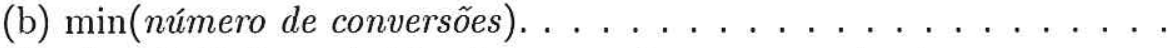

5.15 Nós da rede italiana de faixa larga que devem ser equipados com conversores e o percentual de conversões realizadas. 15 comprimentos de onda por enlace e 5 rotas alternativas. (a) $\min ($ probabilidade de bloqueio); e (b) $\min$ (número de conversões) . . . . . . . . . . . . . . . . .

5.16 Nós da rede italiana de faixa larga que devem ser equipados com conversores e o percentual de conversões realizadas. 18 comprimentos de onda por enlace e 5 rotas alternativas. (a) $\min$ (probabilidade de bloqueio); e (b) $\min$ (número de conversões) . . . . . . . . . . . . . . . . .

5.17 Probabilidade de bloqueio para a rede italiana de faixa larga em função do aumento da emanda de tráfego considerando os modelos $\min$ (probabilidade de bloqueio) e $\min ($ número de conversões). $W=12$, 15 e $18 \ldots \ldots \ldots \ldots \ldots \ldots \ldots \ldots \ldots$

5.18 Ocupação média dos enlaces (\%) para a rede italiana de faixa larga em função do aumento de demanda de tráfego e considerando os modelos $\min$ (probabilidade de bloqueio) e $\min ($ número de conversões). $W=12$, 15 e $18 \ldots \ldots \ldots \ldots \ldots \ldots \ldots \ldots \ldots$ 
5.19 Comprimento médio das rotas (número de enlaces) para a rede italiana de faixa larga em função do aumento de demanda de tráfego e considerando os modelos min(probabilidade de bloqueio) e min(número de conversôes $) . W=12,15$ e $18 \ldots \ldots \ldots \ldots \ldots \ldots \ldots$

5.20 Probabilidade de bloqueio em função do tráfego oferecido por nó para a rede italiana de faixa larga com 12 comprimentos de onda e incluíndo as restrições da camada física: (a) PMD; e (b) PMD e ASE. . . . . . .

5.21 Probabilidade de bloqueio em função do tráfego oferecido por nó para rede italiana de faixa larga com 15 comprimentos de onda e considerando as restrições de camada física: (a) PMD; e (b) PMD e ASE. . . . . . . .

5.22 Probabilidade de bloqueio em função do tráfego oferecido por nó para a rede italiana de faixa larga com 18 comprimentos de onda e considerando as restrições de camada física: (a) PMD; e (b) PMD e ASE. . . . . . . .

5.23 Tempo de simulação do AG para a rede italiana de faixa larga em função da demanda de tráfego e considerando os efeitos ASE e PMD. $W=15.128$

5.24 Probabilidade de bloqueio (\%) e imparcialidade em função da quantidade de nós com agregação de tráfego para a rede italiana de faixa larga utilizando comutadores com agregação restrita WSXC, 15 comprimentos de onda e tráfego por nó de 9 erlangs. . . . . . . . . . . . .

5.25 Probabilidade de bloqueio (\%) e imparcialidade em função da quantidade de nós com agregação de tráfego para a rede italiana de faixa larga utilizando comutadores com agregação plena WGXC, 15 comprimentos de onda e tráfego por nó de 9 erlangs. . . . . . . . . . . . . . .

5.26 Probabilidade de bloqueio (\%) e imparcialidade em função da quantidade de nós com agregação de tráfego para a rede italiana de faixa larga utilizando comutadores com agregação plena WGXC e comutadores com agregação restrita WSXC aos outros nós da rede. 15 comprimentos de onda e tráfego por nó de 9 erlangs. . . . . . . . . . . . . . . .

5.27 Ocupação média dos enlaces (\%) em função do número de nós com capacidade de agregação para a rede italiana de faixa larga. Tráfego por nó de 9 erlangs e $W=15$. As curvas com símbolos cheios representam a rede sujeita às restrições ASE e PMD. . . . . . . . . . . . . .

5.28 Comprimento médio das rotas (número de enlaces) em função do número de nós com capacidade de agregação para a rede italiana de faixa larga. Tráfego por nó de 9 erlangs e $W=15$. As curvas com símbolos cheios representam a rede sujeita às restrições ASE e PMD. . . . . . . . . . . .

5.29 Probabilidade de bloqueio em função do tráfego por célula para os esquemas FCA, Q-DCA [100], [101], BDCL [87], GALC (este trabalho) e GASC (este trabalho) . . . . . . . . . . . . . . .

5.30 Ambiente celular formado por 49 células e 70 canais disponíveis. Distribuição heterogênea de tráfego com médias: a) 91,83; e b) 106,53 chamadas por hora (valores indicados entre parênteses). As células em destaque representam a região de interferência co-canal da célula $j$, para

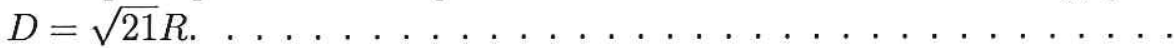


5.31 Probabilidade de bloqueio em função da demanda de tráfego para os esquemas DCA baseado em aprendizagem-Q [100], GALC (este trabalho), GASC (este trabalho) e FCA-BDCL [87]. . . . . . . . . . . . . .

5.32 Algoritmo GALC com $20 \%$ de handoff. (a) Número de gerações para convergência em função do aumento percentual de tráfego; e (b) Probabilidade de bloqueio de novas requisições em função do tempo de operação do sistema. . . . . . . . . . . . . . . . .

5.33 Algoritmo GASC com $20 \%$ de handoff. (a) Número de gerações para convergência em função do aumento percentual de tráfego; e (b) Probabilidade de bloqueio de novas requisições em função do tempo de operação do sistema. . . . . . . . . . . . . . . . . . .

5.34 Algoritmo GALC com $30 \%$ de handoff . (a) Número de gerações para convergência em função do aumento percentual de tráfego; e (b) Probabilidade de bloqueio de novas requisições em função do tempo de operação do sistema. . . . . . . . . . . . . . . . . . . .

5.35 Algoritmo GASC com $30 \%$ de handoff. (a) Número de gerações para convergência em função do aumento percentual de tráfego; e (b) Probabilidade de bloqueio de novas requisições em função do tempo de operação do sistema. . . . . . . . . . . . . . . . .

5.36 Algoritmo GALC com $40 \%$ de handoff. (a) Número de gerações para convergência em função do aumento percentual de tráfego; e (b) Probabilidade de bloqueio de novas requisições em função do tempo de operação do sistema. . . . . . . . . . . . . . . . . . . .

5.37 Algoritmo GASC com 40\% de handoff. (a) Número de gerações para convergência em função do aumento percentual de tráfego; e (b) Probabilidade de bloqueio de novas requisições em função do tempo de operação do sistema. . . . . . . . . . . . . . . . . . .

5.38 Probabilidade de bloqueio das novas chamadas em função da demanda de tráfego para os modelos GALC e GASC, considerando distribuição heterogênea de tráfego com média 91,83 chamadas por hora e taxas de handoff 0,20 e $40 \%$. . . . . . . . . . . . . .

5.39 Probabilidade de bloqueio de handoff em função da demanda de tráfego para GALC e GASC, considerando distribuição heterogênea de tráfego com média 91,83 chamadas por hora e $40 \%$ de taxa de handoff. . . . .

5.40 Número de gerações em função da demanda de tráfego para os algoritmos GALC e GASC, considerando distribuição heterogênea de tráfego com média 91,83 chamadas por hora e taxas de handoff 0, 20 e $40 \%$. .

5.41 Ocupação média dos canais (\%) em função da demanda de tráfego para os modelos GALC e GASC, considerando distribuição heterogênea de tráfego com média 91,83 chamadas por hora e taxas de handoff $0,20 \mathrm{e}$

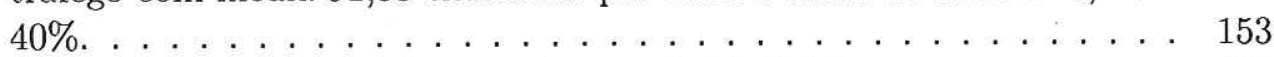

5.42 Padrão de tráfego de um dia útil típico [100], [101] . . . . . . . . . . 155

5.43 Probabilidade de bloqueio de novas chamadas dos algoritmos GALC e GASC considerando variação temporal do tráfego (Figura 5.42) e distribuição heterogênea de tráfego com média 91,83 chamadas por hora. 
5.44 Probabilidade de bloqueio de handoff dos algoritmos GALC e GASC considerando variação temporal do tráfego (Figura 5.42) e distribuição heterogênea de tráfego com média 91,83 chamadas por hora. . . . . .

5.45 Número de gerações para convergência dos algoritmos GALC e GASC considerando variação temporal do tráfego (Figura 5.42) e distribuição heterogênea de tráfego com média 91,83 chamadas por hora. . . . . .

5.46 Probabilidade de bloqueio em função do tempo para restrição co-site, $\csc \in\{1,2,3,4,5\}$, considerando $0 \%$ de aumento na demanda de tráfego. Algoritmos: (a) GALC; e (b) GASC. . . . . . . . . . . . . . . . . . . .

5.47 Probabilidade de bloqueio em função do tempo para restrição co-site, $c s c \in\{1,2,3,4,5\}$, considerando $20 \%$ de aumento na demanda de tráfego. Algoritmos: (a) GALC e (b) GASC. . . . . . . . . . . . . . . . . .

5.48 Probabilidade de bloqueio em função do tempo para restrição co-site, $c s c \in\{1,2,3,4,5\}$, considerando $40 \%$ de aumento na demanda de tráfego. Algoritmos: (a) GALC; e (b) GASC. . . . . . . . . . . . . . . . . . .

5.49 Probabilidade de bloqueio em função do tempo para restrição co-site, $c s c \in\{1,2,3,4,5\}$, considerando $60 \%$ de aumento na demanda de tráfego. Algoritmos: (a) GALC e (b) GASC. . . . . . . . . . . . . . . . . . .

5.50 Probabilidade de bloqueio em função do tempo para restrição co-site, csc $\in\{1,2,3,4,5\}$, considerando $80 \%$ de aumento na demanda de tráfego. Algoritmos: (a) GALC; e (b) GASC. . . . . . . . . . . . . . . . . . . .

5.51 Probabilidade de bloqueio em função do tempo para restrição co-site, csc $\in\{1,2,3,4,5\}$, considerando $100 \%$ de aumento na demanda de tráfego. Algori-tmos: (a) GALC; e (b) GASC. . . . . . . . . . . . . . .

5.52 Probabilidade de bloqueio para os algoritmos GALC e GASC em função da restrição co-site, parametrizada pelo aumento de demanda de tráfego com média 91,83 chamadas por hora. . . . . . . . . . . . . . . . . .

5.53 Probabilidade de bloqueio em função do tempo para diferentes restrições eletromagnéticas, considerando $0 \%$ de aumento na demanda de tráfego. Algoritmos: (a) GALC; e (b) GASC. No par ( $x y$ ), $x$ representa a $C S C$ e $y$, a $A C C . \ldots \ldots \ldots \ldots \ldots \ldots \ldots$

5.54 Probabilidade de bloqueio em função do tempo para diferentes restrições eletromagnéticas, considerando $40 \%$ de aumento na demanda de tráfego. Algoritmos: (a) GALC; e (b) GASC. No par ( $x y), x$ representa a $C S C$

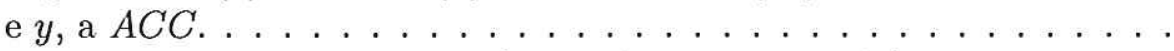

5.55 Probabilidade de bloqueio em função do tempo para diferentes restrições eletromagnéticas, considerando $60 \%$ de aumento na demanda de tráfego. Algoritmos: (a) GALC; e (b) GASC. No par ( $x y$ ), $x$ representa a $C S C$

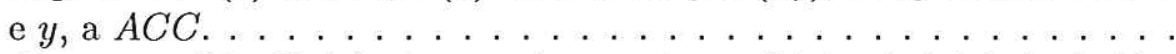

5.56 Algoritmo GALC: (a) Número de gerações; e (b) Probabilidade de bloqueio em função das restrições eletromagnéticas, considerando 0, 20, 40,80 e $100 \%$ de aumento na demanda de tráfego. No par $(x y), x$ representa a $A C C$ e $y$, a $C S C \ldots \ldots \ldots \ldots \ldots$ 
5.57 Algoritmo GALC: (a) Número de gerações; e (b) Probabilidade de bloqueio em função das restrições eletromagnéticas, considerando 0,20 , 40,80 e $100 \%$ de aumento na demanda de tráfego. No par $(x y), x$ representa a $A C C$ e $y$, a $C S C . \ldots \ldots \ldots \ldots \ldots$

5.58 Probabilidade de bloqueio de novas chamadas em função do aumento de demanda de tráfego para os algoritmos GALC e GASC. Distribuição de tráfego heterogênea com média 91,83 chamadas por hora, $20 \%$ de taxa de handoff e incluindo restrições eletromagnéticas. . . . . . . . .

5.59 Probabilidade de bloqueio de handoff em função do aumento de demanda de tráfego para os algoritmos GALC e GASC. Distribuição de tráfego heterogênea com média 91,83 chamadas por hora, 20\% de taxa de handoff e incluindo restrições eletromagnéticas. . . . . . . . . . . .

5.60 Numero de gerações em função do aumento de demanda de tráfego para os algoritmos GALC e GASC. Distribuição de tráfego heterogênea com média 91,83 chamadas por hora, $20 \%$ de taxa de handoff e incluindo restrições eletromagnéticas. . . . . . . . . . . . . . . . . . .

5.61 Ocupação média dos canais (\%) em função do aumento de demanda de tráfego para os algoritmos GALC e GASC, considerando as restrições eletromagnéticas e taxa de handoff de $20 \%$. . . . . . . . . . . . . .

5.62 Robustez dos algoritmos GALC e GASC a falhas nos canais: operação normal e ocorrência de falha em 7 canais por célula entre $10 \mathrm{e}$ 15 h. Tráfego heterogêneo, média 91,83 chamadas por hora com $80 \%$ de acréscimo. . . . . . . . . . . . . . . . . . . .

5.63 Robustez dos algoritmos GALC e GASC a falhas nos canais: ope-ração normal e ocorrência de falha em 7 canais por célula entre 10 e $15 \mathrm{~h}$. Tráfego heterogêneo, média 106,53 chamadas por hora com $60 \%$ de acréscimo. . . . . . . . . . . . . . . . . .

5.64 Probabilidade de bloqueio de handoff dos algoritmos GALC e GASC sob falhas em canais: operação normal e ocorrência de falha em 7 canais por célula entre 10 e $15 \mathrm{~h}$. Tráfego heterogêneo, média 91,83 chamadas por hora com $80 \%$ de acréscimo. . . . . . . . . . . . . . .

5.65 Probabilidade de bloqueio de handoff dos algoritmos GALC e GASC sob falhas em canais: operação normal e ocorrência de falha em 7 canais por célula entre 10 e $15 \mathrm{~h}$. Tráfego heterogêneo, média 106,53 chamadas por hora com $60 \%$ de acréscimo. . . . . . . . . . . . .

5.66 Robustez do algoritmo GASC a falhas em canais: operação normal e falhas em 7 canais no intervalo de 10 às $15 \mathrm{~h}$. Tráfego heterogêneo com médias: (A) 106,53; e (B) 91,83 chamadas por hora, com aumento de 60 e 80 por cento, respectivamente. . . . . . . . . . . . . .

5.67 Robustez do algoritmo GASC a falhas em canais: operação normal e falhas em 7 canais no intervalo de 10 às $15 \mathrm{~h}$. Tráfego heterogêneo com médias: (A) 106,53; e (B) 91,83 chamadas por hora, com aumento de 60 e 80 por cento, respectivamente. . . . . . . . . . . . . . 
5.68 Rede híbrida brasileira formada por enlaces de fibra óptica e via satélite. Os nós roteadores em destaque são equipados com estações de comunicação por satélite. A rede óptica dispõe de $W=4$ comprimentos de onda. Os enlaces em destaque possuem $W=8$ por causa da grande densidade populacional da região. Na rede via satélite há $C=4$ transceptores disponíveis. A agregação utilizada é $g=4 \ldots \ldots \ldots \ldots$. . . .

5.69 Probabilidade de bloqueio (\%) em função do aumento de demanda de tráfego para a rede híbrida brasileira. (a) Sem capacidade de agregação; e (b) utilizando comutadores com agregação plena WGXC. . . . . . . .

5.70 Probabilidade de bloqueio (\%) em função do aumento de demanda de tráfego para a rede brasileira utilizando agregação esparsa. (a) 9 WSXC e 6 WGXC; e (b) 12 WSXC e 9 WGXC. . . . . . . . . . . . . . . . . .

5.71 Tráfego médio por enlace (erlang) em função do aumento de demanda de tráfego para a rede híbrida brasileira. (a) Sem capacidade de agregação; e (b) utilizando comutadores com agregação plena WGXC. . . . . . . .

5.72 Tráfego médio por enlace (erlang) em função do aumento de demanda de tráfego para a rede híbrida brasileira utilizando agregação esparsa. (a) 9 WSXC e 6 WGXC; (b) 12 WSXC e 9 WGXC. . . . . . . . . . .

5.73 Ocupação média dos enlaces (\%) em função do aumento de demanda de tráfego para a rede híbrida brasileira. (a) sem capacidade de agregação; e (b) utilizando comutadores com agregação plena WGXC. . . . . . . .

5.74 Ocupação média dos enlaces (\%) em função do aumento de demanda de tráfego para a rede híbrida brasileira utilizando agregação esparsa. (a) 9 WSXC e 6 WGXC; e (b) 12 WSXC e 9 WGXC. . . . . . . . . .

5.75 Comprimento médio das rotas (no. de enlaces) em função do aumento de demanda de tráfego para a rede híbrida brasileira com agregação plena, esparsa e sem agregação. . . . . . . . . . . . . . . . . .

5.76 Tempo médio por atendimento de requisição $(\mathrm{ms})$ em função do aumento de demanda de tráfego para a rede híbrida brasileira com agregação plena, esparsa e sem agregação. . . . . . . . . . . . . .

B.1 (a) Grafo para o problema de $n$-coloração; (b) Translação para SLE [162]. . . . . . . . . . . . . . . . . . . . . . . . 21 


\section{Lista de Tabelas}

2.1 Classificação das redes em função da dimensão territorial [106]. . . . . .

2.2 Comprimento máximo do lance $(\mathrm{km})$ para parâmetros PMD e taxa de transmissão típicos. $a=0,1 \ldots \ldots \ldots \ldots \ldots$

2.3 Número máximo de lances imposto pela restrição $S N R_{\min } . P_{L}=4$ $\mathrm{dBm} ; \eta_{s p}=2,5 ; h \nu B_{o}=-58 \mathrm{dBm} ; \mathrm{e} G=25 \mathrm{~dB}[67] . \ldots \ldots . . .35$

3.1 Terminologia e conceitos de algoritmo genético. . . . . . . . . . . 48

4.1 Tabela de roteamento e alocação de comprimentos de onda da rota primária para as solicitações de conexão $\rho_{1}$ e $\rho_{2}$. . . . . . . .

4.2 Tabela de roteamento e alocação de comprimentos de onda das rotas primária e secundária para as solicitações de conexão $\rho_{1}$ e $\rho_{2}$. . . . .

4.3 Probabilidade de bloqueio na rede hipotética: comparação entre o modelo analítico e o AG proposto. Roteamento fixo com rota única e $W=4 . \quad 73$

4.4 Representação de um indivíduo formado por vários cromossomos. . . . 73

4.5 Probabilidade de Bloqueio para a rede hipotética: Comparação entre Modelo Analítico, AG Proposto, SP-MU e Aprendizagem-Q. Roteamento fixo com dois percursos e $W=4 \ldots \ldots \ldots$. . . . . . . . 75

4.6 Representação da política do sistema com agregação de tráfego. . . . . 83

4.7 Representação de um indivíduo formado por vários cromossomos. . . . 87

4.8 Tempo de simulação por requisição dos modelo GALC e GASC em função do tráfego oferecido parametrizado pelo número de indivíduos. 95

4.9 Procedimento dos algoritmos genéticos propostos para o problema DCA. 100

5.1 Probabilidade de bloqueio na rede em anel: comparação entre resultados do AG proposto neste trabalho e obtidos por Vijayanand et al. [61]. . 105

5.2 Ocupação média dos enlaces em função do tráfego oferecido para a rede em anel com 8 comprimentos de onda por enlace. . . . . . . . . . . . 105

5.3 Comprimento médio das rotas em função do tráfego oferecido para a rede em anel com 8 comprimentos de onda por enlace. . . . . . . . . . 107

5.4 Tempo de atendimento de requisição de comprimento de onda em função do tráfego para rede em anel com 8 comprimentos de onda. . . . . . . 108

5.5 Probabilidade de bloqueio na rede NSFnet em função do número de rotas alternativas, $n_{a} . W=8 \ldots \ldots \ldots \ldots \ldots \ldots$ 
5.6 Probabilidade de bloqueio na rede NSFnet considerando roteamento fixo alternativo com 5 rotas possíveis e $W=8$ : comparação entre resultados do AG proposto e de Vijayanand et al. [61]. . . . . . . . . . . . . .

5.7 Probabilidade de bloqueio na rede NSFnet: comparação entre roteamento fixo alternativo com 5 rotas possíveis e roteamento dinâmico. $W=8 \ldots \ldots \ldots \ldots \ldots \ldots \ldots \ldots \ldots \ldots$

5.8 Tempo de atendimento de requisição de comprimento de onda em função do tráfego oferecido para a rede NSFnet considerando roteamento fixo alternativo com 5 rotas possíveis e roteamento dinâmico. $W=8$. . . .

5.9 Ocupação média dos enlaces e comprimento médio das rotas em função do tráfego oferecido para a rede NSFnet utilizando conversão plena, esparsa e rede sem conversão. $W=8 . \ldots \ldots \ldots \ldots \ldots$

5.10 Robustez dos algoritmos fixo alternativo dinâmico para a rede NSFnet sob falha no enlace entre os nós 6 e 7: operação normal e ocorrência de falha entre 10 e 15 h. 8 comprimentos de onda. . . . . . . . . . .

5.11 Melhoria no desempenho obtida com o uso de conversores nas redes NSFnet e Anel. . . . . . . . . . . . . . . . . . . . . . . . . . .

5.12 Melhoria no desempenho obtida com o uso do algoritmo genético proposto. . . . . . . . . . . . . . . .

5.13 Probabilidade de bloqueio para a rede italiana de faixa larga considerando os modelos sem conversão, com conversão plena, $\min$ (probabilidade de bloqueio) e $\min$ (número de conversões). $W=12,15$ e 18.

5.14 Ocupação média dos enlaces para a rede italiana de faixa larga em função do tráfego oferecido para os modelos com conversão esparsa $\min$ (probabilidade de bloqueio) e $\min$ (número de conversões). $W=12$, 15 e $18 . \ldots \ldots \ldots \ldots \ldots \ldots \ldots \ldots$

5.15 Comprimento médio das rotas para a rede italiana de faixa larga em função do tráfego oferecido para os modelos com conversão esparsa $\min$ (probabilidade de bloqueio) e $\min$ (número de conversões). $W=12$, 15 e $18 \ldots \ldots \ldots \ldots \ldots \ldots \ldots \ldots$

5.16 Tempo de atendimento de requisição de comprimento de onda em função do tráfego para a rede italiana de faixa larga. $W=12,15 \mathrm{c} 18 . \ldots$. .

5.17 Localização dos conversores e compensadores de PMD na rede italiana de faixa larga. . . . . . . . . . . . . . . . . . .

5.18 Probabilidade de bloqueio na rede italiana de faixa larga com restrições da camada física ASE e PMD. $W=12 \ldots \ldots \ldots \ldots \ldots$

5.19 Probabilidade de bloqueio na rede italiana de faixa larga com restrições da camada física ASE e PMD. $W=15 . \ldots \ldots \ldots \ldots \ldots$

5.20 Probabilidade de bloqueio na rede italiana de faixa larga com restrições da camada física ASE e PMD. $W=18 \ldots \ldots \ldots \ldots \ldots$

5.21 Tempo de simulação para o atendimento de requisição de comprimento de onda em função do tráfego para a rede italiana de faixa larga. $W=15 \ldots \ldots \ldots \ldots \ldots \ldots \ldots \ldots \ldots$

5.22 Seqüencia de disposição dos nós com agregação de tráfego na rede italiana de faixa larga. . . . . . . . . . . . . . . . . . . 
5.23 Probabilidade de bloqueio (\%) para a rede italiana de faixa larga com nós WSXC. $W=15$ e tráfego oferecido por nó de 9 erlangs. . . . . . .

5.24 Probabilidade de bloqueio (\%) para a rede italiana de faixa larga com nós WGXC. $W=15$ e tráfego oferecido por nó de 9 erlangs. . . . . . .

5.25 Probabilidade de bloqueio (\%) para a rede italiana de faixa larga com nós WSXC e WGXC. $W=15$ e tráfego oferecido por nó de 9 erlangs.

5.26 Tempo médio de simulação (milissegundos) do AG para o atendimento de requisição de conexão considerando a rede italiana de faixa larga com e sem os efeitos ASE e PMD. . . . . . . . . . . . . . . . . . .

5.27 Ocupação média dos enlaces (\%) em função do número de nós com capacidade de agregação para a rede italiana de faixa larga. Tráfego por nó de 9 erlangs e $W=15 . \ldots \ldots \ldots \ldots$. . . . . . . . .

5.28 Comprimento médio das rotas (número de enlaces) em função do número de nós com capacidade de agregação para a rede italiana de faixa larga. Tráfego por nó de 9 erlangs e $W=15$.

5.29 Probabilidade de bloqueio em função do tráfego oferecido por célula, para os esquemas FCA, Q-DCA [100, 101], BDCL [87], GALC (este trabalho) e GASC (este trabalho). . . . . . . . . . . . . . . .

5.30 Probabilidade de bloqueio em função do aumento de tráfego oferecido por célula para os esquemas FCA, Q-DCA [100, 101], BDCL [87], GALC e GASC . . . . . . . . . . . . . . . . . . .

5.31 Probabilidade de bloqueio de novas chamadas para os esquemas GALC e GASC. Tráfego heterogêneo com média 91,83 chamadas por hora e taxas de handoff de 0,20 e $40 \%$. . . . . . . . . . . . . . .

5.32 Probabilidade de bloqueio de handoff para os esquemas GALC e GASC. Tráfego heterogêneo com média 91,83 chamadas por hora e taxas de handoff de 20 e $40 \%$. . . . . . . . . . . . . . . . . . . .

5.33 Média do número de gerações para os esquemas GALC e GASC. Tráfego heterogêneo com média 91,83 chamadas por hora e taxas de handoff de 0,20 e $40 \% \ldots \ldots \ldots \ldots \ldots \ldots \ldots \ldots \ldots$

5.34 Ocupação média dos canais (\%) em função da demanda de tráfego para os modelos GALC e GASC. . . . . . . . . . . . . . . . . . . . .

5.35 Probabilidade de bloqueio para os modelos GALC e GASC em função da restrição co-site, parametrizada pelo aumento de demanda de tráfego. . . . . . . . . . . . . . . . . . .

5.36 Probabilidade de bloqueio dos algoritmos GALC e GASC em função das restrições canal adjacente e co-site, parametrizada pelo aumento de demanda de tráfego. . . . . . . . . . . . . . . . . . . . .

5.37 Probabilidade de bloqueio de novas chamadas (\%) dos algoritmos GALC e GASC. Tráfego heterogêneo com média 91,83 chamadas por hora, incluindo $20 \%$ de handoff e restrições eletromagnéticas. . . . . . . . . 168

5.38 Probabilidade de bloqueio de handoff (\%) dos algoritmos GALC e GASC. Tráfego heterogêneo com média 91,83 chamadas por hora, incluindo $20 \%$ de handoff e restrições eletromagnéticas. . . . . . . . . . . . . . . . 
5.39 Numero de gerações para para os algoritmos GALC e GASC. Tráfego heterogêneo com média 91,83 chamadas por hora, incluindo $20 \%$ de taxa de handoff e restrições eletromagnéticas. . . . . . . . . . . . . . .

5.40 Ocupação média dos canais (\%) em função da demanda de tráfego para o algoritmo GASC, considerando restrições eletromagnéticas e taxa de handoff de $20 \% \ldots \ldots \ldots \ldots \ldots$. . . . . . . . . . . . .

5.41 Robustez dos algoritmos GALC e GASC a falhas nos canais: operação normal e ocorrência de falha em 7 canais por célula entre 10 e $15 \mathrm{~h}$.

5.42 Robustez do algoritmo GASC adaptativo a falhas nos canais: operação normal e ocorrência de falha em 7 canais por célula entre 10 e $15 \mathrm{~h}$. .

5.43 Distribuição demográfica do Brasil (mil habitantes) servidos pelos nós roteadores. . . . . . . . . . . . . . . . .

5.44 Probabilidade de bloqueio (\%) em função do aumento de demanda de tráfego para a rede híbrida brasileira utilizando agregação plena, esparsa e sem agregação. . . . . . . . . . . . . . . . . . .

5.45 Tráfego médio por enlace (erlang) em função do aumento de demanda de tráfego para a rede híbrida brasileira utilizando agregação plena, esparsa e sem agregação. . . . . . . . . . . . . . . . . . . . . .

5.46 Ocupação média dos enlaces (\%) em função do aumento de demanda de tráfego para a rede híbrida brasileira utilizando agregação plena, esparsa e sem agregação. . . . . . . . . . . . . . . . . . .

5.47 Comprimento médio das rotas (no. de enlaces) em função do aumento de demanda de tráfego para a rede híbrida brasileira utilizando agregação plena, esparsa e sem agregação. . . . . . . . . . . . . . . .

5.48 Tempo por atendimento de requisição (ms) em função do aumento de demanda de tráfego para a rede híbrida brasileira utilizando agregação plena, esparsa e sem agregação. . . . . . . . . . . . . . . . .

5.49 Tráfego nos enlaces mais carregados (erlang) na rede híbrida brasileira utilizando agregação plena e esparsa. . . . . . . . . . . . . . .

5.50 Uso das chaves com capacidade de agregação de tráfego (\%) na rede híbrida brasileira utilizando agregação plena e esparsa. . . . . . . . . . .

5.51 Uso dos conversores de comprimento de onda (\%) na rede híbrida brasileira utilizando agregação plena e esparsa. 


\section{Lista de Abreviaturas}

\begin{tabular}{|c|c|c|}
\hline $\mathrm{ACC}$ & adjacent channel constraint & restrição canal adjacente \\
\hline ATM & asynchronous transfer mode & modo de tranferência assíncrono \\
\hline ASE & amplified spontaneous emission & emissão espontânea amplificada \\
\hline ASP & alternate shortest path & menor caminho alternativo \\
\hline BDCL & $\begin{array}{l}\text { borrowing with directional } \\
\text { channel-locking }\end{array}$ & $\begin{array}{l}\text { FCA com empréstimo direcional } \\
\text { de canais }\end{array}$ \\
\hline CAC & connection admission control & controle de admissão de conexão \\
\hline CAP & channel assignment problem & problema de alocação de canais \\
\hline $\mathrm{CCC}$ & cochannel constraint & restrição interferência co-canal \\
\hline CSC & cosite channel constraint & restrição co-site \\
\hline DCA & dynamic channel assignment & alocação dinâmica de canais \\
\hline DFG & difference frequency generation & geração da frequiência diferença \\
\hline DWDM & dense WDM & WDM denso \\
\hline EDFA & erbium doped fiber amplifier & $\begin{array}{l}\text { amplificador a fibra dopada } \\
\text { com érbio }\end{array}$ \\
\hline EMC & $\begin{array}{l}\text { electromagnetic compatibility } \\
\text { constraint }\end{array}$ & $\begin{array}{l}\text { restrição de compatibilidade } \\
\text { eletromagnética }\end{array}$ \\
\hline ERB & radio base station & estação rádio base \\
\hline $\mathrm{FCA}$ & fixed channel assignment & alocação fixa da canais \\
\hline FWM & four-wave mixing & mistura de quatro ondas \\
\hline FWC & full-range $W C$ & $\begin{array}{l}\text { conversão plena de comprimentos } \\
\text { de onda }\end{array}$ \\
\hline $\mathrm{GA} ; \mathrm{AG}$ & genetic algorithm & algoritmo genético \\
\hline GALC & GA with locking channel & AG com canais fixos \\
\hline GASC & GA with switching channel & AG com canais reconfiguráveis \\
\hline GMPLS & $\begin{array}{l}\text { generalized multiprotocol } \\
\text { label switching }\end{array}$ & \\
\hline $\mathrm{HCA}$ & hybrid channel assignment & alocação híbrida de canais \\
\hline IA & artificial intelligence & inteligência artificial \\
\hline ILP & integer linear programming & programação linear inteira \\
\hline IP & internet protocol & protocolo de internet \\
\hline LP & linear programming & programação linear \\
\hline LWC & limited-range $W C$ & conversão para um conjunto \\
\hline
\end{tabular}


MPLS multiprotocol label switching

OADM optical add-drop multiplexer

O-E-O optical-electrical-optical

NOLM nonlinear optical loop mirror

NP non-polynomial

OXC optical cross-connect

PDFA praseodymium doped

fiber amplifier

POTS plain old telephone service

PMD polarization mode dispersion

PMX partially matched crossover

RWA routing and wavelength

assignment

SDH synchronous digital hierarchy

SNR signal to noise ratio

SOA semiconductor optical amplifier

SONET synchronous optical network

SP shortest path

TDFA thulium doped fiber amplifier

TE transversal electric

TM transversal magnetic

TOBPF tunable optical band pass filter

XGM cross-gain modulation

XPM cross-phase modulation

WA wavelength assignment

WC wavelength converter

WDM wavelength division multiplexing

WGXC wavelength grooming crossconnect

WSXC wavelength selective crossconnect multiplexador add-drop óptico

conversão óptica-elétrica-óptica

problema não-polinomial

comutador óptico

amplificador a fibra dopada com

praseodímio

antigos serviços telefônicos

dispersão por modo de polarização

cruzamento parcialmente combinado

roteamento e alocação de

comprimento de onda

hierarquia digital síncrona

relação sinal-ruído

amplificador óptico semicondutor

rede óptica síncrona

menor caminho

amplificador a fibra dopada

com túlio

modo elétrico transversal

modo magnético transversal

filtro óptico sintonizável passa-faixa

modulação cruzada de ganho

modulação cruzada de fase

alocação de comprimento de onda

conversor de comprimento de onda

multiplexação por divisão

de comprimento de onda

comutador com agregação de tráfego em comprimento de onda

comutador com agregação de tráfego seletiva em comprimento de onda 


\section{Lista de Símbolos}

\begin{tabular}{|c|c|c|}
\hline$B$ & bps & taxa de transmissão de dados \\
\hline$B_{o}$ & $\mathrm{GHz}$ & largura de faixa óptica \\
\hline$C / I c$ & $\mathrm{~dB}$ & razão portadora por interferência co-canal \\
\hline$D_{P M D}$ & $\mathrm{ps} / \sqrt{\mathrm{km}}$ & parâmetro PMD da fibra óptica \\
\hline$D / R$ & - & fator de redução de interferência co-canal \\
\hline$e_{a}$ & Erl & tráfego oferecido à rede pelo par origem-destino $a$ \\
\hline$F_{r}$ & - & relação de imparcialidade de capacidade \\
\hline$g$ & - & total de subdivisões da capacidade de largura de faixa \\
\hline$G$ & $\mathrm{~dB}$ & ganho de potência \\
\hline$\ell(k)$ & $\mathrm{m}$ & comprimento do $k$-ésimo lance de fibra óptica \\
\hline$f i t(j, k)$ & - & função de adaptação \\
\hline$L_{A}$ & - & número de amplificadores ópticos em uma rota \\
\hline M & - & número de canais de rádio \\
\hline$M_{A}$ & - & número máximo de lances em uma rota \\
\hline$N$ & - & dimensão do sistema \\
\hline$\eta_{s p}$ & - & fator de emissão espontânea \\
\hline$\eta_{m}$ & $\%$ & percentual de indivíduos submetidos à mutação \\
\hline$P_{b}$ & $\%$ & probabilidade de bloqueio de uma solicitação de conexão \\
\hline$P_{b h}$ & $\%$ & probabilidade de bloqueio de handoff \\
\hline$P_{b n c}$ & $\%$ & probabilidade de bloqueio de novas solicitações \\
\hline$p_{b}$ & $\%$ & probabilidade de bloqueio de uma requisição da classe- $b$ \\
\hline$P_{L}$ & $\mathrm{~dB}$ & potência óptica média do sinal no transmissor \\
\hline$P_{\text {div }}$ & - & diversidade dos pais \\
\hline$P_{o p}$ & - & número de indivíduos da população \\
\hline$p_{c}$ & $\%$ & probabilidade de cruzamento \\
\hline$p_{m}$ & $\%$ & probabilidade de mutação \\
\hline$p_{r}$ & $\%$ & probabilidade de reprodução \\
\hline$L_{a}^{(t)}$ & $\%$ & probabilidade de bloqueio de uma rota $a$ \\
\hline$R$ & $\mathrm{~m}$ & raio da célula \\
\hline$R_{a}^{(t)}$ & - & rota associada ao par origem-destino $a$ \\
\hline$S N R_{\min }$ & $\mathrm{dB}$ & nível mínimo aceitável para a relação sinal ruído \\
\hline$t_{h}$ & $\mathrm{~s}$ & tempo de permanência da conexão \\
\hline$W$ & - & número de comprimentos de onda \\
\hline$\Lambda$ & Erl & volume de tráfego \\
\hline$(s, d)$ & - & par origem-destino de uma solicitação de conexão \\
\hline
\end{tabular}




\section{Capítulo 1}

\section{Panorama das Redes Ópticas WDM e das Redes de Comunicação Móvel Celular}

\subsection{Introdução}

A crescente demanda por aumento da largura de faixa, oriunda da oferta de serviços como internet e vídeo interativo, e o aumento exponencial do número de usuários têm exigido constante melhoria do desempenho das redes de telecomunicações. Por conta desta demanda, os serviços de telecomunicações expandiram-se em todos os seus setores, ampliando a complexidade das redes como a de telefonia fixa, de comunicação móvel celular e de satélites. Além disso, a interligação de redes de naturezas distintas, muitas vezes operando com protocolos diferentes e cobrindo imensas áreas territoriais, tem sido outro fator determinante a pressionar, principalmente, as redes de transporte. Felizmente, a tecnologia óptica tem sido capaz de atender a boa parte desta demanda por largura de faixa, sendo a principal alternativa de rede de transporte de volumes elevados de tráfego.

Por outro lado, temos testemunhado um impressionante avanço tecnológico no setor de comunicações móveis, com destaque para os sistemas que utilizam o esquema de reuso de freqüências em áreas geográficas divididas em células. Estas redes foram originariamente concebidas para oferecer serviços de voz mas, nos últimos tempos, novas exigências têm levado à migração para sistemas mais avançados, como os de terceira (3G) [1]-[3] e quarta (4G) [4] gerações. Tais exigências são oriundas dos serviços multimídia, como envio de mensagens de texto e imagens, acesso à Internet e recepção de programas de TV, e da enorme expansão do número de usuários. Como resultado, os novos serviços e aplicações aumentaram significativamente a demanda por largura 
de faixa e acesso simultâneo ao meio de transmissão. Começam a se destacar também as redes sem fio de computadores, projetando um enorme potencial de aplicações. Entretanto, a versatilidade proporcionada pela comunicação móvel tem se defrontado em alguns serviços com largura de faixa aquém da desejada, exigindo enorme esforço tecnológico para atender à demanda. Assim, a evolução das redes de telecomunicações, baseada no crescimento do tráfego, desenvolvimento de novos serviços e avanços tecnológicos [5], transformou a infra-estrutura dos antigos circuitos telefônicos comutados (POTS- plain old telephone service) [6] em um complexo ambiente de transporte de voz e dados comutado a circuito e por pacotes [7]. Portanto, as atuais e futuras redes de telecomunicações têm exigido soluções tecnológicas que permitam atender à crescente demanda por qualidade de serviço.

A convencional expansão proporcional dos recursos físicos para atender à demanda é limitada pelo custo elevado e o gerenciamento eficaz dos recursos das redes passa a ser um dos alvos principais da pesquisa tecnológica. Neste contexto, a rede óptica deve estar provida de esquemas para gerenciar a largura de faixa, lidando com alocação de comprimentos de onda, características de dispositivos e agregação de tráfego. Equivalentemente, a rede de comunicação móvel celular deve lidar com largura de faixa reduzida, melhoria do esquema de reuso de freqüências, handoff e restrições eletromagnéticas. Portanto, a alocação dos recursos disponíveis para ampliar a eficiência e o roteamento do tráfego é característica comum às redes de telecomunicações, especialmente às redes óptica e de comunicação móvel celular. Desta forma, há similaridade entre as características das redes ópticas e de comunicação móvel celular que permite abordagem comum. São elas a engenharia de largura de faixa, via reuso de comprimentos de onda e reuso de frequiências, e as limitações dos dispositivos ópticos e as restrições eletromagnéticas. Portanto, um dos problemas enfrentados por aqueles que lidam com redes de telecomunicações é como utilizar os recursos disponíveis de forma eficiente e garantir aos usuários qualidade de scrviço? Conseqüentemente, o problema de alocação de recursos em redes de telecomunicações tornou-se tema atual de inúmeras pesquisas e as soluções, uma necessidade imperiosa no corrente estágio de expansão e gerenciamento de redes.

\subsection{Rede Óptica WDM}

Em passado recente, a alternativa escolhida para atender à demanda por largura de faixa em redes ópticas era a instalação de novas fibras. Porém, o custo elevado e o tempo de implantação envolvidos inviabilizaram esta solução na maioria dos casos. Uma outra alternativa que pode ser adotada é elevar a taxa de transmissão de canal, dado que as redes ópticas atuais utilizam somente pequena fração da largura de faixa 
disponível nos enlaces de transmissão. Entretanto, esta solução tem conduzido a uma incompatibilidade com as tecnologias atuais de comutação eletrônica, incapazes de lidar com taxas muito elevadas [8]. Além da limitação dos dispositivos eletrônicos, a operação em taxas de bits que podem alcançar $40 \mathrm{Gbps}$ acentua os efeitos causados por limitações da camada física, como a dispersão [9], [10].

Com objetivo de ampliar a utilização da imensa largura de faixa disponível nas fibras ópticas foi proposta a tecnologia de multiplexação por divisão de comprimento de onda (WDM - wavelength division multiplexing). No sistema de transmissão WDM, cada comprimento de onda constitui um canal com taxa de transmissão que pode ser compatível com a tecnologia eletrônica. Os comprimentos de onda são então justapostos e transmitidos em uma única fibra. Desta forma, a tecnologia WDM não só habilita o uso da enorme largura de faixa da fibra, como também provê a rede de canais com largura de faixa individual adequada à capacidade dos dispositivos eletrônicos convencionais de processamento de informação [11].

Os sistemas WDM evoluíram daqueles de 2 canais, por volta de 1994, para os atuais sistemas comerciais DWDM (dense WDM), de 8, 16, 32, 40, ou mais canais. Cada canal pode acomodar taxas entre 1 e $10 \mathrm{Gbps}$, compatíveis com o estágio atual de desenvolvimento tecnológico da comutação eletrônica. Esquemas DWDM futuros poderão ser compostos de até 270 canais, transportando de 1 Tbps (55 canais WDM modulados em $20 \mathrm{Gbps}$ ) [12] a 10 Tbps (270 canais WDM modulados em 40 Gbps) [13].

A versatilidade do esquema WDM vem sendo ampliada com o uso de novos tipos de dispositivos ópticos, como amplificadores, multiplexadores e demultiplexadores adddrop (OADM- optical add-drop multiplexer), comutadores ópticos (OXC- optical crossconnect) e conversores de comprimento de onda. Um componente-chave dos esquemas WDM é o amplificador óptico, com o qual foi possível ampliar as distâncias entre estações das redes sem a necessidade de qualquer tipo de regeneração cletrônica.

Em redes WDM as informações podem ser roteadas, comutadas e selecionadas com base no comprimento de onda, representando um novo marco em comunicações ópticas [14], [15]. As redes deste tipo são chamadas de redes roteadas por comprimento de onda. Em alguns nós de roteamento (estações de acesso) os sinais gerados por inúmeros assinantes podem ser multiplexados e demultiplexados. As redes roteadas por comprimento de onda que interligam as estações de acesso sem qualquer tipo de conversão óptica-elétrica-óptica (O-E-O) são chamadas de redes ópticas transparentes. Se algum estágio de conversão eletroóptica é utilizado, a rede é dita opaca e seu processamento será limitado pela capacidade dos dispositivos eletrônicos.

A eficiência das redes roteadas por comprimento de onda pode ser melhorada com o uso de conversores de comprimentos de onda. Estes dispositivos transferem os dados 
contidos em um comprimento de onda de entrada para um outro comprimento de onda de saída. Esta funcionalidade contribui para diminuir a probabilidade de bloqueio, pois permite solucionar os problemas associados aos conflitos e reuso de comprimento de onda [16], [17]. Em redes sem capacidade de conversão, uma rota estabelecida entre dois nós deve utilizar um único comprimento de onda em todos os enlaces (hops). Esta condição é conhecida como restrição de continuidade de comprimento de onda. Esta restrição pode ser evitada pelo uso de conversão de comprimento de onda [11], adicionando à rede uma importante capacidade para habilitar a ampliação modular e melhorar o desempenho [18]. Por outro lado, a inclusão dos conversores aumenta o custo e a complexidade das redes WDM e introduzem distorção no sinal. Assim devem ser disponibilizados em posições estratégicas da rede. Esta configuração esparsa dos conversores tem se mostrado fundamental para a melhoria da utilização dos recursos da rede sob condições dinâmicas de tráfego [9], permitindo que o desempenho seja próximo daquele de redes operando com conversão plena em que todos os nós são equipados com conversores.

Com o aumento da complexidade das redes, algoritmos eficientes e rápidos têm se tornado uma necessidade imperiosa no gerenciamento dos recursos. Em redes com conversão de comprimento de onda, alocar capacidade de conversão em todos os nós é, em muitos casos, opção antieconômica. Assim, algoritmos de gerenciamento devem responder também à questão crucial: quantos e em quais nós da rede os conversores precisam ser alocados para atender à demanda de tráfego e manter a rede economicamente viável?

Deste modo, algoritmos capazes de alocar comprimentos de onda, rotear o tráfego e alocar eficientemente os conversores em nós estratégicos são exigência crucial para tornar as redes técnica e economicamente viáveis.

\subsubsection{Problema de Roteamento e Alocação de Comprimento de Onda (RWA)}

Uma vez estabelecido um conjunto de demandas (solicitações de conexão), é preciso rotear cada demanda e atribuir a ela um canal no sistema particular de transporte óptico. No caso, este canal é um comprimento de onda. Este processo é conhecido como alocação de comprimento de onda (WA- wavelength assignment). O processo de rotear e alocar comprimentos de onda é conhecido como roteamento e alocação de comprimento de onda (RWA - routing and wavelength assignment). O objetivo do RWA é alocar os recursos disponíveis para satisfazer da melhor forma possível os requisitos impostos. O RWA é um problema de otimização, tendo sido investigado a partir de várias abordagens [19]-[22]. 


\subsubsection{Soluções para o RWA}

Existem duas variações para a solução do problema RWA [23]: a estática, nas quais as solicitações de conexão são previamente conhecidas; e a dinâmica, nas quais os caminhos ópticos são estabelecidos de acordo com a demanda variável de solicitações de conexão. Entretanto, em situações reais pode existir alguma combinação de ambos os casos [11]. Diversos pesquisadores analisaram as soluções estáticas para os métodos do menor caminho (SP - shortest path) e do menor caminho alternativo (ASP - alternate shortest path) [24]-[26]. Embora estes métodos possuam uma implementação simples, eles não permitem que o desempenho da rede seja melhorado em termos da probabilidade de bloqueio, pois os menores caminhos são previamente determinados, e as solicitações são atendidas sem considerar informações do estado corrente (atual) da rede. Por outro lado, os resultados apresentados por [22], [26]-[29] mostram que métodos dinâmicos podem melhorar significativamente o desempenho da rede se comparados aos métodos SP e ASP. Nos modelos dinâmicos, todos os caminhos possíveis entre origem e destino são computados on-line ou off-line, e um deles é selecionado de acordo com um conjunto de critérios específico.

Para obter o melhor desempenho, o roteamento e a alocação de comprimento de onda devem ser considerados simultaneamente (RWA) [23]. Porém, ao se considerar o número máximo de caminhos ópticos, o problema torna-se não-polinomial (NPnon-polynomial) [30]. Assim, na tentativa de solucionar o RWA, foram elaborados métodos analíticos aproximados, obtidas formulações baseadas em programação linear, propostos métodos probabilísticos e desenvolvidos vários algoritmos heurísticos.

\section{Resultados Analíticos para o RWA}

O cálculo da solução exata para um problema RWA é computacionalmente dispendioso, exceto para redes pequenas. Uma forma de contornar esta dificuldade computacional é empregar relaxação em certas restrições na correspondente formulação linear. Assim, diversos autores determinaram limites para diferentes parâmetros como comprimentos de onda, número de conversores e congestionamento.

Aggarwal et al. [31], [32] apresentam o limite superior para roteamento considerando permutação de enlaces em uma rede com $N$ nós utilizando $O(\sqrt{N \log N})$ comprimentos de onda. São considerados dois tipos de redes sem bloqueio: a configurável, na qual as conexões existentes são redistribuídas para atender às novas solicitações, e a de sentido amplo (wide-sense), na qual as conexões já estabelecidas não podem ser alteradas.

Barry e Humblet [33] demonstram que no roteamento oblivious, cuja comunicação precisa utilizar um comprimento de onda de um número fixo $(k<W)$, o número de 
comprimentos de onda ótimo é $\lceil N / 2\rceil+2$, sendo $W$ o número total de comprimentos de onda e $N$ o número de nós da rede.

Ramaswami e Sivarajan [34] propõem um limite superior para o processamento (ou limite inferior para o congestionamento), de qualquer topologia lógica para uma dada matriz de distribuição de tráfego. Também determinam um limite inferior para o número de comprimentos de onda. As restrições de topologia física e os limites do número de comprimentos de onda são ignorados na derivação.

Banerjee e Chen [35] apresentam melhorias na solução de problemas de topologia em árvore de fluxo mínimo baseado no limite inferior do congestionamento. A topologia física consiste em nós roteadores interconectados pelas fibras, enquanto a topologia virtual consiste em um conjunto de caminhos ópticos. Por simplicidade, é adotada que a topologia virtual é regular com grau nodal $d$, cada um dos nós associado a um número $d$ de enlaces. Primeiramente, é determinada uma topologia virtual que maximiza o tráfego com percurso único. Em seguida, é determinada a topologia virtual que maximiza o tráfego utilizando dois enlaces. Este processo é repetido até todo o tráfego ser roteado.

\section{Formulações Baseadas em Programação Linear}

Várias formulações baseadas em programação linear inteira (ILP - integer linear programming) têm sido propostas para solucionar o RWA. Entretanto, estas formulações são computacionalmente dispendiosas, limitando sua utilização a redes pequenas. Assim, as formulações são freqüentemente simplificadas por meio da relaxação ou eliminação de certas restrições para se obter soluções aproximadas. Em alguns casos, a seleção da rota e a alocação do comprimento de onda são separadas para tornar o problema solucionável.

Ramaswami e Sivarajan [36] determinaram um limite superior para o tráfego transportado considerando um conjunto fixo de conexões a ser estabelecido, e obtiveram uma formulação ILP. A partir da relaxação de algumas restrições é obtida uma formulação em programação linear (LP — linear programming), cuja solução fornece um limite superior para o número de conexões que podem ser realizadas com sucesso.

Banerjee e Mukherjee [37] apresentam algoritmos para o projeto de topologias virtuais otimizadas baseada em caminhos ópticos como um problema de otimização em ILP.

\section{Formulações Baseadas em Modelos Probabilísticos}

As abordagens baseadas na análise da probabilidade de bloqueio para redes com conversão plena ou sem conversão mostram a dificuldade para se obter uma correlação 


\section{Panorama das Redes Ópticas WDM e das Redes de Comunicação}

Móvel Celular

precisa entre as demandas de cargas.

Kovacevic e Acampora [24] apresentam um modelo para calcular a probabilidade de bloqueio aproximada com distribuição de Poisson para o tráfego. Este modelo não é apropriado para redes com topologias esparsas, pois não considera a correlação do uso dos comprimentos de onda entre os sucessivos enlaces de uma rota.

Barry e Humblet [38] apresentam um novo modelo considerando esta dependência. Entretanto, consideram que um comprimento de onda é utilizado em um enlace com uma probabilidade fixa independentemente dos outros comprimentos de onda e, desta forma, é ocultada a natureza dinâmica do tráfego.

Birman [25] considera distribuição de Poisson para o tráfego e utiliza um modelo da cadeia de Markov com estados dependentes para as taxas de chegada. É um modelo mais preciso, porém o cálculo das probabilidades de bloqueio é extenso e a análise é tratável somente para redes com um pequeno número de nós.

\section{Métodos Heurísticos}

Os métodos heurísticos são algoritmos que não apresentam garantia de determinação da solução ótima de um problema, mas são capazes de retornar uma solução de qualidade em um tempo adequado para as necessidades da aplicação.

Ramaswami e Sivarajan [36] propõem um algoritmo em que o conjunto dos menores caminhos entre o par origem-destino e seus comprimentos de onda são ordenados aleatoriamente. Para atender a uma solicitação de conexão é escolhido o primeiro caminho mais curto com um comprimento de onda disponível e, se não for possível, a solicitação é bloqueada.

Mukherjee et al. [39] iniciam a solução do RWA com uma configuração de rede virtual aleatória. Em seguida, é executada uma série de operações de troca de nós, obedecendo os nós adjacentes, até se obter o menor atraso médio total. Os estágios aleatórios iniciais permitem obter configurações diferentes, evitando situações de mínimo local. Determinada a topologia virtual, é utilizada uma aproximação otimizada para a atribuição do comprimento de onda.

O algoritmo proposto por Zhang e Acampora [40] atribui iterativamente cada comprimento de onda a todas as conexões possíveis, satisfazendo as restrições físicas. O objetivo é maximizar a quantidade de tráfego de um percurso único. Os comprimentos de onda são atribuídos às conexões em ordem decrescente de demanda de tráfego.

Harai et al. [21] propõem um algoritmo heurístico para minimizar a probabilidade global de bloqueio pela distribuição apropriada dos nós com conversores de comprimento de onda. 


\section{Panorama das Redes Ópticas WDM e das Redes de Comunicação}

Móvel Celular

\section{Modelos Utilizando Algoritmo Genético (AG)}

O problema de alocação de recursos em redes de telecomunicações, em particular o RWA, pode ser modelado como um problema de otimização dinâmica com restrições em grande escala em um ambiente estocástico. Para esta classe de problemas, os métodos de resolução que utilizam aprendizagem, como algoritmos evolucionários [41], aprendizagem por reforço [42]-[45], busca em inteligência artificial (IA) [46] e redes neurais [47], são mais aptos para encontrar uma solução adequada do que os métodos que não consideram auto-adaptação do algoritmo. As abordagens baseadas em algoritmo genético (AG) têm sido empregadas para solucionar problemas para os quais as soluções heurísticas não são possíveis ou freqüentemente conduzem a resultados insatisfatórios [48]-[57]. O AG é uma técnica de otimização inspirada na teoria da evolução pela seleção natural proposta por Darwin, sendo capaz de resolver de forma eficaz problemas NP-completos com múltiplas restrições. O uso de AG demanda poucos requisitos: um mapeamento entre o espaço de busca e os cromossomos, um conjunto de operadores genéticos e uma função de adaptação. As soluções ótimas ou sub-ótimas são obtidas entre os descendentes dos indivíduos mais adaptados, de tal forma que seus atributos tendem a ser preservados nas gerações seguintes [48]. Além disso, o AG é robusto, não requer o conhecimento prévio da solução do problema como os métodos de aprendizagem clássicos que necessitam de uma solução off-line, é apropriado para a adaptação de parâmetros, pode aprender com as mudanças no ambiente e pode gerar simultaneamente diversas soluções aproximadas.

Os AGs apresentam como aspectos positivos: elevada capacidade de generalização, o que contribui para ampliar a utilidade dos algoritmos em diferentes sistemas sem grandes dificuldades de ajustes paramétricos; capacidade de aprendizagem- o algoritmo avalia e armazena as informações do ambiente; e capacidade de adaptação às variações dinâmicas do ambiente - o algoritmo é capaz de se ajustar de forma otimizada às novas situações. Adicionalmente, os AGs apresentam paralelismo implícito, isto é, em cada passo de tempo avaliam simultaneamente todas as soluções, em contraste com outros métodos de inteligência computacional, como aprendizagem por reforço, que em cada passo de tempo escolhem e adaptam uma única solução. Não obstante à robustez deste processo, o uso do AG canônico em sistemas dinâmicos pode fornecer soluções inadequadas caso sejam necessários longos períodos para o algoritmo aprender ou se adaptar às mudanças do ambiente. Para superar esta falta de eficiência, outros mecanismos devem ser adicionados aos operadores do AG canônico.

C. Rose e Yates [58] utilizam AGs para solucionar o problema de admissão de solicitação de serviço em redes de comunicação. São apresentadas três diferentes políticas de admissão, as quais apresentaram, para pequenos problemas, resultados compara- 


\section{Panorama das Redes Ópticas WDM e das Redes de Comunicação}

Móvel Celular

dos aos obtidos pelas políticas ótimas derivadas do processo de decisão de Markov. Para grandes problemas, exibiram desempenho comparável ao melhor algoritmo com política de reserva.

Gazen e Ersoy [59] propõem a otimização das topologias e alocação do fluxo de tráfego em redes multipercurso utilizando AG. O AG proposto considera as topologias como indivíduos de sua população. O algoritmo é testado com diferentes conjuntos de parâmetros e tipos de matrizes de tráfego. Estes testes mostram que as soluções encontradas pelo AG são similares e, em alguns casos, melhores do que aqueles encontrados pelos algoritmos heurísticos existentes.

Saha et al. [60] apresentam um algoritmo meta-heurístico para adaptar uma topologia virtual à rede física considerando limitado o número de comprimentos de onda suportados em cada fibra. Neste trabalho, os autores demonstram o uso do AG padrão com codificação por cromossomos para encontrar um caminho virtual otimizado, para uma dada topologia física e uma matriz de tráfego, cujo objetivo é maximizar o processamento e minimizar o atraso. Também é apresentado um estudo sobre os efeitos da ampliação modular de vários parâmetros, como atrasos no enfileiramento, atrasos de propagação e distância média dos enlaces com o aumento no processamento.

Vijayanand et al. [61] propõem novas formulações em ILP para reduzir o número das conversões na solução do problema de roteamento e alocação do comprimento de onda em sistemas estáticos e dinâmicos, e incluem AGs para posicionar otimamente os conversores nas redes ópticas roteadas por comprimento de onda, com o objetivo de reduzir a probabilidade de bloqueio e a distorção do sinal óptico. Foi observado que se conversores com conversão limitada forem otimamente posicionados em alguns nós, a rede pode exibir praticamente a mesma probabilidade de bloqueio que se fosse adotado o uso de conversores com capacidade de conversão plena colocados em todos os nós. Também, foi observado que o aumento de conversores a partir do número ótimo contribui apenas para uma melhoria marginal na probabilidade de bloqueio.

Na proposta apresenta por Chou et al. [49] para a solução dos problemas de roteamento, os AGs são utilizados para determinar uma topologia em árvore otimizada, conhecendo-se os custos entre os nós e as restrições de grau nodal.

Bisbal et al. [62] apresentam um algoritmo genético capaz de resolver o problema RWA dinâmico. O algoritmo obtém reduzida probabilidade de bloqueio com reduzidos tempos de simulação. Além disso, é capaz de fornecer imparcialidade entre conexões, apresentando qualidade do serviço similar para todos os pares origem-destino. Apresentam ainda uma extensão do algoritmo para tolerância a falhas, atribuindo um caminho óptico reserva para cada conexão. As redes analisadas não incluem conversores de comprimentos de onda. 
Siregar et al. [63] propõem um AG para otimizar a disposição de um determinado número de conversores. A configuração ótima é obtida para a situação que apresenta mínima probabilidade de bloqueio. O algoritmo é aplicado a duas redes japonesas reais, Ibiraki e Kanto com 14 e 82 nós, respectivamente. Em ambos os casos obtém-se a solução otimizada com um pequeno número de gerações.

\subsubsection{Restrições da Camada Física}

A modelagem das redes de telecomunicações tem sido tradicionalmente realizada por meio de abordagens isoladas, divididas em predição-fluxo do tráfego, topologia, comutação, transmissão e desempenho. Atualmente, o desafio-chave é produzir modelos que consideram todos os elementos envolvidos. É necessária uma visão global para gerenciar o acentuado aumento e complexidade da infra-estrutura das telecomunicações. Modelos que forneçam um quadro razoável do estado de redes mais complexas e que possam gerenciar com eficiência os diversos elementos agregados são o grande desafio.

Adicionalmente, o impacto sobre o desempenho de redes ópticas, causado por restrições da camada física (impairments), oriundas de dispositivos e fibra óptica não era considerado na maioria das propostas para solução do problema RWA [11], [17], [64]-[66]. Entretanto, os problemas apresentados na transmissão não podem ser desprezados nos algoritmos de roteamento para redes WDM transparentes, conforme sugerido por pesquisas recentes [67]-[73]. É possível que em redes ópticas WDM operando em grandes áreas de cobertura existam caminhos ópticos com características de transmissão abaixo do aceitável. Se este for o caso, algum esquema da regeneração deve ser adicionado aos trajetos. Se conversores óptico-elétrico-óptico (O-E-O) forem empregados, a arquitetura de rede passará a ser opaca [68], constratando com a rede totalmente óptica, que não utiliza dispositivos O-E-O.

Por outro lado, as novas funcionalidades da camada óptica incluem a agregação (grooming) de tráfego, composto por diferentes solicitações de capacidade de largura de faixa [74]-[78], e imparcialidade (fairness) de capacidade [79], pois as solicitações que demandam frações maiores de capacidade estão sujeitas a probabilidade de bloqueio mais elevada. Esquemas combinando as duas técnicas, agregação de tráfego e imparcialidade de capacidade, podem ser utilizados em conjunto com algoritmos de RWA com intuito de reduzir a probabilidade de bloqueio de solicitações de conexão. Por exemplo, Thiagarajan e Somani [79] propuseram um esquema de controle de admissão de conexão (CAC - connection admission control) utilizando agregação de tráfego com base em dois tipos de nós de rede: seletivos em comprimento de onda (WSXC- wavelength selective crossconnect) e com agregação em comprimento de onda (WGXCwavelength grooming crossconnect). 
Quanto à topologia física das redes, não obstante o uso de diversas técnicas, grande parte dos problemas de agregação de tráfego investigados utilizaram redes em anel [74], [79], mas as topologias do tipo malha também já começam a ser focalizadas [75]-[78].

Os resultados de abordagens que utilizam algoritmos genéticos para o roteamento e alocação de comprimentos de onda em redes ópticas demonstram que a metodologia é bastante promissora. O objetivo desta pesquisa é desenvolver modelos baseados em AG para resolver o RWA em sistemas de comunicação WDM com comportamento dinâmico, priorizando a redução da probabilidade de bloqueio de solicitações de conexão, garantindo a qualidade do sinal óptico e minimizando os custos e dispositivos empregados. Adicionalmente, os modelos proporcionam imparcialidade de capacidade de transmissão e promovem agregação de tráfego. Para demonstrar a vesatilidade do algoritmo proposto, os modelos consideram restrições da camada física como ASE e PMD. Adicionalmente, outras restrições podem ser incluídas de forma similar.

\subsection{Rede de Comunicação Móvel Celular}

A demanda por largura de faixa e o acesso múltiplo ao meio de transmissão têm exigido a realização de grande esforço para melhorar a eficiência do reuso dos canais, que é amplamente empregado como estratégia-chave para gerenciar o limitado espectro eletromagnético alocado aos sistemas de comunicações móveis celulares. De acordo com a técnica de reuso do canal, uma área geográfica de cobertura é dividida em células de tal maneira que canais idênticos podem ser alocados simultaneamente às chamadas em células distintas. Entretanto, o esquema de reuso de canal gera interferências que podem degradar a qualidade da transmissão. Assim, a alocação de canais nas células deve atender às restrições eletromagnéticas (EMC- electromagnetic compatibility). Além disso, uma chamada alocada no sistema de células pode requisitar handoff, isto é, deve permanecer conectada durante o deslocamento do equipamento móvel de um célula para outra.

\subsubsection{Problema de Alocação de Canais (CAP)}

A necessidade de algoritmos eficientes para resolver o problema de alocação de canais (CAP - channel assignment problem) nos sistemas de comunicação móveis é imperiosa e tem recebido significativa atenção [80]-[103].

O CAP pode ser compreendido como um problema de otimização dinâmica, em ambientes estocásticos, considerando vários objetivos e restrições. Os esquemas de alocação de canais em sistemas de comunicação celular podem ser classificados de acordo com a distribuição dos canais no ambiente celular em: alocação fixa da canais 
(FCA - fixed channel assignment), alocação dinâmica de canais (DCA - dynamic channel assignment) e alocação híbrida de canais (HCA- hybrid channel assignment), uma combinação de esquemas FCA e DCA [103].

No esquema FCA, um conjunto de canais é alocado permanentemente a uma célula para seu uso exclusivo. O mesmo conjunto pode ser designado a outras células, de acordo com a restrição de distância de reuso de canal. Esta distribuição uniforme de canais é eficiente se a distribuição do tráfego for também uniforme. Na maioria dos casos, o número de canais alocados à célula é ajustado de acordo com a demanda, por meio de alocação não-uniforme ou de empréstimo de canais [103].

No esquema DCA, qualquer canal pode ser utilizado pelas células para atender a uma solicitação, desde que satisfaçam às restrições eletromagnéticas. No esquema DCA por busca exaustiva, para cada canal $k$ disponível na célula $j$ existe um custo de alocação associado $c(k, j, t)$. Quando surge uma nova solicitação, o sistema indica o canal $k^{*}$ com o mínimo custo,

$$
k^{*}=\arg \left\{\min _{k} c(k, j, t)\right\} .
$$

Para melhorar o desempenho, empregam-se critérios adicionais como disponibilidade máxima de canais, máxima interferência, ou danos mínimos ao sistema. Por exemplo, a estratégia de disponibilidade máxima, denominada MAXAVAIL [104], apresenta o melhor desempenho em ambientes sem a presença de handoff. O método seleciona o canal $k^{*}$ que maximiza o número total de canais disponíveis em todo o sistema. Entretanto, em grandes espaços de estados os métodos de busca exaustiva exigem grande esforço computacional.

\subsubsection{Restrições Eletromagnéticas (EMC)}

O esquema de reuso de canal gera interferências que podem degradar a qualidade da transmissão. Tais interferências compreendem a interferência co-canal e de canal adjacente. A interferência co-canal ( $\mathrm{CCC}$ - cochannel constraint) ocorre devido ao uso simultâneo de um mesmo canal em células vizinhas. A interferência por canal adjacente é causada pelo uso simultâneo de canais adjacentes na mesma célula, restrição co-site (CSC - cosite channel constraint) ou em células vizinhas, restrição canal adjacente (ACC- adjacent channel constraint) [80].

\subsubsection{Soluções para o CAP}

A alocação de canais em sistemas celulares apresenta comportamento dinâmico com um elevado grau de correlação entre os canais, e algoritmos para resolver o CAP devem ter a versalidade de ajustar prontamente seus parâmetros às variações do ambiente, 
incluindo falhas nos canais. Vários autores propuseram algoritmos heurísticos para resolver FCA [85]-[96] e DCA [97]-[102]; investigaram o impacto no desempenho do sistema das restrições de EMC [89]-[94]; e analisaram o desempenho do sistema em atender às solicitações de handoff [81]-[86], [98]. Entretanto, ainda não foram apresentados algoritmos heurísticos adaptáveis para o método DCA no ambiente celular que consideram simultaneamente o handoff e as três restrições eletromagnéticas.

Dentre as várias soluções propostas para resolver o CAP, Zhang e Yum [87] consideraram uma estratégia FCA com empréstimo direcional de canais (BDCL-borrowing with directional channel-locking). Nesse modelo, uma dada célula que usa todos os seus canais nominais pode pedir canais livres de suas células vizinhas para atender a novas solicitações, caso o empréstimo não interfira nos canais previamente alocados. Entretanto, se muitas células operarem sob tráfego elevado, o empréstimo de um canal pode redundar em múltiplos empréstimos. Conseqüentemente, o desempenho do esquema diminui, pois existe uma penalidade associada a cada empréstimo de canal.

Alternativamente, as aproximações baseadas em inteligência computacional, como a aprendizagem por reforço, a busca heurística orientada, as redes neurais e os algoritmos evolucionários [92], são atualmente empregadas para resolver esta classe de pro-blema com resultados promissores [100], [101]. A aprendizagem-Q aplicada ao esquema DCA é a base da estratégia proposta por Nye e Haykin [100], [101]. Na aprendizagem- $Q$, os agentes interagem com o ambiente e aprendem como agir de forma otimizada, isto é, aprendem a determinar a alocação para o canal ótimo $k^{*}$ com a maior recompensa acumulada em todos os estados futuros. Os valores $Q$ são primeiramente aprendidos off-line, por um período de tempo suficientemente longo, sendo armazenado nas tabelas para guiar as atribuições. O desempenho obtido com o uso da estratégia de aprendizagem-Q é similar à estratégia MAXAVAIL [104].

\section{Modelos Utilizando Algoritmo Genético (AG)}

O uso de AG para resolver o CAP foi investigado por diversos autores [92]-[97] e os algoritmos propostos incluem FCA [92]-[96], DCA [97], o efeito das restrições de EMC (CCC, ACC, e CSC) na probabilidade de bloqueio de novas chamadas [92]-[94], e o controle de admissão de chamadas [86], [95]. Não obstante a robustez dos AGs, o uso do modelo canônico em DCA pode fornecer soluções inadequadas, já que pode necessitar de longos períodos para aprender ou para se adaptar às mudanças do ambiente. Assim, algumas características devem ser fornecidas para superar a falta de eficiência do AG canônico.

Lai e Coghill [92] representam a solução por meio de seqüência de símbolos (string) com o número dos canais. A evolução do AG empregou o operador mutação padrão e 
o cruzamento parcialmente combinado (PMX - partially matched crossover) [105]. O AG foi utilizado para distribuir 73 canais em uma rede heterogênea formada por 25 células, considerando uma demanda de tráfego específica. O AG apresentado utiliza taxa de mutação adaptável, compõe a população inicial com indivíduos previamente definidos, e substitui as freqüências inválidas. Os autores observaram que uma pequena diferença entre a restrição co-canal (CCC) e a restrição co-site (CSC) acelera a convergência do algoritmo, reduzindo significativamente o número médio de gerações. Entretanto, para problemas mais extensos, a melhor solução pode conter atribuições inválidas.

Ngo e Li [93] consideraram o mesmo ambiente celular de [92] e incluíram a restrição de canal adjacente (ACC). Neste caso, para alguns problemas combinatórios de otimização, as soluções práticas são subconjuntos de tamanho fixo. A representação binária dos canais permitiu o uso do operador cruzamento convencional e possibilitou a redução do espaço da busca utilizando uma codificação denominada separação mínima.

Xiao et al. [86] consideraram um sistema com diferentes classes de usuários por célula e dois tipos de serviço: atendimentos a novas solicitações e handoff. A decisão do controle de admissão foi codificada em um conjunto binário, no qual o valor da posição $c$ representa a decisão de aceitar ou rejeitar uma solicitação na classe-c.

Yener e Rosa [95] consideram admissão de solicitação com informação de estado incompleta, isto é, utilizam políticas de admissão baseadas somente na informação local de uso do canal. Em um sistema unidimensional, uma estação-base que opera com uma política de localidade $k$ utiliza a informação de estado de seus $k$ vizinhos mais próximos à direita, de seus $k$ vizinhos mais próximos à esquerda, além de seu próprio estado.

As abordagens apresentadas utilizando AGs foram aplicadas a sistemas de alocação fixa, sem considerar as características dinâmicas do tráfego. Além disso, o ambiente celular adotado utiliza um número reduzido de canais, dificultando a avaliação da confiabilidade e da robustez dos algoritmos. Em todas as aproximações mencionadas, o método DCA, as restrições EMC e a capacidade do handoff não foram tratados simultaneamente.

Neste trabalho são propostas duas estratégias utilizando algoritmos genéticos para otimização da alocação dinâmica de canais em um sistema de comunicações móveis. Na primeira abordagem, denominada GALC (genetic algorithm with locking channel), os canais previamente indicados são mantidos fixos durante todo o tempo de permanência da chamada. Na segunda, GASC (genetic algorithm with switching chan$n e l)$, as chamadas podem ser comutadas para diferentes canais durante o tempo de conexão. O desempenho dos modelos propostos é avaliado em um arranjo formado por 49 células e 70 canais disponíveis, considerando distribuições de tráfego uniforme 
e não-uniforme. As simulações consideram o handoff e as diferentes restrições de compatibilidade eletromagnética (EMC). O objetivo do algoritmo consiste em determinar uma solução otimizada para a alocação dos canais, sujeita às restrições EMC, minimizando a probabilidade de bloqueio global.

\subsection{Escopo da Pesquisa}

A abordagem proposta nesta pesquisa para resolver o problema de alocação dinâmica de recursos em redes ópticas e de comunicação móvel celular é baseada em algoritmos genéticos. Os AGs determinam uma política otimizada de alocação de recursos, sejam comprimentos de onda ou canais ou, ainda, dispositivos da rede óptica. São considerados como parâmetros dos algoritmos propostos as restrições devidas às características físicas dos dispositivos utilizados nas redes ópticas e as restrições eletromagnéticas às quais está sujeito o sistema móvel celular. Condições ainda não analisadas na literatura, como o uso de $A G$ em redes ópticas com agregação dinâmica de tráfego sujeita às restrições da camada física e o uso de $A G$ em sistemas de comunicações móveis com handoff simultaneamente sujeito às três restrições eletromagnéticas, foram investigadas e fazem parte do conteúdo desta tese.

Para superar a falta de eficiência do AG canônico e para encontrar soluções ótimas em um curto intervalo de tempo, os modelos propostos neste trabalho incluem mecanismos adicionais aos operadores canônicos do AG. Assim, o mecanismo de inserção de imigrantes aumenta a diversidade da população, adicionando novos indivíduos à geração existente. A política elitista (greedy policy) garante a sobrevivência do indivíduo mais adaptado. O esquema da seleção por truncamento e um reservatório capaz de armazenar os melhores indivíduos das gerações anteriores para ajudar a formação da próxima população são também utilizados. O cruzamento em múltiplos pontos apresenta ganhos na convergência do AG. Além disso, os modelos propostos empregam mecanismos adaptáveis para ajustar as taxas de mutação, cruzamento e reprodução de acordo com a diversidade dos pais.

\subsubsection{Redes Ópticas}

Em redes WDM operando sob tráfego dinâmico, o objetivo consiste em resolver o RWA por meio de algoritmo genético para atender à demanda de solicitações de conexão com a menor probabilidade de bloqueio possível, utilizando uma distribuição ótima ou sub-ótima dos recursos da rede. As propostas apresentadas neste trabalho incluem conversores de comprimento de onda, agregação dinâmica de tráfego, imparcialidade de capacidade de largura de faixa e restrições da camada física. As restrições consideradas 
são a emissão espontânea amplificada (ASE— amplified spontaneous emission) e a dispersão por modo de polarização (PMD - polarization mode dispersion). A técnica proposta avalia o conjunto de restrições impostas ao sistema, limita o número de amplificadores em cascata e reduz o número de conversões de comprimentos de onda, mantendo a qualidade de transmissão do sinal óptico. Adicionalmente, os modelos incluem agregação de tráfego dinâmico e controle de admissão de conexão.

O modelo proposto foi avaliado por meio de simulação computacional de tráfego dinâmico na topologia de rede em anel, rede NSFNet [22], [60], [61] e rede italiana de faixa larga [69]. Os resultados numéricos apresentam desempenho promissor em termos de probabilidade de bloqueio e tempo de processamento e demonstram a elevada capacidade do modelo em otimizar a distribuição dos conversores na rede. Os modelos utilizando roteamento dinâmico e fixo alternativo são avaliados na rede NSFNet considerando rede sem conversão, com conversão esparsa e plena, e sob condição de falha em enlaces. Para a rede italiana são analisados o impacto das restrições da camada física no desempenho da rede. Adicionalmente, são incluídas na rede italiana duas arquiteturas de roteadores com capacidade de agregação: seletivo em comprimento de onda (WSXG) e com agregação de tráfego em comprimento de onda (WGXC) [79]. O desempenho do modelo incluindo o controle de admissão de conexão (CAC) foi avaliado para as configurações de rede com agregação esparsa, restrita e plena.

\subsubsection{Rede de Comunicação Móvel Celular}

Em rede de comunicação móvel celular, os algoritmos genéticos propostos têm como objetivo encontrar uma política de alocação de canais que apresente a menor probabilidade de bloqueio para solicitações de handoff e de novas chamadas. Dois AGs adaptáveis são propostos. No esquema GALC os canais alocados são mantidos fixos durante o tempo de permanência da chamada e o algoritmo procura por canais desocupados para alocar as novas solicitações de chamada. Alternativamente, no esquema GASC as chamadas podem ser comutadas para canais diferentes durante o tempo de conexão, isto é, o AG está livre para escolher a política mais apropriada para atender a todas solicitações de chamada.

O desempenho dos AGs propostos foi avaliado por meio de simulações em computador que consideram ambiente celular padrão formado por 49 células com 70 canais disponíveis. A alocação de canais está simultaneamente sujeita a três tipos de restrições eletromagnéticas: co-canal, canal adjacente e co-site. As requisições de novas chamadas e handoff são dinâmicas e obedecem à distribuição de Poisson com médias de tráfego distribuído de forma heterogênea no ambiente celular. O tempo de permanência das requisições é exponencialmente distribuído com média $1 / \mu=180 \mathrm{~s}$. 
Os resultados numéricos apresentam desempenho promissor dos algoritmos propostos em termos de probabilidade de bloqueio e tempo de processamento e demonstram a elevada capacidade dos modelos em otimizar o uso dos recursos no ambiente celular. As principais contribuições englobam: o uso de algoritmo genético adaptativo, em vez dos canônicos ou não-adaptativo; AGs para solucionar o DCA, em vez de FCA, representando um ambiente celular mais prático; a investigação do impacto simultâneo no desempenho do sistema das três restrições de EMC, em vez da restrição padrão CCC; e o aumento do desempenho do sistema considerando novas chamadas e handoff.

\subsubsection{Rede Híbrida Brasileira de Comunicação Óptica e Via Satélite}

É apresentada a simulação de uma rede brasileira de comunicação óptica conectada a uma rede de comunicação via satélite, como resultado adicional, para enfatizar a versatilidade do algoritmo proposto. $\mathrm{O}$ uso de satélites em uma rede de comunicação nacional, devido à extensão e presença de regiões isoladas das metrópoles, é uma solução que apresenta melhor custo-benefício. A rede óptica é formada por 44 nós roteadores e 56 enlaces, e está conectada à rede de satélite por meio de 5 estações terrestres estrategicamente localizadas. Os enlaces da rede óptica apresentam distribuição heterogênea de comprimentos de onda. Cada comprimento de onda pode ser agregado em $g=4$ sub-bandas. A banda básica é de 2,5 Gbps, com taxa total de 10 Gbps. A rede de satélite é formada por 14 estações terrestres, das quais 5 estão interligadas à rede óptica. As estações são equipadas com transceptores digitais com 4 canais de 2,5 Gbps. Cada canal pode ser agregado em $g=4$ sub-bandas, com banda básica de $622 \mathrm{Mbps}$. A comunicação entre estações é realizada por meio de um enlace englobando um satélite geoestacionário. A distribuição de tráfego é dinâmica, heterogênea e proporcional ao número de habitantes das regiões atendidas pelos nós roteadores. O tempo de permanência das requisições é exponencialmente distribuído com média $1 / \mu=60 \mathrm{~s}$.

O AG gerencia simultaneamente a demanda de tráfego nas duas redes abordadas integradamente. A probabilidade de bloqueio é minimizada considerando características das duas redes. Os resultados numéricos indicam a aplicabilidade da abordagem proposta na gerência integrada de redes distintas, identificando rotas e dispositivos mais utilizados.

\subsection{Artigos Publicados sobre Resultados desta Pesquisa}

Esta pesquisa gerou até esta data os seguintes artigos sobre o tema e assunto correlato apresentados em conferências [50]-[57]: 
1. Marcos A.C. Lima, Aluizio F.R. Araújo e Amílcar C. César, "Agregação Dinâmica de Tráfego em Redes Ópticas WDM sob Impacto de ASE e PMD Utilizando Algoritmo Genético", XXI Simpósio Brasileiro de Telecomunicações-SBT'04, pp. 1-6 (CD-ROM), Belém, PA, 6 a 9 de setembro de 2004;

2. Marcos A.C. Lima, Aluizio F.R. Araújo e Amílcar C. César, "Agregação Dinâmica de Tráfego em Redes Ópticas WDM Utilizando Algoritmo Genético", 110 SBMOSimpósio Brasileiro de Microondas e Optoeletrônica (MOMAG 2004), pp. 1-6 (CD-ROM), ISSN-1807-0809, São Paulo, SP, 16 a 19 de agosto de 2004;

3. Marcos A.C. Lima, Amílcar C. César e Aluízio F.R. Araújo, "Optical Network Optimization with Transmission Impairments Based on Genetic Algorithm", 2003 SBMO/IEEE MTT-S International Microwave and Optoelectronics Conference - IMOC 2003 Proc., vol. 1, pp. 361-365, Foz do Iguaçu, Brasil, 20 a 23 de setembro de 2003;

4. Marcos A.C. de Lima, Aluízio F.R. Araújo e Amílcar C. César, "Roteamento e Alocação de Comprimentos de Onda em Redes Ópticas Usando Algoritmo Genético", XX Simpósio Brasileiro de Telecomunicações-SBT'03, pp.1-5 (CDROM), Rio de Janeiro, RJ, 5 a 8 de outubro de 2003;

5. Licinius D. S. Alcantara, Marcos A. C. Lima, Aluizio F.R. Araújo, A.C. César e Ben-Hur V. Borges, "Projeto de Isolador Óptico Utilizando Algoritmo Genético", XX Simpósio Brasileiro de Telecomunicações-SBT'03, pp. 1-5 (CD-ROM), Rio de Janeiro, RJ, 5 a 8 de outubro de 2003;

6. Marcos A.C. de Lima, Aluízio F.R. Araújo e Amílcar C. César, "Dynamic Channel Assignment in Mobile Communications Based on Genetic Algorithms", The 13th IEEE International Symposium on Personal, Indoor, Mobile Radio Communications, Lisboa, Portugal, 15 a 18 de setembro de 2002;

7. Marcos A.C. de Lima, Aluízio F.R. Araújo e Amílcar C. César, "Dynamic Channel Assignment Using Genetic Algorithms for Mobile Communications", X Simpósio Brasileiro de Microondas e Optoeletrônica- SBMO 2002, vol.1, pp.458-462, Recife, PE, 12 a 16 de agosto de 2002;

8. Marcos A.C. de Lima, Aluízio F.R. Araújo e Amílcar C. César, "Alocação Dinâmica de Canais em Sistemas de Comunicações Móveis Utilizando Algoritmos Genéticos", XIX Simpósio Brasileiro de Telecomunicações-SBT' 2001, vol.1, pp.1-6 (CD-ROM), Fortaleza, CE, 03 a 06 de setembro de 2001. 


\subsection{Organização do Texto}

Esta tese está organizada da seguinte forma. No Capítulo 2 estão apresentadas as características principais das redes de comunicação óptica e de comunicação móvel celular. No Capítulo 3 estão abordados os principais conceitos relativos aos algoritmos genéticos. No Capítulo 4 estão apresentados o problema de alocação de recursos em redes de telecomunicações e os algoritmos genéticos propostos para solução do problema. No Capítulo 5 estão apresentados os resultados obtidos para otimização do roteamento e alocação de comprimentos de onda em diferentes topologias de rede óptica WDM, para otimização da alocação de canais em um sistema celular e para otimização do roteamento e alocação de recursos em uma rede híbrida brasileira de comunicação óptica e via satélite. No Capítulo 6 estão apresentadas as principais conclusões da pesquisa e sugestões para trabalhos futuros. 


\section{Capítulo 2}

\section{Características das Redes Óptica e de Comunicação Móvel Celular}

\subsection{Introdução}

No passado, as redes de telecomunicações estavam restritas às da telefonia fixa, baseada em comutação de circuitos. As centrais locais, às quais os usuários eram conectados, interligavam-se entre si e com centrais locais de outras localidades por meio de centrais tandem ou diretamente às centrais de tráfego interurbano. As inúmeras interligações formaram uma hierarquia de centrais que atingiu dimensão mundial. Cabos coaxiais eram empregados para cobrir pequenas distâncias e, no caso de grandes distâncias, enlaces de microondas e cabos elétricos submarinos. A partir de 1960, o sistema via satélite passou a integrar os enlaces continentais e, em 1977, os sistemas ópticos foram definitivamente incorporados ao cenário das telecomunicações. Às redes implantadas somaram-se as de comunicações sem fio, com destaque para as redes de comunicações móveis celulares e via satélite, e as redes de computadores, com destaque para a onipresente Internet. Atualmente, começam a se destacar as redes sem fio de computadores e equipamentos, baseadas em protocolos Bluetooth e Wi-Fi. Todos estes tipos de redes, transportando serviços distintos e operando sob protocolos diferentes estão, de certa forma, interligados e compartilhando tecnologias. Como exemplo, podemos citar a interligação entre sites da telefonia móvel celular, feita por sistema rádio ou fibra óptica, entre a planta de telefonia fixa e a das redes celulares, e entre as redes continentais, feitas por fibra ou satélite. 


\subsection{Características das Redes}

\subsubsection{Classificação das Redes de Acordo com a Dimensão Territorial}

Um critério para classificar os tipos de redes baseia-se na dimensão territorial, conforme mostra a Tabela 2.1 [106]. As redes podem ser dos tipos local, metropolitana ou geograficamente distribuída.

Tabela 2.1: Classificação das redes em função da dimensão territorial [106].

\begin{tabular}{|c|c|c|}
\hline $\begin{array}{c}\text { Distância entre } \\
\text { Estações }\end{array}$ & $\begin{array}{c}\text { Localização das } \\
\text { Estações }\end{array}$ & $\begin{array}{c}\text { Tipo de } \\
\text { Rede }\end{array}$ \\
\hline \hline $10 \mathrm{~m}$ & Sala & \\
$100 \mathrm{~m}$ & Prédio & LAN \\
$1 \mathrm{~km}$ & Campus & \\
\hline $10 \mathrm{~km}$ & Cidade & MAN \\
$100 \mathrm{~km}$ & País & \\
\hline $1000 \mathrm{~km}$ & Continente & WAN \\
\hline $10000 \mathrm{~km}$ & Planeta & Internet \\
\hline
\end{tabular}

\section{Redes Locais- LAN}

As redes locais (LAN- local area network) são redes privadas situadas em prédio, campus universitário ou planta industrial, cobrindo alguns quilômetros. Geralmente, são utilizadas para conectar computadores pessoais, permitindo o compartilhamento de recursos e a troca de informações. As LANs tradicionais operam em velocidades de 10 a 100 Mbps mas, atualmente, já estão disponíveis as que operam em 1 e até 10 Gbps.

\section{Redes Metropolitanas- MAN}

Uma rede metropolitana (MAN- metropolitan area network) é basicamente uma versão ampliada de uma LAN e, geralmente, utiliza a mesma tecnologia. Uma MAN pode abranger um grupo de escritórios vizinhos ou uma cidade e pode ser pública ou privada. Essa rede é capaz de transportar dados e voz, podendo ser conectada à rede de TV a cabo local.

\section{Redes Geograficamente Distribuídas- WAN}

Uma rede geograficamente distribuída (WAN- wide area network) abrange uma ampla área geográfica, como grupo de cidades, países ou continentes. Tradicionalmente, 
os equipamentos que compõem uma WAN são chamados de servidores. Os servidores são conectados através de uma sub-rede de comunicação (subnet). A função da subnet é transportar mensagens de um servidor para outro. Na maioria das WANs, a subnet consiste de dois componentes distintos: os enlaces físicos e os elementos comutadores ou roteadores.

As arquiteturas de rede podem ser baseadas em aplicações e protocolos, distâncias entre estações, padrões de uso e acesso, e topologias de rede anteriormente instalada. A partir da ampliação, complexidade, protocolos e larguras de faixas distintos esta classificação se tornou flexível.

\subsubsection{Características de Tráfego e Probabilidade de Bloqueio}

A técnica convencional de predição de tráfego em sistemas de telecomunicações é o modelo de Poisson com suposição exponencial do tempo de retenção do recurso [107]. O processo de chegada das solicitações de uso de um recurso ou conjunto deles resulta da superposição de um grande número de sessões independentes. Observações confirmam a propriedade de predição da chegada das solicitações de uso de recursos, que se assemelha a um processo de Poisson [108]. Isto significa que a probabilidade de uma nova solicitação em um intervalo $d t$ é igual a $\lambda d t$, sendo $\lambda$ a intensidade da requisição, independentemente das sessões anteriores. Um processo de Poisson resulta naturalmente quando o tráfego tem origem em atividades independentes de uma grande população de usuários, individualmente com uma intensidade muito pequena.

O desempenho do tráfego é dado pela fórmula de Erlang, que fornece a probabilidade de bloqueio de uma requisição, $E$, quando um certo volume de tráfego, $\Lambda$, é oferecido a um dado número de recursos, $N$ [108], [109]:

$$
E(\Lambda, N)=\frac{\Lambda^{N} / N !}{\sum_{i=0}^{N} \Lambda^{i} / i !} .
$$

Nas redes ópticas consideradas neste trabalho, o desempenho do algoritmo de alocação de comprimentos de onda em relação a uma carga particular de tráfego pode ser avaliado pela probabilidade de bloqueio de uma solicitação de conexão, $P_{b}$, dada por

$$
P_{b}=\frac{\text { número de requisições bloqueadas }}{\text { total de requisições }} \text {. }
$$

No caso das redes de comunicação móvel celular há dois tipos de solicitação: a de novas chamadas e a de handoff. A probabilidade de bloqueio de novas solicitações, $P_{b n c}$, e de handoff, $P_{b h}$, são critérios usualmente empregados para avaliar o desempenho dos sistemas, sendo dadas por

$$
P_{b n c}=\frac{\text { número de novas solicitacões bloqueadas }}{\text { total de novas solicitaçôes }},
$$




$$
P_{b h}=\frac{\text { número de solicitações de handoff bloqueadas }}{\text { total de solicitaçốes de handoff }} .
$$

\subsection{Redes Ópticas WDM}

\subsubsection{Introdução}

Os sistemas de comunicações ópticas WDM ponto a ponto são essencialmente formados por transmissor, fibra óptica e receptor. O transmissor é constituído por fonte de sinal laser que pode ser modulada direta ou externamente pelo sinal de informação. O receptor é constituído por estágio de regeneração óptica, fotodetector e amplificador de sinal elétrico. Para compensar a atenuação causada pela fibra óptica, amplificadores ópticos são alocados ao longo do enlace. As atuais redes ópticas em formato de malha podem ser vistas como a interligação de um grande número de enlaces ponto a ponto.

A técnica WDM é transparente à taxa e ao formato do sinal transmitido. Sinais formatados de acordo com os protocolos SDH/SONET, IP, ATM e Frame Relay, ou em taxas de transmissão de $622 \mathrm{Mbps}, 2,5 \mathrm{Gbps}$ ou $10 \mathrm{Gbps}$ podem ser multiplexados em uma mesma fibra, ocupando a largura de faixa disponível em um comprimento de onda.

De forma análoga ao sistema telefônico convencional, nós da rede óptica devem dispor de dispositivos capazes de comutar tráfego. Em rede roteada por comprimentos de onda, o tráfego transportado em um comprimento de onda pode ser comutado de uma fibra para outra ou de um comprimento de onda para outro na mesma ou em fibras distintas. Alguns nós da rede são utilizados como passagem, não havendo multiplexação ou demultiplexação, enquanto outros devem permitir acesso ao meio óptico. Neste caso, tráfego local em um nó da rede necessita ser adicionado a um ou mais comprimentos de onda. Da mesma forma, tráfego que se destina a um determinado nó necessita ser extraído de um ou mais comprimentos de onda. Assim, o tráfego em uma rede óptica precisa ser comutado, extraído e adicionado a um ou mais comprimentos de onda.

O processo de extrair e adicionar tráfego em um nó envolvendo multiplexação, demultiplexação e organização do tráfego é conhecido como agregação (grooming). A finalidade da agregação é dispor as diversas solicitações de tráfego, com diferentes taxas de transmissão, em um ou mais comprimentos de onda, de forma a otimizar a largura de faixa disponível, tornando a rede mais eficiente. No atual estágio tecnológico, a agregação de tráfego proveniente de diferentes solicitações de largura de faixa envolve processo de conversão eletroóptica. Os dispositivos que realizam estas funções na rede são os multiplexadores e demultiplexadores add-drop (OADM- optical add-drop multiplexer), comutadores ópticos (OXC-optical crossconnect), conversores de com- 
primento de onda e transceptores elétricos utilizados para multiplexar e demultiplexar tráfegos de taxas baixas. Assim, algumas partes das redes atuais são inteiramente ópticas, enquanto outras são opacas.

A complexidade das redes tem incorporado vários fatores ao projeto e expansão das malhas, oriundos das características dos dispositivos empregados. Por exemplo, a concatenação de vários amplificadores ao longo de um caminho óptico pode comprometer a taxa de erros por conta da ASE, impondo um número máximo de dispositivos que o sinal pode atravessar. O aumento das taxas de transmissão limita a distância dos enlaces por causa da PMD e dispersão cromática, características das fibras, exigindo a adoção de esquemas de compensação. A degradação da qualidade do sinal óptico, por conta das características da fibra e dispositivos, deve ser considerada nos RWAs. Quando incluídas nos algoritmos, passam a integrar o conjunto de restrições, sendo conhecidas por restrições da camada física.

\subsubsection{Dispositivos Ópticos}

As características principais de amplificadores ópticos, conversores de comprimento de onda, multiplexadores e demultiplexadores add-drop (OADM) e crossconnects ópticos (OXC) são resumidas a seguir.

\section{Amplificadores Ópticos}

A amplificação óptica é baseada em amplificadores a fibra dopada com érbio (EDFAerbium doped fiber amplifier), amplificadores a fibra dopada com túlio (TDFA - thulium doped fiber amplifier), amplificadores ópticos semicondutores (SOA- semiconductor optical amplifier) e amplificadores baseados em efeito Raman. De acordo com o tipo empregado, eles podem cobrir a faixa de 1530 a 1610 nanômetros (bandas C e L), com EDFA [13], [110], [111]; a faixa de 1475 a $1510 \mathrm{~nm}$ (banda S), com TDFA [13], [110], [111]; e a faixa de 1305 a $1325 \mathrm{~nm}$ (banda XS) com amplificadores a fibra dopada com praseodímio (PDFA) [111]. Amplificadores baseados em efeito Raman com múltiplos sinais de bombeio são capazes de cobrir toda a faixa do espectro óptico das fibras, podendo alcançar cerca de $20 \mathrm{~dB}$ de ganho de potência em largura de faixa de comprimento de onda de até $48 \mathrm{~nm}$ [112]. Taxas agregadas de transmissão acima de 1 Tbps em longas distâncias têm sido alcançadas com o uso de WDM e amplificadores ópticos de faixa larga [113].

O SOA é um laser semicondutor no qual as faces exibem baixos valores de refletividade, aproximadamente $R \approx 4 \times 10^{-4}$, para evitar a oscilação [114]-[116]. A largura de banda do amplificador está em torno de $70 \mathrm{~nm}$ e o ganho difere para as polarizações TE e TM, situando-se em torno de 5 a $8 \mathrm{~dB}$, com valores maiores para TE. A sensibi- 
lidade à polarização pode ser reduzida utilizando-se dois amplificadores configurados em série ou em paralelo, ou dupla passagem do sinal pelo mesmo amplificador, mas defasadas em $45^{\circ}$ [117]. O SOA degrada a relação sinal-ruído do sinal amplificado devido à ASE.

\section{Conversores de Comprimento de Onda}

Um conversor de comprimento de onda ( $\mathrm{WC}$ - wavelength converter) converte um comprimento de onda de entrada, $w_{1}$, para um comprimento de onda de saída, $w_{2}$, e são alocados nos nós roteadores da rede WDM [11]. As características principais de um conversor são [18]: a transparência em relação à taxa de bits e formato do sinal; a resposta rápida para ajustar e estabelecer o comprimento de onda de saída; a conversão para comprimentos maiores e menores em relação ao de entrada; a possibilidade de manutenção do comprimento de onda de entrada igual ao da saída; a insensibilidade à polarização do sinal de entrada; o sinal de saída com baixo chirp; a alta razão de extinção; a alta relação sinal-ruído; e a implementação relativamente simples. A distorção do sinal aumenta com a extensão da conversão, ou seja, quando $\left|w_{2}-w_{1}\right|$ aumenta. Assim, a conversão deve ser preferencialmente realizada para os comprimentos de onda adjacentes e que estejam livres. Quando o número de comprimentos de onda adjacentes é limitado, a conversão é denominada conversão parcial com grau

$$
D=\frac{d}{(W-1)}
$$

na qual $D$ é o grau de conversão, $d$ é o número de comprimentos de onda adjacentes, e $W$ é o número de comprimentos de onda [61].

A solução mais simples para conversão utiliza detecção do sinal óptico e modulação eletroóptica de um laser sintonizável pelo sinal elétrico correspondente. Entretanto, desvantagens como complexidade e grande consumo de potência têm direcionado o interesse para os conversores totalmente ópticos. Estes habilitam a translação direta da informação entre dois comprimentos de onda sem utilizar o domínio elétrico. O SOA tem sido uma das principais alternativas para a implementação de dispositivos conversores de comprimento de onda.

A tecnologia dos conversores ópticos está baseada em mistura de ondas (frequiências) e em modulação cruzada de ganho (engatilhamento óptico) ou fase (interferometria) [114]. Conversores baseados em mistura de ondas exibem ampla faixa de transparência, enquanto os conversores baseados em modulação são mais eficientes e apresentam melhor relação sinal-ruído, embora não ofereçam transparência plena.

Conversão por Modulação Cruzada de Ganho (Engatilhamento Óptico) A técnica de conversão chamada engatilhamento óptico é uma das mais utilizadas e tem 


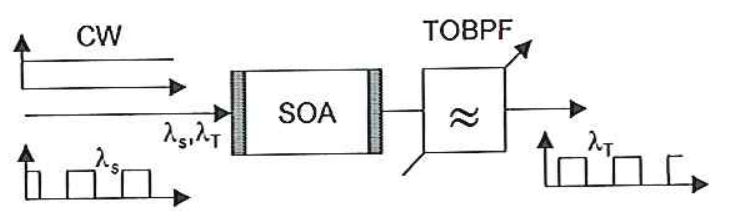

(a) Co-propagante

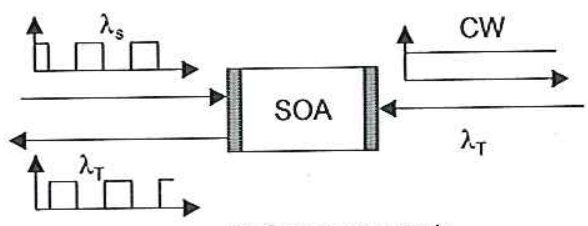

(b) Contra-propagante

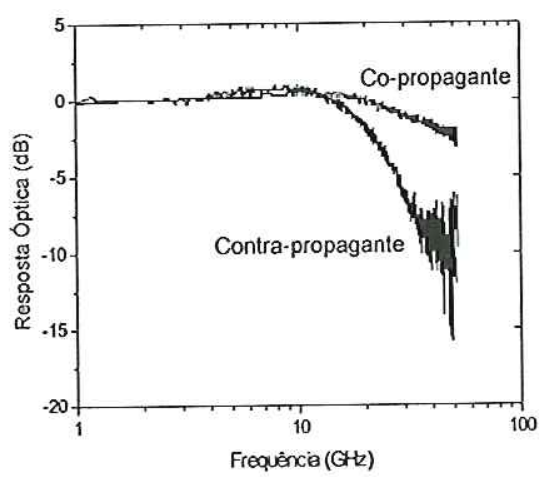

Figura 2.1: Conversão utilizando modulação cruzada de ganho (XGM- cross-gain modulation) em SOA nas configurações: a) co-propagante; e b) contra-propagante. Curva de resposta óptica em função da frequiência [9], [118]. TOBPF: tunable optical band pass filter.

como base a modulação cruzada de ganho (XGM - cross-gain modulation) em SOA. Opera como uma chave em resposta à excitação óptica e o ganho é modulado pelo sinal transportando informação em um comprimento de onda, $\lambda_{s}$. Um sinal óptico contínuo CW (continuous wave) no comprimento de onda alvo, $\lambda_{T}$, também está presente na entrada do dispositivo. O SOA satura quando $\lambda_{s}$ é alto (nível 1) e amplifica $\lambda_{T}$ quando $\lambda_{s}$ é baixo (nível 0). A informação é transferida de $\lambda_{s}$ para $\lambda_{T}$, porém com inversão dos bits. Um filtro óptico sintonizável passa-faixa (TOBPF - tunable optical band pass filter) isola o sinal $\lambda_{T}$ na saída. Um arranjo contra-propagante pode eliminar o uso do filtro. Os dois arranjos e a curva de resposta óptica são mostrados na Figura $2.1[9],[118]$.

As limitações de desempenho deste esquema são causadas pela redução da velocidade de conversão pelo efeito de tempo de trânsito do sinal; degradação da SNR devido à ASE; sensibilidade à polarização- que pode ser reduzida por meio de um projeto adequado; e degradação da razão de extinção quando há conversão de comprimento de onda baixo para alto. As vantagens são a simplicidade, a insensibilidade ao comprimento de onda de entrada e a relativamente elevada eficiência de conversão. Podem ser utilizados para taxa em torno de 10 Gbps e a figura de ruído está na faixa de 7 a $8 \mathrm{~dB}[114]$.

Conversão por Modulação Cruzada de Fase (Interferometria) A técnica de conversão por interferometria é baseada na modulação cruzada de fase (XPM-crossphase modulation) e é usada para melhorar o fator de extinção limitado da técnica XGM. Esta técnica é baseada na dependência do índice de refração, na região ativa, 


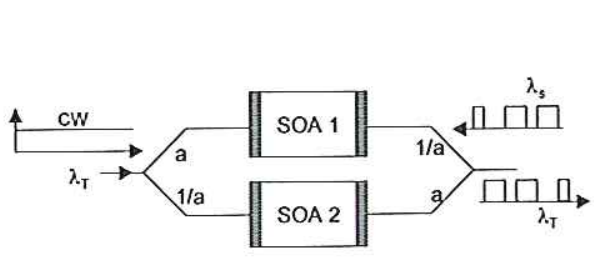

(a)

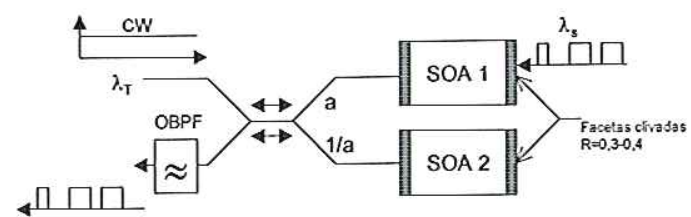

(c)

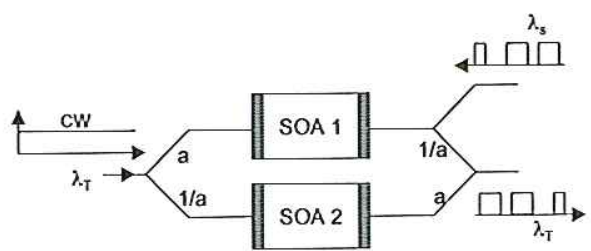

(b)

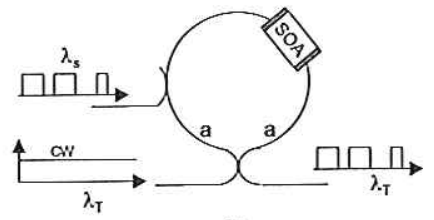

(d)

Figura 2.2: Conversão baseada em modulação cruzada de fase (XPM- cross-phase modulation), ou interferometria, empregando os arranjos: a) Mach-Zehnder assimétrico; b) Mach-Zehnder simétrico com acoplamento assimétrico; c) Michelson; e d) NOLM (nonlinear optical loop mirror) utilizando um SOA como meio não-linear [9], [118].

em relação à densidade de portadores. O sinal de informação, $\lambda_{s}$, modula a densidade de portadores e o índice de refração que, por sua vez, modula em fase um sinal de prova, $\lambda_{T}$, que atravessa o SOA. A variação de fase é transformada em variação de amplitude por meio de estrutura interferométrica, que pode ser do tipo Mach-Zehnder, conforme ilustra a Figura 2.2 (a) e (b), ou Michelson, de acordo com a Figura 2.2 (c). Esta técnica exibe eficiência de conversão melhor do que a XGM. Além destes dois tipos de interferômetros, é possível também implementar uma estrutura conhecida como NOLM (nonlinear optical loop mirror) baseada em um arranjo de Sagnac com meio não-linear desempenhado por um SOA, conforme ilustrado na Figura 2.2 (d) [9], [118].

As vantagens da técnica interferométrica incluem a saída não-invertida, a insensibilidade ao comprimento de onda e à polarização do sinal, baixo chirp e elevada razão de extinção. Entretanto, estes WCs exigem controle preciso da polarização do SOA, por causa da estreita dependência entre o deslocamento de fase do sinal que passa por ele e o ponto de polarização.

Conversão por Mistura de Ondas A mistura de ondas é um efeito não-linear coerente e, normalmente, necessita de controle de polarização e casamento de fase. As duas técnicas de interesse são as baseadas na geração da freqüência diferença (DFGdifference frequency generation) e em mistura de quatro ondas (FWM- four-wave mixing). 


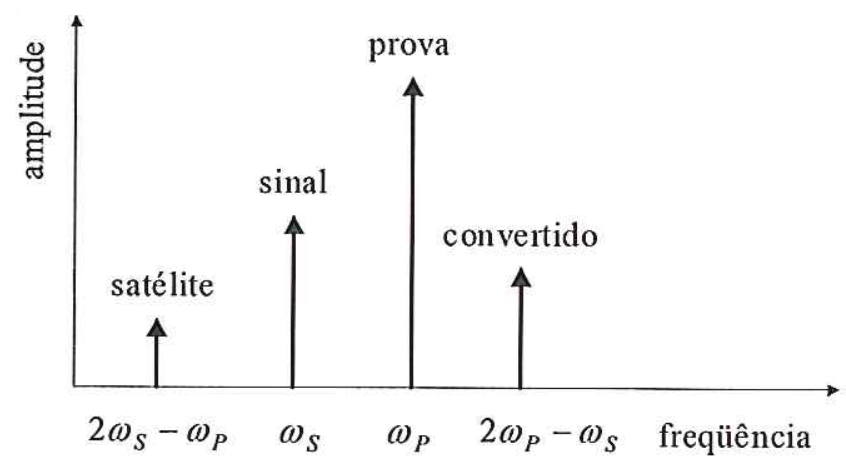

Figura 2.3: Espectro do sinal na saída de amplificador óptico semicondutor (SOA) operando como conversor de comprimento de onda com técnica de mistura de quatro ondas (FWM).

Na técnica DFG, a interação não-linear entre duas ondas é realizada em um guia passivo - niobato de lítio, por exemplo. A eficiência de conversão é da ordem de $-6 \mathrm{~dB}$ com sinal de prova de $100 \mathrm{~mW}$ e comprimento de interação de $2 \mathrm{~cm}$ [114]. Esta técnica apresenta baixos níveis de diafonia.

A FWM pode ser realizada em dispositivos passivos como redes de difração apresentando efeito não-linear. Também, pode ser obtida a partir de SOA, no qual o batimento entre duas ondas provoca a modulação da densidade de portadores que acompanha a envoltória do sinal óptico. $\mathrm{Na}$ entrada do dispositivo estão presentes duas ondas: uma delas é o sinal de prova, $\omega_{P}$, com alta intensidade e a outra, $\omega_{S}$, que transporta a informação. Duas ondas resultam do processo de batimento: uma com frequiência $2 \omega_{S}-\omega_{P}$, cuja intensidade é menor e chamada de sinal satélite, e outra com freqüência $2 \omega_{P}-\omega_{S}$, cuja intensidade é maior e chamada de sinal convertido. A Figura 2.3 ilustra o espectro do sinal na saída do SOA operando como conversor de comprimento de onda com técnica de mistura de quatro ondas.

Apesar do efeito não-linear causar redução no sinal convertido da ordem de $5 \mathrm{~dB}$ para alguns poucos nanômetros de dessintonia, estes conversores são transparentes ao formato do sinal, além de operar independentemente da taxa de bits. Também, não degradam a razão de extinção e são simples de implementar. Por causa de suas vantagens são muito utilizados como dispositivos conversores.

Os conversores de comprimento de onda podem ser ainda classificados em duas categorias, de acordo com o grau de conversão: aqueles que convertem um comprimento de onda de entrada para qualquer comprimento de onda de saída- FWC (full-range wavelength converter), e os que convertem o comprimento de onda de entrada para um conjunto limitado de comprimentos de onda de saída - LWC (limited-range wavelength converter). 


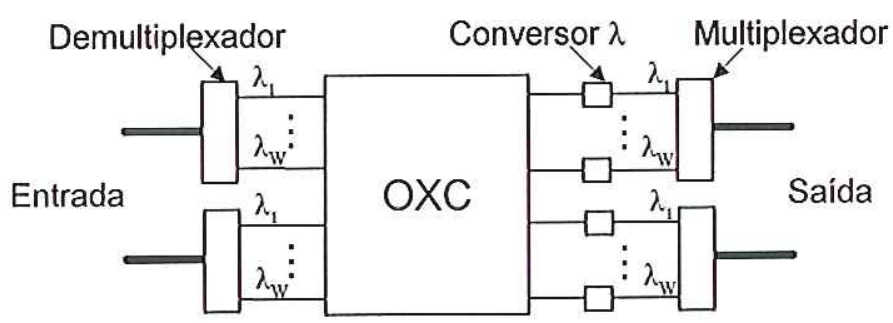

Figura 2.4: Arquitetura genérica de um roteador. Cada fibra óptica comporta $W$ comprimentos de onda. OXC: optical crossconnect.

\section{Roteadores Ópticos}

Em uma rede óptica WDM, o roteador exerce as funções de rotear comprimentos de onda, executando funções como comutação, conversão, multiplexação e demultiplexação de comprimento de onda, e monitoramento de sinal. Eles permitem comutação de diferentes taxas de bits - OC-3, OC-12, OC-48 e OC-192 e formatos - SONET e ATM [119], [120].

A arquitetura genérica de um roteador consiste dos seguintes subsistemas: multiplexador/demultiplexador, comutador (OXC) e, em alguns casos, conversores de comprimento de onda e transceptores elétricos. A Figura 2.4 mostra um tipo de roteador óptico. A informação da porta de entrada a ser roteada é analisada e direcionada para a porta de saída desejada. Cada fibra óptica comporta $W$ comprimentos de onda.

Os roteadores podem ser totalmente ópticos, roteando comprimentos de onda de uma fibra para outra sem conversão eletroóptica. Podem ser construídos utilizando conjuntos de acopladores direcionais [17] ou chaves ópticas do tipo MEMS [121]-[123]. Por outro lado, podem dispor de transceptores que convertem sinais ópticos em sinais elétricos e vice-versa. Neste caso, é possível extrair (drop) e adicionar ( $a d d$ ) tráfego de taxas baixas no referido nó. A agregação de tráfego pode ser realizada no domínio elétrico segundo qualquer padrão conhecido, como SONET/SDH, ATM ou IP (internet protocol).

Se o roteador é dotado de dispositivos de conversão de comprimentos de onda, a complexidade e o custo do equipamento aumentam. Além disso, especialmente nos conversores baseados em mistura de ondas, a distorção do sinal aumenta com o grau e o número de conversões. Assim, é desejável reduzir o número de conversores e minimizar o número de conversões sem degradar o desempenho da rede. A solução mais viável é o uso de conversão esparsa ou limitada em comprimento de onda, usualmente realizada de três formas [61]: com um limitado número de nós habilitados para conversibilidade plena de comprimentos de onda; com um limitado número de conversores com conversão total dispostos em todos os nós (share-per-link ou share-per-node), con- 


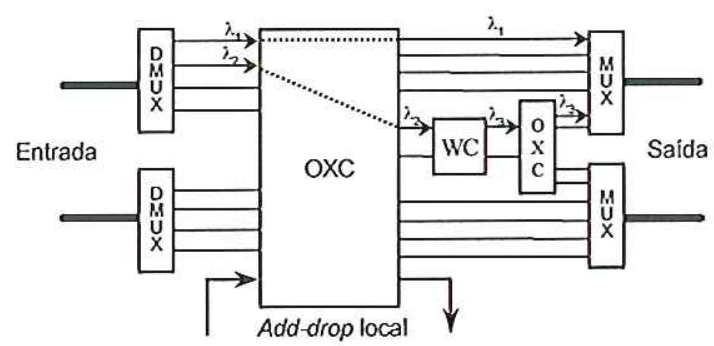

(a)

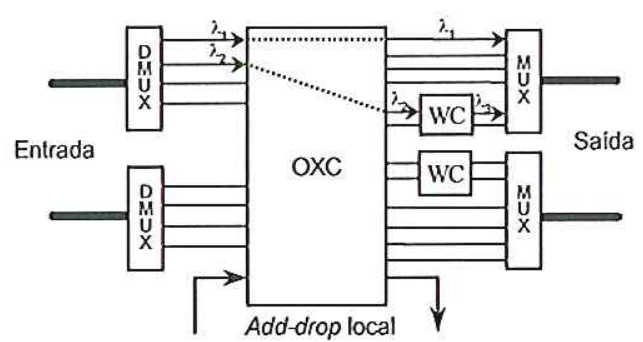

(b)

Figura 2.5: Arquiteturas de roteadores [17], [66]: a) share-per-node; e b) share-per-link. No estágio add-drop local os roteadores podem dispor de transceptores no domínio elétrico para realizar agregação de tráfego em taxas baixas.

forme ilustra a Figura 2.5; ou com uma limitada faixa de conversão de comprimento de onda no nós. Conseqüentemente, é importante estabelecer precisamente o balanço entre custo e benefício que os conversores oferecem às redes ópticas [11].

\subsubsection{Topologia de Rede Óptica e RWA}

A topologia de uma rede pode ser classificada como física ou lógica. A topologia física representa a planta física da rede, considerando o meio físico utilizado e os seus equipamentos, enquanto a topologia lógica representa a rede por meio da interligação dos equipamentos sem considerar a topologia física. A topologia lógica da rede óptica pode ser constituída por enlace único (single-hop) ou por vários enlaces (multihop). Uma característica atraente das redes ópticas é a facilidade de reconfiguração lógica, ou seja, qualquer topologia lógica de rede desejada pode ser configurada sobre qualquer planta de fibra física, sujeita às limitações do número de comprimentos de onda e transceptores disponíveis. As topologias lógicas podem ser classificadas em duas categorias: arbitrária e regular. Os padrões de conexão nodal nas topologias regulares são constantes e bem definidos, o que simplifica as operações de roteamento e gerência. Os exemplos de topologias de rede regulares incluem [124]: redes em anel, em barramento, em estrela, ShuffleNet, toroidal em 2-dimensões (MSN- Manhattan street network), gráfico de Bruijn, Hypercube, GEMNet e TreeNet. Entretanto, é difícil adicionar um número arbitrário de nós a uma topologia regular e ainda manter sua estrutura bem-definida. Na topologia multihop arbitrária não há nenhum modelo padrão de conectividade. Em uma topologia arbitrária, os novos nós podem ser adicionados aos existentes fornecendo-se apenas os recursos necessários, por exemplo, transceptores. A Internet é um exemplo de uma rede com topologia arbitrária. 


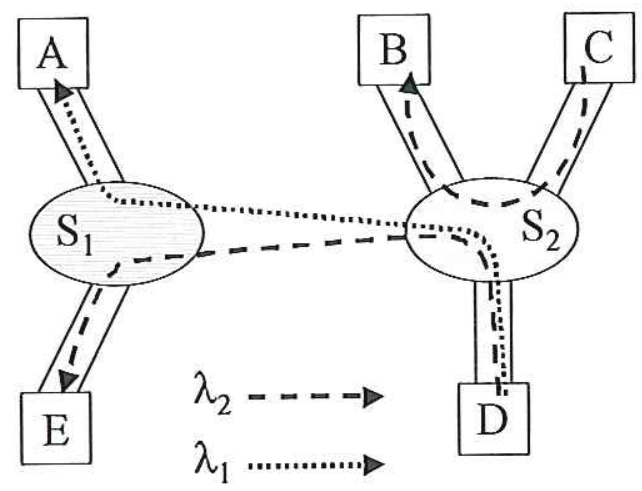

Figura 2.6: Rede óptica roteada por comprimento de onda. Os nós de roteamento são representados por $\mathrm{S}_{1}$ e $\mathrm{S}_{2}$, e as estações ou módulos de acesso por A-E. Três caminhos são apontados neste exemplo: as interligações entre D e A; entre D e E; e entre C e B. As rotas entre D e E e C e B são estabelecidas por meio do comprimento de onda $\lambda_{1}$, enquanto que a rota entre D e A é realizada por meio de $\lambda_{2}$.

\section{Caminho Óptico}

Os caminhos ópticos (rotas) são formados por um ou mais enlaces em redes roteadas por comprimento de onda. Um exemplo de rede roteada por comprimento de onda [66] é mostrado na Figura 2.6.

Para interligar duas estações de acesso, um caminho óptico é estabelecido selecionando-se um comprimento de onda disponível em todas as fibras do enlace. Esta ocupação permanece até que a conexão seja desfeita. Neste caso, haverá bloqueio da solicitação de conexão se em um dos nós de roteamento o comprimento de onda estiver ocupado. Esta é a restrição de continuidade de comprimento de onda. Para remover o bloqueio pode-se utilizar o esquema de conversão de comprimento de onda, conforme esquematizado na Figura 2.7. O caminho entre os nós 1 e 2 é estabelecido por meio de $\lambda_{2}$, enquanto que entre 2 e 3 a conexão é feita por meio de $\lambda_{1}$. Com relação à Figura 2.6 , se os nós $\mathrm{S}_{1}$ e $\mathrm{S}_{2}$ estão interligados por uma única fibra, então as duas rotas devem ser estabelecidas por dois comprimentos de onda diferentes.

Redes com roteamento por comprimento de onda empregam reuso espacial de comprimento de onda, permitindo que o mesmo comprimento de onda possa ser utilizado em múltiplos caminhos ópticos dentro da rede, com a condição de que nenhum deles compartilhe o mesmo enlace. Tal reuso viabiliza a ampliação modular nas redes roteadas por comprimento de onda, embora esta ampliação possa ser limitada em redes não-reconfiguráveis [11]. Se a rede óptica estiver equipada com conversores de comprimento de onda, então é permitido o uso de diferentes comprimentos de onda ao longo do caminho. Os conversores contribuem para a melhoria da eficiência do sistema 


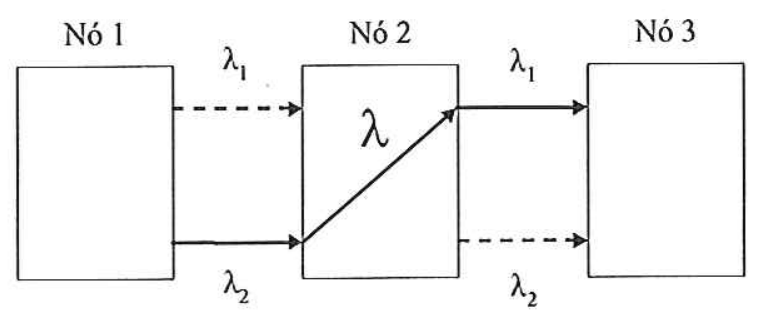

Figura 2.7: Remoção de bloqueio pelo uso de nó com conversor de comprimento de onda. O caminho entre os nós 1 e 2 é estabelecido por meio de $\lambda_{2}$, enquanto que entre 2 e 3 a conexão é feita por meio de $\lambda_{1}$.

e redução da probabilidade de bloqueio global da rede [16]. Entretanto, os conversores são caros e inserem distorções no sinal óptico. Logo, devem ser posicionados em nós da rede estrategicamente escolhidos. Esta passa a ser uma rede com conversão esparsa de comprimento de onda [64], [65].

A distribuição otimizada dos conversores é o objetivo principal de várias proposições. Na sua elaboração devem ser considerados a topologia da rede, o número de conversores e a estatística do tráfego entre os nós. O problema é solucionável desde que existem $\left(\begin{array}{l}N \\ K\end{array}\right)$ possibilidades para distribuir $K$ conversores em uma rede com $N$ nós [65]. No algoritmo proposto por Xiao e Leung [125] a utilização estatística dos conversores em cada nó é gravada e, com base nestas informações, a distribuição de um dado número de conversores de comprimento de onda é otimizada.

Conforme a rede vai se tornando mais complexa, com a interligação de vários nós e um grande número de estações de acesso, fica patente a necessidade de se estabelecer algoritmos para gerenciar a conversão dos comprimentos de onda e reduzir a probabilidade de bloqueio.

\subsubsection{Restrições da Camada Física}

A rede óptica WDM é composta pela fibra e por inúmeros dispositivos. O sinal óptico propagando-se por eles acumula degradação de qualidade, podendo acarretar aumento da taxa de erro. Por exemplo, a atenuação ao longo da fibra limita o comprimento máximo do enlace e exige a adoção de amplificadores ópticos para compensá-la. Por sua vez, o amplificador óptico adiciona ruído ao sinal, limitando também a sua quantidade que pode ser concatenada ao longo do enlace. Conversores de comprimento de onda e OXCs adicionam perdas e provocam diafonia. Além de atenuação, a própria fibra contribui para a degradação da qualidade do sinal por causa de dispersão. As distorções do sinal podem ser reunidas em duas categorias: linear e não-linear. Os efeitos lineares independem da potência do sinal e afetam individualmente os comprimentos 


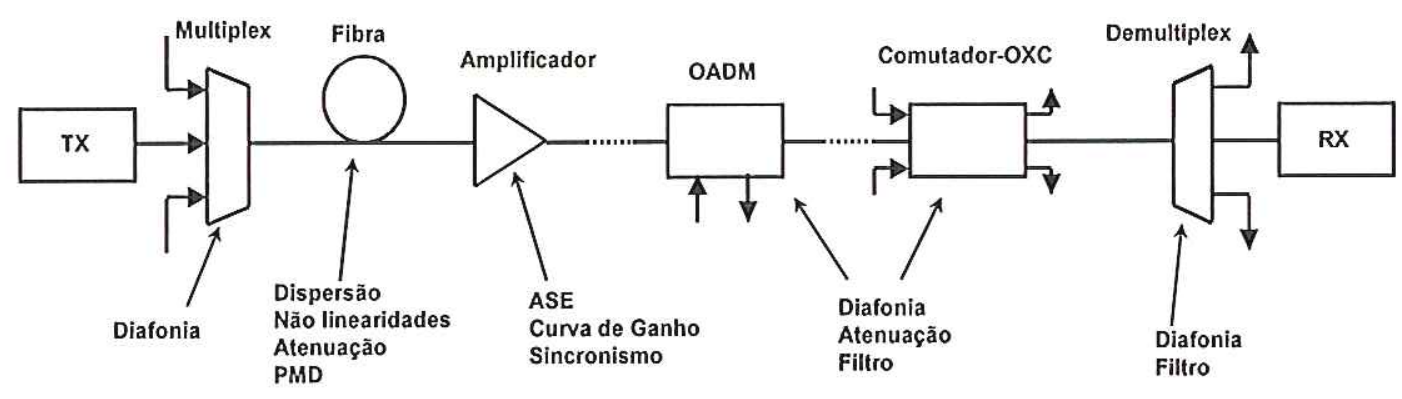

Figura 2.8: Sistema de transmissão WDM e distorções introduzidas no sinal óptico.

de onda. A emissão espontânea amplificada (ASE— amplified spontaneous emission), a dispersão por modo de polarização (PMD - polarization mode dispersion) e a dispersão cromática são exemplos de tais efeitos. As não-linearidades geram dispersão em cada canal e diafonia (crosstalk) entre eles [67].

Um sistema de transmissão WDM típico está ilustrado na Figura 2.8, na qual estão destacadas as posições onde ocorrem os diferentes mecanismos de distorção do sinal, a saber:

1. Distorções lineares - atenuação, dispersão, PMD, características não-ideais de filtros;

2. Distorções não-lineares - modulação em fase nas fibras e efeitos de dispersão;

3. Diafonia - em multiplexadores e comutadores; e

4. Ruído- emissão espontânea amplificada (ASE) gerada nos amplificadores ópti$\cos$.

Muitas vezes, o impacto causado por distorção do sinal (impairments) sobre o desempenho de redes ópticas pode ser significativo, degradando seu desempenho. Duas das distorções são a ASE e a PMD [67]. Afetadas por elas, uma rede óptica WDM abrangendo grande área geográfica pode exibir caminhos ópticos com características de transmissão abaixo do aceitável.

Neste trabalho, serão consideradas como restrições da camada física a ASE e a PMD. A atenuação das fibras já é compensada com a adoção de amplificadores ao longo dos enlaces. O impacto das restrições sobre a probabilidade de bloqueio das redes estudadas atestam a versatilidade dos algoritmos propostos. 
Dispersão por Modo de Polarização (PMD— polarization mode dispersion)

A propagação da luz em uma fibra monomodo exibe dois modos de polarização que podem ser dispostos ao longo de dois eixos ortogonais. Se o núcleo da fibra exibe assimetria, as componentes se propagam com velocidades distintas, provocando alargamento do pulso original. A distorção introduzida no sinal afeta principalmente os sistemas ópticos que operam com taxas de transmissão elevadas, especialmente acima de 10 Gbps. O prejuízo causado pela PMD ao sistema é o estabelecimento de um limite superior para o comprimento do enlace óptico.

Consideremos uma rota dentro de uma rede óptica formada por $M_{L}$ lances de fibras, onde cada lance refere-se a um segmento entre dois amplificadores ópticos. A restrição no atraso médio de tempo diferencial entre dois estados ortogonais de polarização pode ser expressa por [67]:

$$
B \sqrt{\sum_{k=1}^{M_{L}}\left[D_{P M D}(k)\right]^{2} \ell(k)}<a,
$$

na qual $a$ é a fração de duração do bit; $B$ é a taxa de bits; $D_{P M D}$ é o parâmetro PMD da fibra, em $\mathrm{ps} / \sqrt{\mathrm{km}} ;$ e $\ell(k)$ é o comprimento do $k$-ésimo lance. Um valor típico de $a$ é 0,1 . O parâmetro PMD para fibras típicas está entre 0,2 e 0,5. Entretanto, novas fibras podem apresentar PMD da ordem de 0,05 a 0,1 [67]. Alguns valores do comprimento máximo do lance estão apresentados na Tabela 2.2 para parâmetros de PMD e taxas de transmissão típicos.

Tabela 2.2: Comprimento máximo do lance $(\mathrm{km})$ para parâmetros PMD e taxa de transmissão típicos. $a=0,1$.

\begin{tabular}{|c|c|c|c|}
\cline { 2 - 4 } \multicolumn{1}{c|}{} & \multicolumn{3}{c|}{ Comprimento Máximo do Lance $(\mathrm{km})$} \\
\hline Parâmetro PMD $(\mathrm{ps} / \sqrt{\mathrm{km}})$ & $2,5 \mathrm{Gbps}$ & $10 \mathrm{Gbps}$ & $40 \mathrm{Gbps}$ \\
\hline \hline 0,5 & 6.400 & 400 & 25 \\
0,1 & 160.000 & 10.000 & 625 \\
\hline
\end{tabular}

\section{Emissão Espontânea Amplificada (ASE_ amplified spontaneous emission)}

A ASE é o ruído gerado pelo amplificador óptico. O sinal e os fótons gerados espontaneamente são amplificados ao se propagarem pelo amplificador óptico a fibra. Em decorrência, a relação sinal-ruído (SNR - signal to noise ratio) é degradada durante o processo de amplificação óptica. 
Para operar adequadamente, os receptores dos sistemas WDM necessitam receber sinal óptico com valor aceitável de SNR. Conseqüentemente, a degradação do sinal causada pela ASE impõe um limite superior ao número máximo de lances permitidos. Se um enlace óptico entre o transmissor e receptor for composto por $L_{A}$ amplificadores ópticos, o número máximo de lances, $M_{A}$, é dado por [67]:

$$
M_{A} \leq\left[\frac{P_{L}}{2 S N R_{\min } \eta_{s p} h \nu(G-1) B_{o}}\right]
$$

na qual $P_{L}$ é a potência óptica média do sinal no transmissor; $S N R_{\min }$ é o nível mínimo aceitável para a relação sinal ruído; $\eta_{s p}$ é o fator de emissão espontânea; $h=6,63 \times 10^{-34} \mathrm{~J} / \mathrm{Hz}$ é a constante de Planck; $\nu$ é a frequiência do sinal óptico; $G$ é o ganho de potência; e $B_{o}$ é a largura de faixa óptica.

Alguns valores do número máximo de lances estão apresentados na Tabela 2.3, considerando $P_{L}=4 \mathrm{dBm} ; \eta_{s p}=2,5 ; h \nu B_{o}=-58 \mathrm{dBm} ;$ e $G=25 \mathrm{~dB}$ [67].

Tabela 2.3: Número máximo de lances imposto pela restrição $S N R_{\min } . P_{L}=4 \mathrm{dBm}$; $\eta_{s p}=2,5 ; h \nu B_{o}=-58 \mathrm{dBm} ;$ e $G=25 \mathrm{~dB}[67]$.

\begin{tabular}{|c|c|}
\hline$S N R_{\min }(\mathrm{dB})$ & Número Máximo de Lances, $M_{A}$ \\
\hline \hline $\left.20\left(\text { com }_{\mathrm{FEC}}\right)^{1}\right)$ & 10 \\
$25($ sem FEC $)$ & 3 \\
\hline
\end{tabular}

(1) FEC-forward error correction.

\subsubsection{Agregação de Tráfego e Imparcialidade de Capacidade de Lar- gura de Faixa}

Nas redes ópticas WDM, vários comprimentos de onda podem ser alocados na mesma fibra óptica, aproveitando eficientemente sua ampla largura de faixa, e ficando disponíveis para seleção e estabelecimento de conexão entre os nós.

O tráfego na rede pode compreender solicitações de diferentes larguras de faixa, variando de uma fração à capacidade total de largura de faixa disponível em um comprimento de onda. A tarefa de agregar tráfego (grooming) composto por diferentes solicitações de capacidade pode ser efetuada, em parte, pelo multiplexador óptico add/drop (OADM - optical add-drop multiplexer). As técnicas de agregação de tráfego combinam diferentes solicitações de largura de faixa em um ou mais comprimentos de onda para reduzir a probabilidade de bloqueio global [74]. Se houver necessidade de multiplexar e demultiplexar tráfegos de taxas baixas, esta operação pode ser realizada em camadas superiores da rede como SONET/SDH, ATM ou IP. Neste caso, as técnicas 
de agregação de tráfego envolvem conversão eletroóptica e os nós devem ser dotados de transceptores elétricos.

As solicitações que demandam frações maiores de capacidade de largura de faixa tendem a exibir probabilidade de bloqueio mais elevada. Técnicas de imparcialidade de capacidade podem ser utilizadas para reduzir a probabilidade de bloqueio das solicitações de maior largura de faixa, mesmo aumentando levemente a taxa global de bloqueio.

\section{Modelo dos Roteadores com Capacidade de Agregação de Tráfego}

A rede óptica investigada neste trabalho é dotada de dois tipos de nós [79]: nós seletivos em comprimento de onda (WSXC); e nós com agregação de tráfego em comprimento de onda (WGXC). A arquitetura genérica de um nó roteador com capacidade de agregação está apresentado na Figura 2.9 [77]. A arquitetura de comutação do crossconect (OXC) é formada por duas partes: uma arquitetura de comutação de comprimentos de onda, que pode ser totalmente óptica ou eletrônica, e uma arquitetura de comutação eletrônica, denominada arquitetura de agregação (grooming), capaz de comutar fluxos de tráfego de baixa capacidade. A finalidade da agregação é dispor as diversas solicitações de tráfego em um ou mais comprimentos de onda, de forma a otimizar a largura de faixa disponível.

Os nós com WSXC possuem OXC e OADM. O OXC executa comutação espacial completa de comprimentos de onda, entre uma porta de entrada e uma porta de saída, e o OADM agrega os fluxos de tráfego aos comprimentos de onda de entrada e saída. Entretanto, os nós WSXC executam agregação restrita, pois não podem comutar fluxos de tráfego entre os comprimentos de onda. Os nós com WGXC, além de possuirem a funcionalidade de um WSXC, são capazes de comutar fluxos de tráfego nas janelas temporais, via conversão eletroóptica e multiplexação e demultiplexação elétrica em camadas superiores da rede (IP, ATM ou SONET/SDH, por exemplo). Podem, ainda, comutar fluxos de tráfego de um conjunto de janelas temporais em um comprimento de onda presente em uma porta de entrada para um conjunto distinto de janelas temporais em um outro comprimento de onda de uma porta de saída. Consideramos ainda que esta comutação seja inteiramente livre de bloqueios e possa ser executada para todos os comprimentos de onda de todas as portas de entrada para qualquer porta de saída.

Consideremos o exemplo de uma sub-rede como a apresentada na Figura 2.10 [79]. Cada fibra óptica dispõe de $W$ comprimentos de onda, os quais podem ter sua capacidade plena de largura de faixa subdividida em $g$ partes (granularity). Consideremos ainda que um único comprimento de onda com capacidade $C$ esteja disponível e que todos os nós sejam WSXC. 


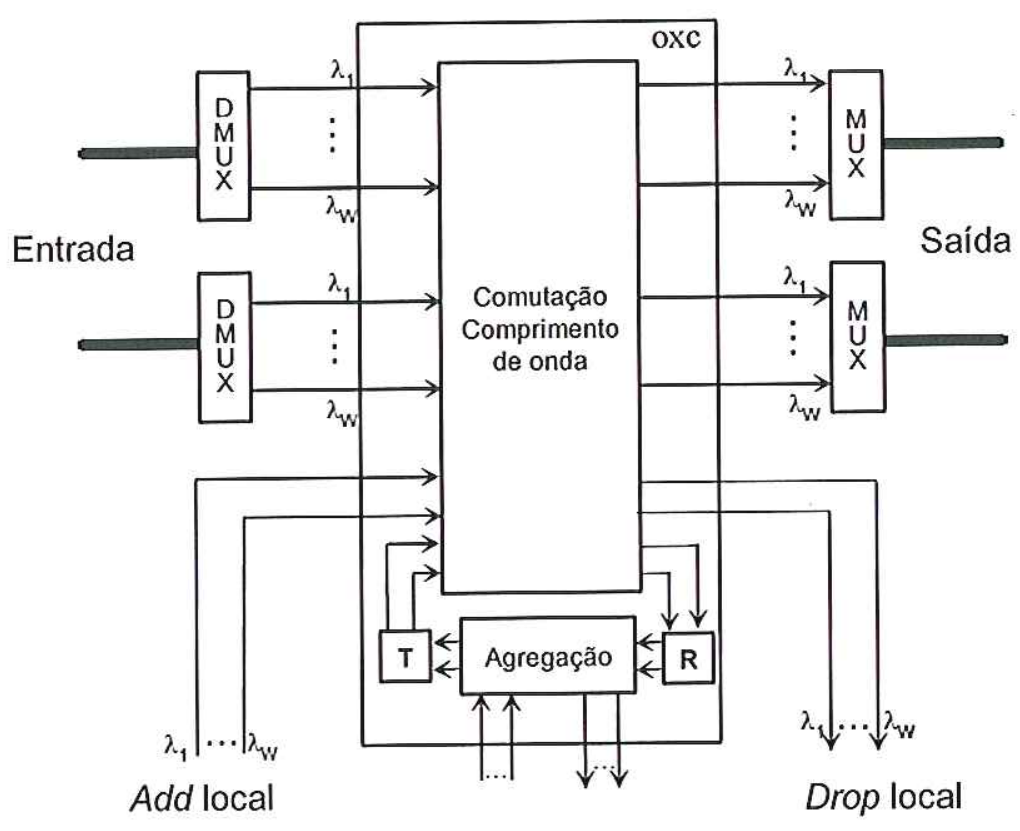

Figura 2.9: Arquitetura genérica de um nó roteador com capacidade de agregação [77]. Cada fibra óptica comporta $W$ comprimentos de onda. OXC: optical crossconnect. T: transmissor. R: receptor.

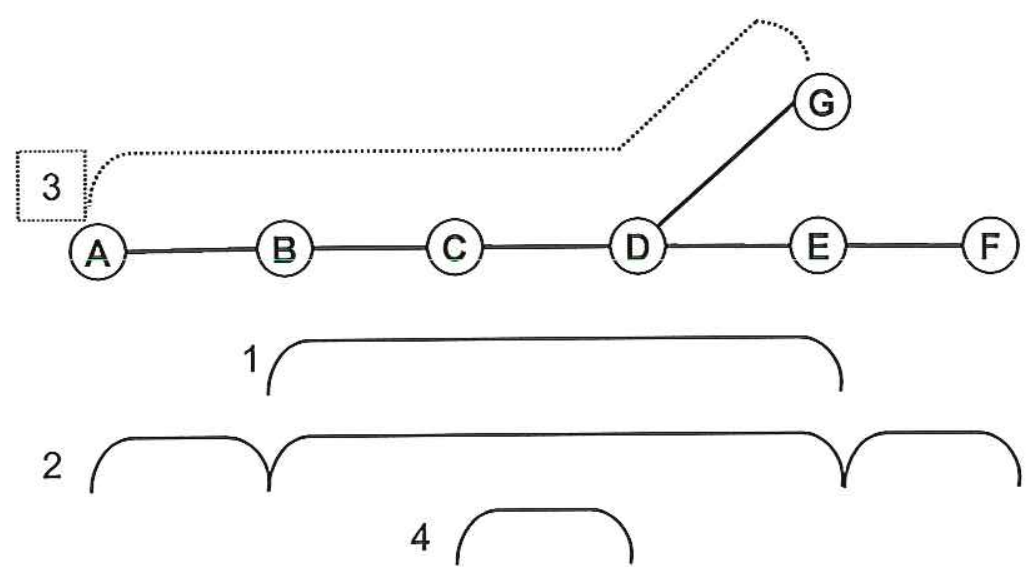

Figura 2.10: Modelo de rede com agregação WSXC para as seguintes requisições: 1) $\mathrm{B} \rightarrow \mathrm{E}$; 2) $\mathrm{A} \rightarrow \mathrm{F}$; 3) $\mathrm{A} \rightarrow \mathrm{G}$, necessita de um comprimento de onda diferente; e 4) $\mathrm{C} \rightarrow \mathrm{D}$, possível se forem utilizados OADMs e OXCs com reconfiguração rápida. Todas as requisições exigem capacidade $C / 4$ [79]. 
Suponha uma requisição de conexão do nó B para o nó $\mathrm{E}$, com capacidade $C / 4$. A conexão é estabelecida configurando-se os OADM nos nós $\mathrm{B}$ e E, e os OXCs em C e D. Observe que o comprimento de onda somente é adicionado ou retirado em B e E. Seja uma segunda requisição de $\mathrm{A}$ para $\mathrm{F}$, com capcidade $C / 4$. A conexão é estabelecida configurando-se os OADMs entre A e B e entre E e F, e utilizando o comprimento de onda estabelecido para a primeira conexão entre B e E. Neste processo, o tráfego inicial não sofre perturbação. Seja uma terceira requisição entre os nós A e G, com capacidade $C / 4$. Desta vez, a conexão será bloqueada, pois em $\mathrm{D}$ a rota se desvia do caminho óptico estabelecido para o comprimento de onda, e os roteadores utilizados são WSXC. Seja uma quarta requisição entre os nós $\mathrm{C}$ e $\mathrm{D}$, com capacidade $C / 4$. A conexão será aceita caso seja permitida uma perturbação temporária no sinal ao se adicionar e retirar o comprimento de onda em $\mathrm{C}$ e D. Esta operação poderá ser realizada utilizando-se OADMs e OXC com reconfiguração rápida.

Todas as requisições serão aceitas se a rede estiver equipada com nós WGXC. Entretanto, a complexidade e o custo do equipamento WGXC são maiores que a do WSXC. Conseqüentemente, espera-se a situação prática para a qual somente alguns nós da rede estão equipados com WGXC e o restante dos nós com WSXC. Tal rede é definida como rede com agregação esparsa. Por outro lado, uma rede com apenas nós WSXC é definida como rede com agregação restrita [79]. No exemplo apresentado, se o nó D for equipado com WGXC e os demais com WSXC, então todas as requisições serão aceitas.

\subsubsection{Alocação de Recursos}

Para transferir dados de uma estação de acesso para outra, uma conexão é estabelecida seguindo a determinação de um caminho óptico (rota) na rede, conectando a estaçãofonte à estação-destino. Então, comprimentos de onda não-utilizados são escolhidos em todos os enlaces do caminho [66]. Entre a origem e o destino em uma rede óptica, a rota final pode ser composta por vários enlaces. Se for possível utilizar o mesmo comprimento de onda em todos os enlaces não haverá necessidade de conversão. Caso contrário, se ocorrerem conflitos de comprimento de onda, a transmissão do sinal será bloqueada, caso não exista conversão. Se a rede for complexa, haverá exigência de um grande número de conversores. Para reduzir o custo global do sistema, poucos conversores devem ser utilizados e a rota deve ser direcionada preferencialmente em um percurso que empregue o maior número de enlaces com o mesmo comprimento de onda para reduzir as conversões. Determinar o caminho entre origem e destino mais viável e os respectivos comprimentos de onda utilizados é tarefa do RWA [17].

No projeto de um sistema WDM devem ainda ser avaliados parâmetros do sis- 
tema como número de comprimentos de onda; taxa de bits por comprimento de onda; espaçamento entre canais; largura de banda disponível (amplificadores ópticos); eficiência de uso da largura de faixa; distância entre os amplificadores; e máxima distância de transmissão sem regeneração.

Conhecendo-se os diversos elementos que influenciam o desempenho de uma rede WDM, o passo seguinte envolve a elaboração de algoritmos para solucionar o problema de roteamento e alocação de comprimentos de onda. A solução do RWA tem como objetivo minimizar o número de dispositivos e comprimentos de onda requeridos, atendendo às restrições impostas. Estes algoritmos devem ter como objetivos: a obtenção da disposição otimizada dos dispositivos na rede - diminuindo os custos; e a redução da probabilidade de bloqueio global - melhorando a qualidade de serviço.

Neste trabalho, um algoritmo RWA heurístico baseado em AG com objetivo de reduzir a probabilidade de bloqueio global das solicitações de conexão em redes ópticas é proposto. O algoritmo utiliza nós roteadores de acordo com as propostas de Thiagarajan e Somani [79], proporciona agregação de tráfego e equalização de capacidade de largura de faixa, incluindo os efeitos da degradação do sinal causado por PMD e ASE. Os nós providos com capacidade de agregação são determinados dinamicamente pelo algoritmo proposto. As simulações foram realizadas considerando tráfego dinâmico nas topologias de rede em anel, da rede italiana de faixa larga, da rede norte-americana NSFNet e de uma rede híbrida brasileira, combinando partes óptica e sem fio, via satélite. Os resultados numéricos mostram desempenho promissor da abordagem proposta.

\subsection{Redes de Comunicação Móvel Celular}

\subsubsection{Introdução}

Nos últimos anos, os sistemas de comunicação móveis experimentaram um progresso tecnológico notável. As novas exigências, oriundas dos serviços multimídia e da enorme expansão do número de usuários, aumentaram significativamente a demanda por largura de faixa e acessos simultâneos ao meio da transmissão. Conseqüentemente, um grande esforço tem sido realizado para melhorar a eficiência do reuso de canais, que é a técnica amplamente empregada como estratégia-chave para gerenciar o limitado espectro eletromagnético alocado aos sistemas de comunicações móveis celulares. De acordo com a técnica de reuso do canal, uma área geográfica de cobertura é dividida em células em tal maneira que os canais idênticos podem ser atribuídos simultaneamente às chamadas em células distintas. Entretanto, o esquema de reuso do canal gera interferências que podem degradar a qualidade da transmissão. Tais interferências 
compreendem a interferência co-canal e por canal adjacente. A interferência co-canal ocorre devido ao uso simultâneo de um mesmo canal em células vizinhas, a interferência por canal adjacente é causada pelo uso simultâneo dos canais adjacentes na mesma célula (co-site) ou em células vizinhas (canal adjacente) [80].

A probabilidade de bloqueio de novas solicitações e de handoff são critérios usualmente empregados para avaliar o desempenho dos sistemas de comunicações móveis celulares. Em sistemas nos quais valores elevados de bloqueio de handoff afetam severamente o desempenho global do sistema, a eficiência do reuso de canais pode ser melhorada com procedimentos apropriados para priorizar as solicitações de handoff [81], [82].

Um canal pode ser utilizado simultaneamente em várias células e uma desejada qualidade de serviço pode ser mantida se um conjunto de demanda de tráfego e de restrições de compatibilidade eletromagnética forem atendidos. Neste caso, o problema de alocação de canais desempenha uma importante função nos sistemas de comunicação móveis.

\subsubsection{Sistema Celular}

A idéia básica do conceito celular é o reuso de freqüência, em que o mesmo subconjunto de canais pode ser reutilizado em diferentes áreas geográficas (células) suficientemente distantes umas das outras para que a interferência eletromagnética esteja dentro de limites toleráveis. No modelo mais simples, denominado alocação fixa de canais, o conjunto de todos os canais disponíveis no sistema é alocado a um grupo de células (cluster), conforme apresentado na Figura 2.11. Para efeito de planejamento, as células são consideradas hexagonais, devido à melhor aproximação ao formato circular. A medida que a estação móvel vai se distanciando da estação base, a intensidade do sinal reduz, até ser necessário a troca de canal para a célula vizinha. Este processo, chamado handoff ou handover, é automático e será bem sucedido se a célula vizinha dispuser de canais livres. Caso contrário, a conexão será desfeita. O maior problema na alocação fixa é a sua incapacidade de lidar com alteração repentina de tráfego. Neste caso, recomenda-se a alocação dinâmica de canais. Na alocação dinâmica, os canais não são previamente alocados a nenhuma estação base e formam um conjunto único a partir do qual a alocação ocorre sob demanda.

As especificações básicas requerem que os serviços celulares sejam oferecidos com a qualidade dos serviços da rede fixa. A probabilidade de bloqueio não deve exceder $2 \%$ e a qualidade de transmissão deve ser considerada boa em $90 \%$ do tempo e em $90 \%$ da área de cobertura. Os parâmetros de qualidade de transmissão dizem respeito à relação sinal-ruído. Seja um ambiente celular no qual $R$ é o raio da célula, $D_{i}$ é a 


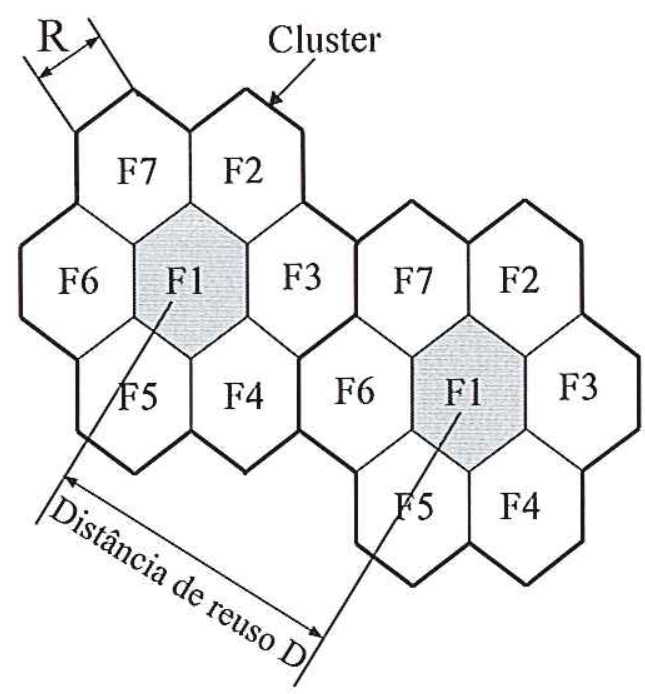

Figura 2.11: Cluster formado por $N=7$.

distância entre os centros da célula de referência $j$ e da $i$-nésima célula de interferência co-canal, e $\alpha$ é o coeficiente de perda por percurso, $2 \leq \alpha \leq 6$. A razão portadora por interferência co-canal, $(C / I c)$, recebida por um usuário localizado na borda da célula $j$ representa o pior caso para o nível de potência de sinal. Considerando que todas as $M$ células interferentes sejam eqüidistantes da célula de referência [126],

$$
\frac{C}{I c}=\frac{C}{\sum_{i=0}^{M} I c_{i}}=\frac{R^{-\alpha}}{\sum_{i=0}^{M} D_{i}^{-\alpha}} \approx \frac{1}{M}\left(\frac{R}{D}\right)^{-\alpha} .
$$

Por meio de testes subjetivos de qualidade de voz no sistema celular analógico foram determinados os requisitos mínimos para a razão $C / I c$ de acordo com a largura de banda do canal utilizado: $C / I c \geq 18 \mathrm{~dB}(30 \mathrm{kHz}) ; C / I c \geq 24 \mathrm{~dB}(15 \mathrm{kHz}) ;$ e $C / I c \geq$ $30 \mathrm{~dB}(7,5 \mathrm{kHz})[126]$. A razão $a=D / R$, denominada fator de redução de interferência co-canal, é utilizada como parâmetro-chave para solucionar a restrição de interferência co-canal, independentemente da razão $C / I c$ requerida. Para um sistema formado por grupos de 7 células, com $C / I c \geq 18 \mathrm{~dB}, M=6$ e $\alpha=4$, a razão $D / R \geq 4$,41. Para um padrão celular, $D / R=\sqrt{3 K}$, no qual $K$ é o número de células que compõem um grupo (cluster), $K=(i+i j+j), i, j \in \mathbb{N}$. Neste caso, $D / R=\sqrt{21}$.

\subsubsection{Handoff}

Normalmente, nos sistemas celulares as conexões estão associadas à movimentação do assinante. Durante a conversação, se o assinante estiver se deslocando de uma deter- 
minada célula para outra célula adjacente, os níveis de sinais recebidos pela estação rádio-base $(\mathrm{ERB})$ e pela estação móvel $(\mathrm{EM})$ irão decrescer à medida que a $\mathrm{EM}$ se afasta da ERB e se aproxima do limite da célula. Nesta situação, há troca do canal de conversação, de um canal alocado na primeira ERB para outro pertencente à área de cobertura da ERB da célula adjacente. Assim, garante-se a continuidade da conversação da EM em deslocamento. Essa característica dos sistemas celulares recebe a denominação de handoff.

O problema consiste em determinar qual célula deverá receber a EM. Para isto, a central de comutação e controle ordena às células adjacentes que avaliem a intensidade do sinal da EM. Aquela célula que estiver recebendo maior intensidade de sinal oriundo da EM receberá a mesma, em breve. Feito isto, a central informa às duas células envolvidas o handoff iminente e indica à ERB recebedora qual canal deverá ser alocado à EM. Após a confirmação de reconhecimento do novo canal pela estação móvel, a central ordena que o transceptor do canal alocado seja acionado e que o transceptor do canal pertencente à ERB anterior seja desligado. Com isso, a operação de handoff foi completada.

A aproximação utilizada neste trabalho, para determinar a probabilidade de uma célula vizinha $i$ receber a EM proveniente de uma célula $j$, utiliza a relação de proporção entre as demandas de tráfego,

$$
p_{i}=\frac{\Lambda_{i}}{\sum_{1}^{q} \Lambda_{j}}
$$

na qual $\Lambda_{j}$ representa a demanda de tráfego na célula $j$ e $q$ o número de células vizinhas a $j$.

\subsubsection{Restrições Eletromagnéticas}

A região de serviços em um ambiente celular é gerenciada como um conjunto de células hexagonais disjuntas. Cada célula ocupa uma área da unidade e fornece serviços de comunicação aos usuários que estão situados em sua área de cobertura. Quando um usuário realiza requisição de uma chamada, um canal deve ser atribuído para comunicação entre a EM e uma ERB. Esta alocação de canal deve satisfazer às restrições para evitar interferência eletromagnética. Nesta pesquisa foram considerados os três tipos de restrições eletromagnéticas [91]:

1. Restrição co-canal (CCC- cochannel constraint): um determinado canal não pode ser reutilizado nas células que estão situadas dentro de uma distância de reuso especificada na rede de células. Este conjunto de células cujos canais possuem reuso proibido é denominado cluster (aglomerado); 
2. Restrição canal adjacente (ACC-adjacent channel constraint): os canais adjacentes não podem ser alocados simultaneamente às células adjacentes. Ou seja, qualquer par de canais alocados às células adjacentes deve guardar uma distância especificada. A distância para ACC é geralmente maior do que aquela para CCC;

3. Restrição co-site (CSC- cosite channel constraint): qualquer par de canais na mesma célula deve guardar uma distância específica. A distância para CSC é geralmente maior do que aquela para ACC.

Desta forma, sejam $c s c$, acc e $c c c$, valores inteiros associados às restrições CSC, ACC e CCC. O valor $n$ associado à restrição EMC significa que os $(n-1)$ canais adjacentes para ambos os lados esquerdo e direito do espectro não estão disponíveis para o uso. As restrições se relacionam de acordo com $c s c \geq a c c \geq c c c$, e estabelecem um conjunto de restrições para o uso do espectro de frequiências de acordo com a distância de separação dos canais e da disposição das células vizinhas. Considere um ambiente celular hexagonal cuja distância de reuso que satisfaz à interferência co-canal é $D=\sqrt{21} R$. Neste caso, a restrição $c c c$ permite o reuso de um canal somente nas células que estão afastadas por três fileiras da célula de referência. O impacto sobre a alocação de canais considerando-se as três restrições eletromagnéticas está apresentado na Figura 2.12.

Dado uma rede celular e um conjunto de requisições de chamada, o AG proposto tem como objetivo encontrar uma alocação de canais otimizada para atender aos pedidos de requisição de chamada tal que sejam satisfeitos os três tipos de restrições de interferência eletromagnética.

\subsubsection{Esquemas Propostos de Alocação de Canais}

Nesta pesquisa foram elaboradas duas estratégias utilizando algoritmos genéticos para otimização da alocação dinâmica de canais em um sistema de comunicações móveis [51]. O objetivo dos algoritmos é minimizar a probabilidade de bloqueio de handoff e novas solicitações em sistemas canalizados, considerando simultaneamente três tipos de restrições de compatibilidade eletromagnética. Na primeira abordagem, os canais previamente indicados são mantidos fixos durante todo o tempo de permanência da chamada (GALC - genetic algorithm with locking channel). Na segunda (GASCgenetic algorithm with switching channel), as chamadas podem ser comutadas para diferentes canais durante o tempo de conexão. O desempenho dos modelos propostos é avaliado em um arranjo formado por 49 células, considerando distribuições de tráfego uniforme e não-uniforme. Os resultados numéricos obtidos atestam a versatilidade dos algoritmos propostos em alocar canais em um ambiente de comunicação móvel celular. 


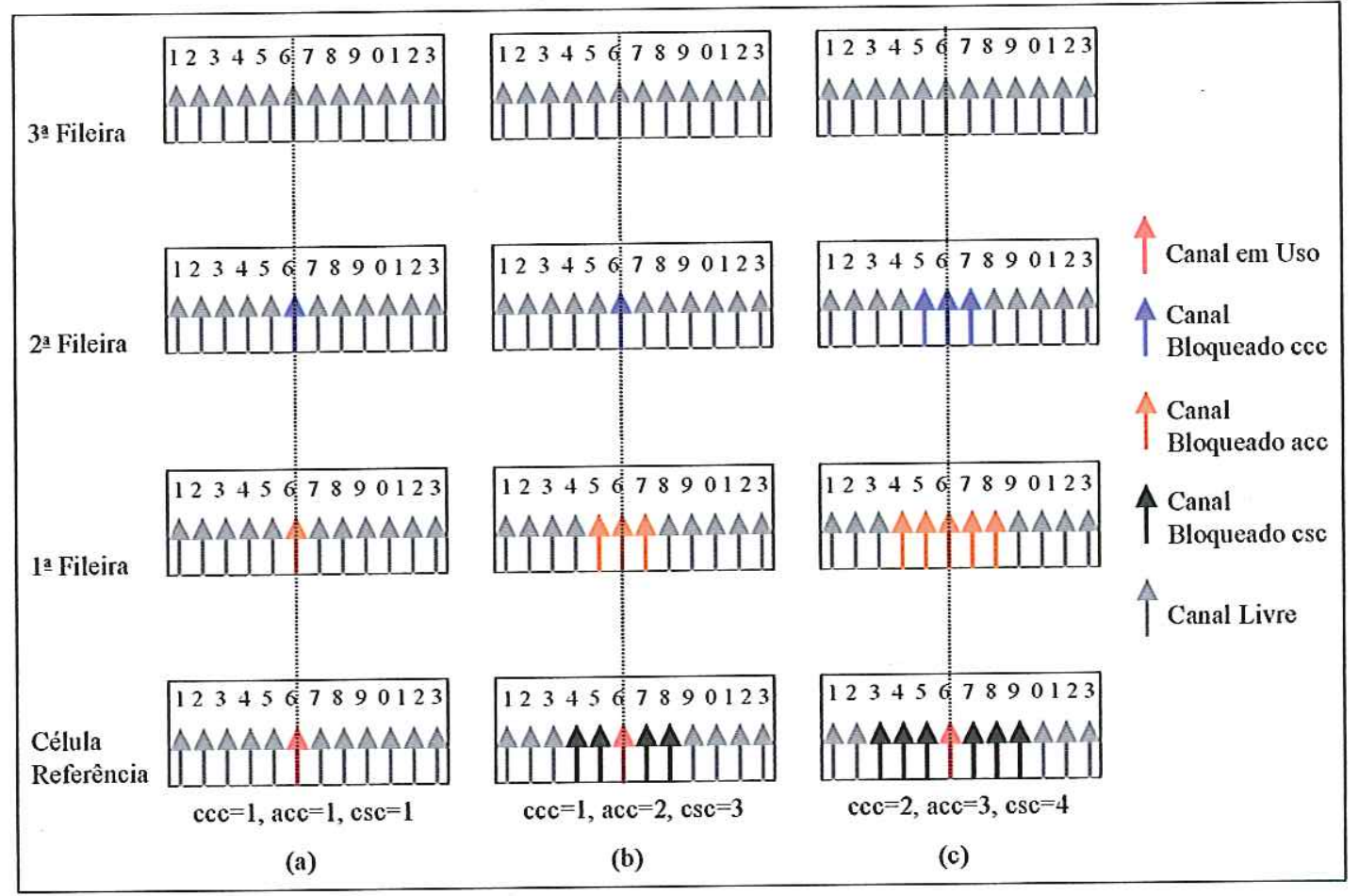

Figura 2.12: As três restrições eletromagnéticas consideradas na alocação de canais: co-canal, co-site e canal adjacente, para três condições particulares. As fileiras representam a vizinhança em relação a uma célula de referência. Distância co-canal $D=\sqrt{21} R$. 


\section{Capítulo 3}

\section{Formulação de Problema de Otimização com Algoritmos Genéticos}

\subsection{Introdução}

O conceito de otimização de um processo ou função se traduz na determinação da solução de forma mais eficiente possível. As técnicas de otimização são divididas em dois grandes grupos: programação linear (PL), aplicada a problemas descritos por sistemas de equações lineares; e programação não-linear (PNL), aplicada a problemas descritos por sistemas de equações não-lineares. A PNL é subdividida em métodos determinísticos, estocásticos e enumerativos. Os métodos determinísticos são baseados no cálculo de derivadas, necessitando de informações do gradiente da função. Os métodos enumerativos fazem uma varredura completa (busca exaustiva) de todas as possíveis soluções, o que exige tempo de cálculo inaceitável. Os métodos estocásticos utilizam um conjunto de ações que procuram o ótimo de forma "aleatoriamente orientada", sem necessitar de qualquer informação de derivadas ou sobre o comportamento do problema. Entre as técnicas estocásticas destacam-se as estratégias de evolução [127], a programação evolucionária [128], e os algoritmos genéticos [129], estes escolhidos como a técnica-base para a otimização de recursos prosposta nesta tese.

No final dos anos 70, os algoritmos genéticos canônicos, baseados na representação binária, cruzamento em um único ponto e seleção por roleta (elitista ou não), apresentavam-se como uma proposta para solução de problemas de otimização que exigiam eficiência e busca efetiva. A partir dos anos 80, os algoritmos genéticos se tornaram robustos, de fácil utilização, aplicáveis em diversas áreas, como aprendizagem de máquinas, problemas combinatórios, projetos de circuitos integrados (VLSI- 
very large scale integration), e otimização numérica, incluindo problemas com múltiplas variáveis em sistemas dinâmicos [60], [61]. Muitas destas aplicações podem ser consideradas como problemas de otimização, nas quais o algoritmo deve encontrar um conjunto de variáveis com valores reais de modo a aproximar a função objetivo (ou função de adaptação) ao seu ótimo.

Em geral, qualquer problema de busca pode ser entendido como uma otimização. Uma busca tenta selecionar informações para atingir um determinado objetivo, considerando uma função de avaliação e respeitando um conjunto de restrições. Mas, enquanto o processo de otimização tenta encontrar somente uma solução (o mais próxima à ótima possível), uma busca pode encontrar várias candidatas. Assim, é necessário encontrar a solução ótima ou, no mínimo, uma solução próxima ao ótimo, em um intervalo de tempo aceitável.

Os algoritmos genéticos são métodos heurísticos capazes de proporcionar confiabilidade e busca orientada em espaços complexos de soluções [105]. Estes algoritmos são computacionalmente simples e altamente eficazes em sua busca por uma solução ótima. Podem ser utilizados para resolver virtualmente todos os problemas de difícil otimização, como os problemas com ótimos locais, com múltiplas restrições e NP-completos [130]. Deve-se ressaltar que, embora estes algoritmos sejam simples, o processamento pode ser longo, pois os AGs realizam buscas orientadas em diferentes partes do conjunto de possíveis soluções. Goldberg [105] aponta quatro formas pelas quais os algoritmos genéticos diferem dos procedimentos usuais de busca e otimização:

a. Trabalham com um código de conjuntos de parâmetros e não com os próprios parâmetros;

b. Procuram por soluções em uma população de possibilidades e não a partir de uma única;

c. Usam regras de transição probabilística e não regras determinísticas; e

d. Utilizam informações sobre recompensas (função-objetivo) e dispensam o uso de derivações ou conhecimentos auxiliares advindos da inteligência artificial (IA) clássica e de métodos da teoria de otimização de sistemas.

\subsection{Formulação de Problema de Otimização}

Um problema clássico de otimização consiste em minimizar/maximizar uma função objetivo $f(\overline{\mathrm{x}})$, na qual o vetor $\overline{\mathrm{x}}$ apresenta $n$ variáveis independentes $x_{i}$,

$$
\text { minimizar/maximizar } f(\overline{\mathrm{x}})=f\left(x_{1}, x_{2}, \ldots, x_{n}\right)
$$


sujeita às restrições de comportamento,

$$
\left\{\begin{aligned}
g_{j}(\overline{\mathrm{x}}) \geq 0, & j=1,2, \ldots, J \\
h_{k}(\overline{\mathrm{x}})=0, & k=1,2, \ldots, K
\end{aligned}\right.
$$

e restrições laterais nas variáveis independentes,

$$
x_{i}^{(\min )} \leq x_{i} \leq x_{i}^{(\max )} .
$$

Durante o processo de otimização, os valores das variáveis independentes, $x_{i}$, são alterados em um espaço de busca limitado por um conjunto de restrições, na tentativa de se obter o ponto ótimo $\overline{\mathrm{x}}^{*}=\left(x_{1}, x_{2}, \ldots, x_{n}\right)$ que otimiza $f(\overline{\mathrm{x}})$. As restrições são inequações que descrevem situações indesejáveis ou infactíveis.

\subsection{Descrição do Algoritmo Genético}

Os princípios básicos dos AGs foram inicialmente propostos por John Holland em seu livro pioneiro "Adaptation in Natural and Artificial Systems", de 1975 [129]. Eles foram inspirados nos conceitos de evolução por seleção natural descritos por Charles Darwin no livro "On the Origin of Species by Means of Natural Selection", de 1859 [131], segundo o qual os indivíduos mais aptos em um ambiente provavelmente apresentarão maior probabilidade de gerar descendentes que sobrevivam [48], [132].

Os algoritmos genéticos utilizam uma analogia direta com esta evolução natural, pressupondo que uma solução potencial de um dado problema é um indivíduo, representado por um conjunto de parâmetros. Estes parâmetros, considerados genes de um cromossomo, podem ser estruturados por um conjunto de símbolos (strings), geralmente em uma forma binária. Um valor escalar, denominado aptidão (fitness), determinado por meio de uma função de aptidão, é usado para refletir quão bom é um cromossomo em relação à função objetivo do problema [48]. Diferenças na aptidão entre gerações são chamadas de evolução e são decorrentes do processo de seleção natural.

As soluções ótimas ou sub-ótimas de um problema são obtidas entre os descendentes dos indivíduos mais aptos, para quais os atributos do melhor indivíduo tendem a permanecer nas gerações seguintes [48]. Adicionalmente, os AGs são robustos, não exigem o conhecimento prévio sobre a solução do problema, podem utilizar parâmetros adaptativos, podem aprender com as mudanças ocorridas no comportamento do ambiente, e podem gerar soluções múltiplas. Além disso, os AGs podem ser executados em diferentes ambientes sem significativas mudanças de programação e podem encontrar soluções ótimas ou quase-ótimas para problemas que consideram informação local e ou global. 
Em síntese, algoritmos genéticos são processos não-lineares, formados a partir de eventos discretos e estocásticos de busca e otimização que não utilizam (em suas versões mais básicas) formalismo matemático complicado como os métodos clássicos de otimização.

\subsubsection{Fundamentos}

Os algoritmos genéticos apresentam relativamente poucas exigências para sua aplicação, as quais incluem um mapeamento entre o espaço de busca e os cromossomos (representação), um conjunto de operadores, e uma função de adaptação. A terminologia e conceitos utilizados em algoritmos genéticos podem ser resumidos conforme a Tabela 3.1.

Tabela 3.1: Terminologia e conceitos de algoritmo genético.

\begin{tabular}{|l|l|}
\hline Terminologia & \multicolumn{1}{|c|}{ Descrição } \\
\hline \hline Gene & Elemento básico, parte de um cromossomo \\
\hline Cromossomo & $\begin{array}{l}\text { Conjunto de genes agrupados para construir o genótipo } \\
\text { de um indivíduo }\end{array}$ \\
\hline Indivíduo & Formado por um conjunto de cromossomos \\
\hline População & Número de indivíduos em uma geração \\
\hline Geração & Estágio iterativo da evolução das populações \\
\hline Seleção de pais & Escolha dos indivíduos que podem se tornar pais \\
\hline Pais & Indivíduos selecionados para gerar descendentes \\
\hline Descendentes & Indivíduos gerados a partir dos pais \\
\hline Aptidão & $\begin{array}{l}\text { Valor indicativo de quanto um indivíduo está apto a } \\
\text { sobreviver no ambiente }\end{array}$ \\
\hline Cruzamento & Operação em que se trocam genes entre dois indivíduos \\
\hline Mutação & Alteração aleatória de um ou mais genes em um indivíduo \\
\hline Reprodução & $\begin{array}{l}\text { Operação em que indivíduos da população atual são } \\
\text { escolhidos para integrar a nova população }\end{array}$ \\
\hline Política elitista & $\begin{array}{l}\text { Política de escolha de sobreviventes que visa permanecer } \\
\text { com os indivíduos mais aptos na próxima geração }\end{array}$ \\
\hline
\end{tabular}

A escolha da representação é um ponto-chave na operação dos AGs, pois estes algoritmos manipulam representação em código do problema, e uma representação nãoadequada pode limitar severamente a janela pela qual o sistema observa seu mundo.

Em uma aplicação prática de AG, uma população de indivíduos, cada um deles em sua forma mais simples, composto por um só cromossomo, deve ser gerada. Geralmente, esta população é iniciada aleatoriamente. Em cada ciclo da evolução genética, uma geração subseqüente é formada a partir dos cromossomos da população atual. 
Isto é conseguido se um grupo destes cromossomos, chamado pais, for escolhido por um mecanismo de seleção proporcional à aptidão dos indivíduos com respeito ao objetivo [48]. Os genes dos pais são recombinados para a produção de descendentes para a próxima geração via operação de cruzamento. Estes descendentes estão sujeitos à mutação, como em um processo de evolução natural. É esperado deste processo de evolução (manipulação de genes) que os melhores cromossomos apresentem maior probabilidade de gerar o maior número de descendentes, com a maior probabilidade de sobreviver nas gerações futuras [48].

Uma geração existe em cada intervalo contínuo entre seleções, quando os operadores genéticos são aplicados. Em geral, os algoritmos genéticos utilizam os três operadores genéticos mais conhecidos: mutação, cruzamento e seleção. Além destes, quase todos os AGs utilizam outros operadores específicos para reduzir o tempo de convergência em direção à solução. Resultados obtidos neste domínio são ganhos de experimentos, sem um suporte de desenvolvimento completamente teórico.

\subsubsection{Componentes do Algoritmo Genético}

A taxonomia de AGs útil para esta tese é apresentada a seguir.

\section{Tamanho da População}

A teoria clássica a respeito dos AGs [129] supõe populações com tamanhos infinitos e, conseqüentemente, um AG que age em populações finitas pode apresentar um comportamento irregular. Os operadores genéticos aplicados a uma população finita podem conduzir o algoritmo para convergência em pontos sub-ótimos do espaço de busca (genetic drift) [48]. Assim, um ponto crucial para a evolução é manter elevada a diversidade da população [130].

O modelo analítico para determinar o tamanho ótimo da população exige o conhecimento do valor da aptidão e de sua variância [105], [133], [134]. Entretanto, estes valores podem apresentar comportamento não-linear em ambientes complexos, com múltiplos objetivos e múltiplos ótimos locais. Uma alternativa consiste em determinar o tamanho da população de forma empírica. Grefenstette [135] aplicou um meta-AG para controlar os parâmetros de um outro AG (incluindo tamanho da população), e determinou o tamanho da população entre 30 e 80. Entretanto, Schaffer et al. [136], após exaustivos testes, recomendam o tamanho da população entre 20 e 30. Hesser et al. [137] observaram que o maior aumento na variabilidade da população ocorre quando são utilizados de 30 a 110 indivíduos. Uma escolha adequada para o tamanho da população pode situar-se nesta faixa. 


\section{Seleção}

A seleção envolve a escolha dos pais, escolha dos candidatos a passarem para a próxima geração (por exemplo, seguindo uma taxa de reprodução) e escolha dos indivíduos que devem obrigatoriamente estar na próxima geração (por exemplo, seguindo uma política elitista). Este operador controla ao mesmo tempo a velocidade de convergência e a diversidade da população. Se a pressão de seleção de indivíduos de uma geração para a outra for elevada, a população pode convergir prematuramente para um ponto ótimo local. Se a pressão de seleção for baixa, o algoritmo deve demandar longo tempo para alcançar uma solução aceitável [138].

Para gerar descendentes mais aptos ao ambiente é necessário haver um mecanismo eficiente para a seleção dos pais. Por exemplo, eles podem ser gerados utilizando uma seleção por roleta (roulette wheel selection), para qual a probabilidade de seleção de cada indivíduo da população, $p_{s_{i}}$, formada por $P_{o p}$ indivíduos, é proporcional à sua função de aptidão, $f_{i}$ [105], [139]:

$$
p_{s_{i}}=\frac{f_{i}}{\sum_{j} f_{j}}, \quad j=1 . . P_{o p} .
$$

Na seleção por amostragem universal estocástica (SUS - stochastic universal sampling) proposta por Baker [139], os indivíduos são mapeados em segmentos contíguos de uma linha proporcionais à aptidão. Ponteiros igualmente espaçados são colocados sobre a linha para a seleção dos indivíduos. Na seleção por ordenamento (ranking selection) [140], a população é classificada de acordo com o valor da função objetivo utilizando uma escala uniforme. O pior indivíduo recebe aptidão 1 e o melhor recebe aptidão $P_{o p}$. Este método pode conduzir a uma convergência mais lenta, pois os valores de aptidão dos melhores indivíduos são semelhantes. Na seleção por torneio (tournament selection) [140], um número de indivíduos, $T_{\text {our }}$, é escolhido aleatoriamente e o indivíduo mais apto deste grupo é selecionado como pai. Este processo é repetido até completar a seleção.

Godberg e Deb [140] comparam diferentes esquemas de seleção e demonstram que a seleção por roleta e a SUS são significativamente inferiores aos esquemas de seleção por ordenamento e por torneio, os quais apresentam desempenho idêntico.

Muhlenbein e Schlierkamp-Voosen [141] incluíram o mecanismo de seleção por truncamento (truncation selection) em seu algoritmo genético denominado BGA (breeder genetic algorithm). Neste esquema, os melhores T\% indivíduos são selecionados e combinados aleatoriamente até que o número de descendentes seja igual ao tamanho da população. No BGA, os descendentes substituem a população anterior e cruzamentos entre indivíduos idênticos são proibidos. Finalmente, o melhor indivíduo encontrado permanecerá em grande parte na população. O BGA é considerado um dos AGs 
disponíveis mais eficientes na otimização de parâmetros contínuos [142].

Para evitar a perda do bom material genético obtido pelas gerações anteriores, alguns indivíduos da população atual devem ser incluídos na geração seguinte. Koza [132] define esta operação como reprodução e seleciona os indivíduos utilizando o mecanismo de seleção por roleta de acordo com uma taxa da reprodução, $p_{r}$.

\section{Cruzamento}

O operador cruzamento é aplicado a dois indivíduos por meio de cortes em pontos idênticos, escolhidos aleatoriamente para cada indivíduo. Em seguida, seleciona-se um ou mais segmentos do indivíduo, recombinando-se as partes de cada um para formar os descendentes. A taxa do operador cruzamento, $p_{c}$, tipicamente variando entre 0,6 e 1, 0, é freqüentemente usada como probabilidade de cruzamento [48].

O número de pontos de cruzamento, que determina quantos segmentos são trocados, é freqüentemente mantido em um valor constante muito baixo: 1 ou 2 pontos [129]. De Jong e Spears [143], [144] e Spears [145], [146] obtiveram os valores apropriados dos parâmetros para cruzamento em $n$-pontos e uniforme. Eles demonstraram que o cruzamento em 2 pontos geralmente atinge melhor desempenho.

\section{Mutação}

O operador mutação modifica aleatoriamente um indivíduo por meio da mudança do valor de um ou mais genes com probabilidade $p_{m}$. Como o operador cruzamento é aplicado a dois indivíduos já na população, recombinando-se as partes de cada indivíduo, o operador mutação procura impedir que o AG convirja prematuramente, introduzindo diversidade na população. A taxa de mutação deve ser escolhida com cuidado: uma taxa de mutação pequena torna o operador ineficaz, enquanto uma taxa de mutação alta pode destruir o bom material genético encontrado pelos outros operadores (seleção e cruzamento). Em um AG, devem-se equilibrar estes dois operadores: o cruzamento responsável por combinar o bom material genético e a mutação responsável por introduzir novo material genético.

Goldberg [105] ajustou a probabilidade de mutação, $p_{m}$, para pequenos valores. Em uma aplicação particular, utilizou $p_{m}=1 / \ell$, na qual $\ell$ está associado ao comprimento em bits de um indivíduo. No BGA [141], a taxa é sempre $p_{m}=1 / n$, na qual $n$ é o número de parâmetros independentes. Bäck [147] mostrou que $p_{m}=1 / \ell$ é a melhor escolha para as funções unimodais, enquanto para as funções multimodais é recomendada uma taxa de mutação variável para superar as soluções em pontos de ótimo local. 


\section{Condição de Parada}

A condição de parada é outro parâmetro de controle dos AGs. Entre os mecanismos existentes, o mais simples é estabelecer um número fixo de gerações ou especificar o tempo de processamento. Em adição, a implementação utiliza um operador freqüentemente encontrado no mundo dos AGs, o elitista. Ele é utilizado para garantir a presença do melhor indivíduo na geração subseqüente, caso o "melhor" indivíduo não esteja incluso na nova população.

Man et al. [48] sugerem como critérios para o controle da condição de parada o uso da quantidade de variação de indivíduos entre gerações sucessivas ou de um valor de aptidão (fitness) previamente definido.

\section{Aptidão e Função de Adaptação}

A função de adaptação nos problemas envolvendo AG fornece o mecanismo para avaliar a aptidão de cada indivíduo ao ambiente. Esta é uma ligação importante entre o AG e o problema tratado. Para manter uniformidade nos domínios dos problemas, o valor da função de adaptação é convertido em aptidão [105], [132].

Man et al. [48] descrevem três formas para conversão: linear, na qual o valor da aptidão de um indivíduo possui uma relação linear com a função de adaptação; por potenciação, na qual o valor da aptidão é obtido como a $k$-ésima potência da função de adaptação; e sigma, na qual a aptidão é calculada de acordo com o desvio padrão da função de adaptação da população.

\section{Algoritmo Genético Canônico}

A forma canônica do algoritmo genético proposto por Man et al. [48] está apresentada esquematicamente na Figura 3.1. Uma população inicial, formada por $P_{o p}$ indivíduos, é gerada aleatoriamente. Em seguida, é avaliada a aptidão de todos os indivíduos aos quais são aplicados os operadores genéticos: seleção, cruzamento e mutação. O procedimento de evolução é repetido até o critério de parada ser atingido.

A principal dificuldade no uso dos AGs em sistemas dinâmicos é a necessidade de um grande intervalo de tempo para a aprendizagem do algoritmo canônico [129]. Tal limitação pode prejudicar as adaptações rápidas da solução com respeito às mudanças no ambiente.

Uma possível fonte de problemas no uso dos AGs canônicos refere-se à falta de garantia de sobrevivência dos indivíduos com elevados valores de aptidão nas gerações seguintes. Durante a busca, a composição da população pode sofrer mudanças significativas e, então, algumas soluções obtidas podem ser perdidas durante a transição 
- Inicie o contador de gerações $(t=0)$

○ Gere uma população aleatória de indivíduos $P_{o p}(t)$

- Enquanto o critério de parada não for atingido

" Avalie a aptidão de todos os indivíduos $P_{o p}(t)$

- Selecione uma sub população como potenciais pais, Seleção dos pais

- Recombine os genes dos pais, Cruzamento

- Provoque uma alteração aleatória nos genes da prole, Mutação

- Selecione indivíduos para próxima geração, Reprodução

- Incremente o contador de gerações $(t=t+1)$

- Fim

Figura 3.1: Algoritmo genético canônico [48].

das gerações. Goldberg [105] considerou um modelo elitista para assegurar a sobrevivência do melhor indivíduo na geração seguinte. Uma inconveniência, entretanto, é que ocasionalmente a busca pode se concentrar exclusivamente na melhor solução encontrada nas primeiras gerações do $\mathrm{AG}$, em detrimento de uma busca mais extensiva para outras soluções.

A convergência prematura e pontos de ótimo local em AG podem ser evitados com o uso de técnicas que modificam os valores dos parâmetros [148]-[150]. Estes métodos podem controlar dinamicamente as taxas dos operadores (algoritmos genéticos adaptáveis) ou inserir novos indivíduos à população existente (inserção de imigrantes [48]), procurando equilibrar exploração e aproveitamento (exploration and exploitation).

\section{Inserção de Imigrantes}

A tendência dos AGs de convergir rapidamente reduz sua habilidade em identificar regiões no espaço de busca que poderiam se tornar mais atraentes durante as mudanças do ambiente. O mecanismo de inserção de imigrantes [48], [151] pode ser usado para otimizar a característica variante do sistema no tempo. Este mecanismo aumenta a diversidade da população incluindo indivíduos novos na geração existente para responder às mudanças ocorridas no ambiente.

Grefenstette [151] avalia o desempenho dos algoritmos genéticos off-line e on-line em ambientes não-estacionários utilizando diferentes taxas de inserção de imigrantes. Para os sistemas off-line, determinou como máximo desempenho o uso de uma taxa de inserção de $30 \%$. Para os sistemas on-line foi constatado que o uso de taxas de inserção mais elevadas reduz o desempenho do AG, pois torna a busca mais aleatória. 


\subsubsection{Algoritmos Genéticos Adaptáveis}

O emprego de um AG para um dado problema limitava-se à escolha dos parâmetros de controle, como as taxas de mutação e cruzamento e o tamanho da população. As escolhas destes parâmetros eram baseadas em tentativa e erro. Assim, ajustar os vários parâmetros exige uma enorme quantidade de experimentos que apresentam freqüentemente dificuldades como:

a. Os parâmetros não são independentes, mas é praticamente impossível tentar todas as combinações;

b. O processo de ajuste de parâmetros usualmente exige longo tempo, mesmo se forem modificados um a um;

c. Para um dado problema, os valores dos parâmetros selecionados não são necessariamente ótimos, mesmo se o ajuste inicial for quase ótimo.

Eiben et al. [149] distinguiram duas formas para ajustar os valores dos parâmetros: sintonia e controle. No ajuste dos parâmetros por meio da sintonia, os valores dos parâmetros são ajustados antes do processo evolucionário, tipicamente de forma individual, conduzindo a escolha geralmente para pontos quase-ótimos. Um inconveniente relacionado à sintonia dos parâmetros é que o funcionamento de um AG é um processo adaptativo intrinsecamente dinâmico. Portanto, o uso de parâmetros fixos estaria se contrapondo a esta premissa [149]. Adicionalmente, diferentes valores dos parâmetros podem ser ótimos em diferentes estágios do processo evolucionário. Por exemplo, nos AGs deveriam ser utilizadas elevadas taxas de mutação nas gerações iniciais para aumentar a exploração do espaço de busca, e taxas menores de mutação nas gerações finais para priorizar o ajuste dos cromossomos quase-ótimos. Logo, o uso de parâmetros estáticos pode reduzir o desempenho do algoritmo.

Para solucionar as dificuldades apresentadas pela sintonia, foi elaborado o ajuste dos parâmetros por meio do controle que tem como objetivo ajustar o algoritmo ao problema durante a busca pela solução. $\mathrm{O}$ controle dos valores dos vários parâmetros de um algoritmo evolucionário é uma das mais importantes e promissoras áreas de pesquisa em computação evolucionária, e foi classificado por Eiben et al. [149] em três categorias: determinístico; adaptável e auto-adaptável. Na Figura 3.2 está apresentada a classificação dos ajustes dos parâmetros [149].

A forma direta para resolver os inconvenientes dos ajustes por meio da sintonia é obtida por meio da inclusão de uma das três estratégias de controle no algoritmo. 


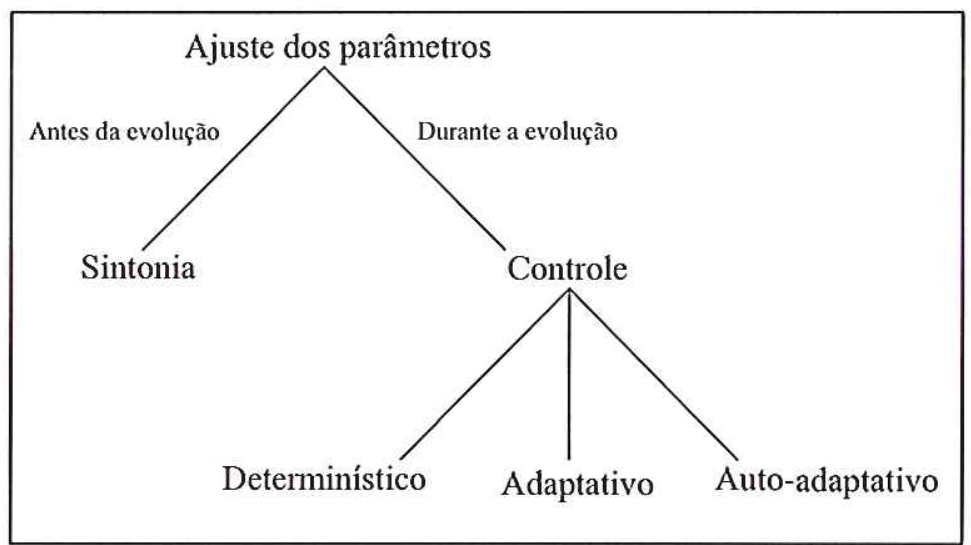

Figura 3.2: Classificação dos ajustes dos parâmetros [149].

\section{Determinístico}

É caracterizado por ajuste paramétrico realizado por regra determinística. Esta regra não inclui o uso de realimentações provenientes da busca realizada pelo AG. Geralmente, empregam-se regras que variam no tempo, ou seja, regras que podem mudar de acordo com o número de gerações decorridas. Muhlenbein e Schlierkamp-Voosen [141] observaram que o operador mutação influencia o desempenho dos AGs mais que o operador cruzamento quando as soluções estão distantes do ótimo, e constataram que o operador cruzamento é mais eficiente se as soluções estiverem perto do ótimo. Conseqüentemente, sugeriram diminuir a taxa de mutação e aumentar a taxa de cruzamento durante a evolução do algoritmo para melhorar o desempenho do AG.

\section{Adaptativo}

Este tipo de ajuste paramétrico emprega realimentação da busca do AG para determinar a direção e ou a amplitude da mudança do parâmetro. A atribuição do valor do parâmetro da estratégia pode envolver recompensas e a ação do AG pode determinar se o novo valor persiste ou se propaga por toda a população. Rechenberg [127] propôs a regra de $1 / 5$ de sucesso (1/5 success rule) que indica que a razão de mutações bem sucedidas, aquelas que produzem descendentes melhores que seus pais sobre todas as mutações, deve ser $1 / 5$. Assim, se a relação for maior que $1 / 5$, a taxa de mutação deve ser aumentada e, se a relação for menor que $1 / 5$, a taxa de mutação deve ser reduzida.

\section{Auto-adaptativo}

Os parâmetros neste tipo de ajuste são codificados em cromossomos e submetidos a operadores genéticos, tais como mutação e cruzamento, caracterizando um processo 
de evolução simulada para tais parâmetros. Bäck e Schwefel [152], Bäck [153] e Saravanan et al. [154] investigaram a robustez dos métodos auto-adaptáveis usados na programação evolucionária e em estratégias de evolução. Bäck [155] incorporou as características auto-adaptáveis nos AGs utilizando taxas adaptáveis de mutação. John Holland [129] propôs que qualquer problema envolvendo sistemas capazes de se adaptar pode ser formulado em termos genéticos e, freqüentemente, pode ser resolvido por algoritmos genéticos. Este trabalho pioneiro mostrou que os AGs podem ser amplamente utilizados em aplicações científicas e de engenharia.

\section{Combinando Formas de Controle}

Vários estudos sobre métodos adaptáveis consideram somente o controle de um único parâmetro, devido à facilidade de relatar resultados positivos em casos simples, nos quais a exploração das potencialidades da adaptação pode ser realizada experimentalmente. Combinar formas de controle pode ser uma tarefa difícil, pois as interações entre os ajustes, mesmo para parâmetros estáticos e para diferentes componentes dos algoritmos evolucionários, não são bem compreendidas e dependem freqüentemente da função objetivo e da representação. Entretanto, o modelo tem duas vantagens: a confiabilidade e o tempo requerido para encontrar a solução ótima.

Yao et al. [156] adaptam o tamanho do passo da mutação por meio de uma combinação de funções Gaussiana e Cauchy. O tamanho do passo da mutação é autoadaptativo e usado para gerar dois novos indivíduos: um por distribuição de Cauchy e outro por distribuição Gaussiana. O pior indivíduo em termos da aptidão é rejeitado. Similarmente, Chellapilla [157] propõe uma combinação linear utilizando mutações Gaussiana e Cauchy produzindo melhores soluções com menor esforço computacional. As mutações de Cauchy são mais úteis em escapar de ótimos locais enquanto as mutações Gaussianas fornecem uma convergência local relativamente mais rápida em funções convexas.

Lis e Lis [158] propõem um controle adaptativo para ajustar as probabilidades de mutação e de cruzamento e o tamanho da população. Um AG paralelo foi utilizado sobre um número de épocas. Em cada época foram determinados os ajustes dos parâmetros para o AG. Ao término de cada época, a média dos parâmetros é ajustada para a época seguinte.

Tongchim e Chongstitvatana [159] apresentam um algoritmo adaptativo para ajustar os parâmetros e as taxas de cruzamento e mutação do AG de acordo com o desempenho observado. A população é dividida em subpopulações, que evoluem independente e simultaneamente em processadores diferentes. Após um período de tempo pré-definido, alguns indivíduos selecionados são trocados por meio de um processo de 
migração. As subpopulações operam usando diferentes valores de parâmetros que são combinados para formar a nova população.

Para otimização de funções multimodais utilizando AG são necessárias duas características: capacidade de convergir para um ótimo (local ou global); e capacidade de explorar novas regiões do espaço de solução na busca pelo ótimo global. Spears e De Jong [160] obtêm o ajuste destas características por meio dos valores de $p_{m}, p_{c}$ e o tipo de cruzamento empregado.

Deve-se salientar que qualquer combinação de formas de controle pode provocar problemas adicionais relacionados ao comportamento transitório do algoritmo. Assim, considere uma população organizada em um número disjunto de subpopulações, cada uma utilizando um diferente cruzamento. Se o tamanho atual das subpopulações depender do mérito do cruzamento, o pior operador (em algum estágio do processo) teria dificuldades para recuperar o tamanho de sua subpopulação. Isto reduziria as possibilidades para utilizar bons operadores nos estágios finais do processo.

\subsection{Algoritmos Genéticos Propostos}

Os modelos de AGs propostos nesta tese são direcionados à otimização de problemas de alocação de recursos em redes de telecomunicações. Estes problemas envolvem a otimização de uma complexa função com múltiplos objetivos, múltiplos pontos de ótimo local, um abrangente conjunto de restrições e condições dinâmicas de operação. No primeiro caso, um AG é utilizado para solucionar basicamente o problema de roteamento e alocação de comprimentos de onda (RWA) em redes de comunicações ópticas. No segundo, duas propostas de AGs adaptativos são utilizadas para realizar alocações de canais (CAP) em sistemas de comunicações móveis celulares.

\subsubsection{Rede Óptica}

O modelo proposto para o problema RWA baseado em AG procura estabelecer a conexão do par origem-destino por meio do caminho mais curto. O modelo prioriza a alocação para o comprimento de onda mais utilizado, equaliza a distribuição das cargas de tráfego nos enlaces, realiza agregação dinâmica de tráfego e imparcialidade de capacidade de largura de faixa, e está condicionado às restrições da camada física. O modelo considera gerenciamento centralizado da rede de comunicação.

O tamanho da população e o número de gerações foram estabelecidos para se obter o máximo desempenho na operação da rede óptica com o menor tempo para convergência do algoritmo. O modelo utiliza o mecanismo de seleção por truncamento garantindo a continuidade dos melhores individuos por todas as gerações. Inclui tam- 
bém um procedimento similar ao BGA [142], no qual os descendentes substituem um percentual da população anterior e cruzamentos entre um mesmo indivíduo são proibidos. Incorpora o mecanismo de inserção de imigrantes compensando eventuais perdas na diversidade da população. O uso do cruzamento em 3 pontos aumenta a velocidade de convergência do modelo. A taxa de mutação é adaptativa, associando a cada cromossomo do indivíduo uma particular probabilidade de mutação de acordo com sua aptidão.

\subsubsection{Rede de Comunicação Móvel Celular}

Dois modelos baseados em AG são propostos para otimizar o CAP em redes de comunicações móveis celular. Os modelos estabelecem uma conexão entre o usuário móvel e a estação rádio-base atribuindo um canal de forma a otimizar o desempenho da rede tanto para novas chamadas quanto para handoff. Os modelos priorizam a alocação para o canal mais utilizado, equalizam a distribuição dos canais no ambiente celular, e estão condicionados às restrições de interferência eletromagnética.

Os modelos incluem todas as características exibidas pelo algoritmo desenvolvido para rede óptica, acrescido de um mecanismo denominado reservatório que auxilia a formação da população inicial, além de um modelo de AG adaptativo para as taxas de cruzamento, mutação e reprodução em função da diversidade dos pais. Resultados das simulações para determinação do tamanho ótimo da população e o número de pontos de cruzamento são apresentados.

\subsubsection{Rede Híbrida Óptica e Via Satélite}

O modelo proposto baseado em AG é utilizado na solução do problema RWA de uma rede brasileira de comunicação óptica conectada a uma rede de comunicação via satélite. O modelo gerencia simultaneamente a demanda de tráfego nas duas redes, óptica e via satélite, abordadas integradamente. O algoritmo prioriza a alocação para o comprimento de onda ou canal mais utilizado, equaliza a distribuição das cargas de tráfego nos enlaces, e realiza agregação dinâmica de tráfego.

O AG utiliza os mesmos operadores e parâmetros apresentados para o caso da rede óptica: tamanho da população, número de gerações, seleção por truncamento, um procedimento similar ao BGA [142], mecanismo de inserção de imigrantes, cruzamento em 3 pontos e taxa de mutação adaptativa.

Os resultados numéricos indicam a aplicabilidade da abordagem proposta na gerência integrada de redes distintas, identificando rotas e dispositivos mais utilizados. 


\section{Capítulo 4}

\section{Formulação do Problema de Otimização de Recursos}

\subsection{Introdução}

A expansão das redes de comunicações, sobretudo a evolução das arquiteturas de redes regulares para redes arbitrárias, tornou difícil a obtenção de modelos analíticos exatos. Ainda, a complexidade matemática para a alocação ótima de comprimentos de onda em redes WDM sujeita à conversão esparsa de comprimentos de onda inviabiliza o uso em tempo real dos modelos existentes, mesmo em redes de dimensões moderadas. Neste trabalho, a proposta heurística para a solução do problema RWA tem como base os algoritmos genéticos. O modelo proposto permite incluir facilmente o uso de conversores e diferentes restrições da camada física. Ainda, possibilita o uso de nós roteadores com capacidade de agregação dinâmica de tráfego e admite o controle da imparcialidade de capacidade de largura de faixa por meio do controle de admissão de conexão.

Na solução do problema de alocação dinâmica de canais nas redes de comunicações móveis são propostos os esquemas GALC (genetic algorithm with locking channel) e GASC (genetic algorithm with switching channel). Estes modelos utilizam algoritmo genético adaptativo capaz de adaptar dinamicamente as taxas dos operadores genéticos em função da diversidade dos pais. Por meio de exaustivos testes é obtido o tamanho ótimo da população em função do desempenho e do tempo de simulação para os modelos propostos. Os modelos ainda permitem a inclusão do handoff e das diferentes restrições eletromagnéticas. 


\subsection{Redes Ópticas WDM}

Para que dados possam ser transferidos de uma estação para outra nas redes de telecomunicações de próxima geração, uma conexão necessita ser estabelecida, de forma similar ao caso de uma rede fixa telefonia. Esta operação é executada por meio da determinação de uma rota na rede, conectando as estações origem e destino, e pela alocação de um único ou diferentes comprimentos de onda nos diversos enlaces da rota. A largura de banda disponível nesta rota é alocada para a conexão durante o intervalo de duração da chamada. Durante este intervalo, os comprimentos de onda correspondentes não poderão ser alocados para nenhuma outra conexão. Quando a transmissão é finalizada, o caminho associado é liberado e os respectivos comprimentos de onda estarão livres novamente em todos os enlaces da rota.

\subsubsection{Modelagem de Redes e Probabilidade de Bloqueio de Conexão}

A probabilidade de bloqueio para redes ópticas está disponível na forma analítica somente se forem adotados determinadas simplificações, modelos típicos de tráfego ou RWAs específicos. Uma breve revisão dos modelos analíticos disponíveis para as arquiteturas de redes regulares e arbitrárias é apresentada. Todos os modelos utilizam as seguintes considerações:

1. Cada caminho óptico utiliza a largura de faixa inteira de um comprimento de onda;

2. Cada enlace unidirecional está associado a uma única fibra;

3. Todas as fibras possuem o mesmo número, $W$, de comprimentos de onda;

4. Todo roteador possui $W$ transmissores e $W$ receptores para cada um dos enlaces pertencentes ao nó;

5. A rede somente suporta tráfego ponto-a-ponto, não havendo tráfego pontomúltiplos pontos (multicast);

6. Requisições de conexão não são enfileiradas. Se uma requisição for bloqueada ela é imediatamente descartada (erlang-B).

\section{Arquiteturas Regulares}

Considere um sistema de comunicação sem conversores de comprimento de onda. Neste caso, a solicitação de uma conexão entre dois usuários será bloqueada caso não exista algum comprimento de onda disponível em todos os enlaces da rota. Seja $W$ o número 
de comprimentos de onda em cada enlace; $T$ o tempo médio de duração de uma conexão; e $\lambda_{i}$ a taxa de solicitação de comprimento de onda no $i$-ésimo enlace da rota. Seja $L_{i}$ a carga média oferecida no $i$-ésimo enlace de uma rota. Então,

$$
L_{i}=\lambda_{i} \cdot T .
$$

Seja $p_{k}^{(i)}$ a probabilidade de que $k$ comprimentos de onda estejam em uso no $i$-ésimo enlace da rota. Considerando distribuição de Poisson para o tráfego e exponencial para o tempo de permanência da conexão, então [24]

$$
p_{k}^{(i)}=\frac{\left(\lambda_{i} \cdot T\right)^{k}}{k !} p_{0}^{(i)}=\frac{\frac{L_{i}^{k}}{k !}}{\sum_{l=0}^{W} \frac{L_{i}^{l}}{l !}} .
$$

Para uma conexão requisitando um único enlace, a probabilidade de bloqueio é igual a $p_{W}^{(1)}$, ou seja, a probabilidade de que $W$ comprimentos de onda estejam ocupados no enlace conectando origem e destino.

Seja $q_{k}^{(n)}$ a probabilidade de que existam $k$ comprimentos de onda ocupados nos primeiros $n$ enlaces de uma rota. Nas conexões estabelecidas por um enlace tem-se que

$$
q_{k}^{(1)}=p_{k}^{(1)}, \quad k \in 1, \ldots, W .
$$

Considere inicialmente o caso em que o número de enlaces seja igual a dois. Seja $a$ o primeiro e $b$ o segundo enlace da rota. Sejam $n_{a}$ e $n_{b}$ os números de comprimentos de onda livres nos enlaces $a$ e $b$, respectivamente. A probabilidade de que existam $k$ comprimentos de onda disponíveis para uma conexão é igual à probabilidade de que existam $k$ comprimentos de onda que estejam livres em ambos os enlaces. Conside que as distribuições dos comprimentos de onda nos enlaces $a$ e $b$ sejam mutuamente independentes. Assim, a probabilidade condicional de que existam $k$ comprimentos de onda disponíveis para uma conexão, dado que $n_{a}$ e $n_{b}$ comprimentos de onda estejam livres nos enlaces $a$ e $b$ é calculada por meio de [24]

$$
R\left(k \mid n_{a}, n_{b}\right)=\left\{\begin{array}{l}
\frac{\left(\begin{array}{c}
n_{a} \\
k
\end{array}\right)\left(\begin{array}{c}
W-n_{a} \\
n_{b}-k
\end{array}\right)}{\left(\begin{array}{c}
W \\
n_{b}
\end{array}\right)}, \text { se } \max \left(0, n_{a}+n_{b}-W\right) \leq k \leq \min \left(n_{a}, n_{b}\right) \\
0, \quad \text { caso contrário. }
\end{array}\right.
$$


Observe que o número de comprimentos de onda livres em ambos os enlaces não pode ser menor que

$$
W-\left[\left(W-n_{a}\right)+\left(W-n_{b}\right)\right]=n_{a}+n_{b}-W .
$$

Utilizando esta probabilidade condicional pode-se determinar a distribuição de comprimentos de onda ocupados em dois enlaces da rota [24],

$$
q_{k}^{(2)}=\sum_{i=0}^{W} \sum_{j=0}^{W} R(W-k \mid W-i, W-j) \cdot p_{i}^{(1)} \cdot p_{j}^{(2)} .
$$

A probabilidade de bloqueio de uma conexão composta por dois enlaces é dada por

$$
P^{(2)}=q_{W}^{(2)} .
$$

É possível estender os resultados anteriores para determinar a probabilidade de bloqueio de uma conexão que utiliza $n$-enlaces por meio de uma fórmula recursiva que determina a distribuição dos comprimentos de onda ocupados sobre uma rota de $n$-enlaces. Assim, dada a distribuição dos comprimentos de onda ocupados nos primeiros $(n-1)$ enlaces do caminho e a distribuição dos comprimentos de onda no $n$-ésimo enlace, para $n>1$, tem-se que [24]

$$
q_{k}^{(n)}=\sum_{i=0}^{W} \sum_{j=0}^{W} R(W-k \mid W-i, W-j) \cdot p_{i}^{(n-1)} \cdot p_{j}^{(n)},
$$

resultando na probabilidade de bloqueio de uma conexão composta por $n$ enlaces,

$$
P^{(n)}=q_{W}^{(n)} .
$$

Se os conversores de comprimentos de onda estiverem disponíveis em todos os nós da rede, a restrição exigindo que uma conexão necessita utilizar o mesmo comprimento de onda em todos os enlaces da rota é removida. Portanto, a solicitação somente será bloqueada caso não exista nenhum comprimento de onda disponível no enlace. Assim, podem ser utilizados os resultados obtidos por meio da teoria clássica dos circuitos comutados. A probabilidade de bloqueio para uma conexão com $n$-enlaces será [18], [24], [66]

$$
P^{(n)}=1-\prod_{i=1}^{n}\left(1-q_{W}^{(i)}\right) .
$$

Se a carga média em todos os enlaces for a mesma, $q_{W}^{(i)}=p_{W}$, a probabilidade de bloqueio pode ser expressa por 


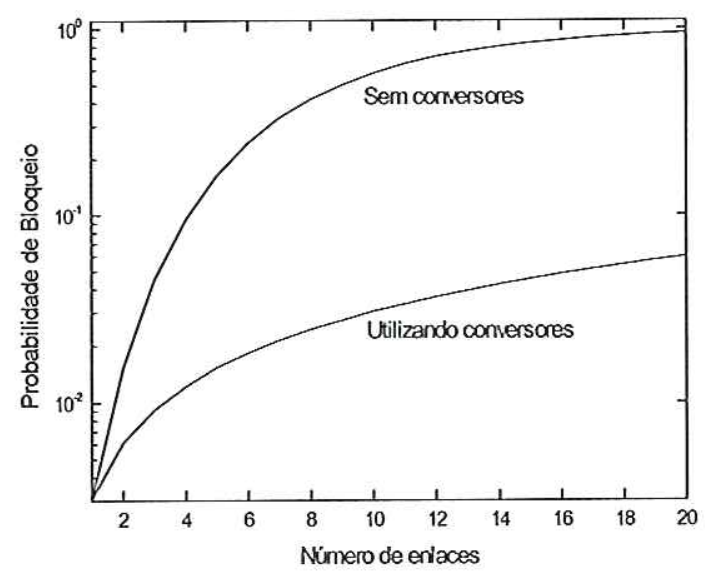

(a)

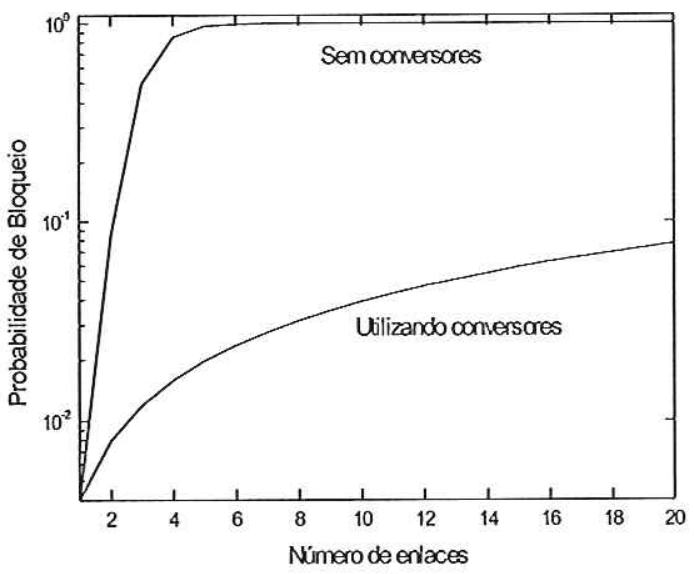

(b)

Figura 4.1: Probabilidade de bloqueio em função do número de enlaces de uma rota, com e sem conversores. O número de comprimentos de onda $(W)$ e a carga em cada enlace são, respectivamente: (a) $W=5$ e 1 erlang; e (b) $W=100$ e 80 erlangs [24].

$$
P^{(n)}=1-\left(1-p_{W}\right)^{n} .
$$

A Figura 4.1 apresenta os gráficos da probabilidade de bloqueio em função do número de enlaces para uma rota com múltiplos enlaces, ambos com e sem conversores de comprimento de onda [24]. Na Figura 4.1 (a) foram disponibilizados 5 comprimentos de onda por enlace e a carga oferecida por enlace é 1 erlang. Por meio do gráfico constata-se a diferença entre o desempenho dos esquemas com e sem conversores de comprimento de onda com o aumento do número de enlaces. A Figura 4.1 (b) compara o desempenho quando o número de comprimentos de onda é 100 e a carga oferecida por enlace é igual a 80 erlangs. Neste caso, a diferença no desempenho aumenta muito mais acentuadamente com o aumento do número de enlaces.

No modelo analítico apresentado [24], a carga de tráfego e a probabilidade de ocupação dos comprimentos de onda nos enlaces são considerados independentes. Em conseqüência, o modelo não pode ser aplicado a redes esparsamente conectadas, como no caso de redes em anel, devido à elevada correlação de cargas entre os enlaces de uma rota, o que invalida a consideração de independência carga-enlace.

Vijayanand et al. [61] consideram a ocupação dos comprimentos de onda estatisticamente independente entre os enlaces. Adotam $W$ como o número de comprimentos de onda em uma fibra, $x$ como a probabilidade de indisponibilidade de um dado comprimento de onda, e definem $P_{n w c}$ como a probabilidade de que a solicitação de uma rota do nó $s$ para o nó $d$, consistindo de $L$ enlaces, seja bloqueada caso não existam conversores no percurso. Isto é equivalente à probabilidade de que cada comprimento 
de onda esteja em uso no mínimo em um dos $L$ enlaces, podendo ser determinada por

$$
P_{n w c}=\left[1-(1-x)^{L}\right]^{w} .
$$

Além disso, Vijayanand et al. [61] definem $P_{w c}$ como a probabilidade de que uma solicitação do nó $s$ para o nó $d$, consistindo de $L$ enlaces, seja bloqueada, estando os nós equipados com conversores de comprimento de onda. Equivale à probabilidade de que todos os comprimentos de onda estejam em uso no mínimo em um dos $L$ enlaces, determinada por meio de

$$
P_{w c}=1-(1-x)^{L} .
$$

Um gráfico da probabilidade de bloqueio em função do número de enlaces e probabilidade de ocupação está apresentado na Figura 4.2 [61]. Por intermédio do gráfico observa-se que a probabilidade de bloqueio aumenta com a probabilidade de ocupação do enlace, e que este aumento é mais acentuado em redes sem conversores. Observa-se também que os conversores reduzem a probabilidade de bloqueio em rotas com número elevado de enlaces, ou seja, em redes longas os conversores contribuem para melhorar o desempenho do sistema.

É importante quantificar a melhoria no desempenho das redes de comunicação com a inclusão dos conversores. Esta melhoria depende da topologia da rede, da demanda de tráfego e do número de comprimentos de onda disponíveis. Quando uma rede se torna mais densa em quantidade de enlaces, pode ser esperada uma redução na utilidade dos conversores, visto que os caminhos lógicos são mais curtos. No caso limite, no qual todos os nós estão interligados por meio de um único enlace, os conversores não apresentam efeito no desempenho da rede, pois todas as seções são percurso único. Por outro lado, uma rede esparsamente conectada tende a não combinar bem as solicitações, provocando uma correlação de carga em enlaces sucessivos e reduzindo a utilidade dos conversores [64]. Em um destes casos limites, a rede em anel, Subramaniam et al. [64] constataram que os conversores são mais úteis quando o número de comprimentos de onda por fibra é maior e a carga é reduzida. Quando o número de comprimentos de onda é maior, os bloqueios ocorrem não por falta de recursos, mas devido à inabilidade de utilizar os recursos eficientemente. Em condição de carga elevada, os bloqueios são devidos à falta de comprimentos de onda em número suficiente, e a presença dos conversores não melhora o desempenho.

Os modelos analíticos apresentados consideram roteamento fixo, tráfego dinâmico, alocação aleatória dos comprimentos de onda e apresentam moderada complexidade computacional. Entretanto, supõem independência carga-enlace e não podem ser aplicados às arquiteturas de redes arbitrárias. 


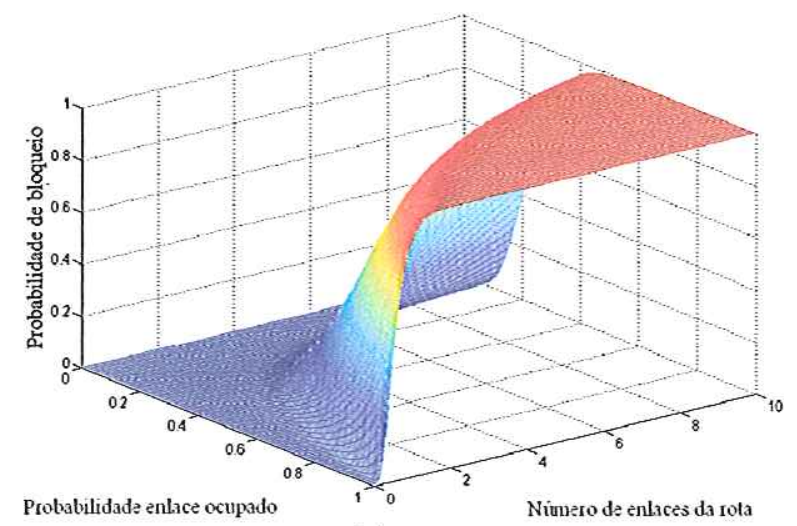

(a)

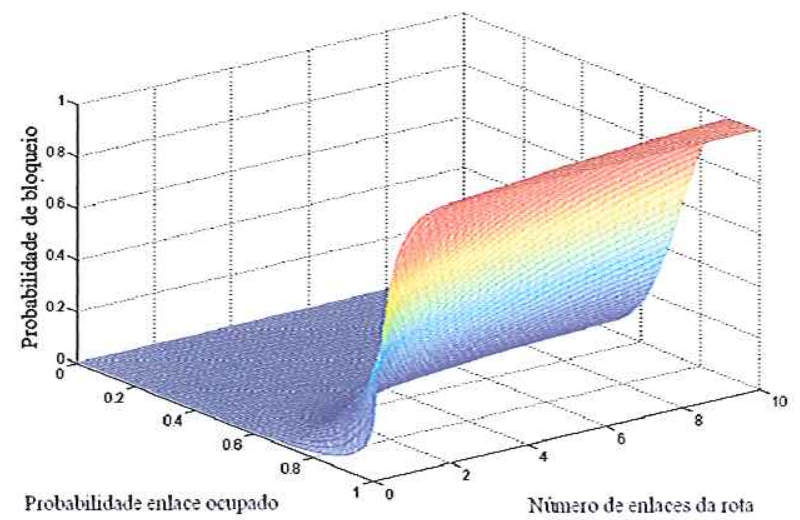

(b)

Figura 4.2: Probabilidade de bloqueio em função do número de enlaces e probabilidade de ocupação dos enlaces utilizando 8 comprimentos de onda: (a) sem conversores de comprimento de onda; e (b) após a inclusão dos conversores [61].

\section{Arquiteturas Arbitrárias}

Utilizando o método de aproximação de carga reduzida pode-se obter a probabilidade de estado para o número de comprimentos de onda em cada enlace [21], [25], [28], [161]. O modelo considera distribuição de Poisson para o tráfego e utiliza um modelo de Markov com taxas de requisição dependentes do estado. A aproximação de [25], [28] aplica-se a redes sem conversâo ou com conversão plena, enquanto o modelo de [21], [161] estende-se para redes com conversão esparsa.

Redes com conversão esparsa podem apresentar desempenho similar às redes com conversão plena com o incremento da redução dos custos com dispositivos de rede.

A seguir são apresentados os modelos analíticos para roteamento e alocação de comprimentos de onda em percurso único [21] e multipercurso [161] para redes com conversão esparsa. 
RWA em Percurso Único Seja $P_{k}(k=0, . ., M)$ a probabilidade de bloqueio média de todos os pares origem-destino quando $k$ nós conversores são disponibilizados na rede; $L_{a}^{(t)}$ a probabilidade de bloqueio de uma rota $R_{a}^{(t)}$ para o par origem-destino $a$; e $e_{a}$ o tráfego oferecido à rede pelo par $a$,

$$
P_{k}=\frac{\sum_{a} e_{a} L_{a}^{(t)}}{\sum_{a} e_{a}}
$$

O objetivo é minimizar $P_{M}$ distribuindo adequadamente os conversores e decidindo as rotas para os pares origem-destino. Considerar $X_{j}$ uma variável aleatória representando o número de comprimentos de onda desocupados em um enlace $j$. Seja $q_{j}\left(m_{j}\right)$ a probabilidade de que $m_{j}$ comprimentos de onda estejam livres no enlace $j$, denotada por

$$
q_{j}\left(m_{j}\right)=P\left(X_{j}=m_{j}\right), \quad m_{j}=0, \ldots, W .
$$

O estado da rede pode ser representado por $\overline{\mathbf{m}}=\left(m_{1}, m_{2}, \ldots, m_{j}\right)$. Assim, o espaço de estados se torna $\mathfrak{M}=\{0, \ldots, W\} \times \ldots . \times\{0, \ldots, W\}$. Adotando que as variáveis aleatórias $X_{j}, j \in\{1, \ldots, J\}$ são independentes,

$$
q(\overline{\mathrm{m}})=\prod_{j=1}^{J} q_{j}\left(m_{j}\right), \quad \overline{\mathrm{m}} \in \mathfrak{M} .
$$

As requisições de conexão que chegam em um enlace $j$ são consideradas obedecendo à distribuição de Poisson com taxa $\alpha_{j}$. De acordo com essas considerações, o comportamento de chegada e partida de tráfego dos enlaces forma um sistema Markoviano e pode ser resolvido por

$$
q_{j}\left(m_{j}\right)=\frac{W(W-1) \ldots\left(W-m_{j}+1\right)}{\alpha j^{m_{j}}} q_{j}(0), \quad m_{j}=1, \ldots, W
$$

na qual,

$$
q_{j}(0)=\left[1+\sum_{m_{j}=1}^{W} \frac{W(W-1) \ldots\left(W-m_{j}+1\right)}{\alpha j^{m_{j}}}\right]^{-1} .
$$

Para determinar $\alpha_{j}$,considere um enlace $j$ qualquer. Incluindo todas as rotas que utilizam o enlace $j$, a taxa total de requisições no enlace $j$ é dada por

$$
\alpha_{j}=\sum_{R_{a} \in R_{j}} \frac{e_{a}\left(1-L_{a}^{(t)}\right)}{1-q_{j}(0)} .
$$

Considere que a localização dos nós conversores e as rotas são conhecidas. Seja $u_{i}\left(m_{j} ; R_{a}^{(t, k)}\right)$ a representação da probabilidade de que se $m_{j}$ comprimentos de onda estão livres no enlace $j$, o número $i$ de comprimentos de onda estão livres na sub-rota 
$R_{a}^{(t, k)}$ que inclui o enlace $j$. Representado por $h\left(R_{a}^{(t, k)}\right)$ o número de enlaces da subrota $R_{a}^{(t, k)}$, e considerando $\left\{j, j_{1}, j_{2}, \ldots, j_{h\left(R_{a}^{(t, k)}\right)-1}\right\}$ o conjunto de enlaces da sub-rota $R_{a}^{(t, k)}$, a probabilidade $u_{i}\left(m_{j} ; R_{a}^{(t, k)}\right)$ pode ser obtida por

$$
\begin{aligned}
& u_{i}\left(m_{j} ; R_{a}^{(t, k)}\right)=\sum_{m_{j_{1}}=0}^{W} \sum_{m_{j_{2}}=0}^{W} \ldots \sum_{m_{j}} \sum_{h\left(R_{a}^{(t, k)}\right)-1}^{W}=0 \\
& \left\{\begin{array}{c}
h\left(R_{a}^{(t, k)}\right)-1 \\
\left.\prod_{l=1}^{h} q_{j_{l}}\left(m_{j_{l}}\right) \times p_{i}^{h\left(R_{a}^{(t, k)}\right)}\left(m_{j}, m_{j_{1}}, m_{j_{2}}, \ldots, m_{j_{\left(R_{a}^{(t, k)}\right)-1}}\right)\right\},
\end{array}\right.
\end{aligned}
$$

na qual $p_{i}^{n}(\cdot)$ é determinado pelas seguintes relações recursivas:

$$
\begin{gathered}
p_{i}^{n}\left(m_{j}, m_{j_{1}}, m_{j_{2}}, \ldots, m_{j_{h\left(R_{a}^{(t, k)}\right)-1}}=\sum_{k=0}^{W} p_{i}^{2}\left(k, m_{j_{n}}\right) p_{k}^{n-1}\left(m_{j_{1}}, m_{j_{2}}, \ldots, m_{j_{h\left(R_{a}^{(t, k)}\right)-1}}\right),\right. \\
p_{i}^{2}(x, y)=\left\{\begin{array}{lc}
\beta(x, y, i), & \text { se } x \geq i, y \geq i, x+y-i \leq W, 0 \leq x, y \leq w \\
0, & \text { caso contrário, }
\end{array}\right.
\end{gathered}
$$

na qual,

$$
\beta(x, y, i)=\left(\prod_{k=1}^{i} \frac{y-k+1}{i-k+1}\right)\left(\prod_{k=1}^{x} \frac{x-k+1}{W-k+1}\right)\left(\prod_{k=1}^{x-i} \frac{W-y-k+1}{x-i-k+1}\right) .
$$

Se existirem $w_{a}^{i}$ nós conversores de comprimento de onda na rota, existirão $w_{a}^{i}+1$ sub-rotas. Assim, pode-se determinar, aproximadamente, a probabilidade de bloqueio $L_{a}^{(t)}$ por

$$
L_{a}^{(t)}=1-\prod_{k=1}^{w_{a}^{i}+1}\left[1-\sum_{m_{j}=0}^{W} q_{j}\left(m_{j}\right) u_{i}\left(m_{j} ; R_{a}^{(t, k)}\right)\right],
$$

assim que a rota for determinada para o par origem-destino.

Em resumo, a probabilidade de bloqueio $L_{a}^{(t)}$ para cada par origem-destino, $a$, pode ser determinada utilizando o algoritmo a seguir [21]:

1. Escolher $\alpha_{j}, j=1, \ldots, J$ arbitrariamente para todos enlaces. Iniciar $L_{a}^{(t)}=0$ para todo $a$;

2. Determinar $\{q(\overline{\mathbf{m}}): \overline{\mathbf{m}} \in \mathfrak{M}\}$ utilizando (4.17) e (4.18);

3. Calcular $\alpha_{j}, j=1, \ldots, J$ utilizando (4.19); 
4. Calcular $L_{a}^{(t)}$ para todo par origem-destino $a$. Se os novos valores de $L_{a}^{(t)}$ convergirem para os anteriores, encerrar a iteração. Caso contrário, retornar ao passo 2. Nos resultados númericos apresentados, o critério de convergência adotado foi $10^{-6}$

5. Determinar a probabilidade de bloqueio global, $P_{k}(k=0,1, . . M)$, utilizando (4.14).

Entretanto, o método é computacionalmente dispendioso e tratável somente para redes densamente conectadas com um número reduzido de nós.

Exemplo de RWA em Percurso Único Seja uma rede hipotética formada por 5 nós e 7 enlaces bidirecionais conforme ilustra a Figura 4.3. Adota-se que todas as rotas são pré-determinadas e fixas, e que uma única rota para cada par origemdestino, $R_{a}^{(1)}$, está disponível, conforme apresentado na Tabela 4.1. Adota-se, ainda, 4 comprimentos de onda por enlace, e que cada par origem-destino, $a$, requisita da rede duas conexões, $\rho_{1}$ e $\rho_{2}$. O tempo de permanência das conexões é infinito. Uma possível solução obtida com AG para a alocação dos comprimentos de onda está apresentada na Tabela 4.1 e ilustrada na Figura 4.3. Os números dos comprimentos de onda em destaque referem-se ao atendimento à solicitação $\rho_{2}$, e $B$ indica o enlace em que a solicitação foi bloqueada. Observar que as solicitações são bloqueadas devido ao uso inadequado dos recursos da rede, imposto pela condição do roteamento do menor caminho. Se fossem disponibilizadas duas rotas para cada par origem-destino, uma primária, $R_{a}^{(1)}$, e outra secundária, $R_{a}^{(2)}$, segundo a Tabela 4.2 , então todas as solicitações de conexão seriam atendidas, conforme ilustra a Figura 4.4.

Considere um modelo de tráfego dinâmico em que as requisições origem-destino obedecem à distribuição de Poisson, com médias 0,$1 ; 0,2 ; 0,3 ; 0,4$ e 0,5 solicitações por minuto, e o tempo de permanência das conexões é exponencialmente distribuído com média $1 / \mu=60 \mathrm{~s}$. Seja a rede hipotética apresentada na Figura 4.3 , com 4 comprimentos de onda por enlace. O roteamento é fixo e há disponibilidade de uma única rota para cada par origem-destino, $R_{a}^{(1)}$, de acordo com a Tabela 4.1. Uma comparação de desempenho, em termos da probabilidade de bloqueio, entre os resultados do modelo analítico e do AG proposto está apresentada na Figura 4.5, cujos valores estão relacionados na Tabela 4.3. Foram considerados três casos: rede sem conversores; com um único nó conversor (2); e com dois nós conversores $(2 ; 5)$. Os resultados demonstram um boa aproximação entre os resultados teóricos e de simulação. Para o caso mais crítico, rede sem conversão, a aproximação utilizando probabilidade de estado para o número de comprimentos de onda em cada enlace, adotada pelo modelo analítico, subestima o desempenho da rede. 


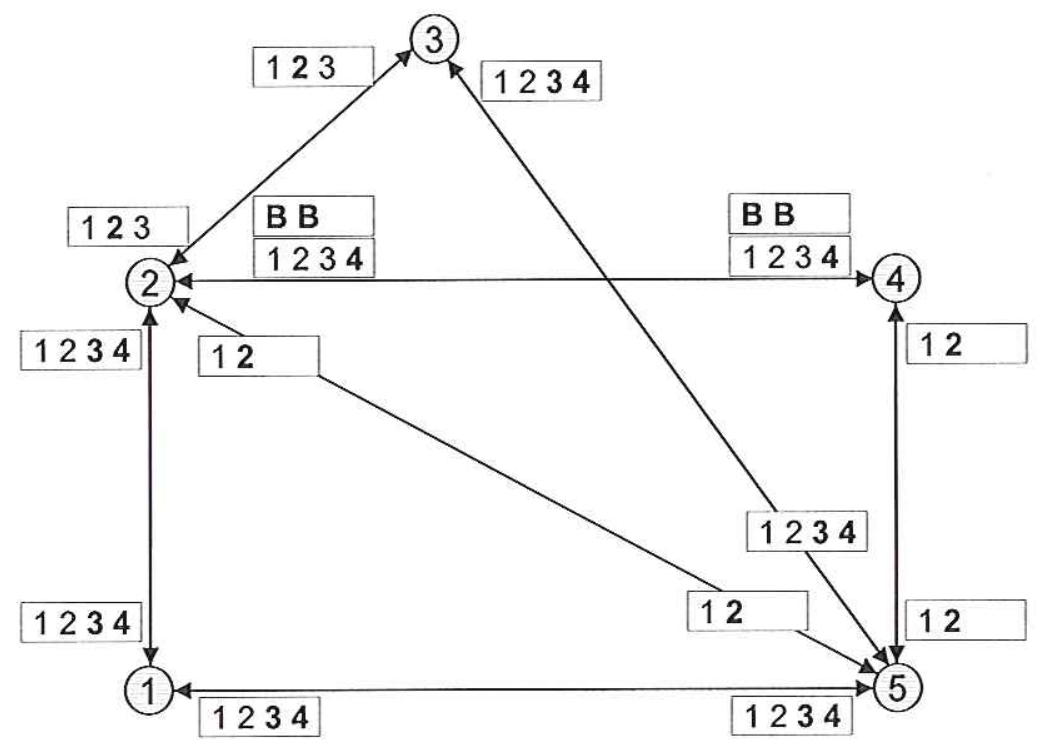

Figura 4.3: Alocação dos comprimentos de onda nos enlaces utilizando roteamento fixo com rota única para cada par origem-destino. $\mathrm{B}$ indica requisição bloqueada. $W=4$.

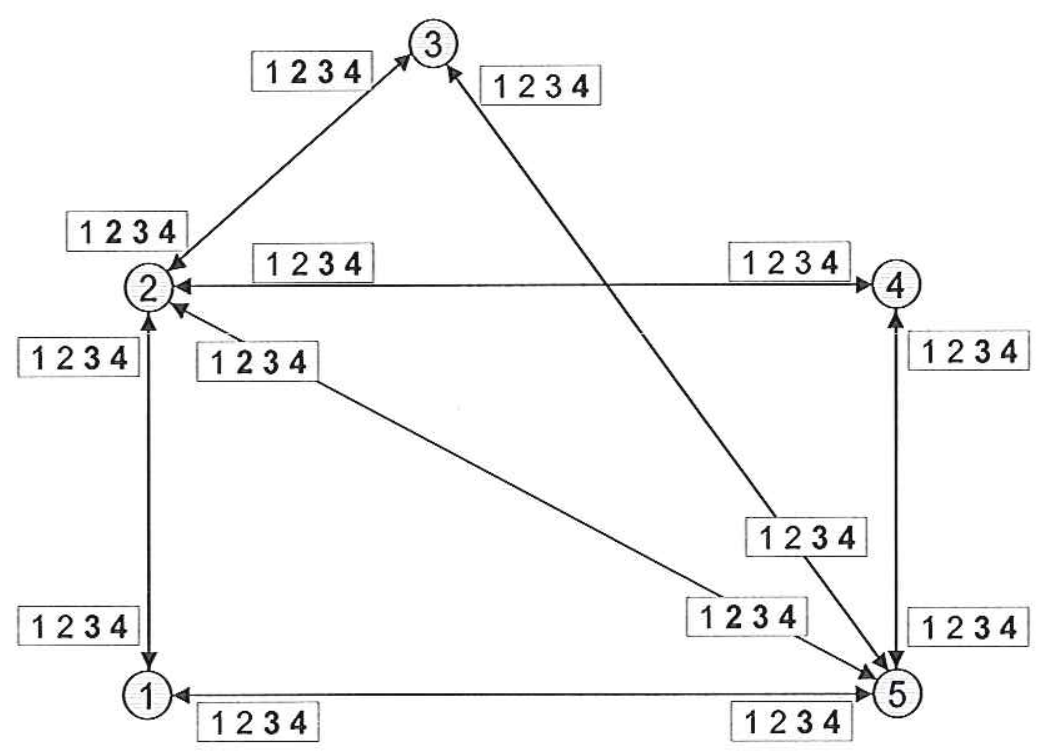

Figura 4.4: Alocação dos comprimentos de onda nos enlaces utilizando roteamento fixo com dois percursos distintos para cada par origem-destino. $W=4$. 
Tabela 4.1: Tabela de roteamento e alocação de comprimentos de onda da rota primária para as solicitações de conexão $\rho_{1}$ e $\rho_{2}$.

\begin{tabular}{|c|c|c|}
\hline & \multicolumn{2}{|c|}{ Comprimentos de Onda } \\
\hline$R_{a}^{(1)}$ & $\rho_{1}$ & $\rho_{2}$ \\
\hline $1 \rightarrow 2$ & 1 & 3 \\
\hline $1 \rightarrow 5 \rightarrow 3$ & 11 & 33 \\
\hline $1 \rightarrow 2 \rightarrow 4$ & 22 & 44 \\
\hline $1 \rightarrow 5$ & 2 & 4 \\
\hline $2 \rightarrow 1$ & 1 & 3 \\
\hline $2 \rightarrow 5 \rightarrow 3$ & 11 & 2 \\
\hline $2 \rightarrow 4$ & 1 & req. bloqueada \\
\hline $2 \rightarrow 5$ & 1 & 2 \\
\hline $3 \rightarrow 5 \rightarrow 1$ & 11 & 33 \\
\hline $3 \rightarrow 2$ & 1 & 2 \\
\hline $3 \rightarrow 2 \rightarrow 4$ & 33 & req. bloqueada \\
\hline $3 \rightarrow 5$ & 2 & 4 \\
\hline $4 \rightarrow 2 \rightarrow 1$ & 22 & 44 \\
\hline $4 \rightarrow 2$ & 1 & req. bloqueada \\
\hline $4-2 \rightarrow 3$ & 33 & req. bloqueada \\
\hline $4 \rightarrow 5$ & 1 & 2 \\
\hline $5 \rightarrow 1$ & 2 & 4 \\
\hline $5 \rightarrow 2$ & 1 & 2 \\
\hline $5 \rightarrow 3$ & 2 & 4 \\
\hline $5 \rightarrow 4$ & 1 & 2 \\
\hline
\end{tabular}

Considere que sejam disponibilizadas duas rotas para cada par origem-destino, apresentadas na Tabela 4.2. Caso fossem verificadas todas as combinações de rotas para os pares origem-destino, $\left\{R_{a}^{(t)} ; t=1, . ., n_{a}\right\}$, seria possível determinar a melhor rota para cada par a que minimiza a probabilidade de bloqueio. Entretanto, isto exige um esforço computacional $O\left(\prod_{a} n_{a}\right)$. No modelo analítico, Harai et al. [21] utilizam duas aproximações para coordenação do roteamento por meio dos algoritmos descent e sequential. A proposta do algoritmo descent consiste em substituir heuristicamente uma rota do par origem-destino por outra, em cada iteração, tal que a probabilidade de bloqueio seja reduzida. No algoritmo sequential a rota utilizando o enlace mais sobrecarregado é escolhida como candidata para substituição. O resumo das estratégias está apresentado no Apêndice A. Em resumo, as aproximações consideram roteamento fixo associando uma única rota ótima para cada par $a$, exigem um grande esforço computacional e não se aplicam à solução de redes dinâmicas com múltiplos percursos. 
Tabela 4.2: Tabela de roteamento e alocação de comprimentos de onda das rotas primária e secundária para as solicitações de conexão $\rho_{1}$ e $\rho_{2}$.

\begin{tabular}{|c|c|c|c|c|c|}
\hline \multicolumn{3}{|c|}{ Rota Primária } & \multicolumn{3}{|c|}{ Rota Secundária } \\
\hline$R_{a}^{(1)}$ & $\rho_{1}$ & $\rho_{2}$ & $R_{a}^{(2)}$ & $\rho_{1}$ & $\rho_{2}$ \\
\hline $1 \rightarrow 2$ & 1 & 3 & $1 \rightarrow 5 \rightarrow 2$ & & \\
\hline $1 \rightarrow 5 \rightarrow 3$ & 11 & & $1 \rightarrow 2 \rightarrow 3$ & & 44 \\
\hline $1 \rightarrow 2 \rightarrow 4$ & 22 & 33 & $1 \rightarrow 5 \rightarrow 4$ & & \\
\hline $1 \rightarrow 5$ & 2 & 4 & $1 \rightarrow 2 \rightarrow 5$ & & \\
\hline $2 \rightarrow 1$ & 1 & 3 & $2 \rightarrow 5 \rightarrow 1$ & & \\
\hline $2 \rightarrow 5 \rightarrow 3$ & 11 & 2 & $2 \rightarrow 5 \rightarrow 3$ & & \\
\hline $2 \rightarrow 4$ & 1 & 3 & $2 \rightarrow 5 \rightarrow 4$ & & \\
\hline $2 \rightarrow 5$ & 1 & 2 & $2 \rightarrow 1 \rightarrow 5$ & & \\
\hline $3 \rightarrow 5 \rightarrow 1$ & 11 & & $3 \rightarrow 2 \rightarrow 1$ & & 44 \\
\hline $3 \rightarrow 2$ & 1 & 2 & $3 \rightarrow 5-2$ & & \\
\hline $3 \rightarrow 2 \rightarrow 4$ & 33 & & $3 \rightarrow 5 \rightarrow 4$ & 22 & 44 \\
\hline $3 \rightarrow 5$ & 2 & & $3 \rightarrow 2 \rightarrow 5$ & & 33 \\
\hline $4 \rightarrow 2 \rightarrow 1$ & 22 & & $4 \rightarrow 5 \rightarrow 1$ & & 33 \\
\hline $4 \rightarrow 2$ & 1 & 3 & $4 \rightarrow 5 \rightarrow 2$ & & \\
\hline $4-2 \rightarrow 3$ & 33 & & $4 \rightarrow 5 \rightarrow 3$ & 22 & 44 \\
\hline $4 \rightarrow 5$ & 1 & & $4 \rightarrow 2 \rightarrow 5$ & & 44 \\
\hline $5 \rightarrow 1$ & 2 & 4 & $5 \rightarrow 2 \rightarrow 1$ & & \\
\hline $5 \rightarrow 2$ & 1 & 2 & $5 \rightarrow 1 \rightarrow 2$ & & \\
\hline $5 \rightarrow 3$ & 2 & & $5 \rightarrow 2 \rightarrow 3$ & & 33 \\
\hline $5 \rightarrow 4$ & 1 & & $5 \rightarrow 2 \rightarrow 4$ & & 44 \\
\hline
\end{tabular}

RWA Multipercurso O modelo analítico utilizado por [161] para redes com conversores e múltiplos percursos inclui a análise do tráfego nos enlaces e do bloqueio das rotas, e resolve o sistema de equações utilizando substituições iterativas. Desta forma, a probabilidade de bloqueio, $L_{a}^{(t)}$, para cada par origem-destino, $a$, pode ser determinada utilizando-se o algoritmo seguinte:

1. Calcular $L_{a}^{(t)}$ para todo par origem-destino $a ; L_{a}^{(t)}$ é a probabilidade de bloqueio da rota $R_{a}^{(t)}$ obtida por meio de (4.24);

2. Iniciar $\alpha_{j}, j=1, \ldots, J$ para todos os enlaces, considerando $R$ o número de rotas origem-destino e $n_{a}$ o número de rotas alternativas para o par $a$, sendo $\left\{R_{a}^{(t)} ; t=1, . ., n_{a}\right\}$, utilizando

$$
\alpha_{j}\left(1-q_{j}(0)\right)=\sum_{a}^{R} \sum_{\substack{t=1 \\ j \in R_{a}^{(t)}}}^{n_{a}}\left\{\prod_{i=1}^{t} L_{a}^{(t-1)} \times e_{a}\left(1-L_{a}^{(t)}\right)\right\}, \quad L_{a}^{(0)}=1
$$




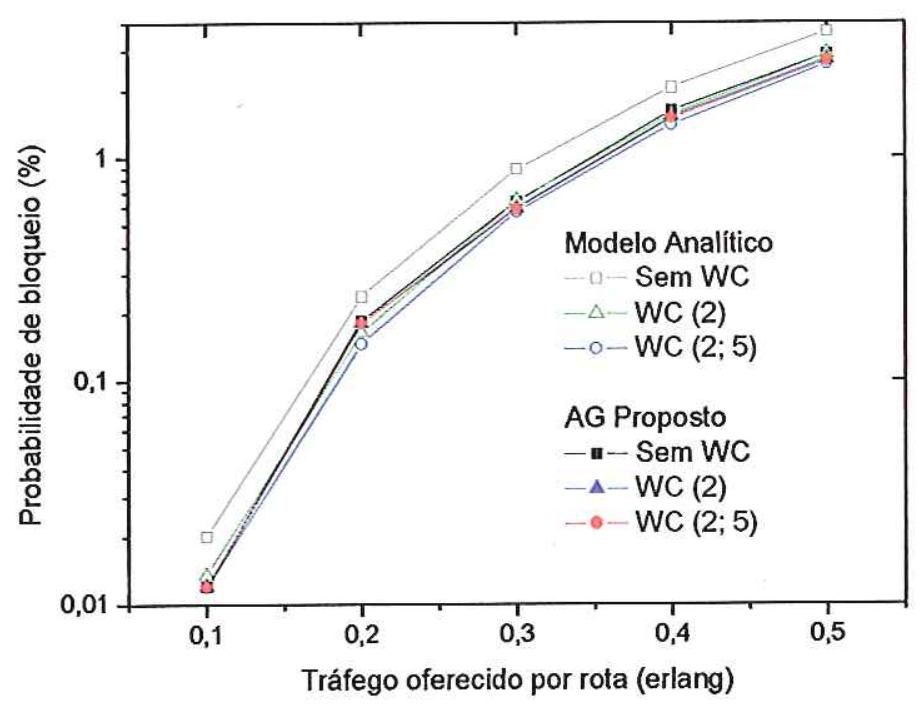

Figura 4.5: Probabilidade de bloqueio em função do tráfego oferecido de uma rede hipotética utilizando roteamento fixo com rota única para cada par origem-destino. $W=4$.

3. Determinar $\{q(\overline{\mathbf{m}}): \overline{\mathbf{m}} \in \mathfrak{M}\}$ utilizando (4.17) e (4.18);

4. Calcular $L_{a}^{(t)}, j=1, \ldots, J$ utilizando (4.20)-(4.24). Se os novos valores de $L_{a}^{(t)}$ convergirem para os anteriores, encerrar a iteração. Caso contrário, retornar ao passo 2. Nos resultados númericos apresentados, o critério de convergência adotado foi $10^{-6}$;

5. Determinar a probabilidade de bloqueio global, $P$, por meio de

$$
P=\frac{\sum_{a} e_{a} \prod_{t=1}^{n_{a}} L_{a}^{(t)}}{\sum_{a} e_{a}}
$$

Para solucionar as dificuldades apresentadas nos modelos analíticos foram propostos modelos heurísticos para o roteamento e alocação de comprimentos de onda.

$\mathrm{O}$ algoritmo de busca exaustiva procura por todos os estados da rede a rota e o respectivo comprimento de onda para atender à solicitação $R_{a}^{(t)}$ que exiba a menor probabilidade de bloqueio. Entretanto, o esforço computacional, $O\left(N \times W \times M_{a}\right)$, torna o modelo inadequado para sistemas que apresentam grandes espaços de estados. Uma alternativa para reduzir o tempo de processamento consiste no estabelecimento de roteamento por meio do menor caminho disponível (shortest-path) associado a uma estratégia de alocação do comprimento de onda mais utilizado (most-used), seguindo as restrições de continuidade do comprimento de onda, a qual denominaremos estratégia SP-MU (shortest-path most-used). 
Tabela 4.3: Probabilidade de bloqueio na rede hipotética: comparação entre o modelo analítico e o AG proposto. Roteamento fixo com rota única e $W=4$.

\begin{tabular}{|c|c|c|c|c|c|c|}
\cline { 2 - 7 } \multicolumn{1}{c|}{} & \multicolumn{6}{c|}{ Probabilidade de Bloqueio (\%) } \\
\hline $\begin{array}{c}\text { Tráfego } \\
\text { por rota } \\
\text { (erlang) }\end{array}$ & \multicolumn{2}{|c|}{ Modelo Analítico } & \multicolumn{2}{c|}{ Algoritmo Genético } \\
\cline { 2 - 7 } & $\begin{array}{c}\text { Sem } \\
\text { Conversão }\end{array}$ & $\begin{array}{c}\text { Esparsa } \\
(2)\end{array}$ & $\begin{array}{c}\text { Esparsa } \\
(2 ; 5)\end{array}$ & $\begin{array}{c}\text { Sem } \\
\text { Conversão }\end{array}$ & $\begin{array}{c}\text { Esparsa } \\
(2)\end{array}$ & $\begin{array}{c}\text { Esparsa } \\
(2 ; 5)\end{array}$ \\
\hline \hline 0,1 & 0,02018 & 0,0134 & 0,0119 & 0,0120 & 0,0120 & 0,0120 \\
0,2 & 0,2391 & 0,1652 & 0,1474 & 0,1851 & 0,1821 & 0,1821 \\
0,3 & 0,8878 & 0,6402 & 0,5715 & 0,6354 & 0,5917 & 0,5877 \\
0,4 & 2,0419 & 1,5436 & 1,3878 & 1,6156 & 1,5172 & 1,5008 \\
0,5 & 3,6280 & 2,8733 & 2,6068 & 2,8818 & 2,7324 & 2,6933 \\
\hline
\end{tabular}

Por outro lado, a aprendizagem-Q é um método de programação dinâmica assíncrona. A operação do algoritmo não necessita do conhecimento das probabilidades de transição de estado do sistema e pode ser utilizado em tempo real. O método é computacionalmente eficiente, pois armazena apenas uma tabela com valores $Q$ que estima a probabilidade de realizar uma ação $a$ no estado $x$. Entretanto, a dimensão da tabela aumenta consideravelmente em redes com grau nodal elevado e com a inclusão de conversores.

O modelo baseado em algoritmos genéticos para roteamento e alocação de comprimentos de onda procura estabelecer a conexão do par origem-destino por meio do caminho mais curto, prioriza a alocação para o comprimento de onda mais utilizado, e equaliza a distribuição das cargas nos enlaces. No AG proposto neste trabalho, o estado de cada comprimento de onda dos enlaces é representado por um gene. Um conjunto de genes forma um cromossomo, representando um enlace. O conjunto de todos os cromossomos forma o indivíduo, que representa uma política por meio de um vetor de dimensão $J \times W$, no qual $J$ é o número de enlaces da rede e $W$ é o número de comprimentos de onda, conforme ilustra a Tabela 4.4. Cada gene, $w_{j k}(j \leq J$; $k \leq W)$, que compõe um cromossomo representa o estado de um comprimento de onda $k$ (utilizado ou não-utilizado) em um enlace $j$.

Tabela 4.4: Representação de um indivíduo formado por vários cromossomos.

\begin{tabular}{|c|c|c|c|c|c|c|c|c|c|c|c|c|}
\hline \multicolumn{10}{|c|}{ Rede } \\
\hline \multicolumn{3}{|c|}{ Enlace 1 } & \multicolumn{3}{c|}{ Enlace 2} & \multicolumn{3}{c|}{ Enlace $J$} \\
\hline \hline$w_{11}$ & $w_{12}$ & $\ldots$ & $w_{1 W}$ & $w_{21}$ & $w_{22}$ & $\ldots$ & $w_{2 W}$ & $\ldots$ & $w_{J 1}$ & $w_{J 2}$ & $\ldots$ & $w_{J W}$ \\
\hline
\end{tabular}




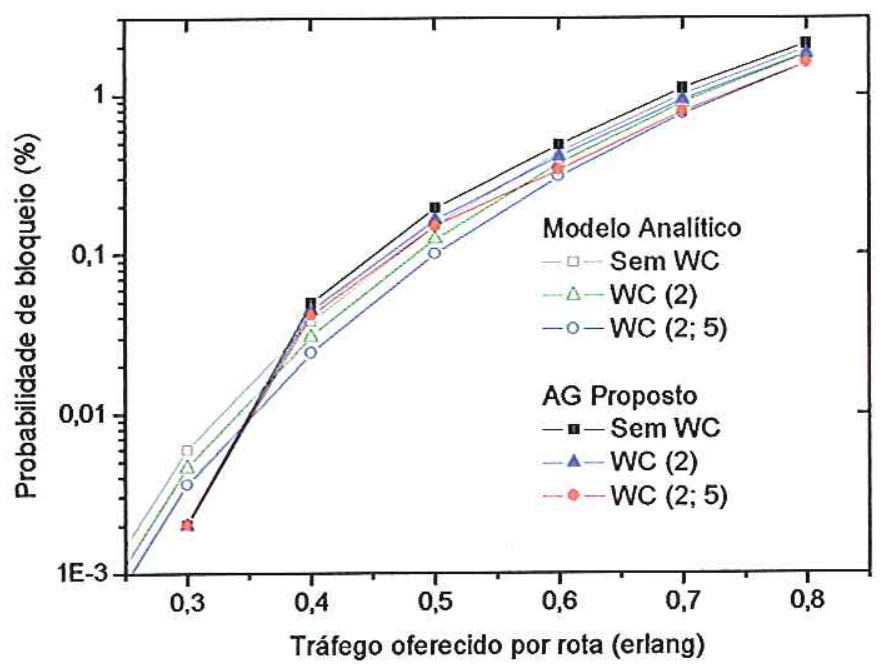

Figura 4.6: Probabilidade de bloqueio em função do tráfego oferecido para uma rede hipotética utilizando roteamento fixo com dois percursos distintos para cada par origem-destino. $W=4$.

A representação de cada gene é definida por

$$
w_{j k}= \begin{cases}1, & \text { para o comprimento de onda } k \text { em uso no enlace } j ; \\ 0, & \text { caso contrário. }\end{cases}
$$

Para efeito de comparação, consideremos a topologia de rede apresentada na Figura 4.3. O tráfego oferecido à rede é dinâmico, para qual as requisições origem-destino obedecem à distribuição de Poisson, com média variando de 0,1 a 0,8 solicitações por minuto e tempo de permanência exponencialmente distribuído com média $1 / \mu=60 \mathrm{~s}$. As requisições de conexão são distribuídas de forma homogênea. Os enlaces da rede dispõem de 4 comprimentos de onda. Os resultados da probabilidade de bloqueio para o modelo analítico e o AG proposto estão ilustrados na Figura 4.6 e apresentados na Tabela 4.5, juntamente com as estratégias SP-MU e aprendizagem-Q.

Todos os modelos apresentam desempenho em termos de probabilidade de bloqueio similar. Adicionalmente, os resultados obtidos com o AG proposto são coincidentes com o modelo analítico, o que demonstra a validade do modelo. Entretanto, caso fosse utilizado um modelo de rede mais complexo, com grau nodal elevado, vários comprimentos de onda e dispositivos conversores, o modelo analítico exigiria um elevado esforço computacional. Neste ambiente de rede complexo, o modelo utilizando aprendizagem-Q exigiria um extensivo gerenciamento para as tabelas de roteamento. Ainda, o AG proposto obtém resultados ligeiramente melhores que o modelo SP-MU. Esta melhoria foi obtida incluindo no modelo AG a rotina SP-MU e um procedimento para equalizar a distribuição das cargas na rede por meio dos estados dos enlaces. 
Tabela 4.5: Probabilidade de Bloqueio para a rede hipotética: Comparação entre Modelo Analítico, AG Proposto, SP-MU e Aprendizagem-Q. Roteamento fixo com dois percursos e $W=4$.

\begin{tabular}{|c|c|c|c|c|c|c|c|c|}
\hline & \multicolumn{8}{|c|}{ Probabilidade de Bloqueio (\%) } \\
\hline \multirow{2}{*}{$\begin{array}{l}\text { Tráfego } \\
\text { por rota } \\
\text { (erlang) }\end{array}$} & \multicolumn{4}{|c|}{ Modelo Analítico } & \multicolumn{4}{|c|}{ Algoritmo Genético $(1 ; 2)$} \\
\hline & $\begin{array}{c}\text { Sem } \\
\text { Conversão }\end{array}$ & $\begin{array}{c}\text { Esparsa } \\
(2)\end{array}$ & $\begin{array}{c}\text { Esparsa } \\
(2 ; 5)\end{array}$ & $\begin{array}{c}\text { Plena } \\
(1 ; 2 ; 3 ; 4 ; 5)\end{array}$ & $\begin{array}{c}\text { Sem } \\
\text { Conversão }\end{array}$ & $\begin{array}{c}\text { Esparsa } \\
(2)\end{array}$ & $\begin{array}{c}\text { Esparsa } \\
(2 ; 5)\end{array}$ & $\begin{array}{c}\text { Plena } \\
(1 ; 2 ; 3 ; 4 ; 5)\end{array}$ \\
\hline 0,1 & $2,3399 \mathrm{E}-6$ & $1,6746 \mathrm{E}-6$ & $1,2627 \mathrm{E}-6$ & $1,2591 \mathrm{E}-6$ & 0 & 0 & 0 & 0 \\
\hline 0,2 & $3,6912 \mathrm{E}-4$ & $2,7343 \mathrm{E}-4$ & $2,0977 \mathrm{E}-4$ & $2,0912 \mathrm{E}-4$ & 0 & 0 & 0 & 0 \\
\hline 0,3 & 0,00595 & 0,00463 & 0,00361 & 0,003516 & 0,00199 & 0,00199 & 0,00199 & 0,00199 \\
\hline 0,4 & 0,03837 & 0,03052 & 0,02414 & 0,024092 & 0,04918 & 0,04471 & 0,04173 & 0,04021 \\
\hline 0,5 & 0,15063 & 0,12390 & 0,09972 & 0,099314 & 0,19355 & 0,16418 & 0,14576 & 0,14582 \\
\hline 0,6 & 0,43178 & 0,36847 & 0,30418 & 0,30296 & 0,48175 & 0,40528 & 0,33333 & 0,33135 \\
\hline 0,7 & 0,99084 & 0,87725 & 0,74809 & 0,74518 & 1,07976 & 0,91566 & 0,76945 & 0,76432 \\
\hline 0,8 & 1,92148 & 1,76136 & 1,55851 & 1,55325 & 2,04864 & 1,77894 & 1,55563 & 1,54286 \\
\hline \multirow{2}{*}{$\begin{array}{l}\text { Tráfego } \\
\text { por rota } \\
\text { (erlang) }\end{array}$} & \multicolumn{4}{|c|}{ SP-MU $(2)$} & \multicolumn{4}{|c|}{ Aprendizagem- $Q^{(2)}$} \\
\hline & $\begin{array}{c}\text { Sem } \\
\text { Conversão }\end{array}$ & $\begin{array}{c}\text { Esparsa } \\
(2)\end{array}$ & $\begin{array}{c}\text { Esparsa } \\
(2 ; 5) \\
\end{array}$ & $\begin{array}{c}\text { Plena } \\
(1 ; 2 ; 3 ; 4 ; 5)\end{array}$ & $\begin{array}{c}\text { Sem } \\
\text { Conversão }\end{array}$ & $\begin{array}{c}\text { Esparsa } \\
(2) \\
\end{array}$ & $\begin{array}{c}\text { Esparsa } \\
(2 ; 5) \\
\end{array}$ & $\begin{array}{c}\text { Plena } \\
(1 ; 2 ; 3 ; 4 ; 5)\end{array}$ \\
\hline 0,1 & 0 & 0 & 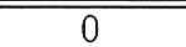 & 0 & 0 & " 0 & 0 & $\begin{array}{l}0 \\
\end{array}$ \\
\hline 0,2 & 0 & 0 & 0 & 0 & 0 & 0 & 0 & 0 \\
\hline 0,3 & 0,00595 & 0,00535 & 0,00533 & 0,00533 & 0,00601 & 0,00400 & 0,00201 & 0,00201 \\
\hline 0,4 & 0,04899 & 0,04071 & 0,03993 & 0,03890 & 0,05177 & 0,04050 & 0,03902 & 0,03130 \\
\hline 0,5 & 0,15924 & 0,14823 & 0,13744 & 0,13082 & 0,17084 & 0,16500 & 0,16391 & 0,13171 \\
\hline 0,6 & 0,43821 & 0,39645 & 0,34870 & 0,33597 & 0,50093 & 0,45570 & 0,33610 & 0,32670 \\
\hline 0,7 & 1,07453 & 0,91772 & 0,79609 & 0,78707 & 1,11913 & 0,91056 & 0,80210 & 0,78847 \\
\hline 0,8 & 1,98761 & 1,76834 & 1,56858 & 1,55857 & 2,02868 & 1,76381 & 1,59382 & 1,53620 \\
\hline
\end{tabular}

(1) 10 indivíduos, 20 gerações;

(2) valores obtidos sobre média em um período de $150 \mathrm{~h}$. 


\section{Complexidade do RWA}

Para avaliar a complexidade da alocação ótima de comprimentos de onda, considere a rede $G(V, E, W)$, na qual $V$ representa o conjunto dos $N$ nós; $N=|V| ; E$ representa o conjunto dos enlaces de fibras entre os nós $V$; e $W$ representa o conjunto de comprimentos de onda em cada enlace $W=w$. Uma requisição de caminho óptico objetiva conectar um par origem-destino. Considerando uma rede sem conversão, para se estabelecer um caminho óptico é necessário encontrar um comprimento de onda desocupado e idêntico em todos os enlaces da rota.

Definição 1 Problema de estabelecimento estático de caminhos ópticos (SLE - static lightpath establishment) - Dada uma rede $G(V, E, W), W \geq 3$, e um conjunto de caminhos ópticos $L$, é possível estabelecer todos os caminhos ópticos?

O procedimento da prova de que o SLE é NP-completo consiste em demonstrar que o problema é equivalente ao problema de coloração em grafos [162]. Encontrar o número mínimo de comprimentos de onda que poderiam acomodar as demandas condiciona determinar o número de cores do grafo, $n$, correspondente ao número de comprimentos de onda, $w$.

Teorema 2 SLE é NP-completo.

Prova. Veja Apêndice B

Considerando uma rede equipada com conversores, a restrição de continuidade de comprimento de onda em todos enlaces da rota é eliminada. No Apêndice $\mathrm{C}$ pode ser vista uma prova de que o problema de alocação de comprimento de onda em redes equipadas com conversores (CWA - convertible wavelength assignment), um caso mais simples que o problema de alocação e roteamento dinâmico proposto neste trabalho, é computacionalmente intratável [17]. Isto demonstra que o uso de métodos heurísticos é inevitável. Devido às vantagens dos algoritmos genéticos para solução de problemas mencionadas no Capítulo 3, em particular para solução de problemas NP-completo, propõe-se neste trabalho uma heurística baseada em AG para resolver diferentes problemas de roteamento e alocação de comprimentos de onda em redes de comunicação.

\subsubsection{Redes WDM com Conversão de Comprimentos de Onda Uti- lizando Algoritmos Genéticos}

A abordagem escolhida para esta pesquisa se baseia na alocação esparsa dos conversores de comprimentos de onda. O uso de conversores em todos os nós torna a 
rede onerosa e, em muitos casos, não apresenta redução associada da probabilidade de bloqueio, conforme ilustrado na Tabela 4.5. Por este motivo, a distribuição dos conversores pelos nós da rede deve ser otimizado. Uma das soluções propostas para superar este inconveniente se baseia na distribuição esparsa de conversores, dotando apenas alguns nós com capacidade de conversão de comprimento de onda [61], [64], [65], [125].

$\mathrm{O}$ algoritmo genético proposto aloca os comprimentos de onda às rotas, minimiza o número de conversões e a probabilidade de bloqueio, e determina a disposição otimizada dos conversores. A cada geração, o algoritmo realiza uma busca para obter conexões com o menor número de conversões. Isto tem influência direta na redução do custo da rede. O cálculo da função de adaptação envolve a análise da alocação de comprimentos de onda para as novas solicitações, utilizando o menor número de conversões em cada rota e considerando o estado atual do sistema.

Para o sistema investigado, a função de adaptação é calculada por

$$
f i t_{\text {tot }}=\sum_{j=1}^{J} \sum_{k=1}^{W} f i t(j, k),
$$

na qual a função de adaptação do enlace $j$ considerando o comprimento de onda $k$ é calculada por meio da soma de pesos

$$
f i t(j, k)=n_{1}(k) r_{1}+n_{2}(k) r_{2}+n_{3}(k) r_{3}+n_{4}(k) r_{4}+n_{5}(k) r_{5} .
$$

Em (4.29), $n_{1}(k)$ é o número de comprimentos de onda disponíveis no enlace $j$, no qual o comprimento de onda $k$ não está em uso; $n_{2}(k)$ é o número de enlaces que estão utilizando o comprimento de onda $k ; n_{3}(k)$ é o comprimento do enlace $j$; $n_{4}(k)$ é o número de conversões no enlace $j$ ao se alocar o comprimento de onda $k ; n_{5}(k)$ é o número de bloqueios ao se alocar o comprimento de onda $k$; e $r_{i}$ são constantes ponderadas de custo associadas às condições mencionadas e relacionadas a $n_{i}(k)$. A função de adaptação (4.28) calcula a adequação relativa à alocação de cada comprimento de onda $k$ para cada enlace $j, j \in R_{a}^{(t)}$. Particularmente, é o custo de se escolher o comprimento de onda $k$ para atender à solicitação presente na rota $R_{a}^{(t)}$. Os enlaces $j \in R_{a}^{(t)}$ são analisados e a disponibilidade de comprimentos de onda é verificada. Considerando a rota $R_{a}^{(t)}$ como referência, os coeficientes são ordenados por $r_{i}>r_{i+1}$, para os quais foi estabelecido de forma heurística após exaustivos testes de simulação os valores $r_{1}=+5, r_{2}=+1, r_{3}=-2, r_{4}=-5$, e $r_{5}=-50$. A função de adaptação penaliza as políticas que apresentam maior rota, considerando o número de enlaces e o comprimento físico, enlaces com tráfego elevado, uso de conversores e um número maior de comprimentos de onda bloqueados. 
Para se obter a disposição dos conversores foi utilizado o seguinte procedimento heurístico, adaptado das propostas de Vijayanand et al. [61] e Xiao e Leung [125]:

1. Colocar os conversores nos nós que apresentam a maior utilização;

2. Colocar os conversores nos nós com maior grau nodal;

3. Colocar os conversores de tal forma que exista no mínimo um conversor em cada laço (formado pelos enlaces) na rede;

4. Colocar os conversores de tal forma que eles estejam espalhados pela rede (alocação esparsa).

\section{Casos-limites: Nós com e sem Conversão}

Para efeito de comparação de resultados de probabilidade de bloqueio foram adotados dois casos-limites: rede sem conversão e com conversão completa. Conversão completa significa que todos os nós são dotados de conversores (alocação plena), podendo cada um deles converter cada comprimento de onda em qualquer outro. Por outro lado, rede sem conversão significa que nenhum nó é dotado de conversor de comprimento de onda. Conversão parcial é aquela para qual somente alguns nós são dotados de conversores (alocação esparsa), podendo cada um deles converter qualquer comprimento de onda em outro.

\subsubsection{Parâmetros de Simulação}

As considerações e parâmetros utilizados nas simulações são as seguintes:

1. As solicitações de comprimentos de onda obedecem à distribuição de Poisson com médias uniformes entre os tempos de solicitações;

2. A taxa média de solicitação de comprimento de onda é $\Lambda$;

3. O tempo de duração das solicitações, $t_{h}$ (tempo de permanência da conexão), é dado por uma distribuição exponencial com duração média $1 / \mu$. Estabelecidos a rota e os comprimentos de onda, todos os recursos da rede utilizados somente serão disponibilizados para nova alocação após o período $t_{h}$;

4. O modelo de tráfego adotado é dinâmico, segundo qual cada nó-origem pode realizar solicitação de conexão aos demais nós (destino) de acordo com a distribuição de Poisson. O tráfego oferecido, $e_{a}$, pelo par origem-destino $a$ é dado por $e_{a}=\Lambda_{a} / \mu$; 
- Inicie o contador de gerações $(t=0)$

- Leia a demanda de ocorrência de solicitações $\Lambda(t)$

- Gere uma população aleatória de indivíduos $P_{o p}(t)$

- Enquanto o critério de parada não for atingido

- Calcule a função aptidão para cada indivíduo

" Escolha a porcentagem de indivíduos mais aptos

- Aplique os operadores genéticos

- Selecione indivíduos para próxima geração

- Incremente o contador de gerações $(t=t+1)$

- Realize o RWA definido pelo AG

- Atualize os estados do sistema

- Fim

Figura 4.7: Algoritmo genético proposto para o RWA.

5. As redes são formadas por $N$ nós e $J$ enlaces unidirecionais. São disponibilizados $W$ comprimentos de onda em cada enlace, embora este número possa ser diferenciado para cada enlace de acordo com a demanda de tráfego;

6. As solicitações bloqueadas são eliminadas (Erlang-B);

7. O desempenho do algoritmo de alocação de comprimentos de onda para uma carga particular de tráfego pode ser avaliado pela probabilidade de bloqueio, $\mathrm{Pb}$, dada por

$$
P b=\frac{\text { número de requisiçôes bloqueadas }}{\text { total de requisiçốes }} .
$$

O modelo do algoritmo genético proposto para o problema RWA está apresentado esquematicamente na Figura 4.7. Inicialmente, o AG recebe a informação de ocorrência de solicitações de conexão na rede óptica operando on-line. Uma população inicial, formada por $P_{o p}$ indivíduos, é gerada aleatoriamente. Em seguida, é avaliada a aptidão de todos os indivíduos aos quais são aplicados os operadores genéticos: seleção, cruzamento e mutação. O procedimento de evolução é repetido até o critério de parada ser atingido. Após o processo de evolução, o AG estabelece as rotas e os respectivos comprimentos de onda para o atendimento às solicitações. Finalmente, os estados dos enlaces e dos dispositivos de rede são atualizados.

\subsubsection{Inclusão das Restrições da Camada Física}

Neste estudo é investigado um conjunto de protocolos para estabelecer e encerrar conexões ópticas dinamicamente. Quando o roteador necessita estabelecer uma nova conexão, o algoritmo determina o caminho mais curto ao destino, dado o estado atual 
da rede. Este roteamento considera ambos os aspectos lógicos como a disponibilidade de comprimentos de onda e a viabilidade da transmissão óptica em termos da qualidade do sinal [69]. As considerações de viabilidade da transmissão são obtidas com a eliminação dos enlaces inviáveis e ou por meio da regeneração do sinal em nós intermediários, estrategicamente posicionados ao longo do percurso.

O algoritmo genético proposto procura determinar a melhor rota e alocar comprimentos de onda aos enlaces, minimizando o número de conversores de comprimento de onda sem reduzir o desempenho da rede, e considerando a degradação causada pelos efeitos ASE e PMD. Informações adicionais de estado serão solicitadas pelo algoritmo para cada tipo de degradação considerado. Para os dois efeitos previamente considerados, os parâmetros requisitados são $D_{P M D}(k), L(k), G(k)$, e $n_{s p}(k)$. É adotado que os parâmetros da camada física não mudam de valor de forma rápida e podem ser armazenados em alguma base de dados. Entretanto, geralmente os parâmetros da camada física especificados não são conhecidos na totalidade requerida. Caso o nó origem de um enlace óptico execute a seleção de trajeto, estes parâmetros necessitariam estar disponíveis [67].

Para simplificar o problema de RWA, ele é dividido em dois sub problemas: determinação da posição dos nós com conversores de comprimentos de onda e dos nós com compensadores de PMD; e determinação dinâmica da rota com o respectivo comprimento de onda para cada requisição de conexão. O objetivo é determinar uma posição otimizada de um dado número de nós com conversores tal que a probabilidade de bloqueio seja minimizada. O algoritmo calcula a função de custo associada com a rota como a soma dos custos individuais devido ao uso do comprimento de onda, dos conversores e dos amplificadores. O uso de um comprimento de onda diminui a quantidade disponível de comprimentos de onda, aumentando desse modo o potencial de bloqueio de requisições futuras, e o uso de um conversor ou amplificador introduz distorção que degrada a SNR. Para o sistema investigado, a função de adaptação é calculada por

$$
f i t_{t o t}=\sum_{j=1}^{J} \sum_{k=1}^{W} f i t(j, k),
$$

na qual a função de adaptação do enlace $j$ considerando o comprimento de onda $k$ é calculada por meio da soma de pesos

$$
f i t(j, k)=n_{1}(k) r_{1}+n_{2}(k) r_{2}+n_{3}(k) r_{3}+n_{4}(k) r_{4}+n_{5}(k) r_{5}+n_{6}(k) r_{6}+n_{7}(k) r_{7} .
$$

Em (4.31), $n_{1}(k)$ é o número de comprimentos de onda disponíveis no enlace $j$, no qual o comprimento de onda $k$ não está em uso; $n_{2}(k)$ é o número de enlaces que estão utilizando o comprimento de onda $k ; n_{3}(k)$ é o comprimento do enlace $j ; n_{4}(k), n_{5}(k)$ e $n_{6}(k)$ são, respectivamente, o número de compensadores, amplificadores em cascata 
e conversores no enlace $j$ ao se alocar o comprimento de onda $k ; n_{7}(k)$ é o número de bloqueios ao se designar o comprimento de onda $k$; e $r_{i}$ são constantes ponderadas de custo associadas às condições mencionadas e relacionadas a $n_{i}(k)$. A função de adaptação (4.31) calcula a adequação relativa à alocação de cada comprimento de onda $k$ para cada enlace $j, j \in R_{a}^{(t)}$. Particularmente, é o custo de se escolher o comprimento de onda $k$ para atender à solicitação presente na rota $R_{a}^{(t)}$. Os enlaces $j \in R_{a}^{(t)}$ são analisados e a disponibilidade de comprimentos de onda é verificada. Considerando a rota $R_{a}^{(t)}$ como referência, os coeficientes são ordenados de acordo com $r_{i}>r_{i+1}$, para os quais foram estabelecidos de forma heurística após exaustivos testes de simulação os valores $r_{1}=+5, r_{2}=+1, r_{3}=-2, r_{4}=-3, r_{5}=-5, r_{6}=-10 \mathrm{e}$ $r_{7}=-50$. A função de adaptação penaliza as políticas que apresentam maior rota, considerando o número de enlaces e o comprimento físico, enlaces com tráfego elevado, uso de dispositivos de rede e um número maior de comprimentos de onda bloqueados.

\subsubsection{Agregação Dinâmica de Tráfego}

Thiagarajan e Somani [79] definem agregação de tráfego em redes WDM como o procedimento de multiplexar, demultiplexar e comutar tráfego na forma eletrônica composto por distintas capacidades de largura de faixa em canais ópticos de alta capacidade. A tarefa de multiplexar e demultiplexar as taxas de tráfego em comprimentos de onda pode ser executada pelos OADMs, enquanto a ação de comutar as taxas de tráfego de um comprimento de onda para outro pode ser executada pelos OXCs, via comutação de conjunto de janelas temporais de um comprimento de onda para outro [79].

Considere uma dada distribuição de tráfego e uma rede com capacidade de $R$ caminhos ópticos. Cada enlace possui $W$ comprimentos de onda com capacidade $C$. O problema consiste em determinar uma topologia virtual com o menor número de caminhos ópticos e distribuir cada fluxo de tráfego nestes caminhos ópticos. Dado o estado inicial da rede e uma demanda dinâmica de tráfego, o roteamento de $m$ fluxos de tráfego do nó $s$ para o nó $d, \lambda_{s d}(m)$, por meio de uma topologia virtual com $L$ caminhos ópticos, pode ser denotada por um inteiro não-negativo, $b_{p q}^{s d}$, representando o número de fluxos de tráfego do nó $p$ para o nó $q$, roteados por meio dos $L$ caminhos ópticos, provenientes do nó $s$ em direção ao nó $d$. Os caminhos ópticos do nó $s$ para $d$ transportam o tráfego agregado, $\lambda^{s d}$. A quantidade deste tráfego devida à demanda de tráfego do nó $p$ para o nó $q, \lambda_{p q}$, é denotada por $\lambda_{p q}^{s d}$. O indicador de comprimento de onda do caminho óptico, $c_{p q}^{l m}(k)$, é 1 se tal caminho óptico utiliza o comprimento de onda $k$ no enlace físico de $l$ para $m$ e 0 , caso contrário. O problema da agregação de tráfego consiste em minimizar uma das seguintes funções [74]: O número total de 
caminhos ópticos, $\sum_{p, q} b_{p q}$; o número total de comutação eletrônica, $\sum_{s, d, p, q} \lambda_{p q}^{s d}-$ $\sum_{s, d} \lambda^{s d}$; o número máximo de caminhos ópticos terminando/iniciando em um nó, $\max _{p}\left(\max \left(\sum_{q} b_{p q}, \sum_{q} b_{p q}\right)\right)$. Estas funções estão sujeitas às seguintes restrições [74]:

1. Restrições de roteamento de caminho óptico,

$$
\begin{gathered}
\sum_{l=0}^{N-1} b_{p q}^{m l}-\sum_{l=0}^{N-1} b_{p q}^{l m}=\left\{\begin{array}{lr}
b_{p q}, & m=p \\
-b_{p q}, & m=q \\
0, & m \neq p, m \neq q
\end{array}, \quad \forall m, p, q\right\}, \\
\sum_{p, q} b_{p q}^{l m} \leq W, \quad \forall l, m ;
\end{gathered}
$$

2. Restrições de alocação de comprimento de onda ao caminho óptico,

$$
\begin{gathered}
\sum_{k=0}^{W-1} c_{p q}^{l m}(k)=b_{p q}^{l m}, \forall p, q, l, m ; \\
\sum_{p, q} c_{p q}^{l m}(k) \leq 1, \forall k, l, m ; \\
\sum_{l=0}^{N-1} c_{p q}^{m l}(k)-\sum_{l=0}^{N-1} c_{p q}^{l m}(k)=\left\{\begin{array}{lc}
\leq b_{p q}, & m=p \\
\geq-b_{p q}, & m=q \\
0, & m \neq p, m \neq q
\end{array}, \quad \forall p, q, k, m\right\} ;
\end{gathered}
$$

3. Restrições de roteamento de tráfego,

$$
\begin{gathered}
\lambda_{p q}=\sum_{s, d} \lambda_{p q}^{s d}, \quad \forall p, q ; \\
\lambda_{p q} \leq C b_{p q}, \quad \forall p, q ; \\
\sum_{j=0}^{N-1} \lambda_{p q}^{s d}-\sum_{j=0}^{N-1} \lambda_{p q}^{s d}=\left\{\begin{array}{lr}
\lambda^{s d}, & p=s \\
-\lambda^{s d}, & q=d, \\
0, & p \neq s, q \neq d
\end{array}, \quad \forall i, s, d\right\} .
\end{gathered}
$$

Esta formulação representa um problema de programação linear inteira com $O\left(n^{4}\right)$ variáveis, cuja solução se torna impraticável, mesmo para redes de dimensões moderadas [163]. Os problemas de agregação de tráfego podem ser representados por uma combinação entre um problema de programação linear inteira e um problema de grafo, sendo tipicamente NP-completo [164]. Eles devem ser resolvidos por meio de técnicas heurísticas [165], [166] para se obter soluções adequadas em um intervalo de tempo razoável. Neste trabalho, o algoritmo genético é empregado para resolver este tipo de problema. 


\section{Agregação Dinâmica de Tráfego Utilizando Algoritmo Genético}

No modelo proposto, cada gene, $c_{j w k}$, representa em forma binária um estado do comprimento de onda. O conjunto de genes forma um cromossomo, $j_{i}$. Esta condição representa o estado do comprimento de onda dos enlaces. O conjunto de todos os enlaces compõe um indivíduo, $(1, \ldots, J)$, representando uma política. No sistema há $J$ enlaces unidirecionais, cada um com $W$ comprimentos de onda, os quais podem ter sua capacidade plena de largura de faixa subdividida em $g$ partes (granularity). Cada indivíduo é denotado por um vetor de dimensão $C=J \times W \times g$, conforme mostra a Tabela 4.6, na qual

Tabela 4.6: Representação da política do sistema com agregação de tráfego.

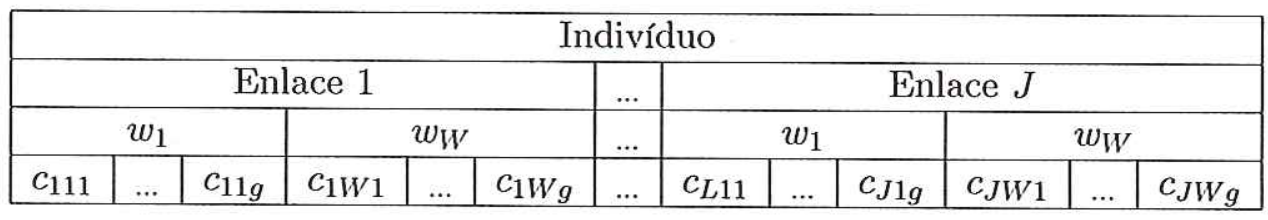

$c_{j k m}= \begin{cases}1, & \text { se o fluxo de tráfego } m \text { no comp. de onda } k \text { estiver em uso no enlace } j ; \\ 0, & \text { caso contrário. }\end{cases}$

$\mathrm{O}$ algoritmo calcula a função custo associada à rota, entendida como a soma dos custos individuais devidos ao uso do comprimento de onda, dos nós WSXC e WGXC, dos amplificadores e do enlace. $\mathrm{O}$ uso de um comprimento de onda diminui a largura de faixa disponível, aumentando o potencial de bloqueio das solicitações futuras, enquanto o uso de um amplificador introduz distorção que degrada a relação sinal-ruído. A dispersão por modo de polarização é proporcional ao comprimento do enlace. O custo do transceptor inclui o custo do equipamento terminal, assim como o do equipamento que realiza o processamento eletrônico.

A função de adaptação estima a adequação de cada indivíduo ao ambiente com respeito ao objetivo. O cálculo da função de adaptação considera diferentes variáveis envolvidas no RWA para estabelecer o maior número de solicitações de forma otimizada, considerando o estado atual do sistema e o custo da rede. Para o sistema atual, a função de adaptação global é dada por

$$
f i t_{\text {tot }}=\sum_{j=1}^{J} \sum_{k=1}^{W} f i t(j, k, m),
$$


na qual a função de adaptação do enlace $j$ para atender à solicitação de $m$ fluxos de tráfego, considerando o comprimento de onda $k$, é calculada pela soma de pesos

$$
f i t(j, k, m)=\sum_{l=1}^{9} n_{l}(k) r_{l} .
$$

Em (4.43), $n_{1}(k)$ é o número de comprimentos de onda disponíveis no enlace $j$, no qual o comprimento de onda $k$ pode transportar $m$ fluxos; $n_{2}(k)$ é o número de enlaces da rota $R_{a}^{(t)}$ que estão atualmente incapazes de suportar $m$ fluxos no comprimento de onda; $n_{3}(k)$ é o comprimento do enlace $j ; n_{4}(k)$ e $n_{5}(k)$ são, respectivamente, o número de compensadores de PMD e o número de amplificadores ópticos em cascata; $n_{6}(k)$ é o número de conversões de comprimentos de onda realizadas pelo nó WGXC; $n_{7}(k)$ e $n_{8}(k)$ são, respectivamente, o número de nós WSXC e de nós WGXC necessários para estabelecer a conexão ao longo da rota $a ; n_{9}(k)$ é o número de bloqueios ao se designar o comprimento de onda $k$; e $r_{i}$ são constantes ponderadas de custo associadas às condições mencionadas e relacionadas a $n_{i}(k)$. A função de adaptação (4.42) estima o custo de cada comprimento de onda $k$ para cada enlace $j, j \in R_{a}^{(t)}$. Isto representa o custo para a escolha do comprimento de onda $k$ servir à solicitação presente na rota $R_{a}^{(t)}$. Considerando a rota $R_{a}^{(t)}$ como referência, os coeficientes são ordenados por $r_{i}>$ $r_{i+1}$, para os quais foram estabelecidos heuristicamente os valores $r_{1}=+5, r_{2}=-1$, $r_{3}=-3, r_{4}=-4, r_{5}=-5, r_{6}=-8, r_{7}=-10, r_{8}=-12$ e $r_{9}=-50$. A função de adaptação penaliza as políticas que apresentam maior rota, considerando o número de enlaces e o comprimento físico, enlaces com tráfego elevado, uso de dispositivos de rede e um número maior de comprimentos de onda bloqueados. $\mathrm{O}$ desempenho do algoritmo, para uma taxa de tráfego particular de $m$ fluxos, e o desempenho global do algoritmo podem ser avaliados, respectivamente, pelas probabilidades de bloqueio $p_{m}$ e $P_{b}$ dadas por

$$
\begin{gathered}
P_{b}=\frac{\text { número de requisiçôes bloqueadas }}{\text { total de requisiçốes }}, \\
p_{m}=\frac{\text { número de } m \text { requisições bloqueadas }}{\text { total de } m \text { novas requisiçôes }} .
\end{gathered}
$$

\subsubsection{Imparcialidade de Capacidade de Largura de Faixa e Controle de Admissão de Conexão}

Em uma rede, na qual os usuários pagam de acordo com a largura da faixa requerida, é importante que todos tenham a mesma qualidade de serviço. Embora este conceito seja simples, um mecanismo de controle para assegurar a imparcialidade resulta em degradação do desempenho em outras características da rede. As requisições de alta capacidade de largura de faixa tendem a ser bloqueadas mais freqüentemente que aquelas de menor capacidade. 
A imparcialidade (fairness) de capacidade de largura de faixa é alcançada quando a probabilidade de bloqueio de $c$ requisições de taxa de transmissão $b$ for igual a probabilidade de bloqueio de $b$ requisições de taxa de transmissão $c$. Se $p_{c}$ for a probabilidade de bloqueio de uma requisição da classe- $c$ e $p_{b}$ for a probabilidade de bloqueio de uma requisição da classe- $b$, para se conseguir a imparcialidade de capacidade, a seguinte condição deve ser satisfeita [79]:

$$
1-\left(1-p_{c}\right)^{b}=1-\left(1-p_{b}\right)^{c}, \quad \forall 1 \leq b, c \leq g .
$$

O algoritmo de controle de admissão de conexão (CAC - connection admission control) deverá alcançar imparcialidade de capacidade e manter a probabilidade de bloqueio global em um nível aceitável. Não serão considerados casos para os quais a solicitação pode ser dividida em taxas de transmissão ou entre enlaces. A probabilidade de bloqueio global da rede pode ser definida em termos da probabilidade de bloqueio por unidade de taxa de transmissão. Quando a imparcialidade é obtida considerando taxa de transmissão unitária $(b=1)$, de acordo com (4.46) tem-se que

$$
p_{c}=1-\left(1-p_{1}\right)^{c}
$$

ou

$$
p_{1}=1-\sqrt[c]{1-p_{c}}
$$

Assim, utilizando (4.48) pode-se obter uma estimativa do valor de $p_{1}$ em função de $p_{c}$. Esta estimativa, $\hat{p}_{c}$, é a probabilidade de bloqueio por unidade de taxa de transmissão de uma classe de transmissão $c$. A estimativa da probabilidade de bloqueio global por unidade de taxa de transmissão, $\hat{P}$, é dada por

$$
\hat{P}=\frac{\sum_{i=1}^{g} \hat{p}_{\cdot i}}{\sum_{i=1}^{g} i} .
$$

Geralmente, a imparcialidade afeta mais as requisições de maior ou menor capacidade do que as requisições de capacidade intermediária. Uma estimativa aproximada pode ser obtida utilizando apenas a probabilidade de bloqueio das taxas de transmissão mais elevadas e mais baixas. A relação de imparcialidade de capacidade, $F_{r}$, é a relação entre a probabilidade de bloqueio por unidade de taxa de transmissão para a solicitação de maior taxa, $\hat{p}_{g}$, e a solicitação de menor taxa, $\hat{p}_{1}[79]$,

$$
F_{r}=\frac{\hat{p}_{g}}{\hat{p}_{1}}
$$

Se o valor de $F_{r}$ for maior que 1 , o algoritmo favorece as solicitações com taxas maiores em relação àquelas com taxas menores, e vice-versa. Se for próximo de 1 , significa que o algoritmo consegue estabelecer a imparcialidade de capacidade de rede. 
O CAC é definido como um conjunto de decisões a serem tomadas para estabelecer se uma solicitação de conexão será aceita ou rejeitada. Os mecanismos de CAC podem ser usados conjuntamente com os esquemas RWAs para estabelecer imparcialidade entre as diversas solicitações em detrimento aceitável da probabilidade de bloqueio global. O procedimento de CAC determina aceitar uma chamada com capacidade $c$ se $\hat{p}_{c} \geq \hat{P}$ e rejeitar uma chamada com probabilidade $\left(\hat{P}-\hat{p}_{c}\right) / \hat{P}$. Suponha uma solicitação de rota $R_{a}$ entre o par $(s, d)$ com capacidade $c$. O algoritmo CAC está dividido nas seguintes etapas [79]:

1. Verifique se a rota $R_{a}$ é capaz de atender à classe de tráfego $c$, ou seja, se existe capacidade $c$ disponível em todos os enlaces da rota, obedecendo aos critérios de continuidade de comprimento de onda. Se o trajeto não pode ser estabelecido, a solicitação será bloqueada;

2. Obtenha uma estimativa da probabilidade de bloqueio global por unidade de taxa de transmissão e da probabilidade de bloqueio por unidade de taxa de transmissão da classe $c$;

3. Se $\left(\hat{p}_{c} \geq \hat{P}\right)$, aceite a solicitação e avance para o passo 5 ;

4. Rejeite a requisição com probabilidade $q_{m}=\left(\hat{P}-\hat{p}_{c}\right) / \hat{P}$.

5. Se a requisição não for rejeitada, inicie o algoritmo de alocação de comprimentos de onda e atualize os parâmetros de probabilidade de bloqueio.

A taxa média, $q_{m}$, é a probabilidade de rejeição da solicitação. Uma outra estimativa para a probabilidade de rejeição pode ser obtida utilizando o desvio padrão $D$ das probabilidades de bloqueio por unidade de taxa de transmissão, $\hat{p}_{c}, 1 \leq c \leq g$. Neste caso, a taxa de desvio, $q_{D}$, é dada por $q_{D}=\left(\hat{P}-\hat{p}_{c}\right) / D$.

\subsection{Redes de Comunicação Móvel Celular}

Uma das questões fundamentais na operação de um sistema de comunicação móvel é a alocação de canais para as células e para as chamadas. Na gerência de um sistema celular, limitado em número de canais e condicionado a um crescimento dramático no número de usuários, o uso eficiente dos recursos disponíveis não é somente desejável mas também imperativo. Para que uma chamada possa ser atendida em um ambiente de comunicação celular, uma conexão necessita ser estabelecida de forma similar ao caso de uma rede fixa telefonia. Esta operação é executada por meio da alocação de um canal de rádio, conectando as estações móvel e base. A largura de banda disponível 
neste canal é alocada para a conexão durante o intervalo de duração da chamada. Durante este intervalo, as células vizinhas não poderão alocar este canal de rádio para nenhuma outra solicitação que viole as restrições eletromagnéticas.

Devido à característica peculiar do sistema móvel, a mobilidade dos assinantes, a distribuição de tráfego varia no espaço e tempo. Assim, handoffs e roamings estarão sempre ocorrendo, reduzindo o tempo de retenção na célula onde as chamadas são originadas e aumentando a geração de tráfego na célula para onde as chamadas prosseguem, fenômenos não previstos pela fórmula de Erlang-B. Uma modelagem de tráfego que considera todos os fenômenos presentes no sistema móvel é difícil e a obtenção de um formalismo exato é praticamente impossível.

\subsubsection{Alocação de Canais}

Considere um sistema de comunicação móvel celular formado por $N$ células e $M$ canais, no qual uma célula $j(1 \leq j \leq N)$ pode utilizar qualquer canal $k(1 \leq k \leq M)$ disponível no sistema se a escolha deste canal satisfizer à condição de distância de reuso. Desta forma, a avaliação da demanda de alocações exige conhecimento prévio das posições dos canais em cada célula e da informação do estado (status) de cada uma das células.

Nos modelos aqui propostos, cada gene representa o estado de um canal e os canais de uma célula formam um cromossomo. O conjunto de cromossomos de todas as células compõe um indivíduo representando uma política de alocação de canais. Portanto, cada indivíduo é denotado por um vetor de dimensão $I=N \times M$, conforme apresentado na Tabela 4.7 .

Tabela 4.7: Representação de um indivíduo formado por vários cromossomos.

\begin{tabular}{|c|c|c|c|c|c|c|c|c|c|c|c|c|}
\hline \multicolumn{10}{c|}{ Indivíduo } \\
\hline \multicolumn{3}{|c|}{ Célula 1 } & \multicolumn{3}{c|}{ Célula 2} & \multicolumn{3}{c|}{ Célula $N$} \\
\hline \hline$c_{11}$ & $c_{12}$ & $\ldots$ & $c_{1 M}$ & $c_{21}$ & $c_{22}$ & $\ldots$ & $c_{2 M}$ & $\ldots$ & $c_{N 1}$ & $c_{N 2}$ & $\ldots$ & $c_{N M}$ \\
\hline
\end{tabular}

A representação de cada gene é definida por

$$
c_{j k}= \begin{cases}1, & \text { se o canal } k \text { estiver em uso na célula } j \\ 0, & \text { caso contrário. }\end{cases}
$$

Os modelos propostos procuram por uma política, ou seja, um conjunto de estados de todas as células que otimizem o uso do sistema. Os AGs propostos utilizam os operadores genéticos padrão (seleção, cruzamento e mutação), juntamente com mecanismo de inserção de imigrantes [48], parâmetros adaptativos [148], esquema de seleção 
$T \%$ (truncation selection) [141], política elitista (greedy policy) [105], e estratégia de cruzamento em três pontos [144]. O procedimento para o cálculo da aptidão de cada indivíduo considera as diferentes variáveis envolvidas nas alocações de canais, com objetivo de acomodar o maior número de solicitações de chamadas, em uma forma otimizada, considerando o estado atual do sistema.

Considere o ambiente celular apresentado na Figura 4.8, sendo $R$ o raio médio da célula, $D$ a distância de reuso mínima para a restrição co-canal, com $D=\sqrt{21} R$ resultante para relação entre portadora e interferência co-canal, $C / I_{c}=18 \mathrm{~dB}$. Para o sistema investigado, a função de adaptação de uma célula $j$ é calculada da seguinte forma:

$$
f i t(j, k)=n_{1}(k) r_{1}+n_{2}(k) r_{2}+n_{3}(k) r_{3}+n_{4}(k) r_{4} .
$$

Em (4.52), $n_{1}(k)$ é o número de células compact ${ }^{1}$ em referência à célula $j$, nas quais o canal $k$ está sendo utilizado; $n_{2}(k)$ é o número de células co-canais que estão localizadas na terceira fileira distante da célula $j$, e que atualmente não estão utilizando o canal $k ; n_{3}(k)$ é o número das demais células co-canais que estão utilizando o canal $k ; n_{4}(k)$ é o número de canais que serão bloqueados ao se alocar o canal $k$; e $r_{1}, r_{2}, r_{3}$ e $r_{4}$ são constantes de custo associadas às condições mencionadas e relacionadas a $n_{1}(k)$, $n_{2}(k), n_{3}(k)$ e $n_{4}(k)$, respectivamente. A função de adaptação (4.52) é uma extensão daquela proposta por Nye e Haykin [100], [101] considerando o parâmetro adicional $n_{4}(k)$. A função de adaptação total é calculada por

$$
f i t_{t o t}=\sum_{j=1}^{J} \sum_{k=1}^{W} f i t(j, k)+n_{5}(k) r_{5}
$$

na qual $n_{5}(k)$ é o número de solicitações de handoff bloqueadas na célula $j$. A função de adaptação (4.53) estima a qualidade da alocação de cada canal $k$ para cada célula $j$. Particularmente, é o custo de se escolher o canal $k$ para atender a uma tentativa de chamada presente na célula $j$. A idéia básica é associar recompensas menores aos usos nos quais as células co-canais estejam mais distantes da célula $j$. Assim, as maiores recompensas estarão associadas aos usos nos quais as células co-canais estejam em distância compact (mínima permitida). As constantes de custo foram ordenadas por $r_{i}<r_{i+1}$, para as para as quais foram estabelecidos heuristicamente após exaustivos testes de simulação os valores $r_{1}=+5, r_{2}=+1, r_{3}=-1, r_{4}=-15$ e $r_{5}=-60$, penalizando desta forma as políticas que apresentem um maior número de canais bloqueados.

\footnotetext{
${ }^{1}$ células compact são aquelas com distância mínima entre células co-canais.
} 


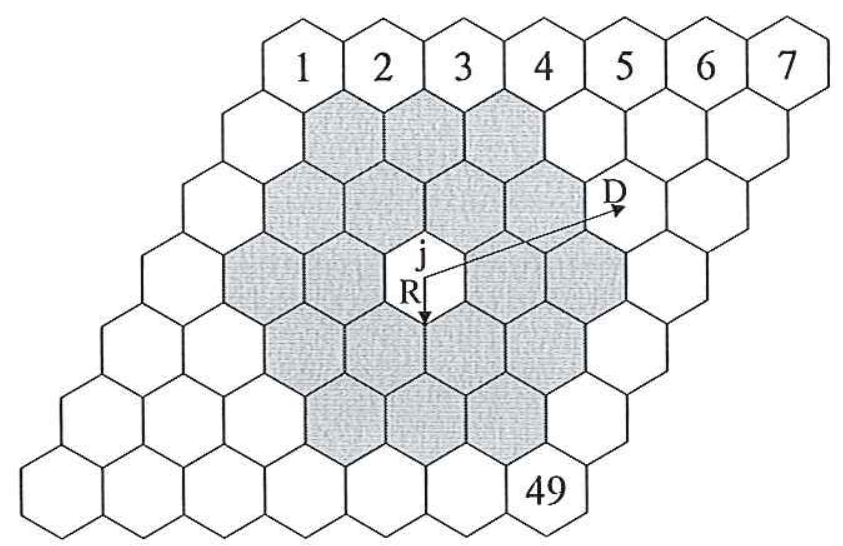

Figura 4.8: Ambiente celular padrão hexagonal $7 \times 7$. Célula $j$ e suas correspondentes células de interferência. $R$ é o raio médio da célula e $D$ a distância de reuso co-canal.

\section{Principais Diferenças entre os Esquemas GASC e GALC}

No esquema GALC os canais previamente alocados são mantidos fixos durante o tempo de permanência da chamada e o algoritmo genético procura por canais disponíveis para alocar as novas solicitações de chamadas. No esquema GASC, as chamadas podem ser comutadas para diferentes canais durante o tempo de conexão e o algoritmo está livre para determinar a política mais adequada para alocar todas as solicitações de canais.

Além dos mecanismos utilizados para compor a população inicial, o esquema GASC utiliza um mecanismo de memória auxiliar formada pelos melhores indivíduos das gerações anteriores. Assim, enquanto a busca no GALC inicia cada interação com os indivíduos gerados aleatoriamente, a busca no GASC pode iniciar próxima à solução ótima, utilizando os indivíduos com maior adequação armazenados na memória. No esquema GALC este mecanismo não está habilitado, uma vez que as chamadas em curso são fixas e não podem ser alteradas para uma configuração diferente.

No GALC a mutação somente é permitida nos genes representando canais desocupados, enquanto no GASC qualquer gene pode sofrer mutação. Enquanto no GALC é necessário um vetor status representado por $N \times M$ elementos informando o estado atual do sistema, no GASC é suficiente apenas um vetor com $N$ elementos informando o número de usuários por célula.

Um importante componente dos modelos aqui propostos diz respeito à formação da população inicial. Nestes modelos, a população inicial é composta por três mecanismos: geração aleatória de indivíduos; reinserção dos indivíduos mais aptos da última geração na geração atual; e inclusão dos melhores indivíduos das populações anteriores na geração atual. Para manter elevada a diversidade da população, as taxas de mutação, cruzamento e reprodução são adaptáveis de acordo com a diversidade dos pais. 


\subsubsection{Algoritmo Genético Adaptativo}

Os valores dos parâmetros de controle do AG, incluindo o tamanho da população, a mutação, o cruzamento e as taxas da seleção, podem ser modificados em cada geração dependendo de algumas características da população. Os parâmetros de controle adaptável objetivam acelerar a convergência do algoritmo e fornecer um mecanismo para evitar ótimos locais como solução. A melhor escala de valores para cada parâmetro do controle adaptativo foi determinada heuristicamente por um elevado número de simulações.

\section{Tamanho, Diversidade e População Inicial}

Tamanho, diversidade e conjunto inicial de indivíduos em uma população são vitais para permitir ao AG aproveitar eficientemente soluções promissoras e explorar alternativas. Então, para encontrar um ótimo ou uma solução sub-ótima, dentro de um intervalo de tempo viável, um AG deve ter: tamanho de população gerenciável; número de indivíduos promissores na população inicial; e quantidade adequada de diversidade na população. Hesser et al. [137] discutem que em algumas classes de problemas, o aumento mais elevado na variabilidade ocorre, frequientemente, com as populações que variam de 30 a 110 indivíduos. Tendo em vista este intervalo, simulações preliminares foram realizadas. O desempenho do sistema em termos da probabilidade de bloqueio das novas solicitações em função do tempo está apresentado nas Figuras 4.9-4.14, respectivamente. Consideramos cinco valores para o número do indivíduos, a saber, 25, 50, 75, 100 e 125; As requisições de novas chamadas são dinâmicas e obedecem à distribuição de Poisson com tráfego distribuído de forma heterogênea com média 91,83 chamadas por hora; e aumento de demanda de tráfego de 0, 20, 40, 60, 80 e 100\%. O tempo de permanência das requisições é exponencialmente distribuído com média $1 / \mu=180 \mathrm{~s}$.

Em todas as simulações mostradas nas Figuras 4.9 - 4.14 foram observadas as seguintes características:

1. O número baixo de gerações até à convergência: médias menores que 100 gerações até com $100 \%$ de sobrecarga;

2. Para uma determinada demanda de tráfego, o número de gerações não varia significativamente com o número de indivíduos;

3. A probabilidade de bloqueio tende a se estabilizar com o tempo, demonstrando a robustez dos modelos. Durante o período de estabilização o desempenho apresenta derivada negativa por causa da capacidade de aprendizado do AG; 


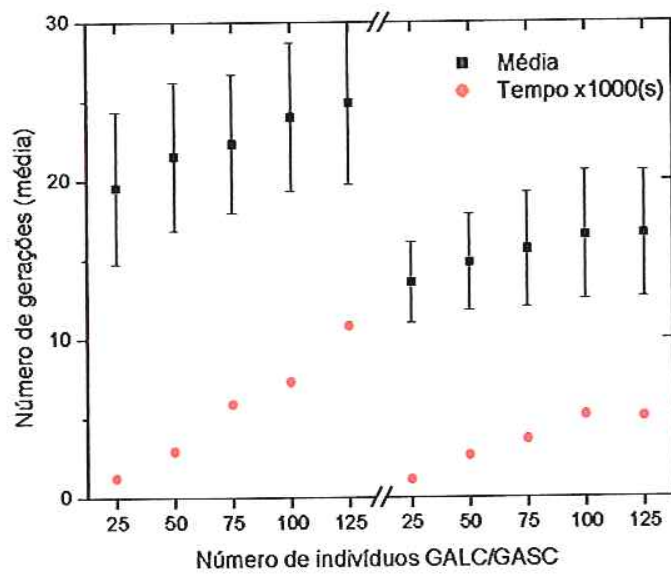

(a)

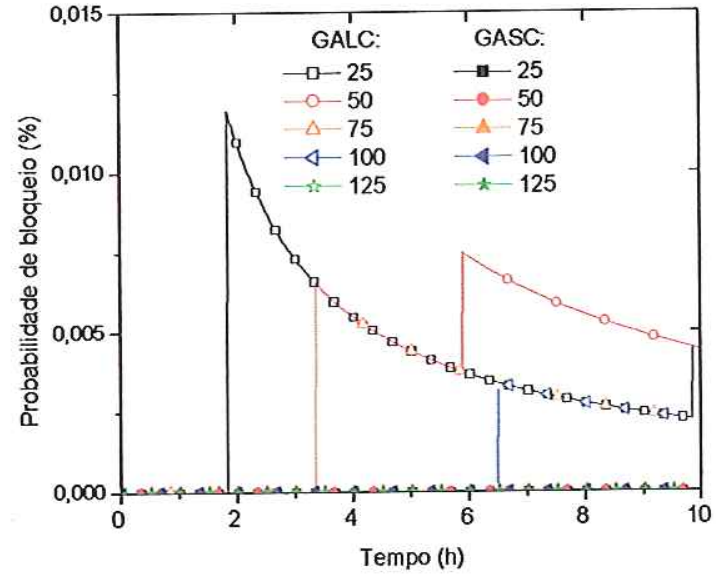

(b)

Figura 4.9: (a) Número de gerações (média e desvio padrão) e tempo de simulação em função do número de indivíduos considerando $0 \%$ de aumento de tráfego para os modelos propostos GALC e GASC; e (b) Probabilidade de bloqueio em função do tempo de operação do sistema.

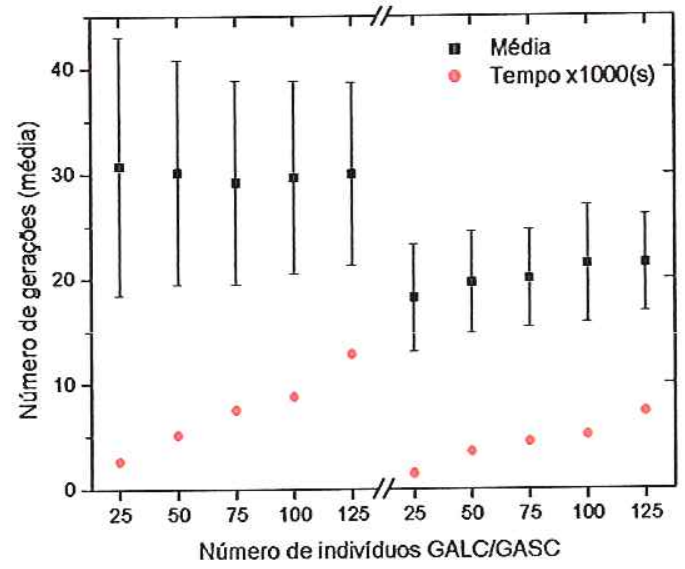

(a)

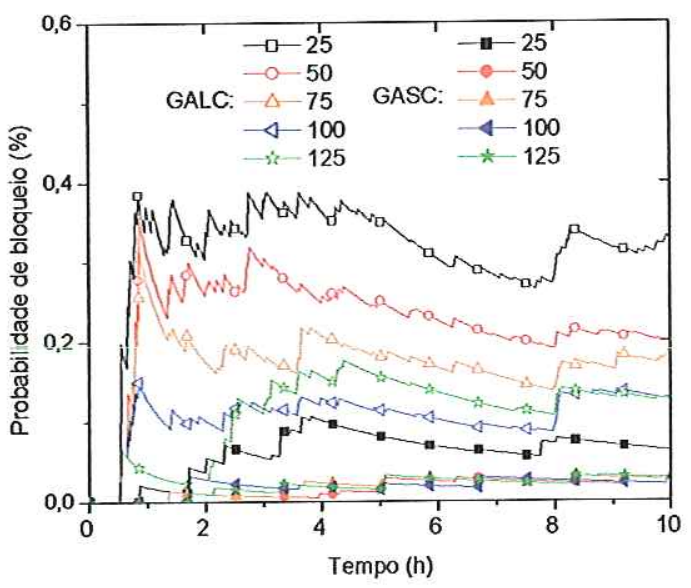

(b)

Figura 4.10: (a) Número de gerações (média e desvio padrão) e tempo de simulação em função do número de indivíduos considerando $20 \%$ de aumento de tráfego para os modelos propostos GALC e GASC; e (b) Probabilidade de bloqueio em função do tempo de operação do sistema. 


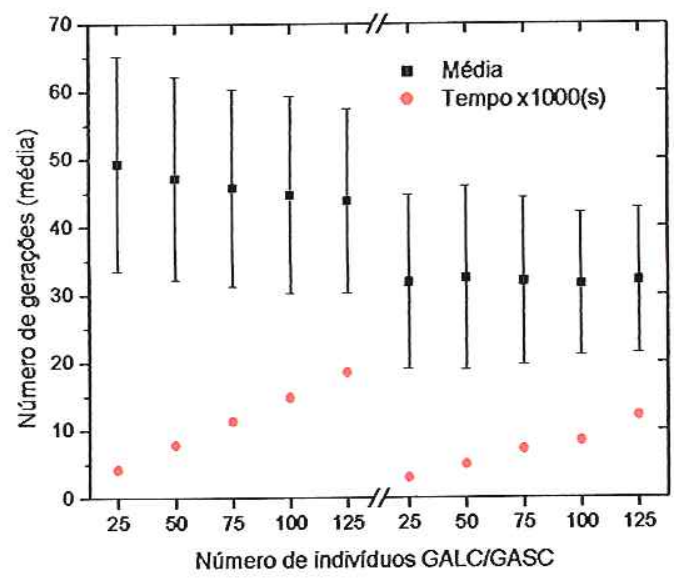

(a)

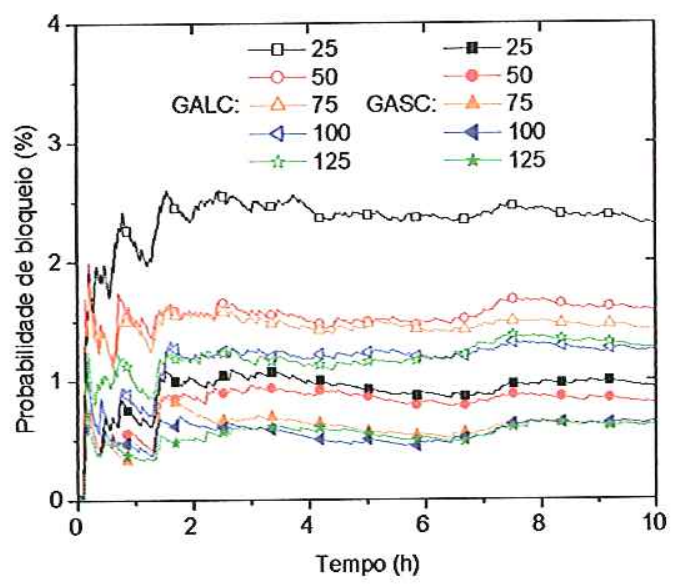

(b)

Figura 4.11: (a) Número de gerações (média e desvio padrão) e tempo de simulação em função do número de indivíduos considerando $40 \%$ de aumento de tráfego para os modelos propostos GALC e GASC; e (b) Probabilidade de bloqueio em função do tempo de operação do sistema.

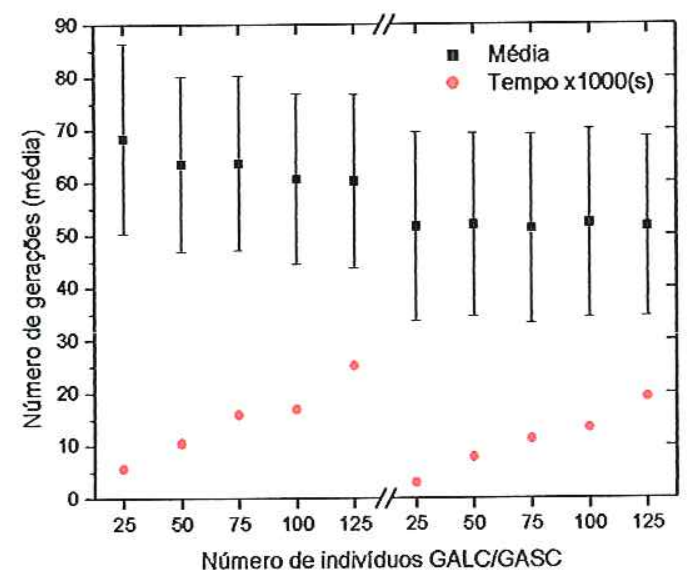

(a)

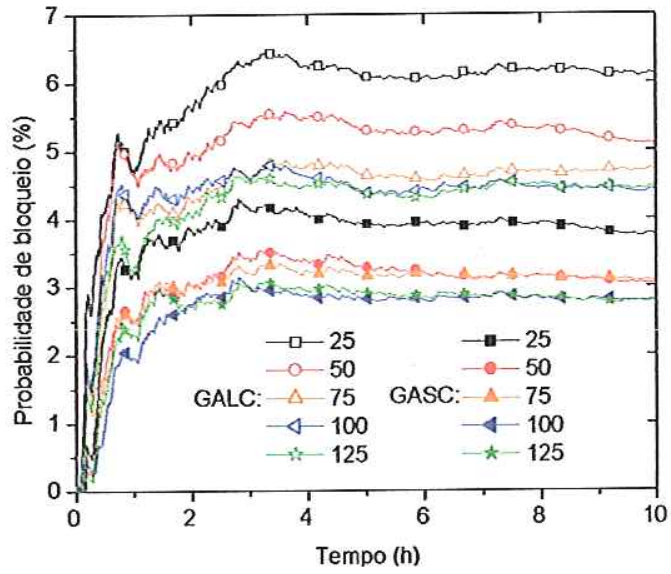

(b)

Figura 4.12: (a) Número de gerações (média e desvio padrão) e tempo de simulação em função do número de indivíduos considerando $60 \%$ de aumento de tráfego para os modelos propostos GALC e GASC; (b) Probabilidade de bloqueio em função do tempo de operação do sistema. 


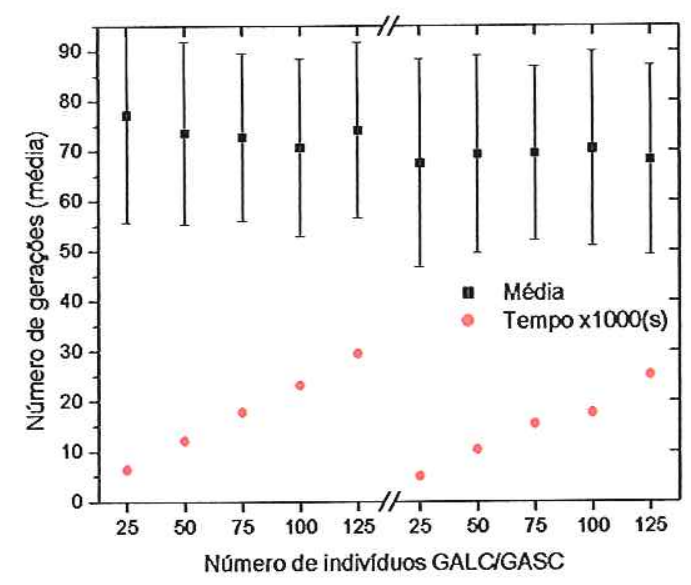

(a)

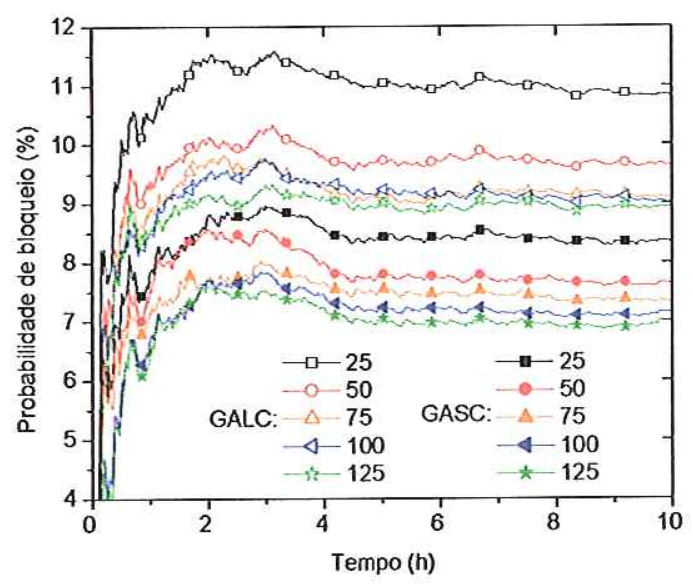

(b)

Figura 4.13: (a) Número de gerações (média e desvio padrão) e tempo de simulação em função do número de indivíduos considerando $80 \%$ de aumento de tráfego para os modelos propostos GALC e GASC; e (b) Probabilidade de bloqueio em função do tempo de operação do sistema.

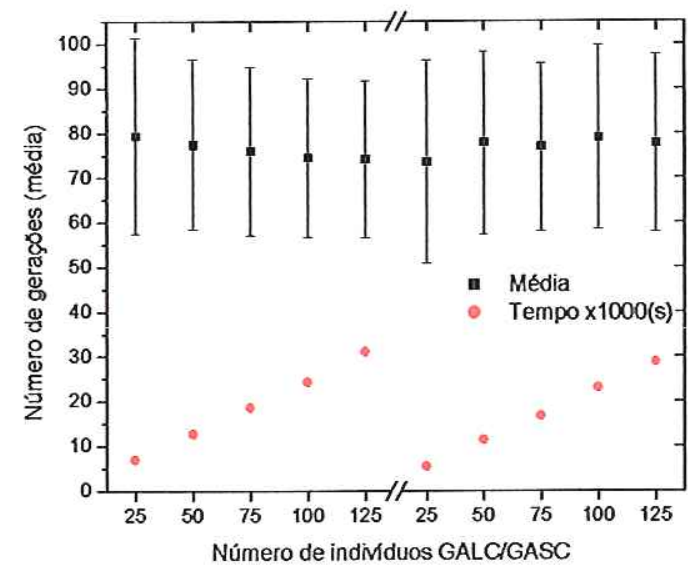

(a)

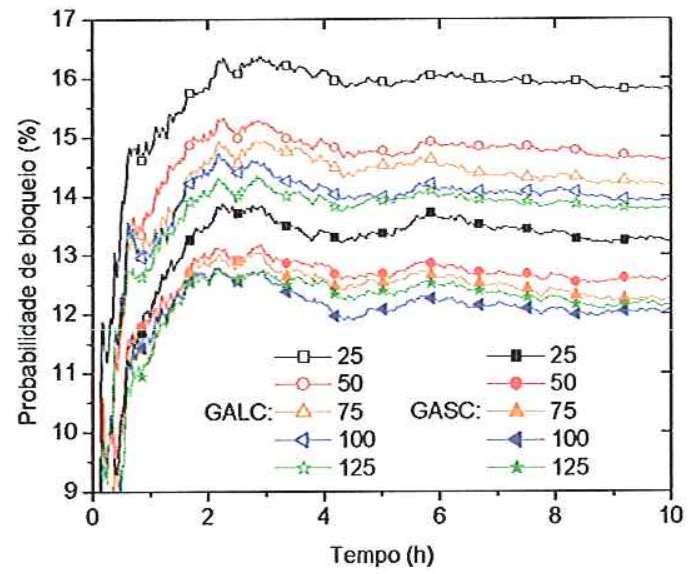

(b)

Figura 4.14: (a) Número de gerações (média e desvio padrão) e tempo de simulação em função do número de indivíduos, considerando $100 \%$ de aumento de tráfego para os modelos propostos GALC e GASC; e (b) Probabilidade de bloqueio em função do tempo de operação do sistema. 


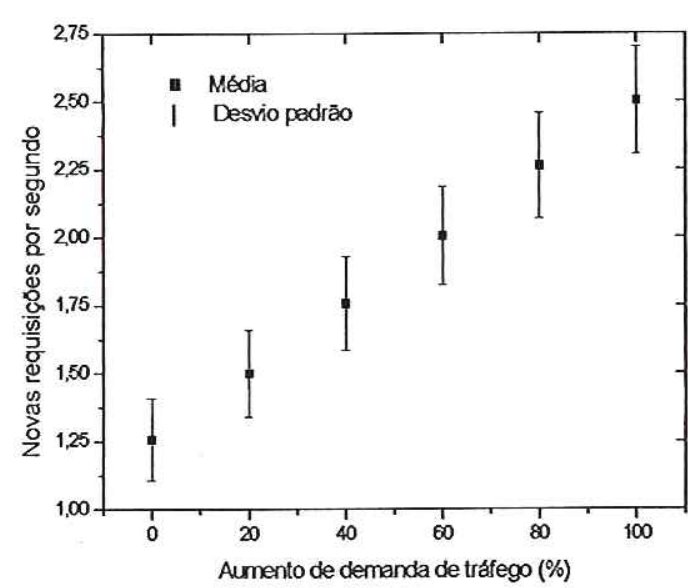

(a)

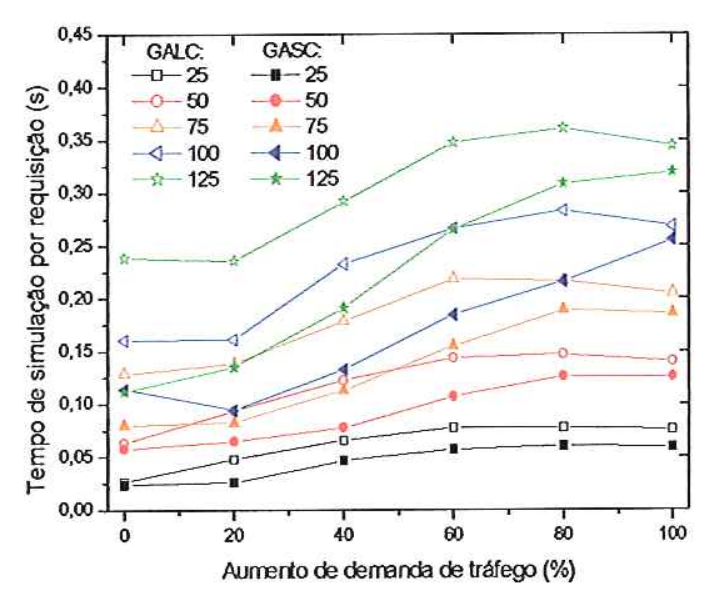

(b)

Figura 4.15: (a) Número de novas requisições por segundo (média e desvio padrão); e (b) Tempo de simulação por requisição em função do aumento de tráfego, parametrizada pelo número de indivíduos. Distribuição heterogênea de tráfego com média 91,83 chamadas por hora.

4. A probabilidade de bloqueio tende a melhorar até um certo número de indivíduos por geração (100 para o GALC e 75 para o GASC) e depois piora ou estabiliza;

5. O modelo GASC apresenta probabilidade de bloqueio menor que o GALC para todas as demandas de tráfego;

6. Os tempos de simulações (evolução do modelo) aumentam de maneira diferenciada com o aumento da sobrecarga para diferentes números de indivíduos na população, mas não há aumento exponencial;

7. O GASC converge mais rapidamente que o GALC;

8. O desempenho do sistema tendem a atingir um valor constante para o qual converge o número de chamadas bloqueadas;

9. Os desvios no número de gerações são aproximadamente constantes para número diferentes de indivíduos com mesma carga;

10. O tempo de processamento cresce proporcionalmente ao número de indivíduos e não exponencialmente.

Os resultados demonstram a melhoria em eficiência obtida com o modelo GASC. Este modelo é capaz de minimizar a probabilidade de bloqueio global do sistema utilizando um número reduzido de gerações e, conseqüentemente, utilizando tempo de 
Tabela 4.8: Tempo de simulação por requisição dos modelo GALC e GASC em função do tráfego oferecido parametrizado pelo número de indivíduos.

\begin{tabular}{|c|c|c|c|c|c|c|c|}
\hline \multicolumn{8}{|c|}{ Tempo de simulação por requisição do modelo GALC (segundos) } \\
\hline \multirow{2}{*}{$\begin{array}{l}\text { Tráfego } \\
(\%)^{(2)}\end{array}$} & \multicolumn{2}{|c|}{ (requisições/s) $^{(1)}$} & \multicolumn{5}{|c|}{ Número de Indivíduos } \\
\hline & média & tstd & 25 & 50 & 75 & 100 & 125 \\
\hline 0 & 1,2569 & 1499 & 02648 & 0,063 & 0,12863 & 0,16016 & 0,23825 \\
\hline 20 & 1,5010 & 0,1598 & & 0,093 & 0,138 & 0,16 & 0,23575 \\
\hline 40 & 1,7574 & 0,1722 & 6563 & 0,122 & 0,17832 & 0,232 & 0,29188 \\
\hline 60 & 2,0063 & 0,1816 & 7740 & 0,14351 & 0,21850 & 0,26608 & 0,34759 \\
\hline 80 & 2,2639 & 0,1935 & 0,07734 & 0,14697 & 0,21684 & 0,28293 & 0,36065 \\
\hline 100 & 2,5020 & 0,1965 & 0,07626 & 0,14022 & 0,20509 & 0,26825 & 0,34401 \\
\hline
\end{tabular}

\begin{tabular}{|c|c|c|c|c|c|c|c|}
\hline \multicolumn{8}{|c|}{ Tempo de simulação por requisição do modelo GASC (segundos) } \\
\hline \multirow{2}{*}{$\begin{array}{l}\text { Tráfego } \\
(\%)^{(2)}\end{array}$} & \multicolumn{2}{|c|}{ (requisições/s) $^{(1)}$} & \multicolumn{5}{|c|}{ Número de Indivíduos } \\
\hline & média & \pm std & 25 & 50 & 75 & 100 & 125 \\
\hline 0 & 1,2569 & 0,1499 & 024 & 0,05764 & 0,08013 & 0,113 & 0,11158 \\
\hline 20 & 1,5010 & 0,1598 & 0,02624 & 0,06467 & 0,08252 & 0,09418 & 0,13511 \\
\hline 40 & 1,7574 & 0,1722 & 0,04663 & 0,07775 & 0,11328 & 0,13271 & 0,19123 \\
\hline 60 & 2,0063 & 0,1816 & 0,05712 & 0,10695 & 0,15482 & 0,18459 & 0,26527 \\
\hline 80 & 2,2639 & 0,1935 & 0,06041 & 0,12604 & 0,18891 & 0,21618 & 0,30870 \\
\hline 100 & 2,5020 & 0,1965 & 0,05946 & 0,12578 & 0,18567 & 0,25558 & 0,31943 \\
\hline
\end{tabular}

(1) tráfego heterogêneo média 91,83 chamadas por hora;

(2) porcentual de aumento de demanda de tráfego.

simulação reduzido. Os resultados numéricos sugerem que a população com tamanho de 75 indivíduos fornece o melhor compromisso entre o desempenho e o tempo de convergência. Os tempos de simulação dos algoritmos GALC e GASC por solicitação de chamada em função do aumento da demanda de tráfego para diferentes números de indivíduos sấo mostrados na Figura 4.15 e na Tabela 4.8. Os algoritmos GALC e GASC exibiram tempos de simulação por solicitação de chamada médios de 0,18 e 0,13 segundos, respectivamente, para 75 indivíduos, que é um valor plausível. Os algoritmos foram desenvolvidos em linguagem $\mathrm{C}$ e as simulações foram realizadas em microcomputador com processador Pentium IV, 2,2 GHz de freqüência de clock, 512 MB de memória RAM e plataforma Microsoft Windows XP.

A formação da população inicial é auxiliada por um reservatório em que foram armazenados os melhores indivíduos das soluções precedentes. Conseqüentemente, a população inicial em cada intervalo (no qual uma solução deve ser encontrada) é composta de 75 indivíduos divididos em três grupos: 20 armazenados no reservatório; 50 gerados aleatoriamente; e os 5 mais adaptados da última busca reintroduzidos na geração atual. Para obter os 5 indivíduos mais adaptados quando o sistema é 
iniciado, considera-se a alocação em um padrão de sete células. Neste instante, o reservatório está vazio e será preenchido com o melhor elemento de cada geração até atingir sua capacidade plena. O AG proposto atualiza taxas de mutação, de cruzamento e de seleção em função da diversidade dos pais, $P_{\text {div }}$, calculada como função dos pais repetidos entre o total selecionado, de acordo com

$$
P_{\text {div }}=1-\frac{\text { número de pais repetidos }}{\text { número de pais selecionados }} \text {. }
$$

Quando a diversidade dos pais se aproxima da unidade, a taxa de mutação deve ser reduzida e as taxas do cruzamento e de reprodução devem ser aumentadas. Tal dinâmica preserva a informação e aumenta a exploração dos melhores indivíduos da população. Quando a diversidade dos pais diminui, deve ocorrer o aumento da taxa de mutação com a diminuição simultânea das outras taxas, permitindo ao algoritmo maior capacidade de exploração do espaço de busca de soluções. Os três parâmetros mencionados não podem diminuir nem aumentar sem limites. A variação de tais parâmetros deve exibir derivada reduzida para a diversidade baixa ou elevada e deve apresentar variação maior para valores médios. Para atender a estas características, a função sigmoidal foi adotada para traduzir a diversidade dos pais em parâmetros adaptáveis.

\section{Seleção}

Para aumentar a probabilidade de haver indivíduos aptos na geração seguinte, um percentual da população é selecionado por meio do mecanismo de seleção por roleta, de acordo com a taxa de reprodução

$$
p_{r}=0,15+0,05\left(\frac{\exp \left(6 P_{d i v}-3\right)-1}{\exp \left(6 P_{d i v}-3\right)+1}\right) .
$$

\section{Cruzamento}

O operador cruzamento é aplicado a dois indivíduos por meio de cortes dentro do mesmo ponto (escolhido aleatoriamente) e recombinação das partes de cada indivíduo para formar os descendentes. O mecanismo de seleção por truncamento escolhe os $10 \%$ indivíduos melhores da população como pais. Então, os pais formam pares escolhidos aleatoriamente para produzir seus descendentes, de acordo com a taxa do cruzamento

$$
p_{c}=0,25+0,10\left(\frac{\exp \left(6 P_{d i v}-3\right)-1}{\exp \left(6 P_{d i v}-3\right)+1}\right) .
$$

Uma determinação freqüentemente tarefa-dependente é o número de pontos do cruzamento. Para determinar a opção mais eficiente ao GALC e ao GASC, alguns casos foram testados exaustivamente e os resultados apontaram para o cruzamento em 3-pontos como a melhor alternativa, conforme indica a Figura 4.16. 


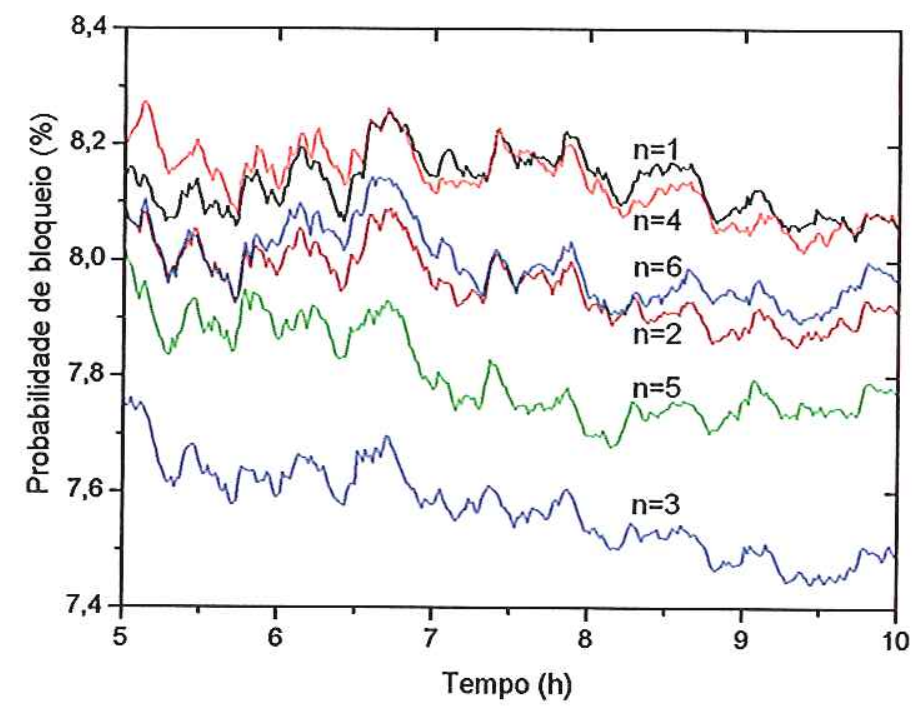

Figura 4.16: Desempenho do AG proposto considerando $n$-pontos para o operador cruzamento.

\section{Mutaçāo}

O percentual de indivíduos da geração atual que se submetem à mutação, os quais serão incluídos na geração seguinte, é determinada por

$$
\eta_{m}=0,30-0,15\left(\frac{\exp \left(6 P_{\text {div }}-3\right)-1}{\exp \left(6 P_{\text {div }}-3\right)+1}\right) \text {. }
$$

Dado que o número de indivíduos que sofrem mutação depende da diversidade dos pais, foi observado nas simulações que o uso de uma probabilidade fixa para a mutação não produz um processo de evolução apropriado. Assim, uma probabilidade adaptativa para a mutação foi utilizada para acelerar o tempo de convergência. Considerando que o desempenho de um indivíduo pode ser melhorado com o aumento da flexibilidade dos cromossomos, cada cromossomo pode ser associado a uma particular probabilidade de mutação de acordo com sua aptidão. Assim, os modelos propostos incluem a probabilidade dos genes de um mesmo cromossomo sofrerem mutação de acordo com a probabilidade de bloqueio da célula considerada.

\section{Controle Adaptativo Sigmoidal}

As taxas de mutação, cruzamento e reprodução obedecem à relação $p_{c}+p_{r}+\eta_{m} \approx 0,70$. As taxas dos operadores em função da diversidade dos pais estão apresentadas na Figura 4.17. A melhoria no desempenho do sistema obtida com a inclusão do controle adaptativo sigmoidal no transitório inicial e em regime estacionário está apresentada na Figura 4.18. 


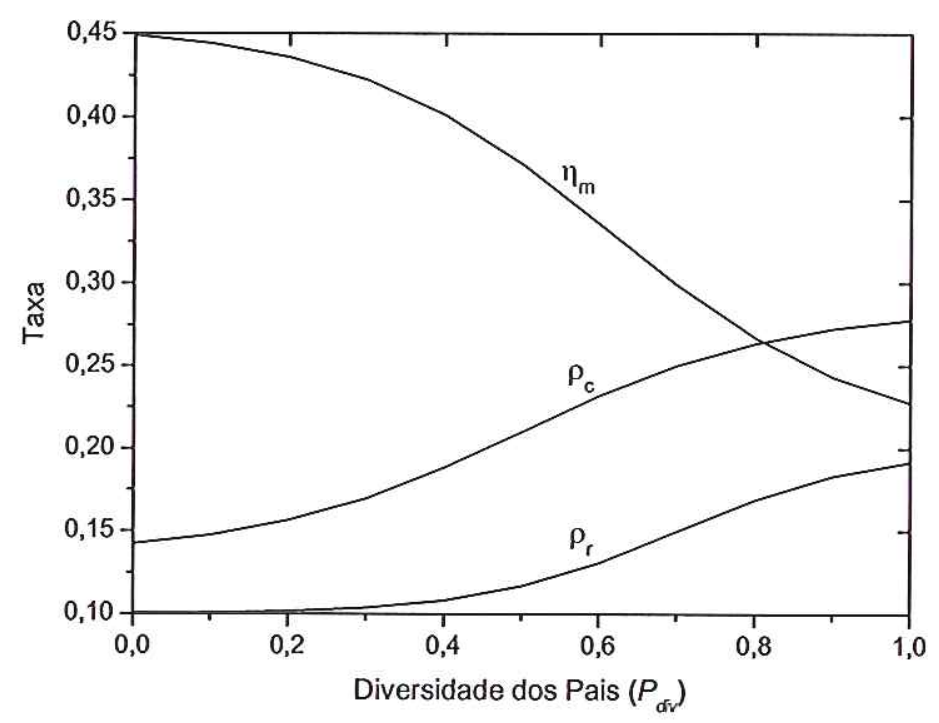

Figura 4.17: Variação dos operadores genéticos cruzamento $\left(\rho_{c}\right)$, reprodução $\left(\rho_{r}\right)$ e percentual de indivíduos que sofrem mutação $\left(\eta_{m}\right)$, em função da diversidade dos pais, $P_{\text {div }}$.

Para testar a utilidade do controle adaptativo sigmoidal foi considerado um período de falha no ambiente celular. Inicialmente, o sistema operava com 70 canais e durante o período de falha, das 10 às $15 \mathrm{~h}$, sete canais, escolhidos aleatoriamente, permaneceram temporariamente indisponíveis para uso em cada célula. O impacto da falha de canais na probabilidade de bloqueio está apresentado na Figura 4.19. Os AGs para o CAP demonstram certo grau de robustez para situação de falha de canais e sugerem que são capazes de se adaptar às variações do ambiente. Particularmente, o AG adaptativo com controle sigmoidal apresentou menor variação na probabilidade de bloqueio.

\section{Inserção de imigrantes}

A nova geração é completada com a inclusão de indivíduos imigrantes gerados aleatoriamente. O mecanismo de inclusão de imigrantes [48] pode ser utilizado para aumentar a diversidade da população incluindo novos indivíduos na geração existente em resposta às mudanças ocorridas no ambiente e para evitar a convergência prematura. Finalmente, cada geração dos modelos propostos é composta por: $10 \%$ dos indivíduos são os melhores pais da geração anterior; $20 \%$ são imigrantes; e $70 \%$ dos indivíduos são formados pelos operadores genéticos reprodução, cruzamento e mutação, de acordo com (4.55)-(4.57), respectivamente. 


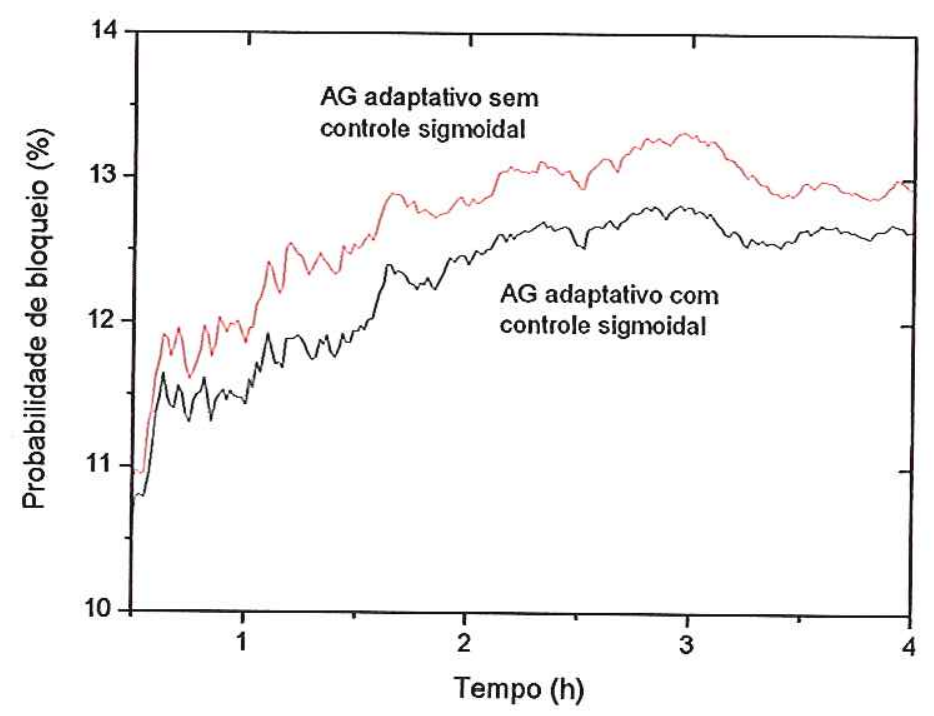

Figura 4.18: Melhoria do desempenho do sistema no transitório inicial e em regime estacionário com a inclusão do controle adaptativo sigmoidal.

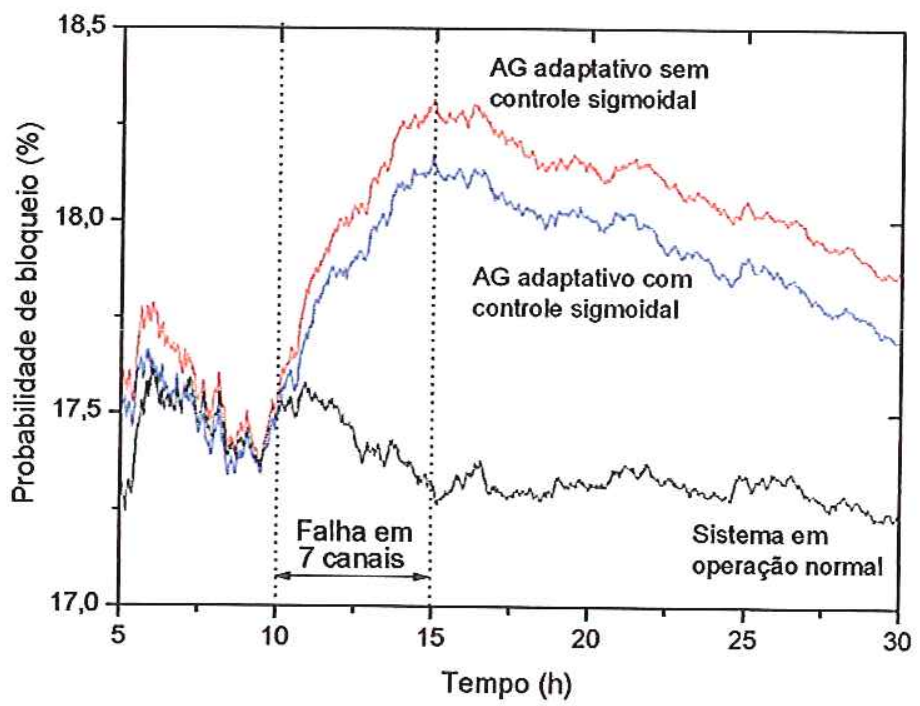

Figura 4.19: Melhoria do desempenho do sistema sob variações na dinâmica do ambiente com a inclusão do controle adaptativo sigmoidal. 


\section{Rotinas dos Esquemas Propostos GASC e GALC}

O procedimento para os algoritmos propostos para determinar a solução do problema DCA está apresentado na Tabela 4.9, obedecendo ao número máximo de gerações ou à convergência do sistema como critério do parada.

Tabela 4.9: Procedimento dos algoritmos genéticos propostos para o problema DCA.

* Iniciar as seguintes variáveis e parâmetros: Tamanho da população, gerações, canais, demanda de tráfego, taxa do handoff, restrições EMC; * Enquanto o tempo da simulação não terminar;

- Gerar solicitações de chamadas no tempo $t$;

- Gerar a população inicial para o tempo $t$;

- Repetir até que o critério de parada seja alcançado;

- Computar a função da aptidão para cada indivíduo, (4.52);

- Escolher os pais de acordo com o mecanismo da seleção

por truncamento;

- Atualizar os parâmetros do operador, (4.54)-(4.57);

- Aplicar os operadores genéticos à população;

- Atualizar a nova geração;

- Terminar o "repita";

- Atribuir os canais às solicitações de chamada;

- Retirar as chamadas que encerraram;

- Atualizar o estado de cada canal;

o Incrementar o tempo $t$;

* Fim do "enquanto". 


\section{Capítulo 5}

\section{Resultados Numéricos}

O desempenho dos algoritmos genéticos propostos neste trabalho é avaliado em três diferentes ambientes de sistemas de telecomunicações que exigem alocação de recursos. No primeiro caso, o AG realiza o roteamento e alocação de comprimentos de onda em redes ópticas WDM. O objetivo é maximizar o desempenho das redes em termos de probabilidade de bloqueio utilizando uma distribuição ótima ou sub-ótima dos recursos. São acrescentados às redes conversores de comprimentos de onda, restrições da camada física ASE e PMD, nós com capacidade de agregação de tráfego e controle de admissão de conexão. As simulações são realizadas utilizando as topologias das redes em anel, NSFnet, italiana e rede híbrida brasileira. No segundo caso, o AG é responsável por solucionar o problema de alocação de canais em um ambiente de comunicação móvel celular. As requisições de novas chamadas e handoff são dinâmicas e obedecem à distribuição de Poisson. A rede de comunicação móvel é exaustivamente avaliada considerando um ambiente celular padrão formado por 49 células sob condições de tráfego heterogêneo. O sistema está sujeito a três tipos de restrições eletromagnéticas: co-canal, canal adjacente e co-site. No último caso, o território brasileiro é coberto por uma rede híbrida de comunicação que combina uma rede óptica WDM e uma sem fio via satélite. O AG deve gerenciar e otimizar a alocação dos recursos disponíveis, sejam comprimentos de onda ou canais de rádio, e atender integradamente às restrições do sistema. O modelo incorpora distribuição de tráfego heterogêneo, inclusão de nós com capacidade de agregação de tráfego, conversores de comprimentos de onda e enlaces com número diferenciado de comprimentos de onda. Este estudo pode representar uma importante contribuição para o projeto e gerenciamento de redes integradas cobrindo, principalmente, grandes extensões territoriais, e pode permitir inovações futuras, facilitadas com o uso do modelo do algoritmo genético proposto.

Os algoritmos foram desenvolvidos em linguagem $\mathrm{C}$ e as simulações foram realizadas em microcomputador com processador Pentium IV, 2,2 GHz de freqüência de 
clock, 512 MB de memória RAM e plataforma Microsoft Windows XP.

\subsection{Rede Óptica}

O modelo proposto baseado em algoritmos genéticos para roteamento e alocação de comprimentos de onda em redes ópticas WDM inclui diferentes mecanismos como inserção de imigrantes, capaz de aumentar a diversidade da população; política elitista (greedy policy) para garantir a sobrevivência do indivíduo mais apto; seleção por truncamento para eleger os melhores indivíduos como candidatos a pais; esquemas adaptáveis para ajustar as taxas de mutação; e cruzamento em três pontos para acelerar a convergência do algoritmo. Estas estratégias aumentam a eficiência combinando a exploração com aproveitamento em função do estado atual do espaço de busca.

O desempenho dos AG propostos na solução do problema RWA foi avaliado por meio de simulações de computador que consideram as seguintes redes de comunicações ópticas: topologia em anel, rede NSFnet, rede italiana e rede híbrida brasileira. As redes foram analisadas sob condição de conversão plena, esparsa e sem conversão.

O impacto da inclusão das restrições da camada física sobre a probabilidade de bloqueio global, considerando a degradação do sinal óptico causada pelos efeitos ASE e PMD, foi avaliado na rede italiana. A agregação dinâmica de tráfego foi incluída a esta rede equipando-se os nós da rede com chaves WSXC e WGXC em diferentes configurações. Para garantir imparcialidade de largura de banda aos usuários foi adicionado ao AG um procedimento de controle de admissão de conexão.

\subsubsection{Roteamento e Alocação de Comprimentos de Onda em Rede em Anel}

A topologia de rede mais simples para aplicação do algoritmo proposto é a rede em anel. Considere uma rede em anel constituída por 12 nós e 12 enlaces bidirecionais conforme apresentada na Figura 5.1 [61]. Cada par origem-destino está associado a duas rotas alternativas. Seja um modelo de tráfego dinâmico para qual cada nó origem realiza solicitações aos demais nós seguindo uma distribuição de Poisson. O tempo de permanência da conexão é distribuído exponencialmente com média $1 / \mu=60 \mathrm{~s}$. As solicitações dos pares origem-destino possuem distribuição de tráfego uniforme, com taxas de solicitação de $20,25,30,35,40,45,50,55$ e 60 solicitações por minuto. Cada enlace dispõe de 8 comprimentos de onda.

A probabilidade de bloqueio da rede em anel em função da demanda de tráfego está apresentada na Figura 5.2 para rede com conversão esparsa e para os casos limites de rede sem conversão e com conversão plena. São consideradas duas configurações de 


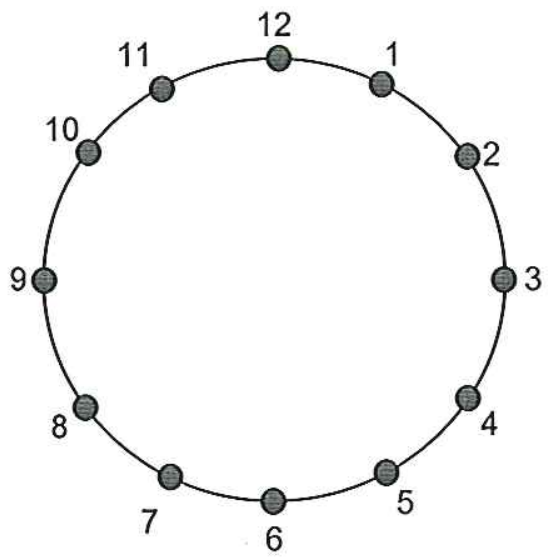

Figura 5.1: Rede em anel constituída por 12 nós e 12 enlaces bidirecionais [61].

alocação esparsa sugeridas pelo AG: nós conversores $(2,5,8,11)$ e $(2,5,11,12)$; e a configuração obtida por Vijayanand et al. [61], simulada e utilizada para comparação de desempenho. Na Tabela 5.1 estão apresentados os valores numéricos correspondentes. A adoção de conversores contribui para a redução da probabilidade de bloqueio. Entretanto, os conversores apresentam um custo elevado e equipar todos os nós com estes dispositivos tornaria a rede onerosa. Por outro lado, há soluções mais viáveis, como a conversão esparsa [64], que disponibiliza conversores em apenas alguns nós da rede, e a conversão parcial [125], que limita a quantidade de conversores disponibilizada nos nós roteadores com o uso de arquiteturas capazes de compartilhar os conversores, como share-per-node ou share-per-link [17], [66]. Estas soluções podem prover as redes de quase o mesmo desempenho daquelas com conversão plena [61].

As disposições dos conversores na rede sugerida pelo AG proposto neste trabalho exibem desempenho em termos de probabilidade de bloqueio superior ao obtido por Vijayanand et al. [61]. Por exemplo, para uma demanda de tráfego de 20 erlangs e considerando os nós $(2,5,8,11)$ equipados com conversores, a probabilidade de bloqueio é $0,135 \%$, enquanto para o modelo de [61] é $0,191 \%$. Para uma demanda de 40 erlangs as probabilidade de bloqueio são $14,10 \%$ e $14,88 \%$, respectivamente. Um aspecto desvantajoso do algoritmo proposto por Vijayanand et al. [61] é a dependência da distribuição dos conversores com a demanda de tráfego, conforme mostrado na Tabela 5.1. Esta condição dificulta a aplicação do algoritmo em ambientes que apresentam freqüentes variações de demanda. O AG proposto neste trabalho obtém uma distribuição única para os conversores na rede para toda a faixa de demanda de tráfego. 


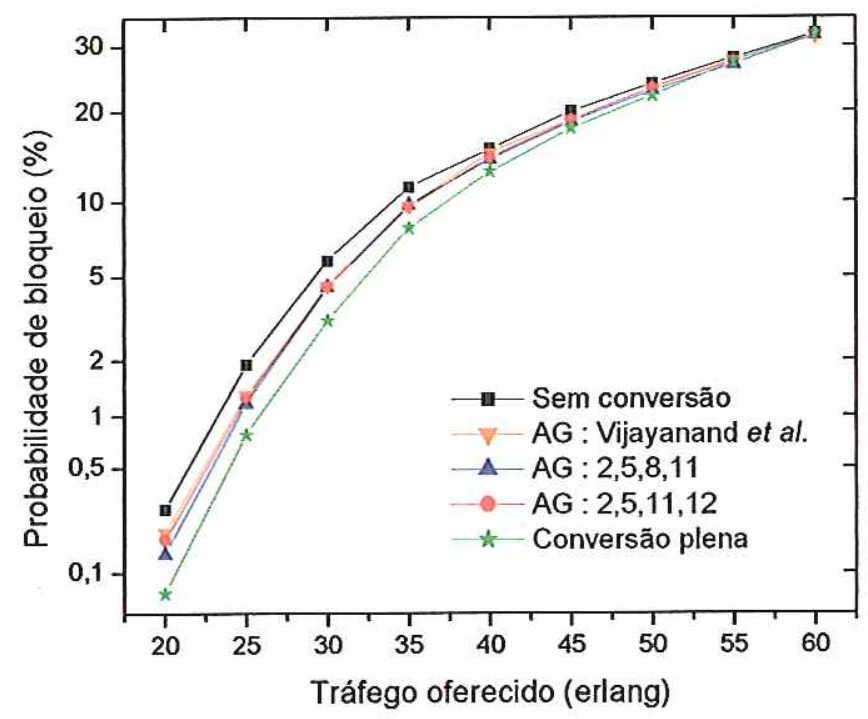

Figura 5.2: Probabilidade de bloqueio em função do tráfego oferecido para a rede em anel com 8 comprimentos de onda por enlace. Resultados obtidos por Vijayanand $e t$ al. [61] são mostrados para efeito de comparação.

A ocupação média dos enlaces, $\bar{E}_{\text {Ocup }}$, traduz a utilização dos comprimentos de onda da rede por meio da seguinte relação:

$$
\bar{E}_{\text {Ocup }}=\frac{\sum_{j=1}^{N_{E n l}} \sum_{i=1}^{N_{R e q}^{(j)}} i \cdot 1 / \mu \cdot 1 / T}{N_{E n l} \cdot W},
$$

na qual $N_{E n l}$ é o número de enlaces unidirecionais, $N_{R e q}^{(j)}$ é o total de requisições do enlace $j, W$ é o número de comprimentos de onda e $T$ é o período de tempo avaliado. A ocupação média dos enlaces em função da demanda de tráfego oferecido na rede em anel está apresentada na Figura 5.3 e na Tabela 5.2.

O comprimento médio das rotas alocadas na rede em número de enlaces, $\bar{L}_{R_{a}}$, é obtido pela relação:

$$
\bar{L}_{R a}=\frac{\sum_{i=1}^{N_{R e q}} \sum_{j=1}^{R_{a}^{h}} j}{N_{R e q}},
$$

na qual $N_{R e q}$ é o número total de requisições, $R_{a}^{h}$ é o número de enlaces da rota $R_{a}$. O comprimento médio das rotas em função da demanda de tráfego oferecido na rede em anel está apresentado na Figura 5.4 e na Tabela 5.3.

Considerando uma demanda de tráfego oferecido de 25 erlangs, as arquiteturas de rede sem conversão, com conversão esparsa e com conversão plena apresentam aproximadamente a mesma ocupação média de $42 \%$ e comprimento médio das rotas de 3,35 enlaces. Para uma demanda de tráfego oferecido de 50 erlangs, as arquiteturas de rede 
Tabela 5.1: Probabilidade de bloqueio na rede em anel: comparação entre resultados do AG proposto neste trabalho e obtidos por Vijayanand et al. [61].

\begin{tabular}{|c|c|c|c|c|c|c|}
\hline \multirow{3}{*}{$\begin{array}{l}\text { Tráfego } \\
\text { (erlang) }\end{array}$} & \multicolumn{6}{|c|}{ Probabilidade de Bloqueio (\%) } \\
\hline & \multirow{2}{*}{$\begin{array}{c}\text { Sem } \\
\text { Conversão } \\
\end{array}$} & \multirow{2}{*}{$\begin{array}{l}\text { Conversão } \\
\text { Plena }\end{array}$} & \multirow{2}{*}{\multicolumn{2}{|c|}{$\begin{array}{l}\text { Vijayanand et al. }[61] \\
\text { (Nós conversores) }\end{array}$}} & \multicolumn{2}{|c|}{ AG (proposto) } \\
\hline & & & & & $(2,5,8,11)$ & $(2,5,11,12)$ \\
\hline 20 & 0,2700 & 0,0710 & 0,1918 & $(1,4,7,10)$ & 0,1350 & 0,1705 \\
\hline 25 & 1,9137 & 0,7860 & 1,3156 & $(1,4,7,10)$ & 1,1846 & 1,2644 \\
\hline 30 & 5,8564 & 3,1602 & 4,5473 & $(1,8,9,11)$ & 4,5106 & 4,5060 \\
\hline 35 & 11,3176 & 7,9369 & 9,6489 & $(2,4,7,12)$ & 9,7554 & 9,5858 \\
\hline 40 & 15,2776 & 12,7951 & 14,8813 & $(2,7)$ & 14,1094 & 14,2902 \\
\hline 45 & 19,9975 & 17,7089 & 18,8563 & $(1,4,7,10)$ & 18,5934 & 18,8068 \\
\hline 50 & 23,9548 & 22,1104 & 23,1808 & $(2,4,12)$ & 22,8063 & 23,2618 \\
\hline 55 & 27,9700 & 27,2743 & 27,5343 & $(2,3,4,7)$ & 26,9099 & 27,3788 \\
\hline 60 & 32,1251 & 32,0884 & 31,6362 & $(2,4,8,12)$ & 31,6890 & 32,0058 \\
\hline
\end{tabular}

sem conversão, com conversão esparsa e com conversão plena apresentam ocupação média de $62,86 \%, 68,02 \%$ e $73,60 \%$ e comprimento médio das rotas de $3,19,3,35$ e 3,60 enlaces, respectivamente. A inclusão dos conversores permite melhor aproveitamento dos recursos disponíveis, possibilita a utilização de rotas com maior número de enlaces por meio da eliminação da condição de continuidade de comprimento de onda, e apresenta melhor desempenho em termos de probabilidade de bloqueio. A conversão esparsa se apresenta como meio-termo entre desempenho, uso eficiente dos recursos e custo dos dispositivos.

Tabela 5.2: Ocupação média dos enlaces em função do tráfego oferecido para a rede em anel com 8 comprimentos de onda por enlace.

\begin{tabular}{|c|c|c|c|c|c|c|}
\cline { 4 - 7 } \multicolumn{1}{c|}{} & \multicolumn{6}{c|}{ Ocupação Média dos Enlaces (\%) } \\
\hline Tráfego & Sem & Conversão & \multicolumn{2}{|c|}{ Vijayanand et al. $[61]$} & \multicolumn{2}{c|}{ AG (este trabalho) } \\
\cline { 6 - 8 } (erlang) & Conversão & Plena & \multicolumn{2}{c|}{ (Nós conversores) } & $(2,5,8,11)$ & $(2,5,11,12)$ \\
\hline \hline 20 & 33,6501 & 33,7753 & 33,6776 & $(1,4,7,10)$ & 33,7116 & 33,6849 \\
25 & 41,6999 & 42,3394 & 42,0855 & $(1,4,7,10)$ & 42,1368 & 42,1166 \\
30 & 49,9283 & 52,5130 & 51,3693 & $(1,8,9,11)$ & 51,2586 & 51,3997 \\
35 & 54,4213 & 59,8820 & 57,0674 & $(2,4,7,12)$ & 57,1542 & 57,1433 \\
40 & 58,4866 & 65,4094 & 59,7750 & $(2,7)$ & 61,5914 & 61,4583 \\
45 & 60,6119 & 69,3981 & 64,4560 & $(1,4,7,10)$ & 64,5240 & 64,3627 \\
50 & 62,8609 & 72,6338 & 65,7024 & $(2,4,12)$ & 66,9408 & 66,5690 \\
55 & 63,7008 & 73,6017 & 67,5701 & $(2,3,4,7)$ & 68,2291 & 67,8059 \\
60 & 65,2640 & 75,3168 & 69,5377 & $(2,4,8,12)$ & 69,3417 & 69,4965 \\
\hline
\end{tabular}




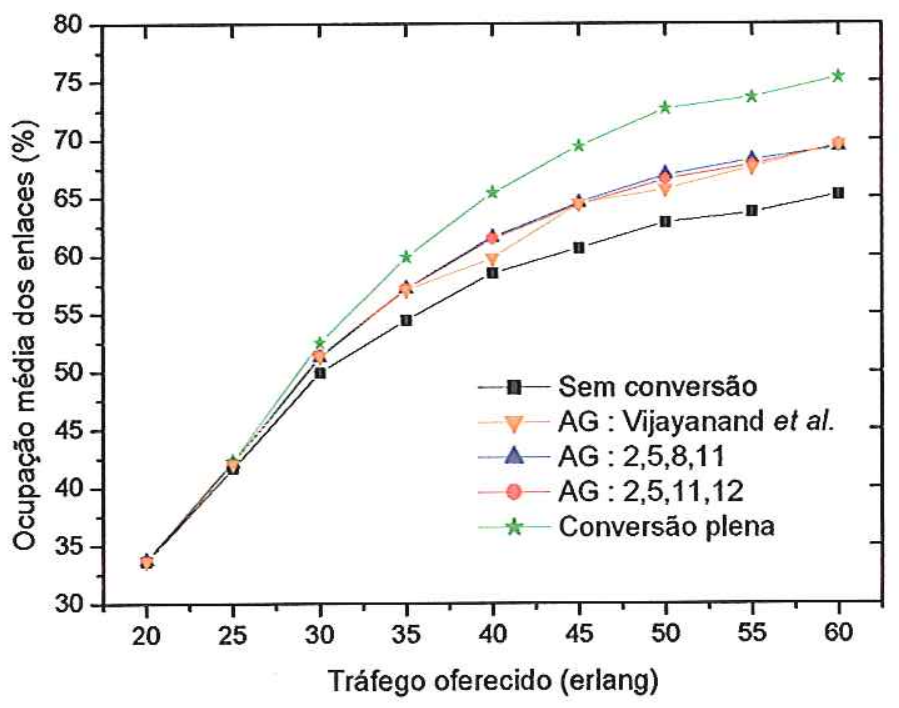

Figura 5.3: Ocupação média dos enlaces em função do tráfego oferecido para a rede em anel com 8 comprimentos de onda por enlace. Resultados obtidos por Vijayanand et al. [61] são mostrados para efeito de comparação.

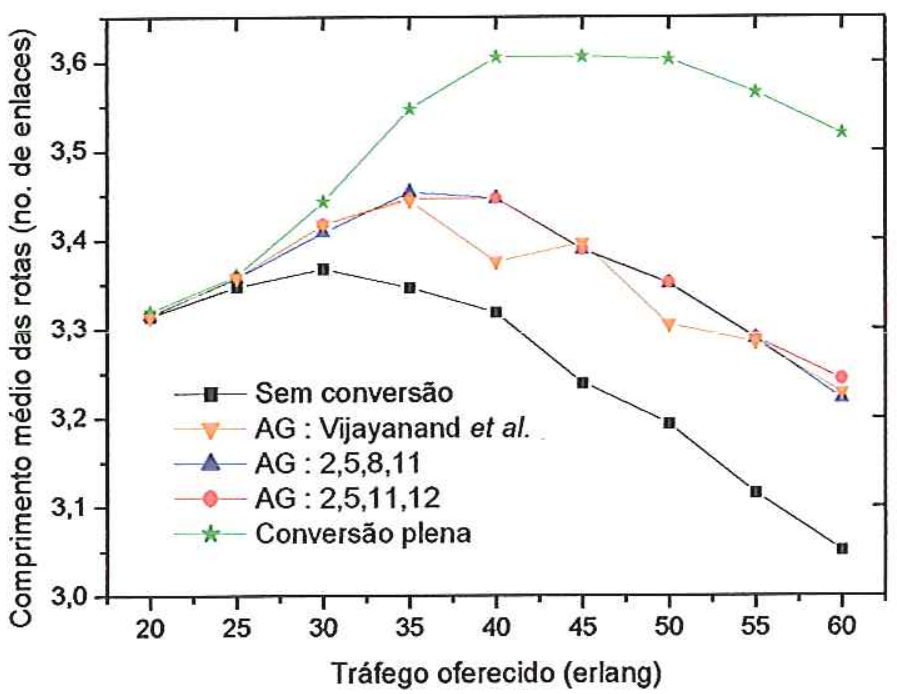

Figura 5.4: Comprimento médio das rotas em função do tráfego oferecido para a rede em anel com 8 comprimentos de onda por enlace. Resultados obtidos por Vijayanand et al. [61] são mostrados para efeito de comparação. 
Tabela 5.3: Comprimento médio das rotas em função do tráfego oferecido para a rede em anel com 8 comprimentos de onda por enlace.

\begin{tabular}{|c|c|c|c|c|c|c|}
\cline { 6 - 7 } \multicolumn{1}{c|}{} & \multicolumn{5}{c|}{ Comprimento Médio das Rotas (número de enlaces) } \\
\cline { 6 - 8 } (erlangego & Sem & Conversão & \multicolumn{2}{|c|}{ Vijayanand et al. $[61]$} & \multicolumn{2}{|c|}{ AG (proposto) } \\
\cline { 6 - 8 } (Nós conversores) & $(2,5,8,11)$ & $(2,5,11,12)$ \\
\hline \hline 20 & 3,3137 & 3,3194 & 3,3138 & $(1,4,7,10)$ & 3,3152 & 3,3138 \\
25 & 3,3472 & 3,3599 & 3,3577 & $(1,4,7,10)$ & 3,3573 & 3,3584 \\
30 & 3,3675 & 3,4432 & 3,4172 & $(1,8,9,11)$ & 3,4085 & 3,4177 \\
35 & 3,3464 & 3,5470 & 3,4443 & $(2,4,7,12)$ & 3,4536 & 3,4465 \\
40 & 3,3180 & 3,6052 & 3,3753 & $(2,7)$ & 3,4467 & 3,4465 \\
45 & 3,2391 & 3,6055 & 3,3961 & $(1,4,7,10)$ & 3,3887 & 3,3891 \\
50 & 3,1934 & 3,6025 & 3,3041 & $(2,4,12)$ & 3,3500 & 3,3512 \\
55 & 3,1154 & 3,5651 & 3,2847 & $(2,3,4,7)$ & 3,2884 & 3,2891 \\
60 & 3,0512 & 3,5192 & 3,2277 & $(2,4,8,12)$ & 3,2211 & 3,2433 \\
\hline
\end{tabular}

O tempo médio para os modelos realizarem o atendimento às solicitações de comprimento de onda em função do tráfego total oferecido está apresentado na Tabela 5.4. Em cada período de tempo o algoritmo verifica as novas requisições, determina a melhor rota e os respectivos comprimentos de onda para estabelecer a conexão. Os tempos de processamento obtidos com o AG são adequados. Na Tabela 5.4, a razão tempo/requisição é o tempo que o algoritmo necessita para atender a uma única requisição (origem-destino). Neste período, o programa avalia todas as possibilidades e determina a melhor rota e os respectivos comprimentos de onda para atender à requisição; (tempo/requisição) $\times$ tráfego é o tempo necessário para atender a todas as requisições ocorridas durante o intervalo de $1 \mathrm{~s}$. O AG proposto necessita em média de apenas 5,34 ms para realizar o atendimento a uma nova requisição. Considerando uma demanda de tráfego de 60 erlangs, o AG necessita de apenas 5,22 ms para atender a todas as solicitações no período de $1 \mathrm{~s}$.

\subsubsection{Roteamento e Alocação de Comprimentos de Onda na Rede NSFnet}

A rede NSFnet, apresentada na Figura 5.5, foi escolhida como exemplo de aplicação do algoritmo proposto por ser bastante utilizada como padrão para comparações [22], [60], [61]. Ela é constituída por 14 nós e 21 enlaces bidirecionais, tendo sido adotados 8 comprimentos de onda por enlace. Nas simulações realizadas foi utilizado $1 / \mu=60$ segundos para o intervalo de tempo de conexão e seguindo uma distribuição exponencial. A distribuição de tráfego gerada nos pares origem-destino é adotada uniforme 
Tabela 5.4: Tempo de atendimento de requisição de comprimento de onda em função do tráfego para rede em anel com 8 comprimentos de onda.

\begin{tabular}{|c|c|c|}
\cline { 2 - 3 } \multicolumn{1}{c|}{} & \multicolumn{2}{c|}{ Tempo de Atendimento de Requisição (ms) } \\
\cline { 2 - 3 } \multicolumn{1}{c|}{} & \multicolumn{2}{c|}{ AG (proposto) $(2,5,8,11)^{1}$} \\
\hline $\begin{array}{c}\text { Tráfego } \\
\text { (erlang) }\end{array}$ & $\begin{array}{c}\text { Tempo por } \\
\text { requisição }\end{array}$ & $\begin{array}{c}\text { Tempo por requisição } \\
\text { x trafégo }\end{array}$ \\
\hline \hline 20 & 5,5586 & 1,8788 \\
25 & 5,3639 & 2,2636 \\
30 & 5,5578 & 2,8011 \\
35 & 5,3031 & 3,1288 \\
40 & 5,3769 & 3,6132 \\
45 & 5,2829 & 4,0044 \\
50 & 5,1555 & 4,3306 \\
55 & 5,2801 & 4,8892 \\
60 & 5,1877 & 5,2292 \\
\hline
\end{tabular}

(1) 2 rotas, 25 indivíduos, 25 gerações;

(2) tempo necessário para atender a todas as requisições no período de $1 \mathrm{~s}$.

com taxas de $60,70,80,90,100,110$ e 120 solicitações por minuto e obedecendo à distribuição de Poisson.

Inicialmente, as soluções representando as menores distâncias entre todos os possíveis pares origem-destino são determinadas com o auxílio do algoritmo de Dijkstra [167]. Em seguida, o algoritmo do menor caminho alternativo [24]-[29] é empregado para calcular a probabilidade de bloqueio da rede em função do número de rotas utilizado nos conjuntos. A probabilidade de bloqueio da rede é mostrada na Figura 5.6, considerando os casos limites sem conversão e com conversão plena de comprimentos de onda.

Os resultados apresentados na Figura 5.6 e na Tabela 5.5 indicam que a adoção de conversores e várias rotas alternativas contribuem para a redução da probabilidade de bloqueio. Dentre as situações mostradas, aquela que utiliza conversão plena e 5 rotas alternativas exibe os menores valores de probabilidade de bloqueio independentemente da demanda de tráfego oferecido.

Os resultados obtidos para rede com alocação esparsa de conversores estão apresentados na Figura 5.7 e os valores numéricos correspondentes exibidos na Tabela 5.6. Foram adotadas 2 disposições distintas para rede esparsa utilizando 4 nós com conversores. O AG determinou equipar com conversores os seguintes nós da rede: $(4,6,7,9)$ e $(4,6,9,10)$, conforme mostrados na Figura 5.5. A quantidade de nós com conver- 


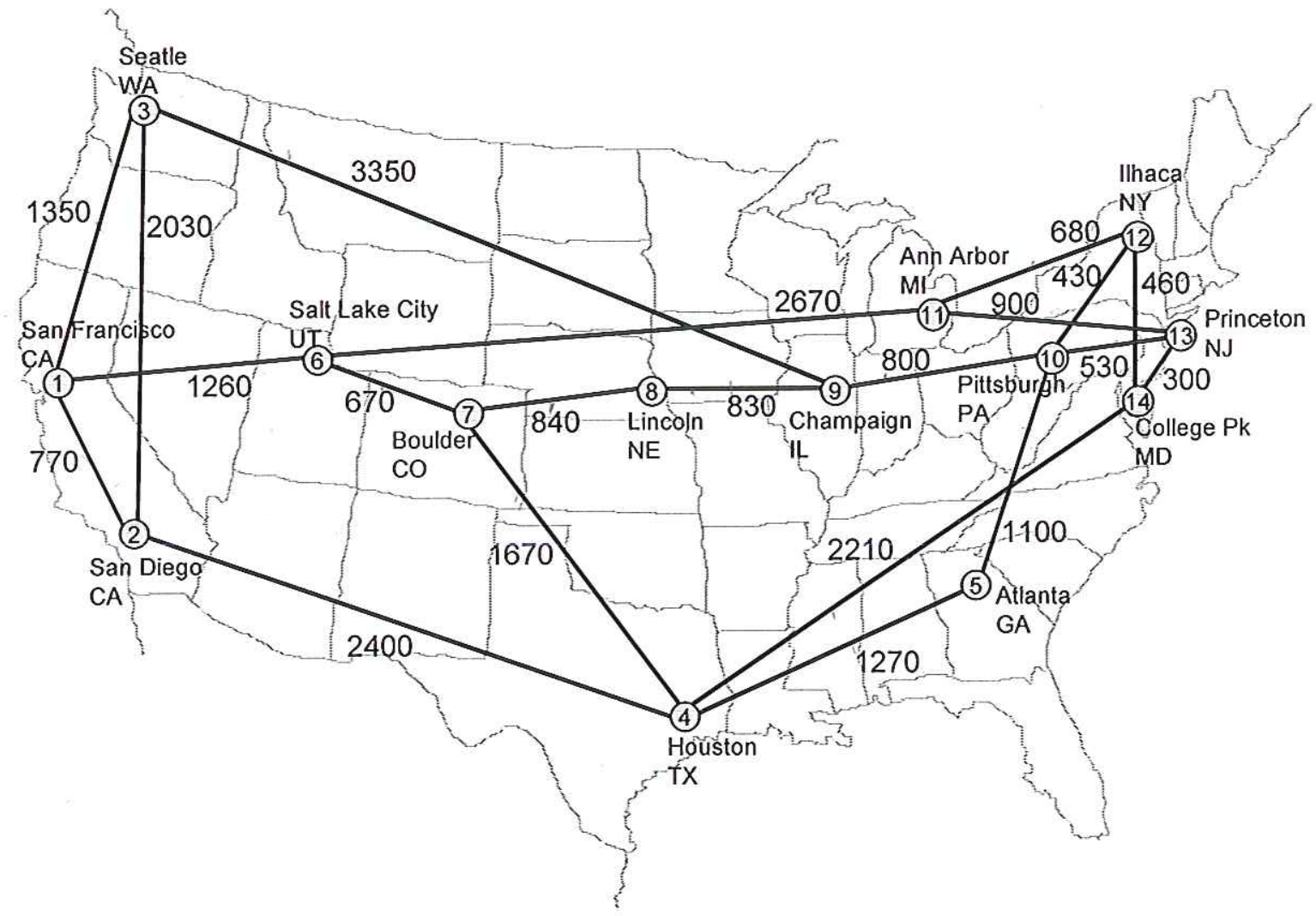

Figura 5.5: Rede norte-americana NSFnet constituída por 14 nós e 21 enlaces bidirecionais [22], [60], [61]. Distâncias em km. 


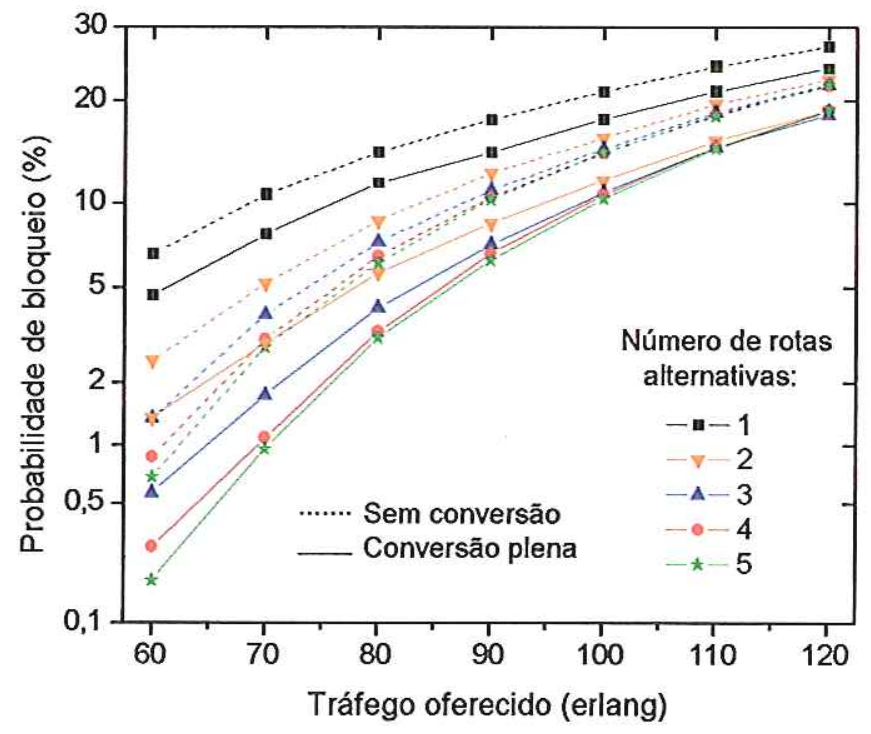

Figura 5.6: Probabilidade de bloqueio em função da demanda de tráfego oferecido para a rede NSFnet com 8 comprimentos de onda por enlace. A parametrização é feita pelo número de rotas alternativas para cada par origem-destino. Rede sem conversão (linha tracejada); e rede com conversão completa (linha contínua).

sores foi escolhida para que os resultados pudessem ser comparados com as disposições sugeridas por Vijayanand et al. [61]. Os casos com conversão plena e sem conversão representam os limites superior e inferior para o desempenho de uma rede com conversão esparsa e são mostrados para efeito de comparação. Ambas as disposições propostas de conversão esparsa apresentam desempenhos similares e exibem valores de probabilidade de bloqueio inferiores ao obtido por Vijayanand et al. [61] em toda a faixa de demanda de tráfego avaliada. Ainda, o algoritmo proposto por Vijayanand et al. [61] apresenta dependência entre a distribuição dos conversores e a demanda de tráfego, conforme mostra a Tabela 5.6. O AG proposto neste trabalho apresenta uma melhoria de desempenho da rede em toda a faixa de demanda avaliada utilizando um número fixo de nós equipados com conversores.

Os resultados apresentados na Tabela 5.6 mostram que a estratégia com AG proposta neste trabalho apresenta melhor desempenho que o obtido por Vijayanand $e t$ al. [61]. Por exemplo, para um tráfego igual a 70 erlangs, as probabilidades de bloqueio para os dois casos são $1,36 \%$ e 2,04\%. Para um tráfego de 80 erlangs, estes valores são $4,07 \%$ e 4,99\%. Estes resultados demonstram, respectivamente, uma redução do número de chamadas bloqueadas para o AG proposto de $33 \%$ e $18 \%$ em relação ao esquema de Vijayanand et al. [61]. Para demandas de tráfego superiores a 100 erlangs, Vijayanand et al. [61] não obtém melhoria satisfatória com a inclusão dos conversores 
Tabela 5.5: Probabilidade de bloqueio na rede NSFnet em função do número de rotas alternativas, $n_{a} . W=8$.

\begin{tabular}{|c|c|c|c|c|c|}
\cline { 2 - 6 } \multicolumn{1}{c|}{} & \multicolumn{5}{|c|}{ Probabilidade de Bloqueio (\%) } \\
\hline Tráfego & \multicolumn{5}{|c|}{ Senversão } \\
\cline { 2 - 6 } (erlang) & $n_{a}=1$ & $n_{a}=2$ & $n_{a}=3$ & $n_{a}=4$ & $n_{a}=5$ \\
\hline \hline 60 & 6,6595 & 2,4935 & 1,3520 & 0,8748 & 0,6924 \\
70 & 10,6044 & 5,1850 & 3,9104 & 3,0889 & 2,8584 \\
80 & 14,3931 & 8,7271 & 7,3547 & 6,5579 & 6,2087 \\
90 & 17,7838 & 12,4852 & 11,0210 & 10,4431 & 10,2736 \\
100 & 21,1387 & 15,7939 & 14,6817 & 14,3026 & 14,3581 \\
110 & 24,3933 & 19,5736 & 18,6271 & 18,3487 & 18,2222 \\
120 & 27,1451 & 22,6661 & 21,9817 & 21,9201 & 21,9887 \\
\hline \hline Tráfego & \multicolumn{5}{|c|}{ Conversão Plena } \\
(erlang) & $n_{a}=1$ & $n_{a}=2$ & $n_{a}=3$ & $n_{a}=4$ & $n_{a}=5$ \\
\hline \hline 60 & 4,6712 & 1,3614 & 0,5707 & 0,2854 & 0,1825 \\
70 & 7,8445 & 2,9628 & 1,7474 & 1,0933 & 0,9613 \\
80 & 11,6016 & 5,6954 & 4,1553 & 3,3308 & 3,1389 \\
90 & 14,3546 & 8,5536 & 7,2158 & 6,6888 & 6,3466 \\
100 & 17,9032 & 11,8267 & 10,8116 & 10,6658 & 10,3298 \\
110 & 21,1666 & 15,5511 & 14,8488 & 14,8589 & 14,7514 \\
120 & 24,1300 & 18,833 & 18,4043 & 18,8411 & 18,8493 \\
\hline
\end{tabular}

e adota uma rede sem conversão.

Também foi implementado para a rede NSFnet um AG para o estabelecimento dinâmico das conexões. O algoritmo genético utiliza as informações do estado atual do ambiente para determinar dinamicamente as rotas e os respectivos comprimentos de onda. Na Figura 5.8 são apresentados os resultados obtidos por simulação para probabilidade de bloqueio da rede NSFnet para os dois modelos de AG propostos utilizando roteamento fixo alternativo, com 5 rotas possíveis, e roteamento dinâmico. Os casos limites com conversão plena e sem conversão foram incluídos para efeito de comparação. Os valores numéricos correspondentes estão exibidos na Tabela 5.7.

Para a rede NSFnet, cujo grau nodal médio é igual a 3,0, o uso do roteamento alternativo com 5 rotas apresenta praticamente todas as soluções de rotas possíveis para todos os pares origem-destino. Enquanto o AG alternativo utiliza as rotas previamente definidas, o AG dinâmico deve encontrar a rota e os respectivos comprimentos de onda. Os dois modelos apresentam resultados similares, conforme mostra a Figura 5.8. As vantagens do modelo dinâmico se destacam em redes que apresentam alterações na topologia, como falha de operação em alguns nós roteadores ou mudanças no número de nós. Nestes casos, o AG dispõe de liberdade para avaliar todas as possibilidades 


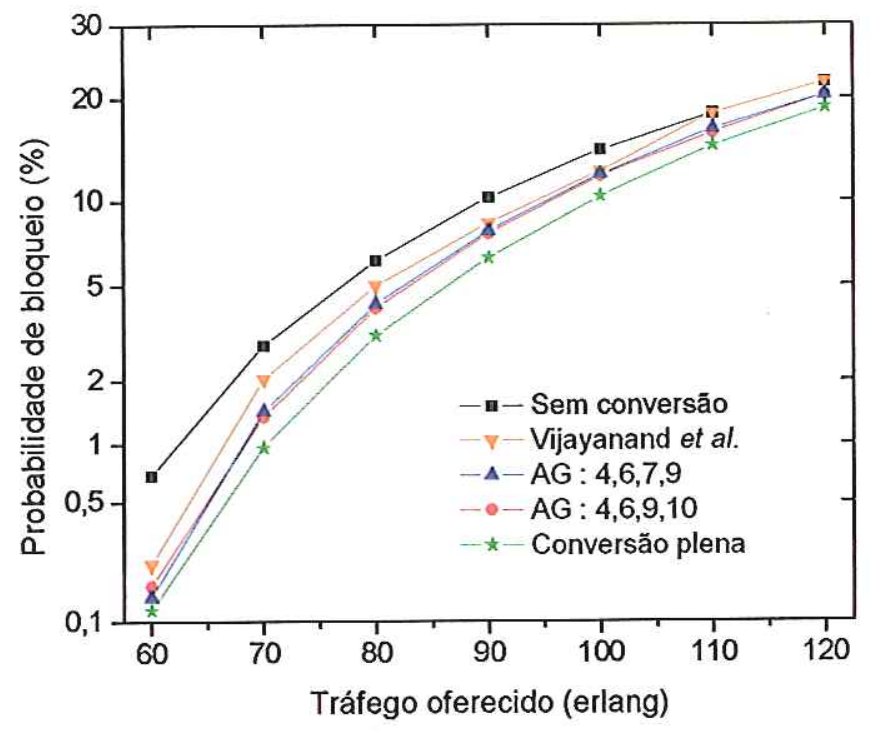

Figura 5.7: Probabilidade de bloqueio em função do tráfego oferecido para a rede NSFnet considerando roteamento fixo alternativo com 5 rotas possíveis e 8 comprimentos de onda por enlace. Resultados obtidos por Vijayanand [61] são mostrados para efeito de comparação.

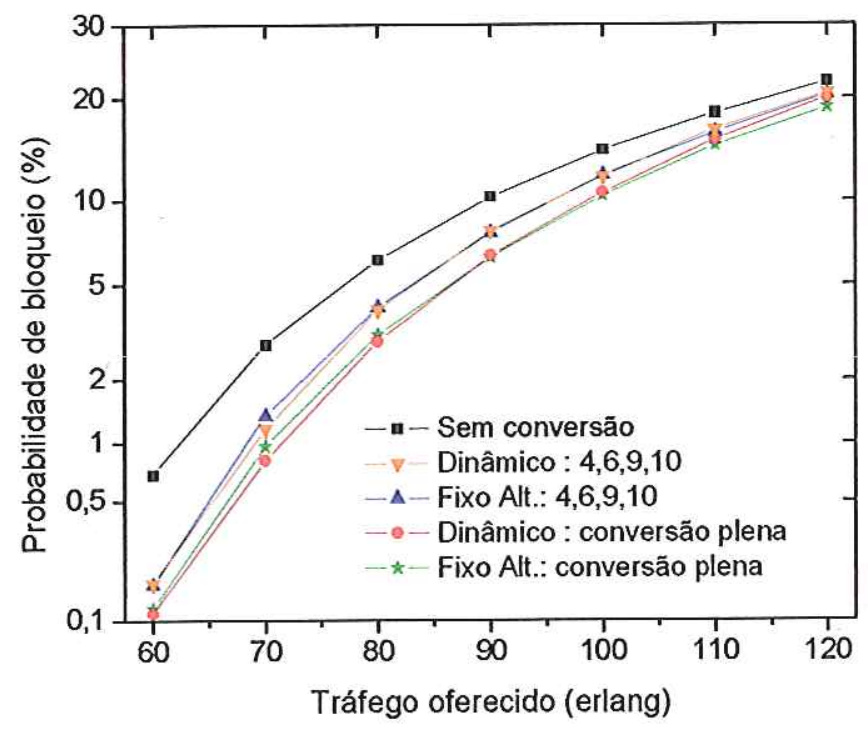

Figura 5.8: Probabilidade de bloqueio em função do tráfego oferecido para a rede NSFnet considerando roteamento fixo alternativo com 5 rotas possíveis e roteamento dinâmico. Há 8 comprimentos de onda por enlace. 
Tabela 5.6: Probabilidade de bloqueio na rede NSFnet considerando roteamento fixo alternativo com 5 rotas possíveis e $W=8$ : comparação entre resultados do AG proposto e de Vijayanand et al. [61].

\begin{tabular}{|c|c|c|c|c|c|c|}
\hline & \multicolumn{6}{|c|}{ Probabilidade de Bloqueio (\%) } \\
\hline \multirow{2}{*}{$\begin{array}{l}\text { Tráfego } \\
\text { (erlang) }\end{array}$} & \multirow{2}{*}{$\begin{array}{c}\text { Sem } \\
\text { Conversão }\end{array}$} & \multirow{2}{*}{$\begin{array}{l}\text { Conversão } \\
\text { Plena }\end{array}$} & \multirow{2}{*}{\multicolumn{2}{|c|}{$\begin{array}{l}\text { Vijayanand et al. [61] } \\
\text { (Nós conversores) }\end{array}$}} & \multicolumn{2}{|c|}{ AG (este trabalho) } \\
\hline & & & & & $(4,6,7,9)$ & $(4,6,9,10)$ \\
\hline 60 & 0,6924 & 0,1179 & 0,2235 & $(4,7,11)$ & 0,1424 & 0,1646 \\
\hline 70 & 2,8584 & 0,9613 & 2,0488 & $(3,7,11,12)$ & 1,4519 & 1,3652 \\
\hline 80 & 6,2087 & 3,1389 & 4,9988 & $(3,4,11,12)$ & 4,2400 & 4,0740 \\
\hline 90 & 10,2736 & 6,3466 & 8,4395 & $(7,9,10)$ & 7,9001 & 7,7583 \\
\hline 100 & 14,3581 & 10,3298 & 12,4182 & $(7,10,11,12)$ & 12,1086 & 11,9989 \\
\hline 110 & 18,2222 & 14,7514 & 18,2222 & & 16,5241 & 16,1078 \\
\hline 120 & 21,9887 & 18,8493 & 21,9887 & - & 20,3202 & 20,3562 \\
\hline
\end{tabular}

existentes antes de realizar o roteamento, sem exigir a reconfiguração de tabela com as novas rotas.

O tempo médio para os modelos realizarem o atendimento às solicitações de comprimento de onda em função do tráfego total oferecido está apresentado na Tabela 5.8. Em cada período de tempo o algoritmo verifica as novas requisições, determina a melhor rota e os respectivos comprimentos de onda para estabelecer a conexão. Os tempos de processamento obtidos com o AG são satisfatórios. No roteamento fixo o AG necessita em média de apenas 14,7 milissegundos para realizar o atendimento de uma nova requisição. No roteamento dinâmico, estimando-se as vantagens deste algoritmo em determinadas configurações, o tempo necessário para o processamento é de apenas 21,8 milissegundos.

A ocupação média dos enlaces c o comprimento médio das rotas em função da demanda de tráfego oferecido estão apresentados nas Figuras 5.9 e 5.10 e na Tabela 5.9. Considerando uma demanda de tráfego oferecido de 60 erlangs, as arquiteturas de rede sem conversão, com conversão esparsa e com conversão plena apresentam aproximadamente a mesma ocupação média de $39,61 \%$ e comprimento médio das rotas de 2,25 enlaces. Para um tráfego oferecido de 120 erlangs, a arquitetura de rede sem conversão, com conversão esparsa e com conversão plena apresenta ocupação média de $64,38 \%, 68,87 \%$ e $73,36 \%$ e comprimento médio das rotas de $2,31,2,43$ e 2,57 enlaces, respectivamente. 


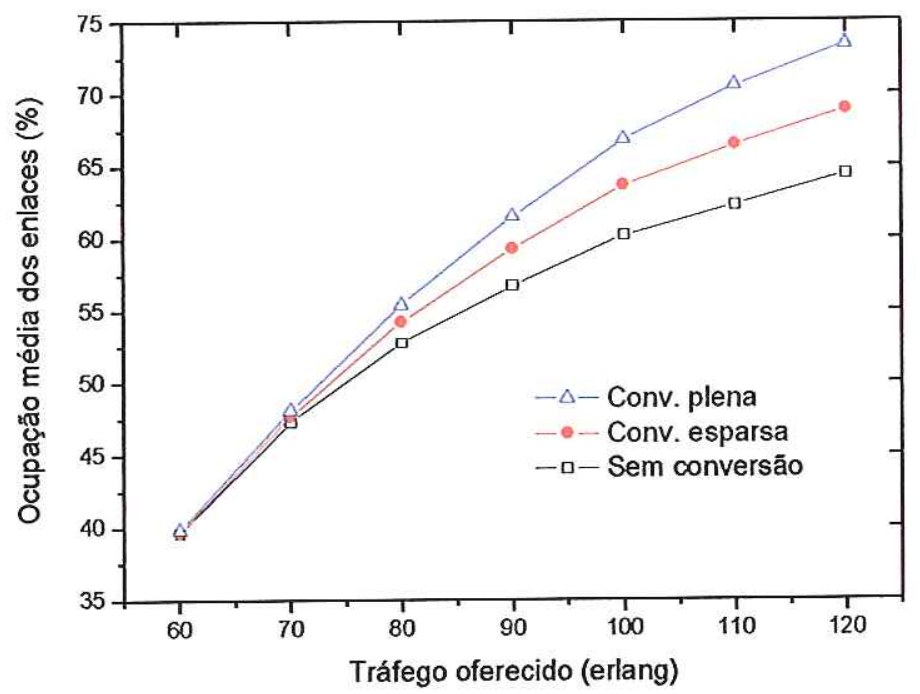

Figura 5.9: Ocupação média dos enlaces (\%) em função do tráfego oferecido para a rede NSFnet utilizando conversão plena, esparsa e rede sem conversão. Há 8 comprimentos de onda por enlace.

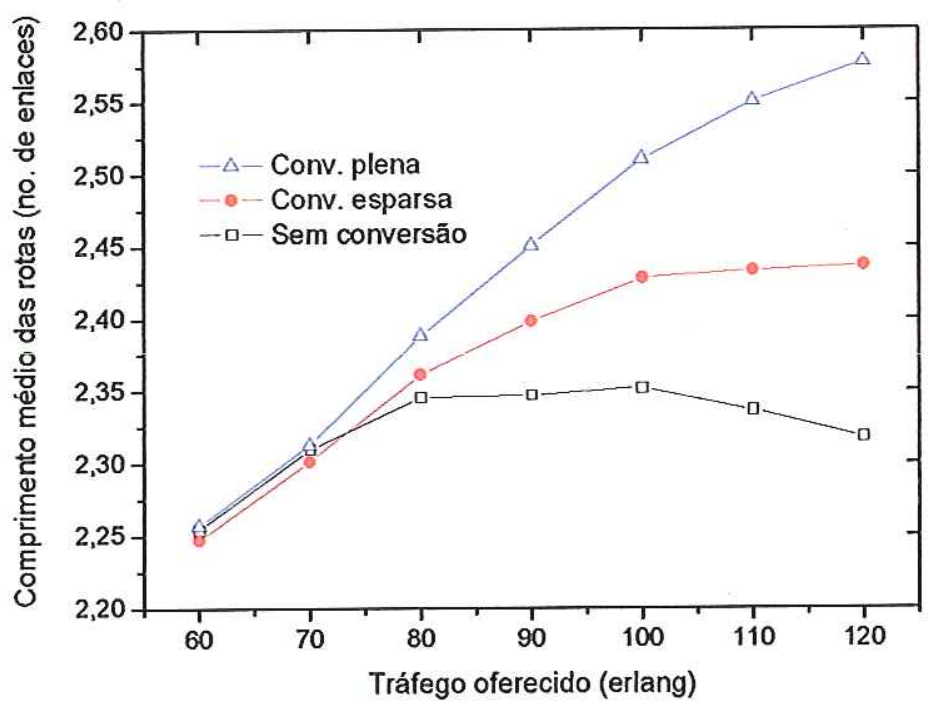

Figura 5.10: Comprimento médio das rotas (número de enlaces) em função do tráfego oferecido para a rede NSFnet utilizando conversão plena, esparsa e rede sem conversão. Há 8 comprimentos de onda por enlace. 
Tabela 5.7: Probabilidade de bloqueio na rede NSFnet: comparação entre roteamento fixo alternativo com 5 rotas possíveis e roteamento dinâmico. $W=8$.

\begin{tabular}{|c|c|c|c|c|c|}
\cline { 3 - 6 } \multicolumn{1}{c|}{} & \multicolumn{5}{c|}{ Probabilidade de Bloqueio (\%) } \\
\hline Tráfego & Sem & Roteamento Fixo Alternativo & \multicolumn{2}{c|}{ Roteamento Dinâmico } \\
\cline { 3 - 6 } (erlang) & Conversão & $\begin{array}{c}\text { Conversão } \\
\text { Plena }\end{array}$ & $\begin{array}{c}\text { Conv. Esparsa } \\
(4,6,9,10)\end{array}$ & $\begin{array}{c}\text { Conversão } \\
\text { Plena }\end{array}$ & $\begin{array}{c}\text { Conv. Esparsa } \\
(4,6,9,10)\end{array}$ \\
\hline \hline 60 & 0,6924 & 0,1179 & 0,1646 & 0,1103 & 0,1684 \\
70 & 2,8584 & 0,9613 & 1,3652 & 0,8175 & 1,1761 \\
80 & 6,2087 & 3,1389 & 4,0740 & 2,9523 & 3,9790 \\
90 & 10,2736 & 6,3466 & 7,7583 & 6,4360 & 7,8570 \\
100 & 14,3581 & 10,3298 & 11,9989 & 10,5853 & 11,9225 \\
110 & 18,2222 & 14,7514 & 16,1078 & 15,3537 & 16,4039 \\
120 & 21,9887 & 18,8493 & 20,3562 & 19,9740 & 20,5375 \\
\hline
\end{tabular}

\subsubsection{Falhas em Equipamentos}

As redes de telecomunicações estão sujeitas a falhas em equipamentos durante o período normal de operação. Uma falha típica é tornar enlaces temporariamente indisponíveis. Esquemas de proteção e restauração devem ser implementados em conjunto com o algoritmo de roteamento e alocação de canais para garantir qualidade de serviço aos usuários. O modelo do algoritmo proposto para restauração reconfigura as rotas que utilizavam o enlace perdido por meio de uma rota alternativa. Esta reconfiguração é realizada preferencialmente em relação às novas requisições de conexão.

Um exemplo do impacto da falha de um enlace sobre a probabilidade de bloqueio para os modelos RWA fixo alternativo, com 5 rotas possíveis, e RWA dinâmico está apresentado nas Figuras 5.11 e 5.12. São consideradas duas distribuições de demanda de tráfego hemogêneo com médias 70 erlangs (Figura 5.11) e 100 erlangs (Figura 5.12). Inicialmente, o sistema operava normalmente com 21 enlaces bidirecionais e 8 comprimentos de onda e, durante o período de falha, das 10 às $15 \mathrm{~h}$, o enlace entre os nós 6 e 7, escolhido aleatoriamente, permaneceu temporariamente indisponível para o uso. Comparando os resultados, mostrados na Tabela 5.10, os modelos propostos exibem certo grau de robustez em situação de falha de enlaces e sugerem que são capazes de se adaptar às configurações do ambiente. Particularmente, sob condição de demanda leve a moderada, o modelo dinâmico apresenta desempenho ligeiramente superior ao modelo fixo alternativo. Sob demanda de tráfego elevada os modelos apresentam desempenho similar. 


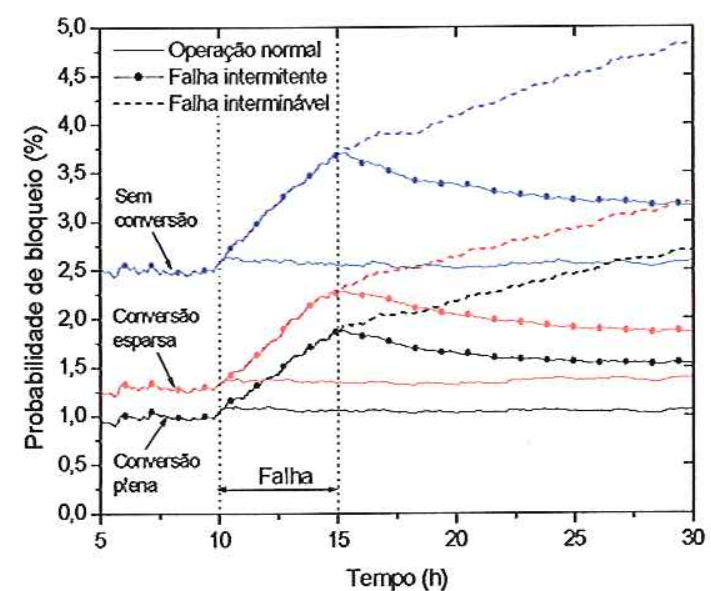

(a)

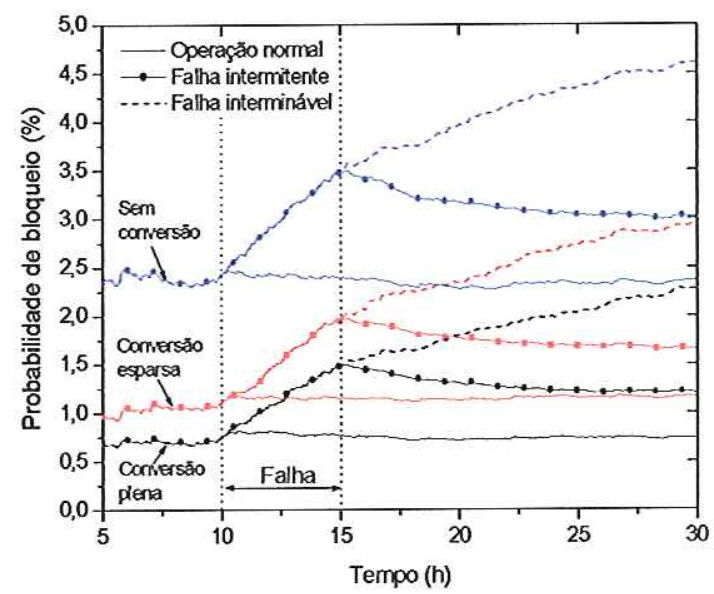

(b)

Figura 5.11: Probabilidade de bloqueio para os algoritmos: (a) Fixo alternativo; e (b) dinâmico. Falha ocorrida no enlace entre os nós 6 e 7 durante o período das 10 às $15 \mathrm{~h}$. Tráfego homogêneo, média 70 erlangs e 8 comprimentos de onda.

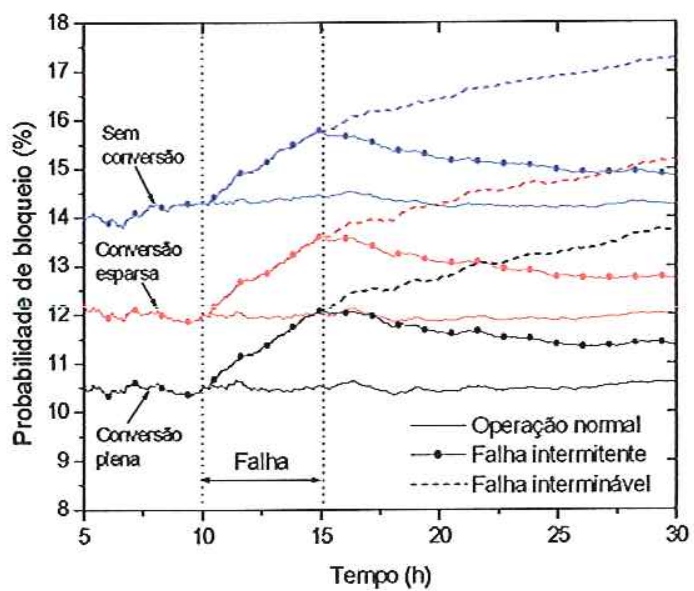

(a)

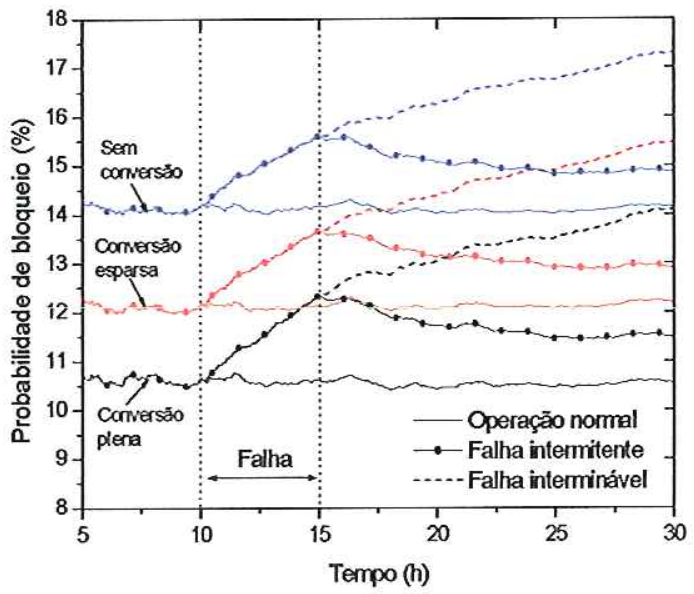

(b)

Figura 5.12: Probabilidade de bloqueio para os algoritmos (a) Fixo alternativo; e (b) dinâmico. Falha ocorrida no enlace entre os nós 6 e 7 durante o período das 10 às $15 \mathrm{~h}$. Tráfego homogêneo, média 100 erlangs e 8 comprimentos de onda. 
Tabela 5.8: Tempo de atendimento de requisição de comprimento de onda em função do tráfego oferecido para a rede NSFnet considerando roteamento fixo alternativo com 5 rotas possíveis e roteamento dinâmico. $W=8$.

\begin{tabular}{|c|c|c|c|c|}
\cline { 2 - 5 } \multicolumn{1}{c|}{} & \multicolumn{4}{c|}{ Tempo de Atendimento de Requisição (milissegundos) } \\
\cline { 2 - 5 } \multicolumn{1}{c|}{} & \multicolumn{2}{c|}{ Roteamento Fixo Alternativo } & \multicolumn{2}{c|}{ Roteamento Dinâmico } \\
\hline $\begin{array}{c}\text { Tráfego } \\
\text { (erlang) }\end{array}$ & $\begin{array}{c}\text { Tempo por } \\
\text { requisição }\end{array}$ & $\begin{array}{c}\text { Tempo por requisição } \\
\text { x trafégo }^{3}\end{array}$ & $\begin{array}{c}\text { Tempo por } \\
\text { requisição }\end{array}$ & $\begin{array}{c}\text { Tempo por requisição } \\
\text { x trafégo }^{3}\end{array}$ \\
\hline \hline 60 & 15,013 & 15,013 & 23,201 & 23,225 \\
70 & 14,893 & 17,375 & 24,625 & 28,959 \\
80 & 15,159 & 20,212 & 24,182 & 32,387 \\
90 & 14,533 & 21,800 & 22,532 & 33,858 \\
100 & 14,677 & 24,462 & 20,690 & 34,470 \\
110 & 14,767 & 27,072 & 19,575 & 35,809 \\
120 & 14,407 & 28,815 & 18,404 & 36,674 \\
\hline
\end{tabular}

(1) 5 rotas, 25 indivíduos, 50 gerações, 4 conversores;

(2) 25 indivíduos, 50 gerações, 4 conversores;

(3) tempo necessário para atender a todas as requisições no período de $1 \mathrm{~s}$.

\subsubsection{Aplicabilidade do Algorimo Genético Proposto}

Nas redes analisadas, rede em anel e rede NSFnet, a melhoria no desempenho proporcionada pelos conversores é considerável sob condições de demanda de tráfego leve a moderada. Em demandas de tráfego elevadas, a flexibilidade obtida com a conversão é perdida devido à quantidade insuficiente de recursos e o ganho é reduzido. Um resumo da melhoria obtida com conversores está apresentada na Tabela 5.11.

Os resultados de simulação revelam que uma melhoria significativa em termos de economia nos custos dos equipamentos pode ser obtida por meio do algoritmo genético proposto. Utilizando um reduzido número de conversores dispostos otimamente em poucos nós obtém-se desempenho similar ao obtido utilizando conversão plena. Além disso, a otimização com o uso do AG permitiu uma disposição para os conversores na rede independentemente da demanda de tráfego. Na Tabela 5.12 estão apresentados alguns resultados referentes à melhoria no desempenho para a probabilidade de bloqueio obtida com o uso dos AGs para a rede NSFnet e para a topologia em anel em relação aos obtidos com a disposição sugerida por Vijayanand et al. [61]. 
Tabela 5.9: Ocupação média dos enlaces e comprimento médio das rotas em função do tráfego oferecido para a rede NSFnet utilizando conversão plena, esparsa e rede sem conversão. $W=8$.

\begin{tabular}{|c|c|c|c|c|c|c|}
\cline { 2 - 7 } \multicolumn{1}{c|}{} & \multicolumn{2}{c|}{ Ocupação Média dos Enlaces (\%) } & \multicolumn{3}{c|}{ Comp. Médio das Rotas (enlaces) } \\
\hline $\begin{array}{c}\text { Tráfego } \\
\text { (erlang) }\end{array}$ & $\begin{array}{c}\text { Sem } \\
\text { Conv. }\end{array}$ & $\begin{array}{c}\text { Conv. Esparsa } \\
(4,6,9,10)\end{array}$ & $\begin{array}{c}\text { Conv. } \\
\text { Plena }\end{array}$ & $\begin{array}{c}\text { Sem } \\
\text { Conv. }\end{array}$ & $\begin{array}{c}\text { Conv. Esparsa } \\
(4,6,9,10)\end{array}$ & $\begin{array}{c}\text { Conv. } \\
\text { Plena }\end{array}$ \\
\hline \hline 60 & 39,6101 & 39,6039 & 39,8098 & 2,25396 & 2,24695 & 2,25661 \\
70 & 47,2773 & 47,7130 & 48,1326 & 2,30955 & 2,30101 & 2,31285 \\
80 & 52,7555 & 54,2187 & 55,4175 & 2,34535 & 2,36119 & 2,38786 \\
90 & 56,6902 & 59,2601 & 61,4892 & 2,34690 & 2,39793 & 2,45035 \\
100 & 60,1553 & 63,6526 & 66,8073 & 2,35224 & 2,42779 & 2,51000 \\
110 & 62,2840 & 66,4374 & 70,5180 & 2,33654 & 2,43286 & 2,55024 \\
120 & 64,3881 & 68,8774 & 73,3626 & 2,31768 & 2,43646 & 2,57685 \\
\hline
\end{tabular}

\subsubsection{Roteamento e Alocação de Comprimentos de Onda na Rede Italiana de Faixa Larga}

Uma terceira topologia de rede analisada foi a rede italiana de faixa larga, consistindo de 21 nós e 36 enlaces bidirecionais, conforme ilustra a Figura 5.13 [69]. Nas simulações foram considerados 12, 15 e 18 comprimentos de onda nos enlaces. Na busca por uma solução para a disposição otimizada dos nós equipados com conversores, o algoritmo genético deve atender a duas condições: reduzir o número de conversões e minimizar a probabilidade de bloqueio global do sistema. Entretanto, estas restrições atuam de forma inversa no comportamento do sistema. Assim, foram elaborados dois modelos, $\min$ (probabilidade de bloqueio) e min(número de conversões), nos quais o algoritmo genético prioriza a condição especificada.

Foi utilizado um modelo de tráfego dinâmico para qual as solicitações origemdestino obedecem à distribuição de Poisson. O tempo de permanência da conexão é distribuído exponencialmente com média $1 / \mu=60 \mathrm{~s}$. A determinação do número e posicionamento dos conversores foi obtida por meio de uma média de utilização dos dispositivos e desempenho do sistema sobre as solicitações dos pares origem-destino, distribuídas de forma uniforme com taxas de 90, 105, 120, 135, 150, 165 e 180 solicitações por minuto, cada uma avaliada em um período de 12 horas.

Considere inicialmente que todos os nós da rede estejam equipados com conversores de comprimento de onda, com capacidade de conversão plena, os quais estão representados em destaque na rede óptica da Figura 5.13. Observe que são conhecidas as distâncias e os enlaces entre os nós da rede. Estas informações são fundamentais na determinação dos caminhos ópticos virtuais e no prognóstico da qualidade do sinal. 


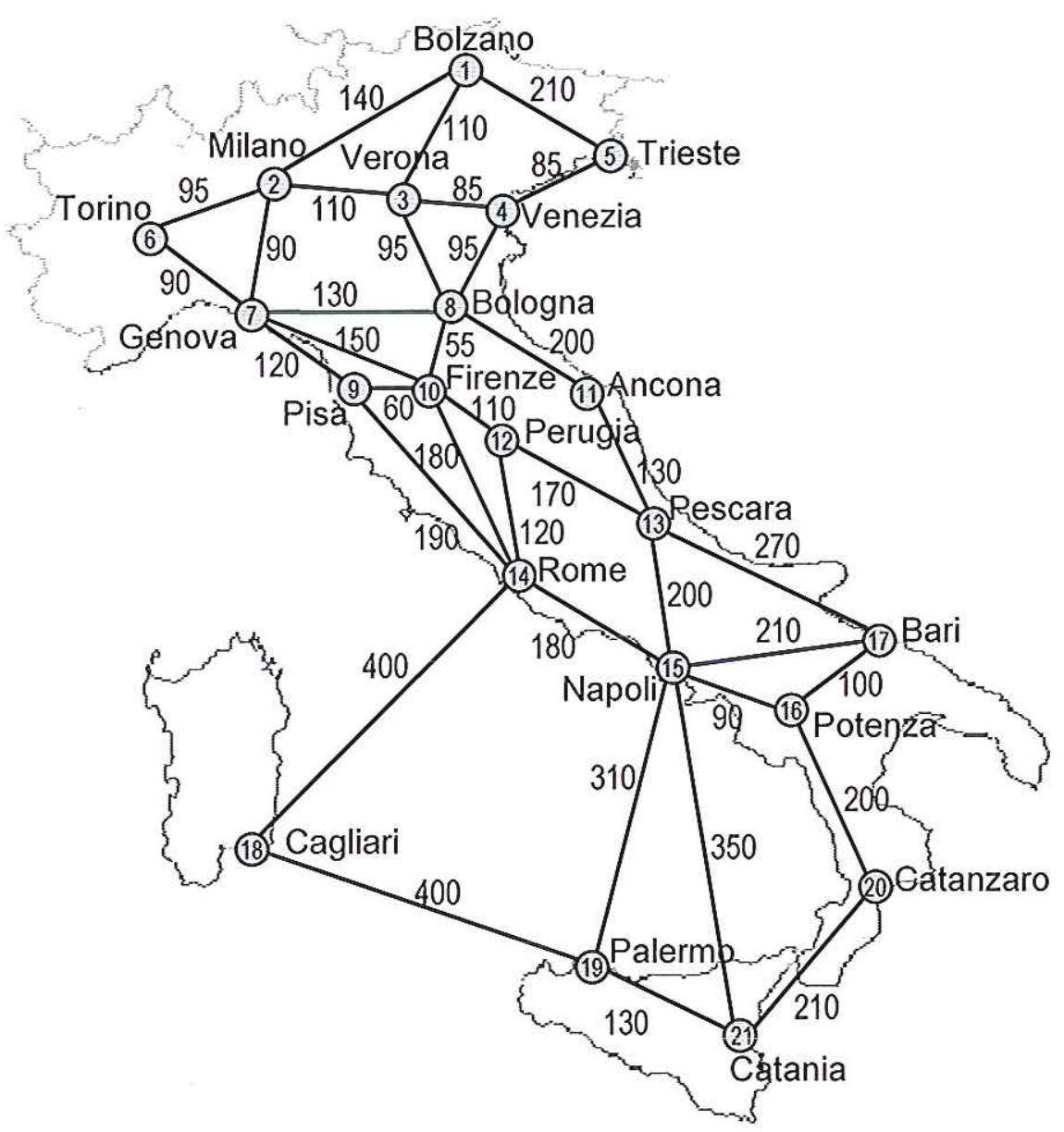

Figura 5.13: Topologia da rede italiana de faixa larga constituída de 21 nós e 36 enlaces bidirecionais [69]. Distâncias em km. 
Tabela 5.10: Robustez dos algoritmos fixo alternativo dinâmico para a rede NSFnet sob falha no enlace entre os nós 6 e 7: operação normal e ocorrência de falha entre 10 e 15 h. 8 comprimentos de onda.

\begin{tabular}{|c|c|c|c|c|c|}
\cline { 2 - 6 } \multicolumn{1}{c|}{} & \multicolumn{5}{c|}{ Probabilidade de Bloqueio Conversão Esparsa (\%) } \\
\cline { 2 - 6 } \multicolumn{1}{c|}{} & \multicolumn{5}{c|}{ RWA Fixo Alternativo } \\
\hline $\begin{array}{c}\text { Tráfego } \\
\text { (erlang) }\end{array}$ & $10 \mathrm{~h}$ & \multicolumn{2}{|c|}{$15 \mathrm{~h}$} & \multicolumn{2}{c|}{$30 \mathrm{~h}$} \\
\cline { 2 - 6 } & Normal & Normal & Falha & Normal & Falha \\
\hline \hline 70 & 1,3455 & 1,3375 & 2,2799 & 1,3970 & 1,8523 \\
100 & 11,9614 & 12,0184 & 13,6109 & 12,0182 & 12,7595 \\
\hline \multicolumn{5}{|c|}{ RWA Dinâmico } \\
\hline $\begin{array}{c}\text { Tráfego } \\
\text { (erlang) }\end{array}$ & $10 \mathrm{~h}$ & \multicolumn{3}{|c|}{$15 \mathrm{~h}$} & \multicolumn{3}{c|}{$30 \mathrm{~h}$} \\
\cline { 2 - 6 } & Normal & Normal & Falha & Normal & Falha \\
\hline \hline 70 & 1,1317 & 1,1464 & 1,9753 & 1,1690 & 1,6543 \\
100 & 12,1349 & 12,1317 & 13,6550 & 12,2086 & 12,9067 \\
\hline
\end{tabular}

(1) 25 indivíduos, 50 gerações, 4 conversores $(4,6,9,10)$;

(2) 5 rotas alternativas.

Considere que 12 comprimentos de onda em cada um dos enlaces estejam disponíveis. As configurações obtidas com o AG priorizando a redução na probabilidade de bloqueio e a diminuição do número de conversões estão ilustradas na Figura 5.14 (a) e Figura 5.14 (b), respectivamente. Os nós em destaque indicam a necessidade do uso dos equipamentos conversores, ao lado do percentual correspondente do número de conversões que serão realizadas para atender à demanda de tráfego exigida. Observe na Figura 5.14 (b) a redução significativa no número de nós com conversões realizadas na rede, representando para a operadora do sistema uma maior confiabilidade e robustez. Porém, a probabilidade de bloqueio mostrada na Figura 5.14 (b) é sensivelmente maior que na configuração da Figura 5.14 (a), conforme apresentado na Tabela 5.13.

Considere agora a mesma distribuição de tráfego do exemplo anterior, porém com 15 comprimentos de onda disponíveis em cada um dos enlaces. A melhoria na otimização dos conversores obtida pelo algoritmo genético proposto pode ser verificada na Figura 5.15. Como último exemplo, considere que 18 comprimentos de onda estejam disponíveis nos enlaces. Os resultados obtidos estão apresentados na Figura 5.16.

A redução de equipamentos e conversões obtidos com o algoritmo genético proposto pode ser verificada nas Figuras 5.14-5.16. Para a rede italiana com 18 comprimentos de onda nos enlaces, a otimização baseada em AG apresenta considerável redução no número de conversões e indica a necessidade de apenas 4 conversores para o modelo $\min$ (probabilidade de bloqueio) e 3 conversores para o modelo min(número de conversões). Os resultados obtidos para probabilidade de bloqueio em função do tráfego 
Tabela 5.11: Melhoria no desempenho obtida com o uso de conversores nas redes NSFnet e Anel.

\begin{tabular}{|c|c|c|c|c|c|}
\hline \multicolumn{5}{|c|}{ Rede em Anel } \\
\hline Tráfego & Sem Conv. & \multicolumn{2}{|c|}{ Conv. Plena } & \multicolumn{2}{c|}{ Conv. Esparsa $(2,5,8,11)$} \\
\hline (erlang) & $P_{b} \mathbf{( \% )}$ & $P_{b}(\%)$ & Melhoria $(\%)$ & $P_{b}(\%)$ & Melhoria (\%) \\
\hline \hline 20 & 0,2700 & 0,0710 & 73,7037 & 0,1350 & 50,000 \\
40 & 15,2776 & 12,7951 & 16,2493 & 14,1094 & 7,6465 \\
60 & 32,1251 & 32,0884 & 0,1142 & 31,6890 & 1,3573 \\
\hline \hline \multicolumn{6}{|c|}{ Rede NSFnet } \\
\hline Tráfego & Sem Conv. & \multicolumn{2}{|c|}{ Conv. Plena } & Conv. Esparsa (4, 6, 9, 10) \\
\hline (erlang) & $P_{b}(\%)$ & $P_{b}(\%)$ & Melhoria (\%) & $P_{b}(\%)$ & Melhoria (\%) \\
\hline \hline 60 & 0,6924 & 0,1179 & 82,9722 & 0,1646 & 76,2276 \\
90 & 10,2736 & 6,3466 & 38,2241 & 7,7583 & 24,4831 \\
120 & 21,9887 & 18,8493 & 14,2773 & 20,3562 & 7,4242 \\
\hline
\end{tabular}

requisitado pelos nós estão apresentados na Figura 5.17 e na Tabela 5.13. O algoritmo $\min$ (probabilidade de bloqueio) apresenta desempenho em termos de probabilidade de bloqueio próximo ao da rede com conversão plena, demonstrando que o AG determina uma topologia de rede esparsa capaz de obter valores muito próximos ao limite inferior para o desempenho. Para o modelo min(número de conversôes), o prejuízo no desempenho se resume a um pequeno acréscimo na probabilidade de bloqueio. Entretanto, este modelo pode apresentar maior confiabilidade, melhor qualidade do sinal óptico e redução no custo global do sistema.

A ocupação média dos enlaces e o comprimento médio das rotas em função da demanda de tráfego oferecido estão apresentados nas Figuras 5.18 e 5.19 e nas Tabelas 5.14 e 5.15 , respectivamente. Devido à maior disponibilidade de dispositivos conversores, o modelo para min( probabilidade de bloqueio) utiliza os enlaces mais efetivamente que o modelo para min(número de conversões) e possibilita rotas com maior número de enlaces. Considerando 15 comprimentos de onda e uma demanda de tráfego oferecido de 90 erlangs, ambos os modelos de conversão esparsa apresentam aproximadamente a mesma ocupação média de $27,12 \%$ e comprimento médio das rotas de 3,19 enlaces. Para um tráfego oferecido de 120 erlangs, os modelos para min(probabilidade de bloqueio) e para min(número de conversões) apresentam ocupação média de $42,41 \%$ e $44,16 \%$ e comprimento médio das rotas de 3,03 e 3,06 enlaces, respectivamente.

O tempo médio para os modelos realizarem o atendimento às solicitações de comprimento de onda em função do tráfego total oferecido está apresentado na Tabela 5.16. Considerando 12,15 e 18 comprimentos de onda, o AG necessita em média de apenas 7,32, 8,62 e 9,19 milissegundos para realizar o atendimento a uma nova requisi- 
Tabela 5.12: Melhoria no desempenho obtida com o uso do algoritmo genético proposto.

\begin{tabular}{|c|c|c|c|c|}
\hline \multicolumn{5}{|c|}{ Rede em Anel } \\
\hline Tráfego & Vijayanand et al. $[61]$ & \multicolumn{2}{c|}{ AG $(2,5,8,11)$} \\
\hline (erlang) & $P_{b}(\%)$ & Nós WC & $P_{b}(\%)$ & Melhoria (\%) \\
\hline \hline 20 & 0,1918 & $(1,4,7,10)$ & 0,1350 & 29,6142 \\
30 & 4,5473 & $(1,8,9,11)$ & 4,5106 & 0,8071 \\
55 & 27,5343 & $(2,3,4,7)$ & 26,9099 & 2,2677 \\
\hline \hline \multicolumn{5}{|c|}{ Rede NSFnet } \\
\hline Tráfego & Vijayanand et al. $[61]$ & AG $(4,6,9,10)$ \\
\hline (erlang) & $P_{b}(\%)$ & Nós WC & $P_{b}(\%)$ & Melhoria (\%) \\
\hline \hline 70 & 2,0488 & $(3,7,11,12)$ & 1,3652 & 33,3658 \\
80 & 4,9988 & $(3,4,11,12)$ & 4,0740 & 18,5004 \\
100 & 12,4182 & $(7,10,11,12)$ & 11,9989 & 3,3764 \\
\hline
\end{tabular}

ção, respectivamente. Considerando uma demanda de tráfego de 180 erlangs, o tempo de processamento necessário para o AG atender a todas as requisições no período de 1 s é $20,06,24,53$ e 27,03 milissegundos para $W=12,15$ e 18 , respectivamente.

A flexibilidade do modelo de AG proposto permite incorporar à solução do problema RWA informações relacionadas à qualidade do sinal óptico. O impacto da inclusão das restrições da camada física ASE e PMD é avaliado na próxima seção considerando a topologia de rede italiana.

\subsubsection{Impacto da Inclusão das Restrições da Camada Física Sobre a Probabilidade de Bloqueio}

O modelo proposto foi avaliado por meio de simulação computacional de tráfego dinâmico na topologia da rede italiana de faixa larga, conforme ilustrado na Figura 5.13 [69]. O número adotado de comprimentos de onda por enlace é 12,15 e 18 . Foi utilizado um modelo de tráfego para qual cada nó de origem solicita conexões aos nós de destino de acordo com a distribuição de Poisson, com médias 2, 3, 4, 5, 6, 7, 8 e 9 erlangs. Seja $N$ o número de nós e $e_{n}$ o tráfego oferecido por nó. O tráfego total oferecido à rede é $e=e_{n} \cdot N$ (erlang). O tempo de permanência de uma conexão é determinado por meio de uma distribuição exponencial com média $1 / \mu=60 \mathrm{~s}$. A degradação do sinal óptico é causada por PMD e ASE. As fibras ópticas da rede exibem dois valores de parâmetros PMD: $0,5 \mathrm{ps} / \sqrt{\mathrm{km}}$ para fibras antigas e $0,1 \mathrm{ps} / \sqrt{\mathrm{km}}$ para as fibras mais novas. Os valores do parâmetro PMD foram atribuídos aleatoriamente ao conjunto de fibras da rede, $50 \%$ para cada valor de parâmetro PMD. A 


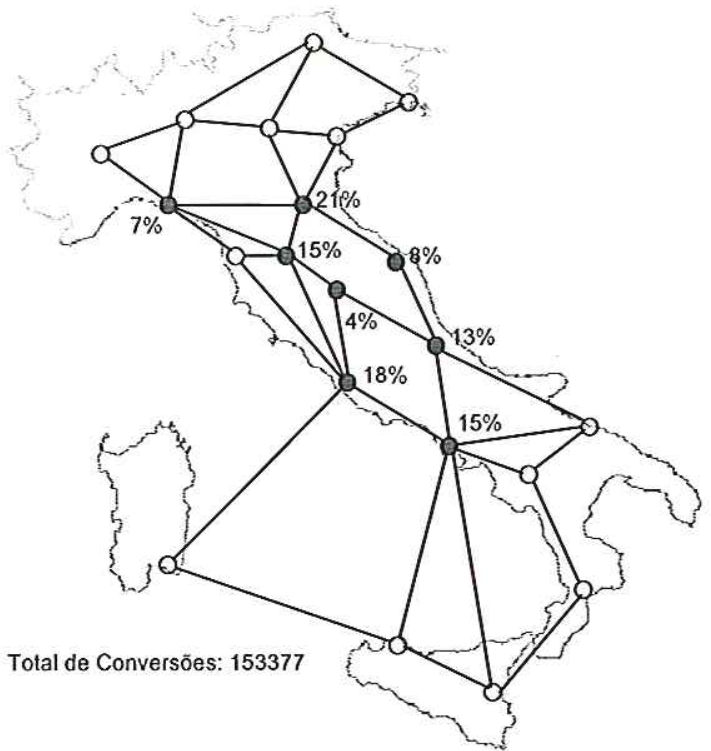

(a)

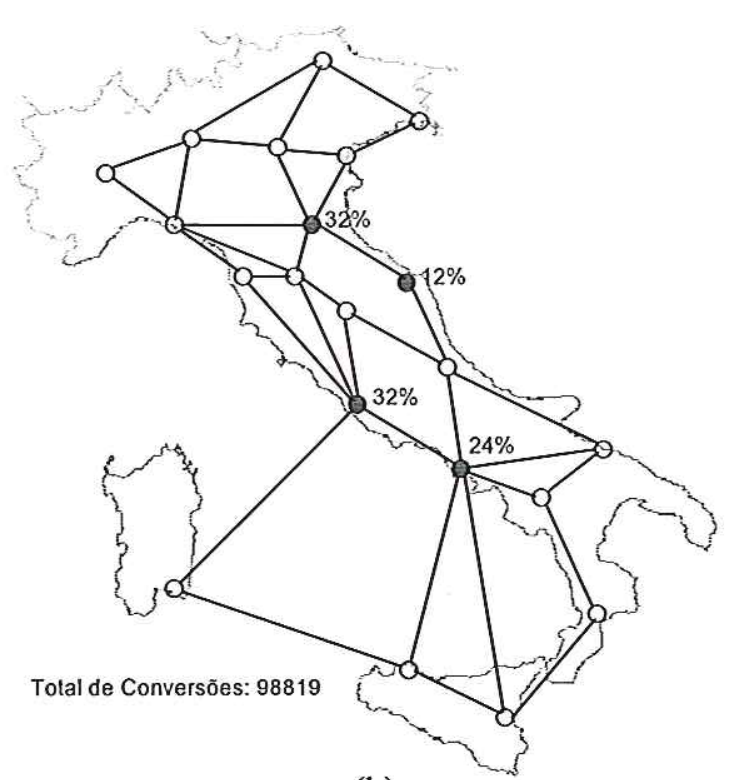

(b)

Figura 5.14: Nós da rede italiana de faixa larga que devem ser equipados com conversores e o percentual de conversões realizadas. 12 comprimentos de onda por enlace e 5 rotas alternativas. (a) $\min$ (probabilidade de bloqueio); e (b) $\min$ (número de conversões).

taxa de transmissão é $10 \mathrm{Gbps}$. Se o comprimento do segmento transparente exceder o limite superior imposto pelo efeito de PMD (Tabela 2.2), a regeneração por meio de um compensador nos nós intermediários será necessária para mitigar a degradação do sinal original. Nesta rede foi determinado e fixado para todas as simulações um número máximo de 4 nós com conversores e 7 com compensadores de PMD.

As fibras ópticas exibem atenuação de $0,2 \mathrm{~dB} / \mathrm{km}$ e os amplificadores ópticos devem ser dispostos a uma distância máxima de $120 \mathrm{~km}$. Todos os nós são equipados com amplificadores ópticos, assim como os enlaces que excedem o comprimento máximo do lance. Foi adotado $S N R_{\min }=20 \mathrm{~dB}$ e o conjunto de parâmetros apresentados na Tabela 2.3. O número máximo permitido de lances é $M_{A}=10$.

Para todos os casos simulados foi utilizado roteamento alternativo com 5 rotas possíveis para cada par origem destino. O algoritmo genético para este modelo possui uma população de 25 indivíduos evoluídos por um máximo de 50 gerações.

Os resultados obtidos são apresentados por meio das Figuras 5.20, 5.21 e 5.22 para 12, 15 e 18 comprimentos de onda, respectivamente. Os compensadores de PMD e os conversores foram dispostos nos nós conforme apresentados na Tabela 5.17. De acordo com os resultados mostrados nos gráficos, o efeito simultâneo da ASE e PMD provoca um bloqueio total em todas as rotas que necessitam usar mais de 10 lances 


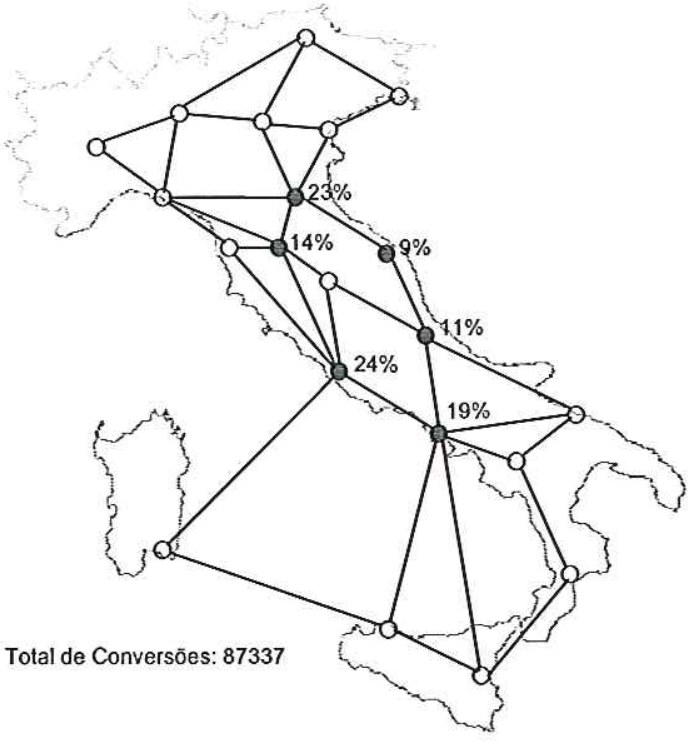

(a)

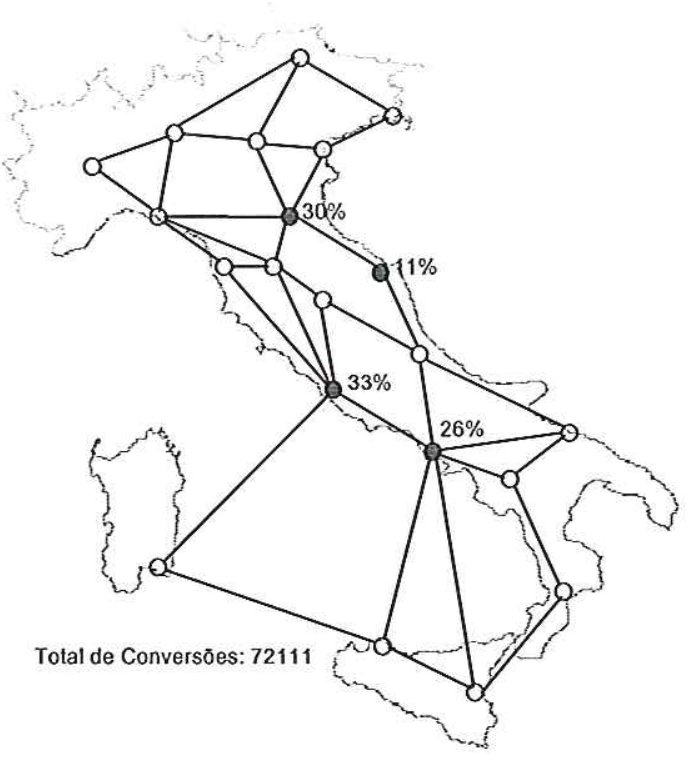

(b)

Figura 5.15: Nós da rede italiana de faixa larga que devem ser equipados com conversores e o percentual de conversões realizadas. 15 comprimentos de onda por enlace e 5 rotas alternativas. (a) $\min$ (probabilidade de bloqueio); e (b) min(número de conversões).

de, aproximadamente, $3 \%$ do tráfego oferecido. Neste caso, será necessário adicionar um esquema da compensação a estes trajetos. Observa-se também que o uso de apenas quatro conversores, alocados estrategicamente (considerando posições ótima ou sub-ótima) pelo algoritmo genético, proporciona probabilidades de bloqueio similares àquelas de uma rede equipada com conversão total. Os resultados das simulações revelam uma melhoria significativa em termos de economia de equipamentos. Nas Tabelas 5.18, 5.19 e 5.20 estão apresentados os resultados númericos para rede com e sem restrições da camada física e considerando 12, 15 e 18 comprimentos de onda por enlace.

O tempo médio necessário para o algoritmo realizar o atendimento às requisições de comprimento de onda em função do tráfego oferecido e a probabilidade de bloqueio para o roteamento fixo alternativo estão apresentados na Tabela 5.21 e na Figura 5.23, considerando tráfego oferecido de 9 erlangs, 5 rotas alternativas e 15 comprimentos de onda.

O roteamento e alocação de comprimentos de onda em redes ópticas WDM foram investigados com base em algoritmos genéticos. Resultados numéricos obtidos a partir de simulação da rede italiana foram apresentados, considerando a degradação de sinal provocada pelos efeitos ASE e PMD na probabilidade global do sistema. Nesta 


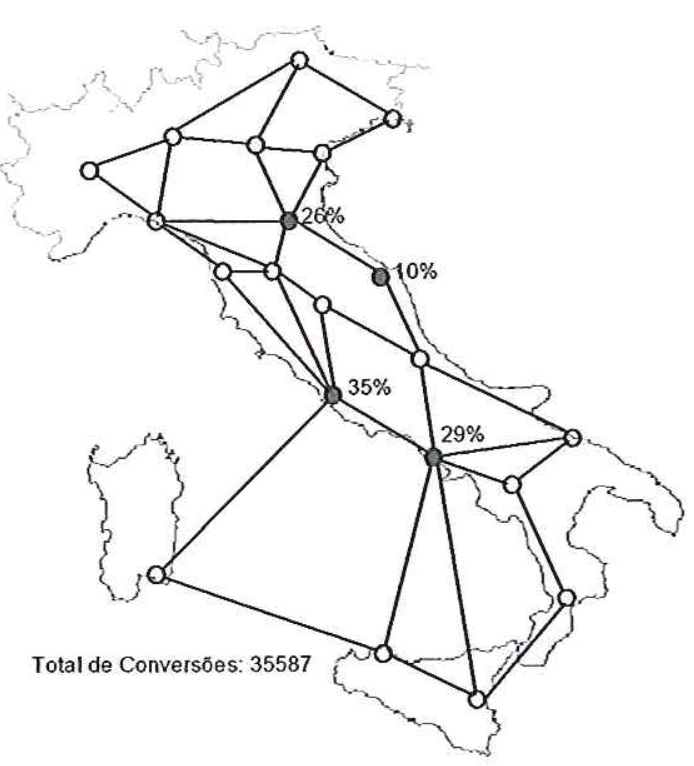

(a)

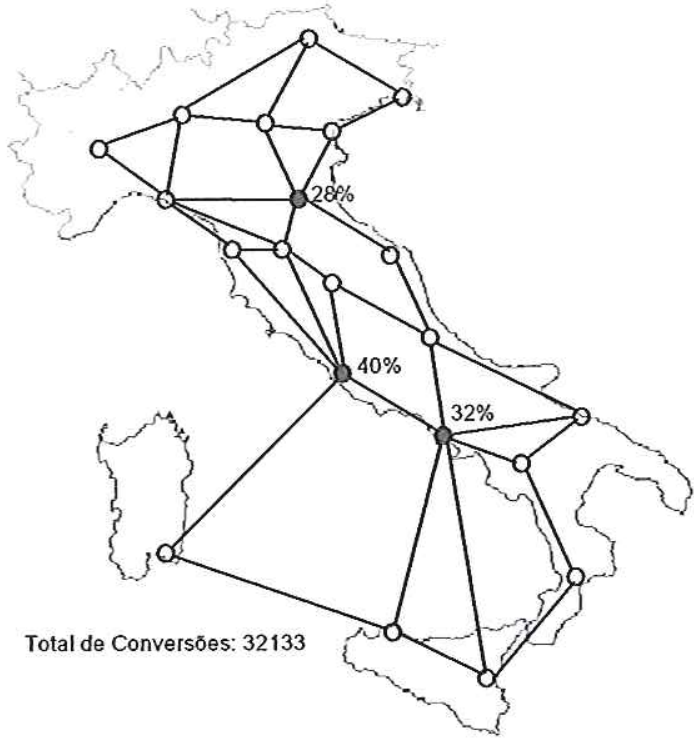

(b)

Figura 5.16: Nós da rede italiana de faixa larga que devem ser equipados com conversores e o percentual de conversões realizadas. 18 comprimentos de onda por enlace e 5 rotas alternativas. (a) $\min$ (probabilidade de bloqueio); e (b) min(número de conversões).

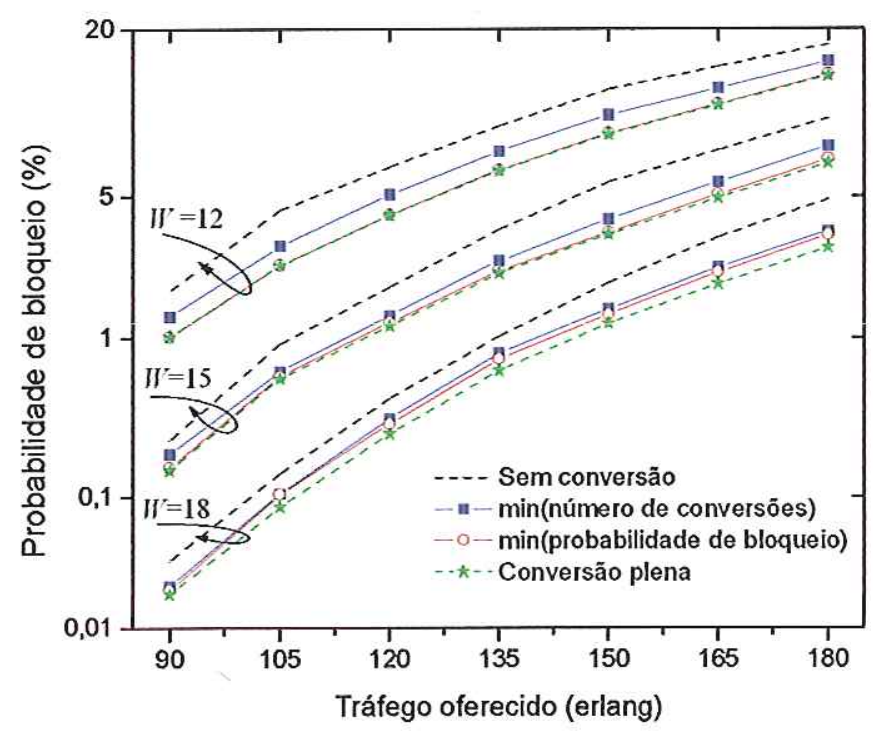

Figura 5.17: Probabilidade de bloqueio para a rede italiana de faixa larga em função do aumento da demanda de tráfego considerando os modelos $\min$ (probabilidade de bloqueio) e $\min ($ número de conversões). $W=12,15$ e 18. 


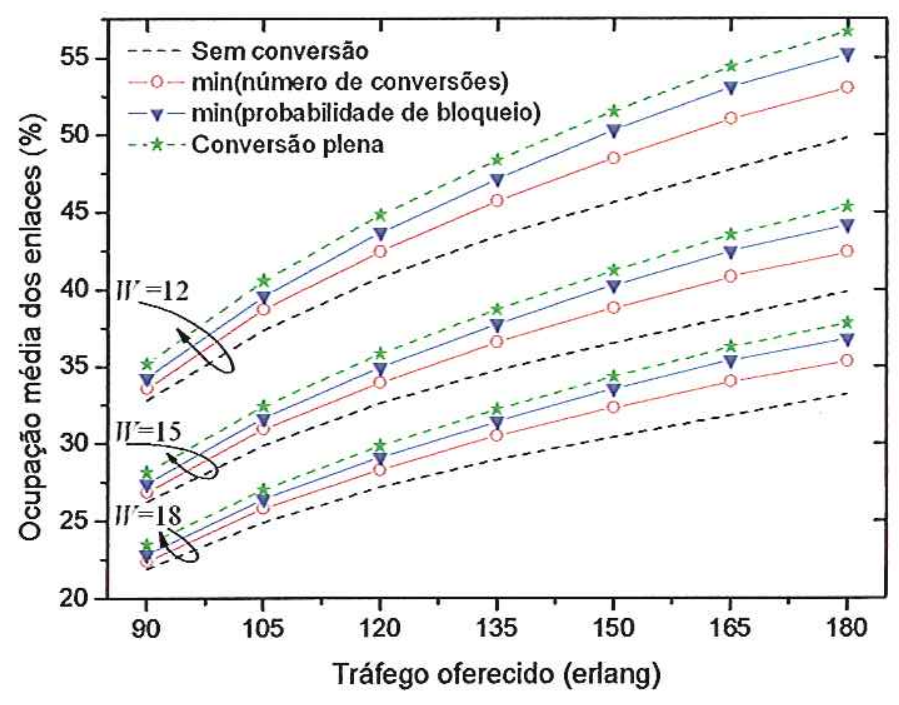

Figura 5.18: Ocupação média dos enlaces (\%) para a rede italiana de faixa larga em função do aumento de demanda de tráfego e considerando os modelos $\min ($ probabilidade de bloqueio) e min(número de conversões). $W=12,15$ e 18 .

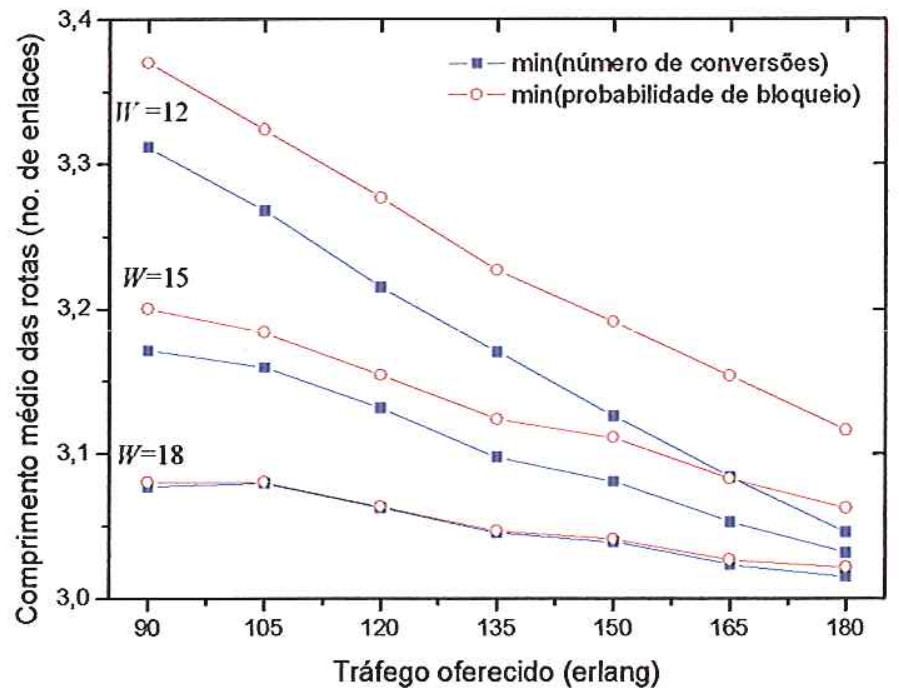

Figura 5.19: Comprimento médio das rotas (número de enlaces) para a rede italiana de faixa larga em função do aumento de demanda de tráfego e considerando os modelos $\min ($ probabilidade de bloqueio) e $\min ($ número de conversões). $W=12,15$ e 18 . 


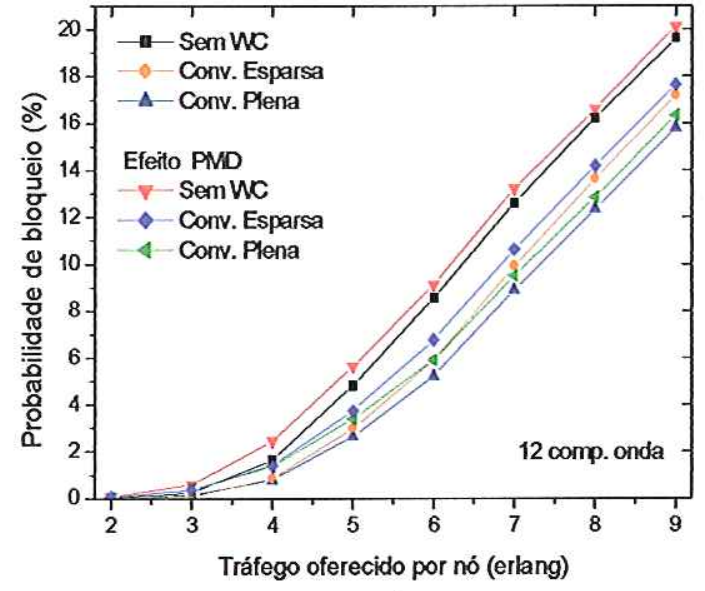

(a)

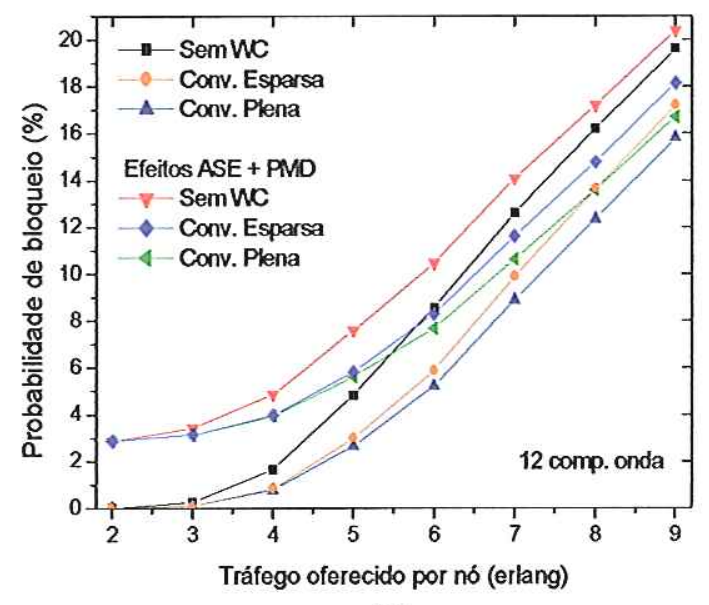

(b)

Figura 5.20: Probabilidade de bloqueio em função do tráfego oferecido por nó para a rede italiana de faixa larga com 12 comprimentos de onda e incluíndo as restrições da camada física: (a) PMD; e (b) PMD e ASE.

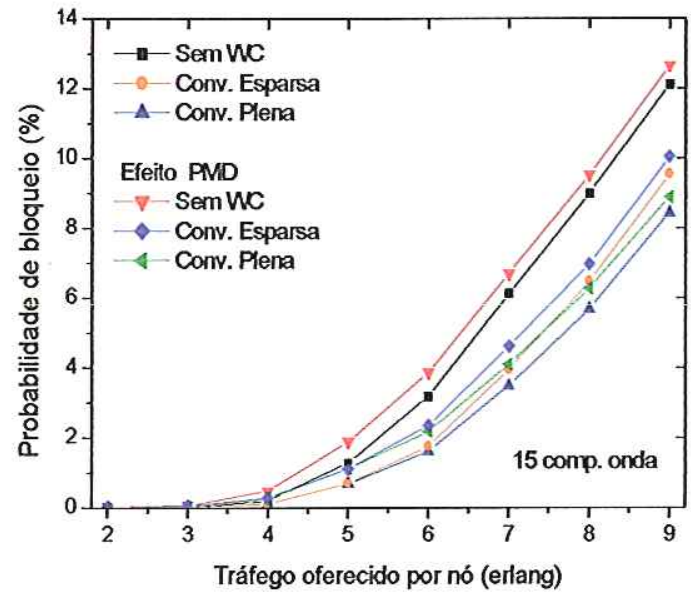

(a)

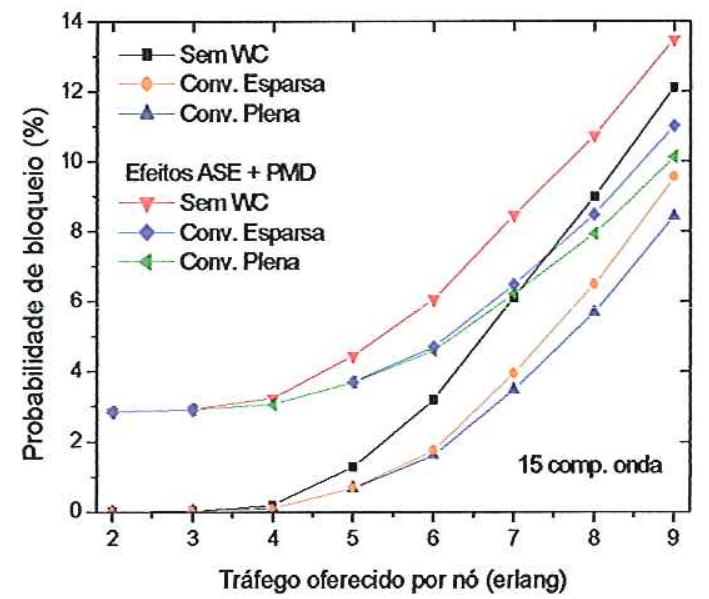

(b)

Figura 5.21: Probabilidade de bloqueio em função do tráfego oferecido por nó para rede italiana de faixa larga com 15 comprimentos de onda e considerando as restrições de camada física: (a) PMD; e (b) PMD e ASE. 


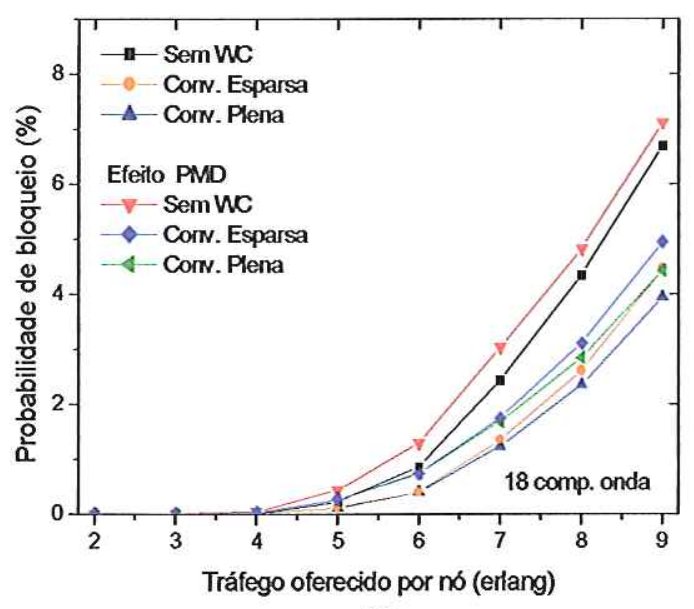

(a)

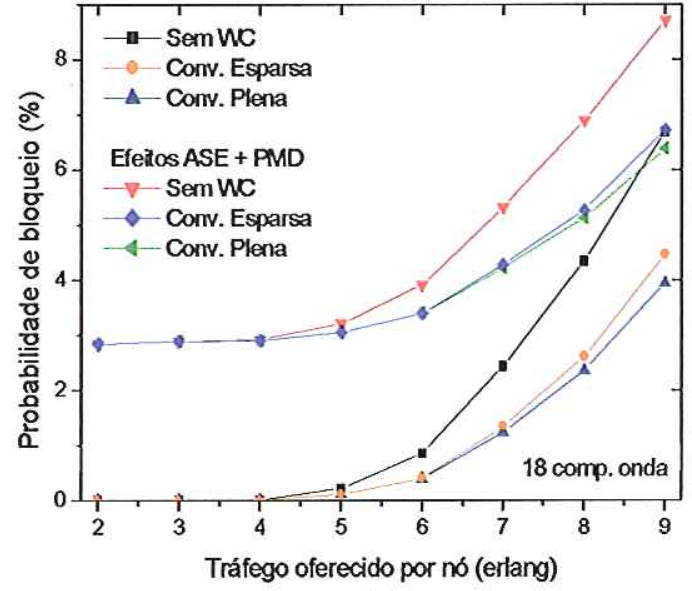

(b)

Figura 5.22: Probabilidade de bloqueio em função do tráfego oferecido por nó para a rede italiana de faixa larga com 18 comprimentos de onda e considerando as restrições de camada física: (a) PMD; e (b) PMD e ASE.

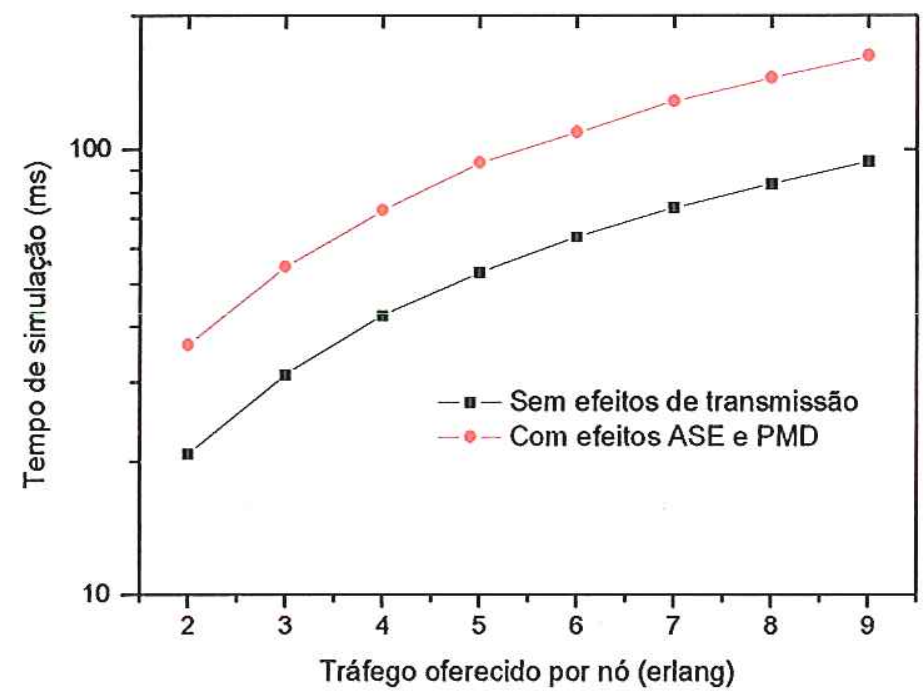

Figura 5.23: Tempo de simulação do AG para a rede italiana de faixa larga em função da demanda de tráfego e considerando os efeitos ASE e PMD. $W=15$. 
Tabela 5.13: Probabilidade de bloqueio para a rede italiana de faixa larga considerando os modelos sem conversão, com conversão plena, $\min$ (probabilidade de bloqueio) $\mathrm{e}$ $\min$ (número de conversões). $W=12,15$ e 18.

\begin{tabular}{|c|c|c|c|c|c|c|}
\cline { 2 - 7 } \multicolumn{1}{c|}{} & \multicolumn{6}{c|}{ Probabilidade de Bloqueio (\%) } \\
\hline $\begin{array}{c}\text { Tráfego } \\
\text { (erlang) }\end{array}$ & \multicolumn{3}{|c|}{ Sem Conversão } & \multicolumn{3}{c|}{ Conversão Plena } \\
\cline { 2 - 7 } & $W=12$ & $W=15$ & $W=18$ & $W=12$ & $W=15$ & $W=18$ \\
\hline \hline 90 & 1,7921 & 0,2435 & 0,0343 & 1,0140 & 0,1530 & 0,0187 \\
105 & 4,3577 & 0,9304 & 0,1462 & 2,4099 & 0,5902 & 0,0857 \\
120 & 6,6185 & 1,8669 & 0,4438 & 4,1423 & 1,1731 & 0,2677 \\
135 & 9,5750 & 3,5642 & 1,0230 & 6,4176 & 2,2104 & 0,6519 \\
150 & 12,8824 & 5,7426 & 1,9691 & 8,9052 & 3,3904 & 1,2085 \\
165 & 15,3390 & 7,7453 & 3,2785 & 11,3896 & 4,9135 & 1,9435 \\
180 & 17,9478 & 10,1913 & 4,8540 & 14,2771 & 6,8613 & 2,9288 \\
\hline \hline Tráfego & min(número de conversões) & min(probabilidade de bloqueio) \\
\cline { 2 - 7 } (erlang) & $W=12$ & $W=15$ & $W=18$ & $W=12$ & $W=15$ & $W=18$ \\
\hline \hline 90 & 1,3132 & 0,1972 & 0,0219 & 1,0174 & 0,1597 & 0,0203 \\
105 & 2,9935 & 0,6464 & 0,1066 & 2,4222 & 0,6069 & 0,1053 \\
120 & 5,0983 & 1,3367 & 0,3350 & 4,1532 & 1,2211 & 0,3085 \\
135 & 7,6856 & 2,5365 & 0,8273 & 6,4559 & 2,2710 & 0,7625 \\
150 & 10,4581 & 3,9673 & 1,4419 & 8,9419 & 3,4427 & 1,3472 \\
165 & 13,0136 & 5,7487 & 2,3441 & 11,4407 & 5,1043 & 2,2224 \\
180 & 15,9502 & 8,0306 & 3,5015 & 14,4498 & 7,1279 & 3,3540 \\
\hline Conversores & 4 & 4 & 3 & 8 & 6 & 4 \\
\hline Conversões & 98.819 & 72.111 & 32.133 & 153.377 & 87.337 & 35.587 \\
\hline
\end{tabular}

rede foi determinado e fixado um número máximo de 4 nós com conversores e 7 com compensadores de PMD. Os resultados mostrados revelam a necessidade de incluir a degradação do sinal óptico nos algoritmos.

\subsubsection{Agregação Dinâmica de Tráfego}

O modelo proposto foi avaliado por meio de simulação computacional de tráfego dinâmico na topologia da rede italiana de faixa larga, mostrada na Figura 5.13 [69]. O número de comprimentos de onda, $W$, por enlace é 15 e a capacidade máxima de cada um deles é $10 \mathrm{Gbps}$. As solicitações de conexão entre os nós origem-destino são geradas de acordo com a distribuição de Poisson, com média 9 erlangs. Foi utilizado roteamento alternativo, isto é, a rota para atender a cada solicitação é selecionada entre um conjunto formado pelos 5 menores caminhos entre o par origem-destino, previamente determinados. A solicitação é bloqueada se nenhuma rota puder acomodá-la. 
Tabela 5.14: Ocupação média dos enlaces para a rede italiana de faixa larga em função do tráfego oferecido para os modelos com conversão esparsa min(probabilidade de bloqueio) e min(número de conversões). $W=12,15$ e 18.

\begin{tabular}{|c|c|c|c|c|c|c|}
\cline { 2 - 7 } \multicolumn{1}{c|}{} & \multicolumn{6}{|c|}{ Ocupação Média dos Enlaces (\%) } \\
\hline $\begin{array}{c}\text { Tráfego } \\
\text { (erlang) }\end{array}$ & min(número de conversões) & \multicolumn{1}{c|}{$\min$ (probabilidade de bloqueio) } \\
\cline { 2 - 7 } & $W=12$ & $W=15$ & $W=18$ & $W=12$ & $W=15$ & $W=18$ \\
\hline \hline 90 & 33,5635 & 26,8508 & 22,3756 & 34,2578 & 27,4062 & 22,8385 \\
105 & 38,7141 & 30,9713 & 25,8094 & 39,6047 & 31,6837 & 26,4031 \\
120 & 42,4548 & 33,9638 & 28,3032 & 43,6982 & 34,9585 & 29,1321 \\
135 & 45,7193 & 36,5754 & 30,4795 & 47,1524 & 37,7219 & 31,4349 \\
150 & 48,4622 & 38,7698 & 32,3081 & 50,3039 & 40,2431 & 33,5359 \\
165 & 50,9966 & 40,7973 & 33,9977 & 53,0875 & 42,4700 & 35,3917 \\
180 & 53,0166 & 42,4133 & 35,3444 & 55,2113 & 44,1691 & 36,8075 \\
\hline
\end{tabular}

As seguintes considerações foram adotadas. Uma dada solicitação de tráfego não pode ser dividida entre comprimentos de onda diferentes. Especificamente, considere que as solicitações podem somente ocupar um comprimento de onda em um enlace na rota. Considere ainda que existem vários OADMs, isto é, receptores/transmissores nos nós, em número suficiente para assegurar atendimento a todo tráfego originado. O tráfego de um nó é limitado pelo grau do nó, pelo número de comprimento de onda nas fibras e pela capacidade dos comprimentos de onda. Cada solicitação de conexão pode dispor de taxa de transmissão $m$, tal que $1 \leq m \leq g$, com $g=4$, geradas com igual probabilidade. O tempo de permanência das solicitações segue uma distribuição exponencial com tempo médio $1 / \mu=60 \mathrm{~s}$. As fibras ópticas que compõem os enlaces foram divididas em dois conjuntos iguais, com parâmetros PMD 0,1 ps/ $\sqrt{\mathrm{km}}$ e $0,5 \mathrm{ps} / \sqrt{\mathrm{km}}$. As fibras foram dispostas nos enlaces de forma aleatória, $50 \%$ para cada valor de parâmetro PMD. Se o comprimento da rota exceder o limite imposto pela PMD, então será necessário alocar um compensador nos nós intermediários para recuperar o sinal original. Os compensadores de PMD foram disponibilizados pelo AG nos nós mostrados na Tabela 5.17. A atenuação nas fibras ópticas é $0,2 \mathrm{~dB} / \mathrm{km}$ e a distância máxima entre os amplificadores ópticos é $120 \mathrm{~km}$. Todos os nós estão equipados com amplificadores ópticos, assim como os enlaces que excedem a distância máxima. Foram adotados $S N R_{\text {min }}=20 \mathrm{~dB} ; P_{L}=4 \mathrm{dBm} ; n_{s p}=2,5 ; G=25 \mathrm{~dB}$ e $h v B_{o}=-58 \mathrm{dBm}$, resultando em um número máximo de lances, $M_{A}=10$. Os nós da rede foram equipados com chaves WSXC e WGXC.

$\mathrm{O}$ algoritmo genético procura uma política que otimiza o desempenho do sistema. O AG proposto usa os operadores genéticos convencionais (seleção, cruzamento e mutação), juntamente com a estratégia de cruzamento em três pontos, política elitista e o 
Tabela 5.15: Comprimento médio das rotas para a rede italiana de faixa larga em função do tráfego oferecido para os modelos com conversão esparsa min(probabilidade de bloqueio) e min(número de conversões). $W=12,15$ e 18.

\begin{tabular}{|c|c|c|c|c|c|c|}
\cline { 2 - 7 } \multicolumn{1}{c|}{} & \multicolumn{5}{c|}{ Comprimento Médio das Rotas (número de enlaces) } \\
\hline $\begin{array}{c}\text { Tráfego } \\
\text { (erlang) }\end{array}$ & min(número de conversões) & \multicolumn{2}{|c|}{$\min ($ probabilidade de bloqueio) } \\
\cline { 2 - 7 } & $W=12$ & $W=15$ & $W=18$ & $W=12$ & $W=15$ & $W=18$ \\
\hline \hline 90 & 3,3115 & 3,1710 & 3,0770 & 3,3699 & 3,1998 & 3,0799 \\
105 & 3,2681 & 3,1596 & 3,0796 & 3,3230 & 3,1838 & 3,0801 \\
120 & 3,2150 & 3,1316 & 3,0626 & 3,2765 & 3,1542 & 3,0634 \\
135 & 3,1702 & 3,0973 & 3,0452 & 3,2266 & 3,1236 & 3,0466 \\
150 & 3,1259 & 3,0807 & 3,0391 & 3,1907 & 3,1109 & 3,0409 \\
165 & 3,0840 & 3,0532 & 3,0234 & 3,1535 & 3,0825 & 3,0263 \\
180 & 3,0457 & 3,0317 & 3,0152 & 3,1162 & 3,0624 & 3,0215 \\
\hline
\end{tabular}

mecanismo de inserção de imigrantes [48]. Para todos os casos investigados foi utilizada uma população composta por 25 indivíduos e 50 gerações. Foi adotada uma política elitista para a seleção dos pais, de tal forma que os melhores indivíduos da população são selecionados com taxa de $20 \%$, aos quais foi aplicado cruzamento, gerando $40 \%$ de novos descendentes. Mutação foi aplicada em $20 \%$ da população e inserção de imigrantes na proporção de $20 \%$. Estes valores foram escolhidos após inúmeras simulações.

Os resultados das simulações, obtidos por meio de (4.44) e (4.50), estão apresentados nas Figuras 5.24-5.26. Os nós com agregação de tráfego são seqüencialmente acrescentados à rede e foram posicionados pelo AG conforme apresentado na Tabela 5.22 .

A probabilidade de bloqueio e a imparcialidade de capacidade de largura de faixa em função da quantidade de nós com agregação de tráfego realizada por meio de comutadores com agregação restrita WSXC estão apresentadas na Figura 5.24. Se os nós da rede óptica são do tipo WSXC, o desempenho em relação à probabilidade de bloqueio global melhora. Entretanto, a imparcialidade de tráfego é degradada caso não seja implementando um CAC. O modelo apresentado garante imparcialidade unitária, mas provoca um inevitável pequeno aumento no bloqueio global das solicitações. Por exemplo, para a rede equipada com 6 e 15 nós WSXC, as probabilidades de bloqueio para a rede, considerando os efeitos ASE e PMD sem CAC, são 10,68\% e 6,89\%, e os valores de imparcialidade são 1,24 e 2,31, respectivamente. Utilizando CAC, as probabilidades de bloqueio são $11,48 \%$ e $8,92 \%$, e a imparcialidade é unitária. O custo da imparcialidade de tráfego se apresenta como um aumento no número de requisições bloqueadas de $6,96 \%$ e $22,75 \%$, respectivamente. 
Tabela 5.16: Tempo de atendimento de requisição de comprimento de onda em função do tráfego para a rede italiana de faixa larga. $W=12,15$ e 18 .

\begin{tabular}{|c|c|c|c|c|c|c|}
\cline { 2 - 7 } \multicolumn{1}{c|}{} & \multicolumn{4}{c|}{ Tempo de Atendimento de Requisição (milissegundos) } \\
\hline $\begin{array}{c}\text { Tráfego } \\
\text { (erlang) }\end{array}$ & \multicolumn{3}{|c|}{ tempo por requisičão } & \multicolumn{1}{c|}{ tempo por requisição x trafégo ${ }^{2}$} \\
\cline { 2 - 7 } & $W=12$ & $W=15$ & $W=18$ & $W=12$ & $W=15$ & $W=18$ \\
\hline \hline 90 & 7,8888 & 8,8279 & 9,1410 & 11,6667 & 13,0556 & 13,5185 \\
105 & 7,7668 & 8,8726 & 9,2544 & 13,6574 & 15,6019 & 16,2731 \\
120 & 7,5324 & 8,8032 & 9,2769 & 15,0925 & 17,6389 & 18,5880 \\
135 & 7,3161 & 8,6847 & 9,2713 & 16,4583 & 19,5370 & 20,8565 \\
150 & 7,1119 & 8,5789 & 9,2288 & 17,7314 & 21,3889 & 23,0093 \\
165 & 6,9258 & 8,4142 & 9,1499 & 18,9583 & 23,0324 & 25,0463 \\
180 & 6,7296 & 8,2278 & 9,0661 & 20,0694 & 24,5370 & 27,0370 \\
\hline
\end{tabular}

(1) 5 rotas, 25 indivíduos, 50 gerações;

(2) tempo necessário para atender todas as requisições no período de $1 \mathrm{~s}$.

Tabela 5.17: Localização dos conversores e compensadores de PMD na rede italiana de faixa larga.

\begin{tabular}{|l|l|}
\hline \multicolumn{1}{|c|}{ Dispositivo } & \multicolumn{1}{c|}{ Localização na Rede Italiana } \\
\hline \hline Conv. de comp. de onda & Bologna, Firenze, Rome, Napoli \\
\hline Compensador de PMD & Bologna, Pisa, Ancona, Roma, Napoli, Cagliari, Palermo \\
\hline
\end{tabular}

Na Figura 5.25 estão ilustradas a probabilidade de bloqueio e a imparcialidade de capacidade de largura de faixa em função da quantidade de nós com agregação de tráfego realizada por meio de comutadores com agregação plena WGXC. O desempenho em relação à probabilidade de bloqueio global é superior ao obtido com nós WSXC. Ainda, o CAC garante imparcialidade unitária com menor degradação no bloqueio global de solicitações. Por exemplo, utilizando 6 e 15 nós WGXC para a rede, considerando os efeitos ASE e PMD sem CAC, as probabilidades de bloqueio são $3,67 \%$ e 2,05\%, e os valores de imparcialidade são 6,92 e 29,10, respectivamente. Utilizando o CAC, as probabilidades de bloqueio são $6,47 \%$ e 5,00\%. Em relação à rede com nós WSXC (ver Figura 5.24), estes resultados representam uma melhoria de $44 \%$ na probabilidade de bloqueio global da rede. Entretanto, os nós WGXC são equipados com dispositivos mais complexos e mais caros que os WSXC.

Uma opção consiste em equipar a rede com uma combinação de nós WSXC e WGXC, uma agregação esparsa. Os resultados desta alternativa são mostrados na Figura 5.26 por meio da probabi-lidade de bloqueio e imparcialidade em função da 
Tabela 5.18: Probabilidade de bloqueio na rede italiana de faixa larga com restrições da camada física ASE e PMD. $W=12$.

\begin{tabular}{|c|c|c|c|c|c|c|}
\cline { 2 - 7 } \multicolumn{1}{c|}{} & \multicolumn{6}{c|}{ Probabilidade de Bloqueio (\%) } \\
\hline Tráfego & \multicolumn{2}{|c|}{ Rot. Fixo Alternativo } & \multicolumn{2}{c|}{ Rot. sob Efeitos PMD e ASE } \\
\hline (erlang) & Sem WC & Esparsa & Plena & Sem WC & Esparsa & Plena \\
\hline \hline 2 & 0,0098 & 0,0065 & 0,0065 & 2,8710 & 2,8612 & 2,8612 \\
3 & 0,2587 & 0,1074 & 0,1184 & 3,4220 & 3,1305 & 3,1305 \\
4 & 1,6656 & 0,8369 & 0,7827 & 4,8571 & 3,9659 & 3,9413 \\
5 & 4,8273 & 2,9922 & 2,6420 & 7,5997 & 5,8172 & 5,6092 \\
6 & 8,5634 & 5,8844 & 5,2133 & 10,4606 & 8,3079 & 7,6763 \\
7 & 12,6106 & 9,9068 & 8,8942 & 14,0796 & 11,6196 & 10,6315 \\
8 & 16,2198 & 13,6473 & 12,3499 & 17,1974 & 14,7749 & 13,5937 \\
9 & 19,6197 & 17,2002 & 15,8119 & 20,3802 & 18,1279 & 16,6920 \\
\hline
\end{tabular}

quantidade de nós com agregação de tráfego. Utilizando 6 e 15 nós WGXC para rede sem CAC, as probabilidades de bloqueio, considerando os efeitos ASE e PMD, são $2,46 \%$ e $2,04 \%$, e os valores de imparcialidade são indeterminados. Utilizando o CAC a rede torna-se imparcial, porém as probabilidades de bloqueio são elevadas para $5,48 \%$ e 5,13\%, respectivamente. A combinação permite a agregação em todos nós da rede e habilita a conexão de rotas extensas com múltiplos enlaces, o que exige maior uso dos recursos da rede.

$\mathrm{O}$ CAC tende a priorizar as solicitações com taxas de tráfego maiores e a bloquear as chamadas com taxas menores. Por outro lado, os efeitos provocados pela ASE e pela PMD são proporcionais ao comprimento do enlace e as solicitações de rotas mais extensas tendem a ser bloqueadas. Um ponto de equilíbrio envolvendo o custo dos equipamentos e o retorno em termos de capacidade do sistema deve ser encontrado. Por exemplo, para a combinação WSXC e WGXC, uma possível solução para se obter o menor custo seria o uso de 3 nós WGXC e 18 WSXC, com probabilidade de bloqueio de $5,81 \%$. Se o objetivo for melhorar o desempenho, 9 nós poderiam ser equipados com WGXC e 12 com WSXC, apresentando bloqueio de 5,37\%.

Os resultados númericos das simulações, considerando as três configurações para os nós WSXC, WGXC e WSXC+WGXC, estão apresentados nas Tabelas 5.23, 5.24 e 5.25, respectivamente. O tempo médio de simulação do AG para o atendimento de requisição de conexão com $\mathrm{CAC}$ está mostrado na Tabela 5.26, considerando a rede sem e sob os efeitos de ASE e PMD. 


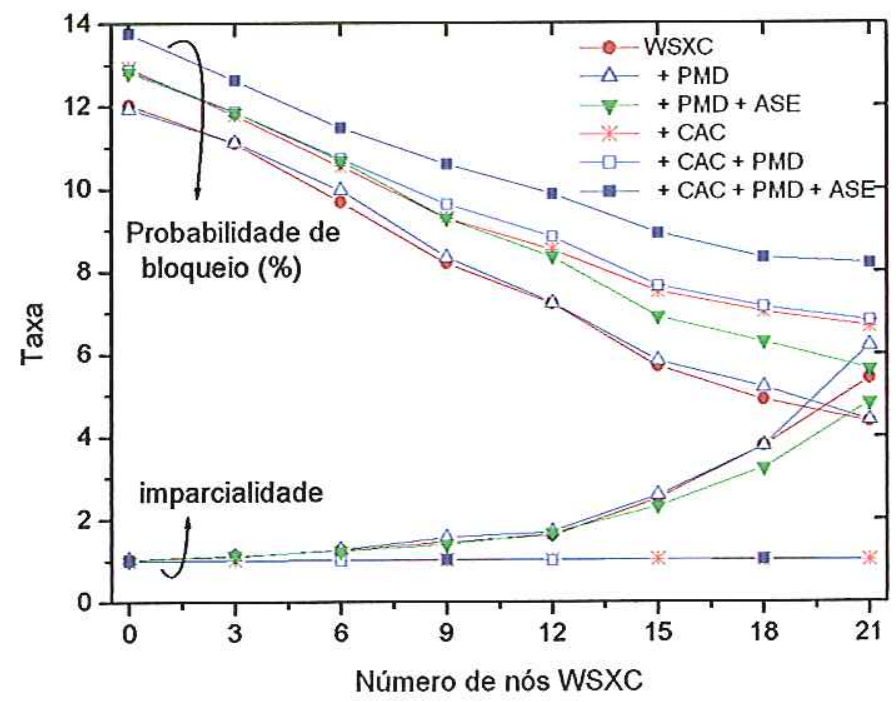

Figura 5.24: Probabilidade de bloqueio (\%) e imparcialidade em função da quantidade de nós com agregação de tráfego para a rede italiana de faixa larga utilizando comutadores com agregação restrita WSXC, 15 comprimentos de onda e tráfego por nó de 9 erlangs.

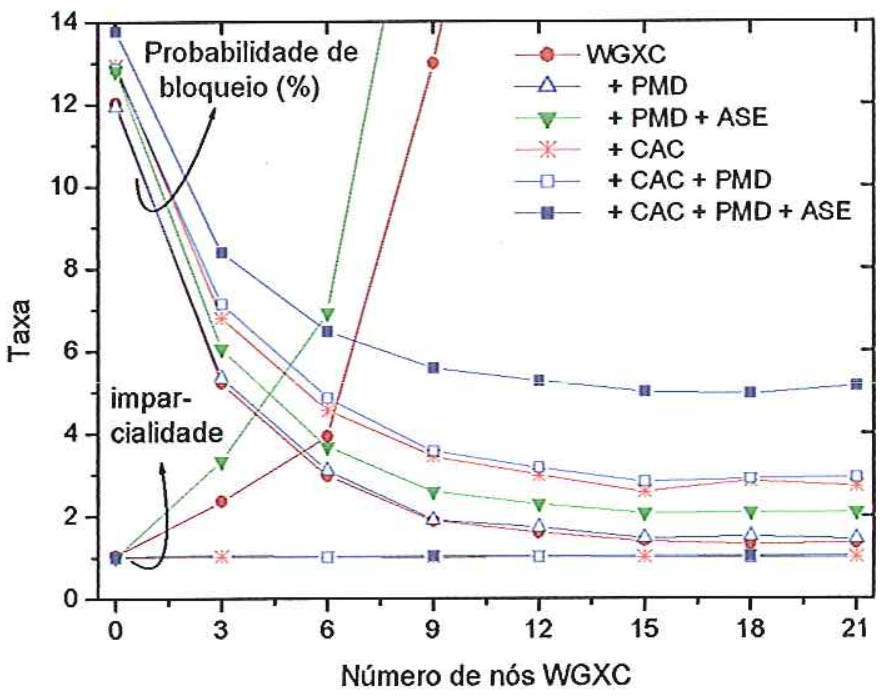

Figura 5.25: Probabilidade de bloqueio (\%) e imparcialidade em função da quantidade de nós com agregação de tráfego para a rede italiana de faixa larga utilizando comutadores com agregação plena WGXC, 15 comprimentos de onda e tráfego por nó de 9 erlangs. 
Tabela 5.19: Probabilidade de bloqueio na rede italiana de faixa larga com restrições da camada física ASE e PMD. $W=15$.

\begin{tabular}{|c|c|c|c|c|c|c|}
\cline { 2 - 7 } \multicolumn{1}{c|}{} & \multicolumn{6}{c|}{ Probabilidade de Bloqueio (\%) } \\
\hline Tráfego & Rot. Fixo Alternativo & \multicolumn{2}{c|}{ Rot. sob Efeitos PMD e ASE } \\
\hline (erlang) & Sem WC & Esparsa & Plena & Sem WC & Esparsa & Plena \\
\hline \hline 2 & 0,0000 & 0,0000 & 0,0000 & 2,8415 & 2,8415 & 2,8415 \\
3 & 0,0175 & 0,0110 & 0,0110 & 2,9233 & 2,9082 & 2,9082 \\
4 & 0,1957 & 0,0904 & 0,0954 & 4,4442 & 2,9646 & 3,0567 \\
5 & 1,2796 & 0,6780 & 0,6714 & 6,0555 & 3,6965 & 3,6978 \\
6 & 3,1802 & 1,7414 & 1,6153 & 8,4576 & 4,7056 & 4,6036 \\
7 & 6,1124 & 3,9441 & 3,4839 & 10,7343 & 6,4803 & 6,2055 \\
8 & 8,9927 & 6,4812 & 5,6775 & 10,7343 & 8,4750 & 7,9327 \\
9 & 12,1061 & 9,5392 & 8,4186 & 13,4702 & 11,0016 & 10,1135 \\
\hline
\end{tabular}

A ocupação média dos enlaces, $\bar{E}_{O c u p}$, para rede com agregação de tráfego é obtida por

$$
\bar{E}_{\text {Ocup }}=\frac{\sum_{j=1}^{N_{E n l}} \sum_{i=1}^{N_{R e q}^{(j)} i \cdot m_{i} \cdot 1 / \mu \cdot 1 / T}}{N_{E n l} \cdot g \cdot W},
$$

na qual $N_{E n l}$ é o número de enlaces unidirecionais, $m_{i}$ é a taxa de transmissão da requisição $i, g$ é o número de divisões da largura de faixa (granularity), $W$ é o número de comprimentos de onda e $T$ é o período de tempo avaliado. A ocupação média dos enlaces em função do número de nós com capacidade de agregação para a rede italiana, incluindo os efeitos devido às restrições ASE e PMD, está apresentada na Figura 5.27 e na Tabela 5.27.

O comprimento médio das rotas em função do número de nós com capacidade de agregação está apresentado na Figura 5.28 e na Tabela 5.28. A rede sem capacidade de agregação apresenta ocupação média de $28,73 \%$ e $27,50 \%$ e comprimento médio das rotas de 2,96 e 2,86 enlaces para rede sem e com restrições da camda fisica, respectivamente. Equipando-se a rede com chaves WSXC em todos os nós, a ocupação dos enlaces é $32,71 \%$ e $31,46 \%$ e comprimento médio das rotas de 3,11 e 3,03 enlaces, para rede sem e com restrições. Se a rede for totalmente equipada com chaves WGXC, os números são $37,07 \%$ e $36,05 \%$ para ocupação e 3,41 e 3,34 enlaces para comprimento das rotas, respectivamente. A melhoria na utilização dos recursos de rede obtida com o uso das chaves WSXC é 14,14\%, enquanto o uso das chaves WGXC possibilita melhoria de $30,06 \%$. 


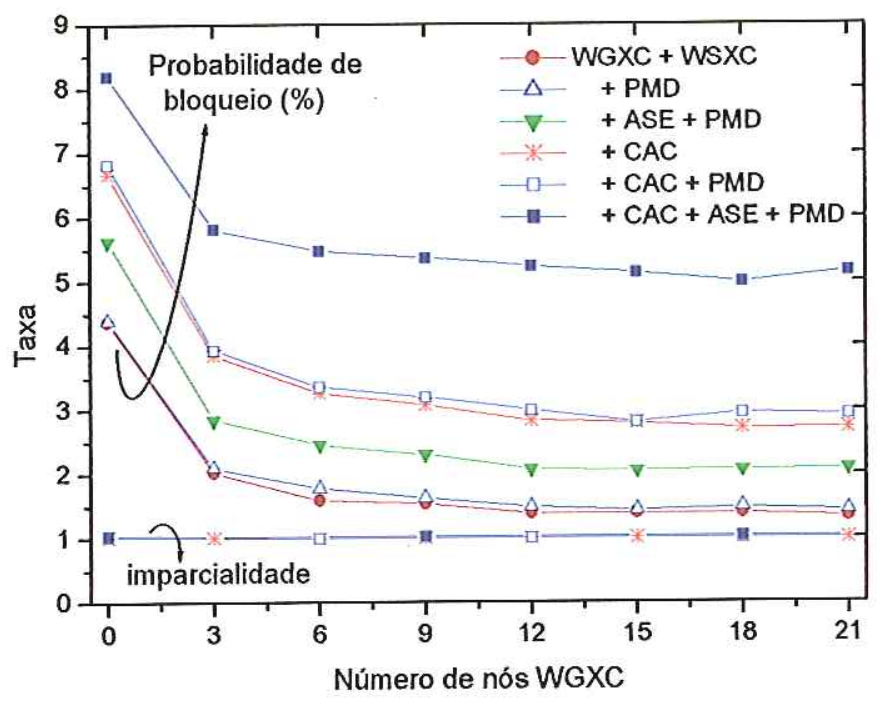

Figura 5.26: Probabilidade de bloqueio (\%) e imparcialidade em função da quantidade de nós com agregação de tráfego para a rede italiana de faixa larga utilizando comutadores com agregação plena WGXC e comutadores com agregação restrita WSXC aos outros nós da rede. 15 comprimentos de onda e tráfego por nó de 9 erlangs.

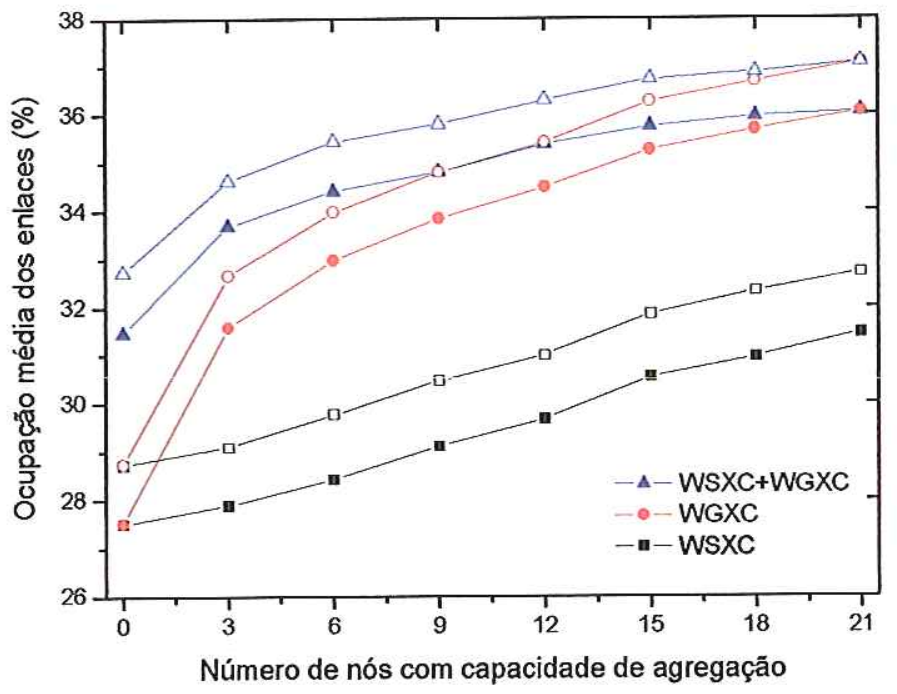

Figura 5.27: Ocupação média dos enlaces (\%) em função do número de nós com capacidade de agregação para a rede italiana de faixa larga. Tráfego por nó de 9 erlangs e $W=15$. As curvas com símbolos cheios representam a rede sujeita às restrições ASE e PMD. 
Tabela 5.20: Probabilidade de bloqueio na rede italiana de faixa larga com restrições da camada física ASE e PMD. $W=18$.

\begin{tabular}{|c|c|c|c|c|c|c|}
\cline { 2 - 7 } \multicolumn{1}{c|}{} & \multicolumn{6}{c|}{ Probabilidade de Bloqueio (\%) } \\
\hline Tráfego & Rot. Fixo Alternativo & \multicolumn{2}{c|}{ Rot. sob Efeitos PMD e ASE } \\
\hline (erlang) & Sem WC & Esparsa & Plena & Sem WC & Esparsa & Plena \\
\hline \hline 2 & 0,0000 & 0,0000 & 0,0000 & 2,8415 & 2,8415 & 2,8415 \\
3 & 0,0000 & 0,0000 & 0,0000 & 2,8887 & 2,8887 & 2,8887 \\
4 & 0,0066 & 0,0033 & 0,0033 & 2,9136 & 2,9005 & 2,9005 \\
5 & 0,2251 & 0,1158 & 0,1119 & 3,2147 & 3,0567 & 3,0528 \\
6 & 0,8597 & 0,4036 & 0,3992 & 3,9193 & 3,4017 & 3,4028 \\
7 & 2,4365 & 1,3458 & 1,2394 & 5,3247 & 4,2782 & 4,2208 \\
8 & 4,3430 & 2,6137 & 2,3549 & 6,9023 & 5,2695 & 5,1269 \\
9 & 6,6922 & 4,4649 & 3,9464 & 8,7112 & 6,7120 & 6,3849 \\
\hline
\end{tabular}

Tabela 5.21: Tempo de simulação para o atendimento de requisição de comprimento de onda em função do tráfego para a rede italiana de faixa larga. $W=15$.

\begin{tabular}{|c|c|c|c|c|}
\hline & \multicolumn{4}{|c|}{ Tempo de Atendimento de Requisição (milissegundos) } \\
\hline \multirow{2}{*}{$\begin{array}{l}\text { Tráfego } \\
\text { por Nó } \\
\text { (erlang) }\end{array}$} & \multicolumn{2}{|c|}{ Roteamento Fixo Alternativo $^{1}$} & \multicolumn{2}{|c|}{ Rot. sob Efeitos PMD e $\mathrm{ASE}^{1}$} \\
\hline & $\begin{array}{l}\text { tempo por } \\
\text { requisição }\end{array}$ & $\begin{array}{l}\text { tempo por requisição } \\
\text { x trafégo }{ }^{2}\end{array}$ & $\begin{array}{l}\text { tempo por } \\
\text { requisição }\end{array}$ & $\begin{array}{l}\text { tempo por requisição } \\
\text { x trafégo }\end{array}$ \\
\hline 2 & 29,3318 & 20,7376 & 51,5598 & 36,4528 \\
\hline 3 & 29,4923 & 31,1734 & 51,6610 & 54,6056 \\
\hline 4 & 30,1062 & 42,3594 & 52,0240 & 73,1978 \\
\hline 5 & 30,1327 & 52,9431 & 53,3147 & 93,6739 \\
\hline 6 & 30,1787 & 63,6922 & 51,8148 & 109,3553 \\
\hline 7 & 30,1524 & 74,1901 & 52,1550 & 128,3276 \\
\hline 8 & 29,8629 & 83,8252 & 51,6233 & 144,9068 \\
\hline 9 & 29,7903 & 94,0480 & 51,4546 & 162,4424 \\
\hline
\end{tabular}

(1) 5 rotas, 25 indivíduos, 50 gerações, 4 conversores;

(2) tempo necessário para atender a todas as requisições no período de $1 \mathrm{~s}$. 
Tabela 5.22: Seqüencia de disposição dos nós com agregação de tráfego na rede italiana de faixa larga.

\begin{tabular}{|c|l|}
\hline \multirow{2}{*}{$\begin{array}{c}\text { Seqüência de } \\
\text { acréscimo de nós }\end{array}$} & \multicolumn{1}{|c|}{ Localização } \\
\cline { 2 - 3 } 3 & - \\
3 & Bologna, Roma, Napoli, \\
6 & Genova, Firenze, Pescara, \\
9 & Verona, Pisa, Ancona, \\
12 & Milano, Veneza, Perugia, \\
15 & Potenza, Bari, Palermo, \\
18 & Bolzano, Cagliari, Catania, \\
21 & Trieste, Torino, Cantazaro. \\
\hline
\end{tabular}

Tabela 5.23: Probabilidade de bloqueio (\%) para a rede italiana de faixa larga com nós WSXC. $W=15$ e tráfego oferecido por nó de 9 erlangs.

\begin{tabular}{|c|c|c|c|c|c|c|}
\cline { 2 - 7 } \multicolumn{1}{c|}{} & \multicolumn{6}{c|}{ Probabilidade de Bloqueio (\%) } \\
\cline { 2 - 7 } \multicolumn{1}{c|}{ Sem controle de conexão } & \multicolumn{3}{c|}{ Com controle de conexão } \\
\hline Agreg. & WSXC & +PMD & +PMD+ASE & WSXC & +PMD & +PMD+ASE \\
\hline \hline 0 & 12,0138 & 11,9319 & 12,8075 & 12,9230 & 12,8661 & 13,7620 \\
3 & 11,1032 & 11,1222 & 11,8545 & 11,7755 & 11,8618 & 12,6233 \\
6 & 9,6765 & 9,9630 & 10,6851 & 10,5521 & 10,7333 & 11,4832 \\
9 & 8,1943 & 8,3347 & 9,2848 & 9,2921 & 9,6312 & 10,5916 \\
12 & 7,2135 & 7,2340 & 8,3537 & 8,5218 & 8,8390 & 9,8636 \\
15 & 5,6904 & 5,8337 & 6,8993 & 7,5059 & 7,6564 & 8,9208 \\
18 & 4,8880 & 5,1949 & 6,2985 & 7,0221 & 7,1419 & 8,3376 \\
21 & 4,3647 & 4,3924 & 5,6305 & 6,6683 & 6,8233 & 8,1958 \\
\hline
\end{tabular}


Tabela 5.24: Probabilidade de bloqueio (\%) para a rede italiana de faixa larga com nós WGXC. $W=15$ e tráfego oferecido por nó de 9 erlangs.

\begin{tabular}{|c|c|c|c|c|c|c|}
\cline { 2 - 7 } \multicolumn{1}{c|}{} & \multicolumn{6}{c|}{ Probabilidade de Bloqueio (\%) } \\
\cline { 2 - 7 } \multicolumn{1}{c|}{} & \multicolumn{3}{c|}{ Sem controle de conexão } & \multicolumn{3}{c|}{ Com controle de conexão } \\
\hline Agreg. & WGXC & +PMD & +PMD+ASE & WGXC & +PMD & +PMD+ASE \\
\hline \hline 0 & 12,0138 & 11,9319 & 12,8075 & 12,9230 & 12,8661 & 13,7620 \\
3 & 5,2256 & 5,3542 & 6,0529 & 6,8013 & 7,1565 & 8,3917 \\
6 & 2,9687 & 3,1032 & 3,6733 & 4,5708 & 4,8748 & 6,4754 \\
9 & 1,8754 & 1,8988 & 2,5931 & 3,4438 & 3,5651 & 5,5867 \\
12 & 1,5830 & 1,7146 & 2,2788 & 2,9819 & 3,1690 & 5,2695 \\
15 & 1,3872 & 1,4529 & 2,0552 & 2,5741 & 2,8255 & 5,0005 \\
18 & 1,3199 & 1,4953 & 2,0815 & 2,8460 & 2,8971 & 4,9596 \\
21 & 1,3360 & 1,4339 & 2,0873 & 2,7159 & 2,9307 & 5,1555 \\
\hline
\end{tabular}

Tabela 5.25: Probabilidade de bloqueio (\%) para a rede italiana de faixa larga com nós WSXC e WGXC. $W=15$ e tráfego oferecido por nó de 9 erlangs.

\begin{tabular}{|c|c|c|c|c|c|c|}
\cline { 2 - 7 } \multicolumn{1}{c|}{} & \multicolumn{6}{c|}{ Probabilidade de Bloqueio (\%) } \\
\cline { 2 - 7 } \multicolumn{1}{c|}{} & \multicolumn{3}{c|}{ Sem controle de conexão } & \multicolumn{3}{c|}{ Com controle de conexão } \\
\hline Agreg. & WS+WG & +PMD & +PMD+ASE & WS+WG & +PMD & +PMD+ASE \\
\hline \hline 0 & 4,3647 & 4,3924 & 5,6305 & 6,6683 & 6,8233 & 8,1958 \\
3 & 2,0245 & 2,1019 & 2,8518 & 3,8501 & 3,9422 & 5,8147 \\
6 & 1,5962 & 1,7877 & 2,4601 & 3,2698 & 3,3605 & 5,4802 \\
9 & 1,5392 & 1,6327 & 2,3095 & 3,0798 & 3,1997 & 5,3703 \\
12 & 1,3784 & 1,4866 & 2,0756 & 2,8313 & 2,9921 & 5,2329 \\
15 & 1,3872 & 1,4281 & 2,0493 & 2,7948 & 2,8065 & 5,1350 \\
18 & 1,3872 & 1,4807 & 2,0625 & 2,7115 & 2,9501 & 4,9888 \\
21 & 1,3360 & 1,4339 & 2,0873 & 2,7159 & 2,9307 & 5,1555 \\
\hline
\end{tabular}


Tabela 5.26: Tempo médio de simulação (milissegundos) do AG para o atendimento de requisição de conexão considerando a rede italiana de faixa larga com e sem os efeitos ASE e PMD.

\begin{tabular}{|c|c|c|c|c|c|c|}
\cline { 2 - 7 } \multicolumn{1}{c|}{} & \multicolumn{5}{c|}{ Tempo Médio de Simulação (milissegundos) } \\
\hline Nós & \multicolumn{2}{|c|}{ WSXC } & \multicolumn{3}{|c|}{ WGXC } & \multicolumn{2}{c|}{ WSXC+WGXC } \\
\cline { 2 - 7 } Agreg. & ideal $^{1}$ & +PMD+ASE & ideal $^{1}$ & +PMD+ASE & ideal $^{1}$ & +PMD+ASE \\
\hline \hline 0 & 53,807 & 62,105 & 53,807 & 62,105 & 66,361 & 69,697 \\
3 & 55,144 & 70,660 & 55,058 & 68,934 & 74,006 & 71,536 \\
6 & 59,004 & 72,927 & 60,981 & 70,183 & 79,955 & 77,295 \\
9 & 59,731 & 75,504 & 69,542 & 70,208 & 81,885 & 78,859 \\
12 & 61,571 & 84,935 & 70,104 & 75,608 & 84,092 & 80,584 \\
15 & 63,335 & 77,792 & 73,666 & 78,084 & 84,910 & 81,607 \\
18 & 64,340 & 78,755 & 74,576 & 79,736 & 85,232 & 82,075 \\
21 & 66,361 & 69,697 & 77,096 & 81,446 & 77,096 & 81,446 \\
\hline
\end{tabular}

(1) sem considerar as restrições da camada física ASE e PMD.

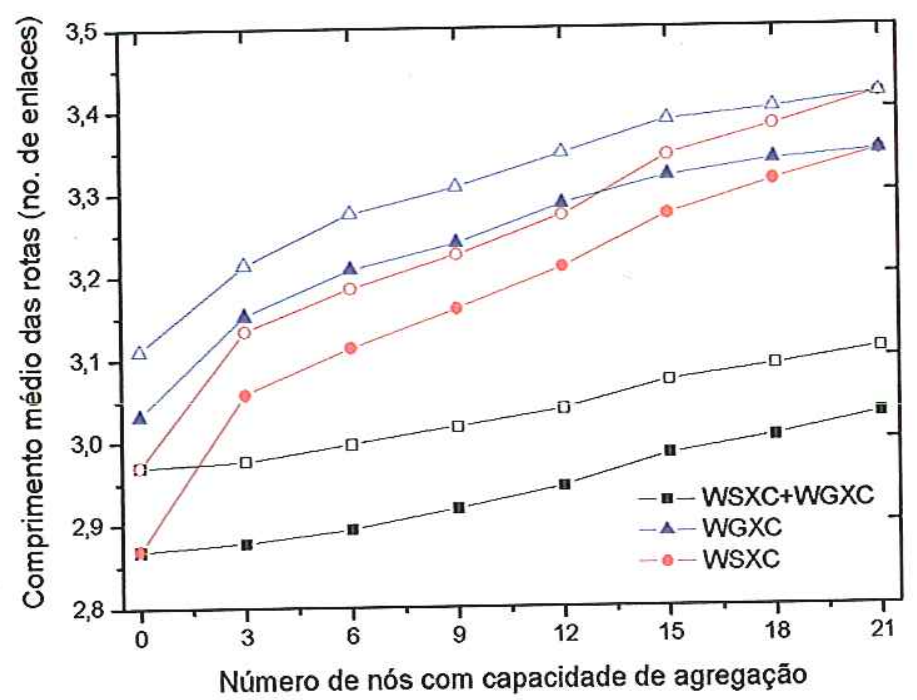

Figura 5.28: Comprimento médio das rotas (número de enlaces) em função do número de nós com capacidade de agregação para a rede italiana de faixa larga. Tráfego por nó de 9 erlangs e $W=15$. As curvas com símbolos cheios representam a rede sujeita às restrições ASE e PMD. 
Tabela 5.27: Ocupação média dos enlaces (\%) em função do número de nós com capacidade de agregação para a rede italiana de faixa larga. Tráfego por nó de 9 erlangs e $W=15$.

\begin{tabular}{|c|c|c|c|c|c|c|}
\cline { 2 - 7 } \multicolumn{1}{c|}{} & \multicolumn{5}{c|}{ Ocupação Média dos Enlaces (\%) $^{1}$} \\
\hline \multirow{2}{*}{$\begin{array}{c}\text { Nós } \\
\text { agregação }\end{array}$} & \multicolumn{3}{|c|}{ Ideal $^{2}$} & \multicolumn{3}{c|}{ +PMD +ASE } \\
\cline { 2 - 7 } & $W S X C$ & $W G X C$ & $W S+W G$ & $W S X C$ & $W G X C$ & $W S+W G$ \\
\hline \hline 0 & 28,7348 & 28,7349 & 32,7118 & 27,5032 & 27,5032 & 31,4602 \\
6 & 29,0982 & 32,6588 & 34,6258 & 27,8949 & 31,5852 & 33,6801 \\
9 & 29,7680 & 33,9855 & 35,4514 & 28,4235 & 32,9804 & 34,4159 \\
12 & 30,4655 & 34,8021 & 35,8077 & 29,1122 & 33,8453 & 34,8029 \\
15 & 31,0019 & 35,4165 & 36,3014 & 29,6815 & 34,4923 & 35,3872 \\
18 & 31,8594 & 36,2649 & 36,7281 & 30,5456 & 35,2525 & 35,7504 \\
21 & 32,3239 & 36,6826 & 36,8788 & 30,9558 & 35,6754 & 35,9562 \\
& 32,7118 & 37,0782 & 37,0782 & 31,4602 & 36,0564 & 36,0565 \\
\hline
\end{tabular}

(1) 5 rotas, 25 indivíduos, 50 gerações;

(2) sem restrições da camada física.

Tabela 5.28: Comprimento médio das rotas (número de enlaces) em função do número de nós com capacidade de agregação para a rede italiana de faixa larga. Tráfego por nó de 9 erlangs e $W=15$.

\begin{tabular}{|c|c|c|c|c|c|c|}
\cline { 2 - 7 } \multicolumn{1}{c|}{} & \multicolumn{4}{c|}{ Comprimento Médio das Rotas (no. de enlaces) $^{1}$} \\
\cline { 2 - 7 } agregação & \multicolumn{3}{|c|}{ Ideal $^{2}$} & \multicolumn{3}{c|}{ +PMD +ASE } \\
\cline { 2 - 7 } & $W S X C$ & $W G X C$ & $W S+W G$ & $W S X C$ & $W G X C$ & $W S+W G$ \\
\hline \hline 0 & 2,9696 & 2,9696 & 3,1102 & 2,8682 & 2,8682 & 3,0313 \\
6 & 2,9764 & 3,1334 & 3,2135 & 2,8776 & 3,0571 & 3,1524 \\
9 & 2,9968 & 3,1848 & 3,2759 & 2,8937 & 3,1133 & 3,2083 \\
12 & 3,0175 & 3,2250 & 3,3069 & 2,9181 & 3,1595 & 3,2394 \\
15 & 3,0382 & 3,2722 & 3,3470 & 2,9449 & 3,2095 & 3,2859 \\
18 & 3,0718 & 3,3439 & 3,3867 & 2,9833 & 3,2728 & 3,3188 \\
21 & 3,0903 & 3,3802 & 3,4005 & 3,0040 & 3,3129 & 3,3383 \\
& 3,1102 & 3,4172 & 3,4172 & 3,0314 & 3,3485 & 3,3485 \\
\hline
\end{tabular}

(1) 5 rotas, 25 indivíduos, 50 gerações;

(2) sem restrições da camada física. 


\subsection{Rede de Comunicação Móvel Celular}

O algoritmo para alocação de canais em sistemas de comunicações móveis celulares proposto neste trabalho é baseado em algoritmos genéticos e inclui mecanismo de inserção de imigrantes para aumentar a diversidade da população; política elitista (greedy policy) para garantia da sobrevivência do indivíduo mais apto; esquema da seleção por truncamento para eleger os melhores indivíduos para candidatos a pais; mecanismos adaptáveis para ajustar as taxas de mutação, cruzamento e reprodução de acordo com a diversidade dos pais; cruzamento em três pontos para acelerar a convergência do AG; e um esquema de reservatório para ajudar a formação da população inicial. Estas estratégias modificam os valores dos parâmetros durante a execução do AG, aumentam a eficiência combinando exploração com aproveitamento em função do estado atual do espaço da busca.

O desempenho dos AG propostos foi avaliado por meio de simulações em computador considerando um ambiente celular padrão formado por 49 células e 70 canais disponíveis. As requisições de novas chamadas e handoff são dinâmicas e obedecem à distribuição de Poisson com médias de tráfego distribuído de forma heterogênea no ambiente celular. O tempo de permanência das requisições é exponencialmente distribuído com média $1 / \mu=180 \mathrm{~s}$. A alocação de canais está simultaneamente sujeita a três tipos de restrições eletromagnéticas: co-canal, canal adjacente e co-site. O tráfego considerado exibe característica heterogênea. Os resultados numéricos sugerem desempenho promisssor dos algoritmos propostos. As principais contribuições englobam: o uso de AG adaptável, em vez dos canônicos ou não-adaptáveis; a proposta de algoritmos genéticos para solucionar o problema DCA, em vez de FCA, representando um ambiente celular mais prático; a investigação do impacto simultâneo no desempenho do sistema das três restrições eletromagnéticas, em vez da restrição padrão CCC; e a melhoria do desempenho do sistema considerando novas chamadas e handoff. Os resultados numéricos foram comparados aos esquemas de alocação fixa de canais (FCA), FCA com empréstimo direcional de canais com retenção (FCA-BDCL) [87] e DCA baseado na aprendizagem-Q (DCA-Q) [100], [101].

\subsubsection{Alocação de Canais e Comparação com Esquemas de Outros Autores}

Considere o ambiente celular padrão hexagonal $7 \times 7$ apresentado na Figura 4.8. Considere que o tráfego seja idêntico nas 49 células e que existam 70 canais disponíveis. Inicialmente, os canais estão sujeitos apenas à restrição co-canal, $c c c=1$, para $D=\sqrt{21} R$ $\left(C / I_{c}=18 d B\right)$. Esta restrição permite o reuso de um canal somente nas células que estão afastadas por três fileiras da célula de referência. Considere que a requisição 


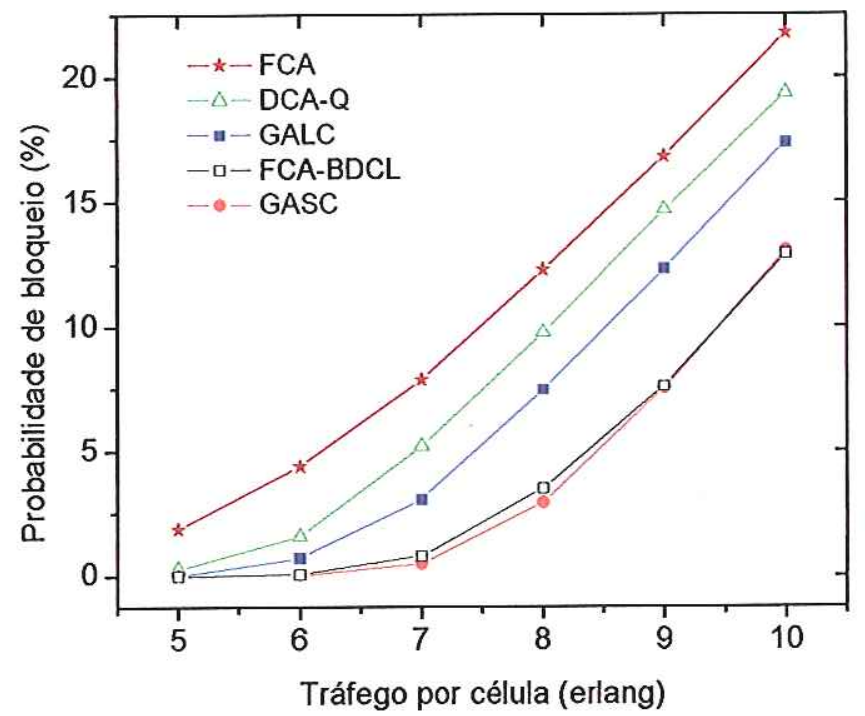

Figura 5.29: Probabilidade de bloqueio em função do tráfego por célula para os esquemas FCA, Q-DCA [100], [101], BDCL [87], GALC (este trabalho) e GASC (este trabalho).

de tráfego em cada uma das células seja uniforme, dinâmica e obedeça à distribuição de Poisson com médias 5, 6, 7, 8, 9 e 10 erlangs, com tempo de permanência das requisições distribuído exponencialmente com média $1 / \mu=180 \mathrm{~s}$. Estes valores são equivalentes às taxas de $100,120,140,160,180$ e 200 chamadas por hora, respectivamente. As probabilidades de bloqueio em função do tráfego nas células para os esquemas FCA, DCA-Q [100], [101], FCA-BDCL [87], GALC e GASC estão apresentadas na Figura 5.29 e na Tabela 5.29. Os resultados mostram que a estratégia GASC apresenta o melhor desempenho, exibindo a menor probabilidade de bloqueio em todas as condições de carga avaliadas. Por exemplo, para um tráfego igual a 7 erlangs, as probabilidades de bloqueio para GASC e FCA-BDCL são, aproximadamente, 0,5\% e $0,8 \%$, respectivamente. Para um tráfego de 8 erlangs, estes valores são $2,9 \%$ e $3,5 \%$, respectivamente. Estes resultados demonstram redução no número de chamadas bloqueadas para o GASC em 37\% e 17\% em relação ao esquema FCA-BDCL [87]. Pode-se observar ainda que o desempenho dos algoritmos propostos é sempre melhor que a estratégia por aprendizagem-Q [100], [101].

Na Figura 5.30 estão apresentados dois casos para os quais as densidades de tráfego em chamadas por hora são distribuídas de forma heterogênea entre as 49 células. A taxa de solicitação média de chamadas é 91,83 (ou 106,53) chamadas por hora. Os resultados numéricos foram comparados aos esquemas de alocação fixa de canais com o esquema de empréstimo direcional de canais com retenção (FCA-BDCL) [87] e com 
Tabela 5.29: Probabilidade de bloqueio em função do tráfego oferecido por célula, para os esquemas FCA, Q-DCA [100, 101], BDCL [87], GALC (este trabalho) e GASC (este trabalho).

\begin{tabular}{|c|c|c|c|c|c|}
\hline \multirow{2}{*}{$\begin{array}{c}\text { Tréfego } \\
\text { (erlang) }\end{array}$} & \multicolumn{5}{|c|}{ Probabilidade de Bloqueio (\%) } \\
\cline { 2 - 6 } & FCA & Q-DCA & BDCL & GALC & GASC \\
\hline \hline 5 & 1,867 & 0,267 & 0,000 & 0,0224 & 0,000 \\
6 & 4,410 & 1,600 & 0,062 & 0,7124 & 0,039 \\
7 & 7,866 & 5,200 & 0,798 & 3,064 & 0,484 \\
8 & 12,267 & 9,733 & 3,489 & 7,453 & 2,912 \\
9 & 16,801 & 14,667 & 7,594 & 12,311 & 7,519 \\
10 & 21,733 & 19,333 & 12,907 & 17,359 & 13,027 \\
\hline
\end{tabular}

o DCA baseado na aprendizagem-Q (DCA-Q) [100], [101]. As taxas de requisição de chamada foram acrescidas em $0,20,40,60,80$ e $100 \%$.

Os resultados obtidos estão apresentados na Figura 5.31 e na Tabela 5.30. A análise dos resultados mostra que o melhor desempenho foi obtido pela estratégia GASC, exibindo a menor probabilidade de bloqueio em ambas as condições de demanda baixa (média 91,83 chamadas por hora) e alta (média 106,53 chamadas por hora). Por exemplo, se o tráfego aumentar $40 \% \mathrm{em}$ ambas as demandas, as probabilidades de bloqueio para o GASC são $0,62 \%$ e $6,17 \%$, respectivamente, valores menores do que os para o esquema FCA-BDCL. Além disso, os desempenhos do GALC e do FCABDCL são muito similares no caso de demanda baixa. O desempenho dos algoritmos propostos é sempre melhor do que o DCA de aprendizagem-Q.

\subsubsection{Alocação Dinâmica de Canais em Sistemas com Handoff}

Confirmado o bom desempenho dos algoritmos propostos, a etapa seguinte inclui as solicitações de handoff no CAP. O processo de handoff ocorre somente para as chamadas já atribuídas no sistema. Se um pedido de handoff ocorrer em uma célula particular $j$, a probabilidade de uma célula $i$ vizinha a $j$ receber a requisição será estimada pela demanda de tráfego da vizinhança da célula $j$. Neste trabalho são adotadas taxas de handoff de $20 \%, 30 \%$ e $40 \%$. Os resultados obtidos para a probabilidade de bloqueio de novas chamadas em função do aumento da demanda de tráfego para os modelos GALC e GASC considerando taxa de handoff de $20 \%$ são mostrados nas Figuras 5.32 e 5.33, respectivamente. O caso sem handoff (taxa de $0 \%$ ) foi incluído para efeito de comparação. O número de gerações para convergência dos modelos em função do aumento percentual de tráfego para os modelos GALC e GASC está apresentado nas Figuras 5.32 (a) e 5.33 (a). O esquema GASC consegue desempenho similar ao caso 


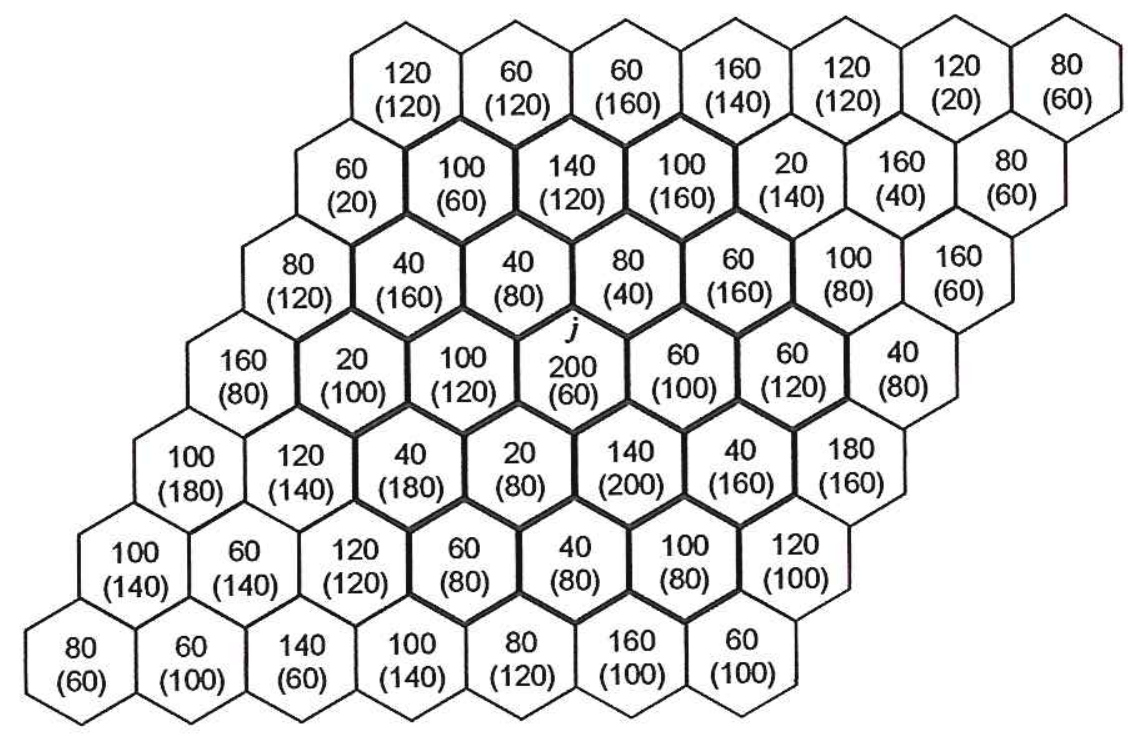

Figura 5.30: Ambiente celular formado por 49 células e 70 canais disponíveis. Distribuição heterogênea de tráfego com médias: a) 91,83; e b) 106,53 chamadas por hora (valores indicados entre parênteses). As células em destaque representam a região de interferência co-canal da célula $j$, para $D=\sqrt{21} R$.

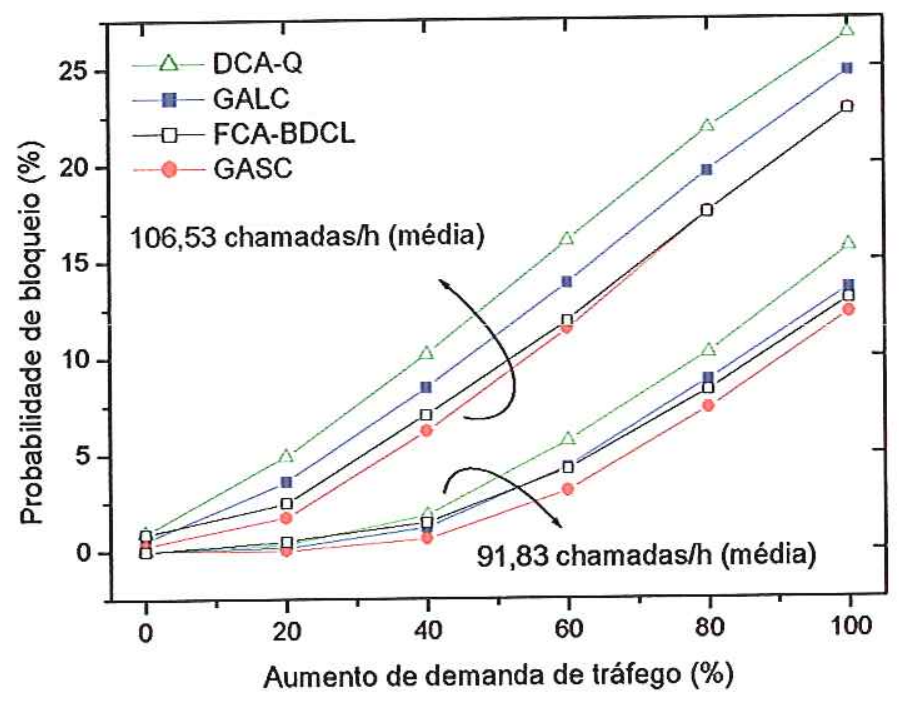

Figura 5.31: Probabilidade de bloqueio em função da demanda de tráfego para os esquemas DCA baseado em aprendizagem-Q [100], GALC (este trabalho), GASC (este trabalho) e FCA-BDCL [87]. 
Tabela 5.30: Probabilidade de bloqueio em função do aumento de tráfego oferecido por célula para os esquemas FCA, Q-DCA [100, 101], BDCL [87], GALC e GASC.

\begin{tabular}{|c|c|c|c|c|c|}
\cline { 2 - 6 } \multicolumn{1}{c|}{} & \multicolumn{5}{c|}{ Probabilidade de Bloqueio (\%) } \\
\hline Aumento de & Distribuição de tráfego: 91,83 chamadas por hora \\
\cline { 2 - 6 } tráfego (\%) & FCA & Q-DCA & BDCL & GALC & GASC \\
\hline \hline 0 & 5,8181 & 0,0000 & 0,0000 & 0,00221 & 0,0000 \\
20 & 9,0901 & 0,3636 & 0,4992 & 0,1869 & 0,03146 \\
40 & 13,2727 & 1,8182 & 1,4568 & 1,2123 & 0,6212 \\
60 & 18,1202 & 5,6363 & 4,2039 & 4,3015 & 3,0679 \\
80 & 22,1819 & 10,1818 & 8,2830 & 8,7935 & 7,3199 \\
100 & 26,1876 & 15,6363 & 12,9864 & 13,5247 & 12,2302 \\
\hline \hline Aumento de & Distribuição de tráfego: 106,53 chamadas por hora \\
\cline { 2 - 6 } tráfego (\%) & FCA & Q-DCA & BDCL & GALC & GASC \\
\hline \hline 0 & 6,5454 & 0,9090 & 0,8790 & 0,5070 & 0,3000 \\
20 & 11,0909 & 4,9090 & 2,4601 & 3,5860 & 1,7283 \\
40 & 16,9090 & 10,1818 & 7,0322 & 8,4409 & 6,1764 \\
60 & 21,2727 & 16,0202 & 11,8680 & 13,8249 & 11,4462 \\
80 & 25,8181 & 21,8102 & 17,4912 & 19,5919 & 17,5000 \\
100 & 29,8181 & 26,6790 & 22,7690 & 24,7665 & 22,7981 \\
\hline
\end{tabular}

sem handoff para as condições de demanda do tráfego de leve a moderada. Isto é devido à grande potencialidade do esquema GASC em encontrar recursos disponíveis para alocação dos canais. Considerando um aumento de demanda de tráfego de $40 \%$, as probabilidades de bloqueio de novas chamadas para os modelos GALC e GASC são $1,607 \%$ e $0,483 \%$, enquanto as probabilidade de bloqueio de handoff são $0,018 \% \mathrm{e}$ $0,036 \%$, respectivamente. Para um acréscimo de demanda de $80 \%$ as probabilidades de bloqueio de novas chamadas são 10,292\% e 7,891\% e de handoff são 0,301\% e 0,414\%, respectivamente. Em condições de demandas de tráfego de leve a moderada, o modelo GASC necessita de um menor número de gerações para convergência. Por exemplo, para $40 \%$ de aumento de demanda o número médio de gerações para os modelos GALC e GASC é 51,79 e 35,19 gerações. Entretanto, para demandas de tráfego elevadas ambos os modelo apresentam resultados similares. Por exemplo, para $80 \%$ os valores para os modelos GALC e GASC são 83,60 e 81,76 gerações, respectivamente.

Resultados similares obtidos para a probabilidade de bloqueio de novas chamadas, de handoff e número de gerações em função do aumento da demanda de tráfego para os modelos GALC e GASC considerando taxas de handoff de $30 \%$ e $40 \%$ são mostrados nas Figuras 5.34-5.37. 


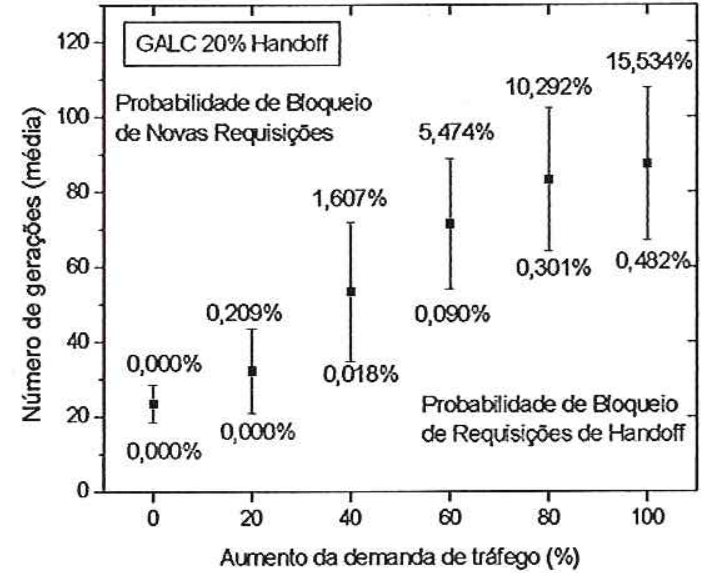

(a)

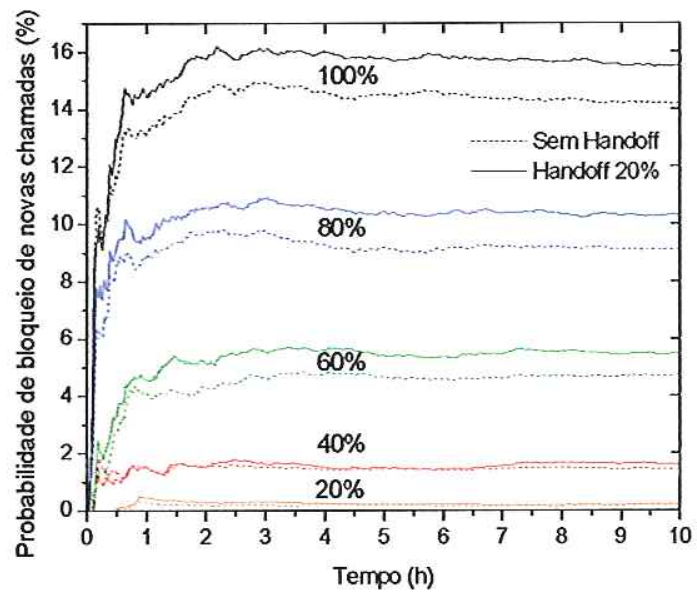

(b)

Figura 5.32: Algoritmo GALC com 20\% de handoff. (a) Número de gerações para convergência em função do aumento percentual de tráfego; e (b) Probabilidade de bloqueio de novas requisições em função do tempo de operação do sistema.

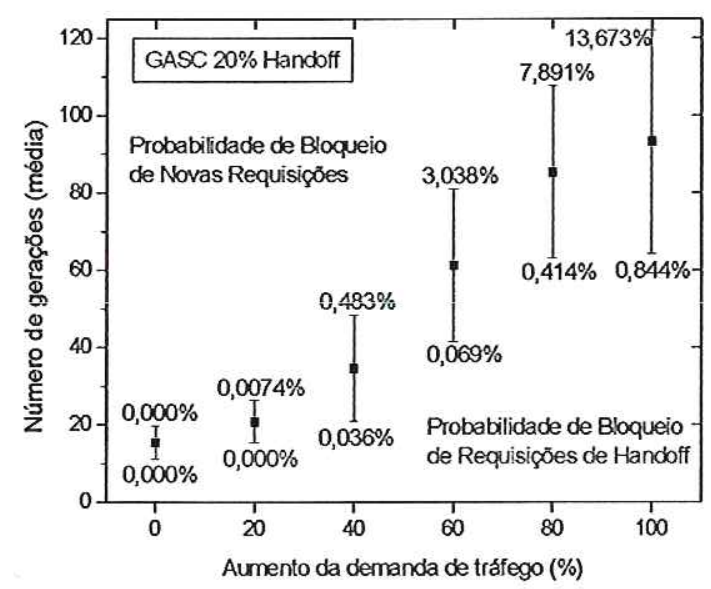

(a)

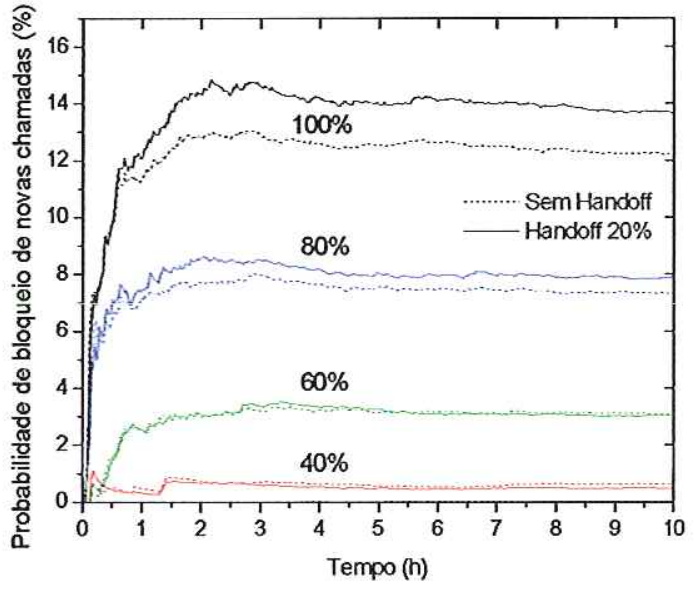

(b)

Figura 5.33: Algoritmo GASC com $20 \%$ de handoff. (a) Número de gerações para convergência em função do aumento percentual de tráfego; e (b) Probabilidade de bloqueio de novas requisições em função do tempo de operação do sistema. 


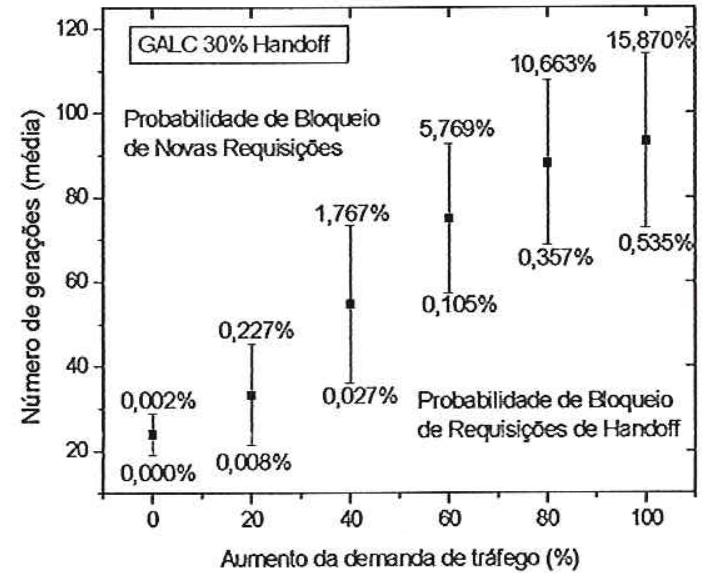

(a)

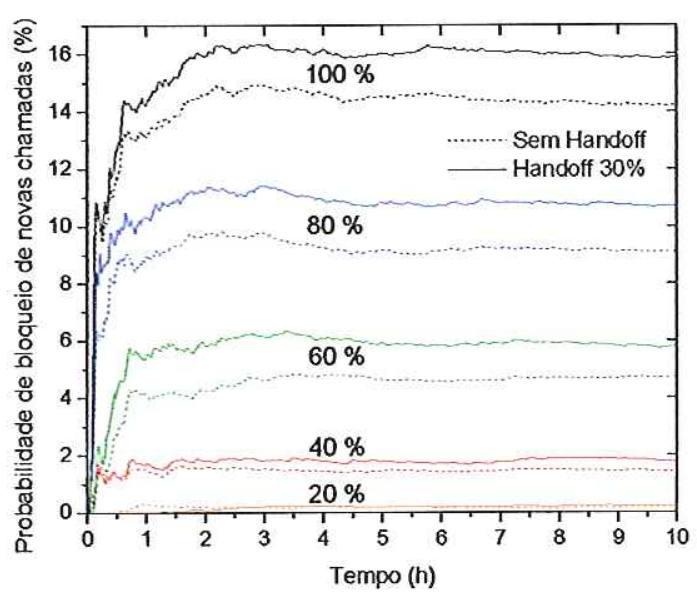

(b)

Figura 5.34: Algoritmo GALC com $30 \%$ de handoff . (a) Número de gerações para convergência em função do aumento percentual de tráfego; e (b) Probabilidade de bloqueio de novas requisições em função do tempo de operação do sistema.

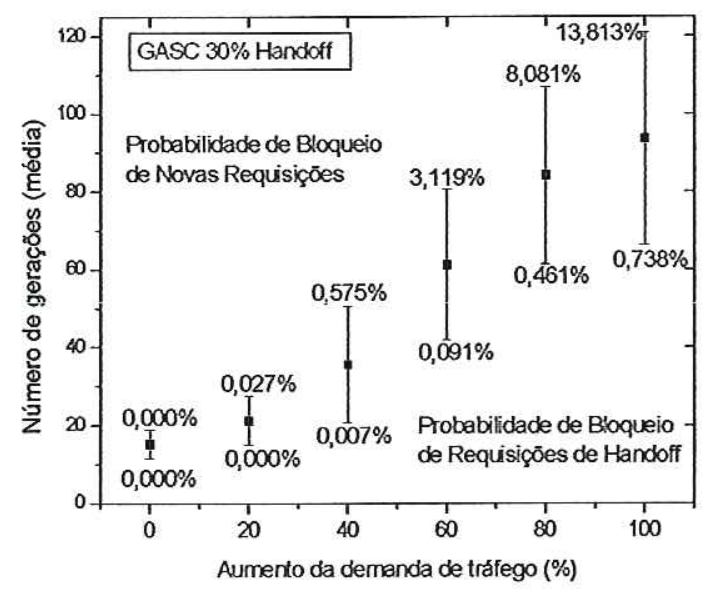

(a)

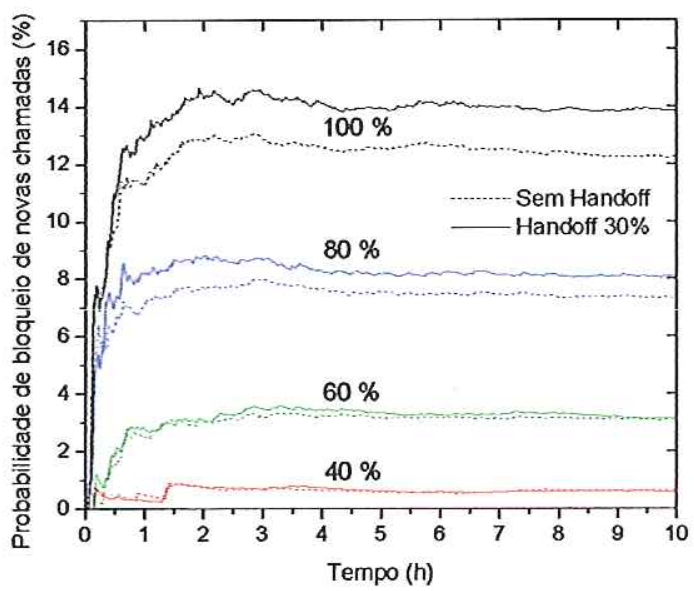

(b)

Figura 5.35: Algoritmo GASC com $30 \%$ de handoff. (a) Número de gerações para convergência em função do aumento percentual de tráfego; e (b) Probabilidade de bloqueio de novas requisições em função do tempo de operação do sistema. 


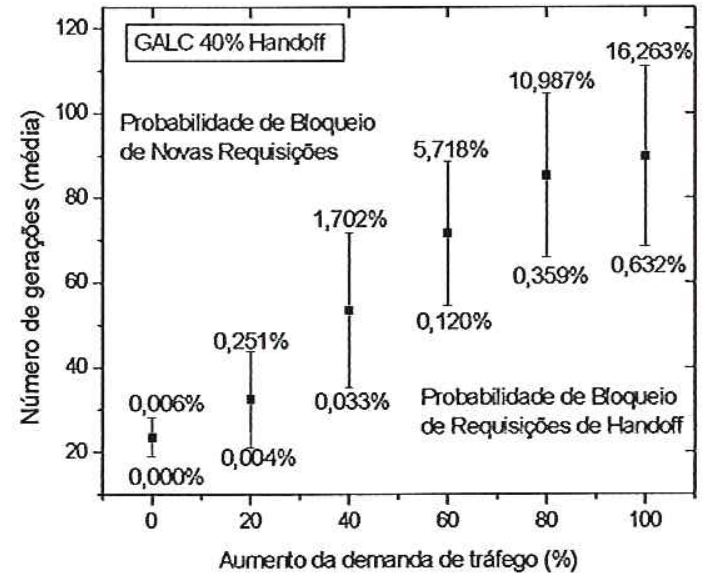

(a)

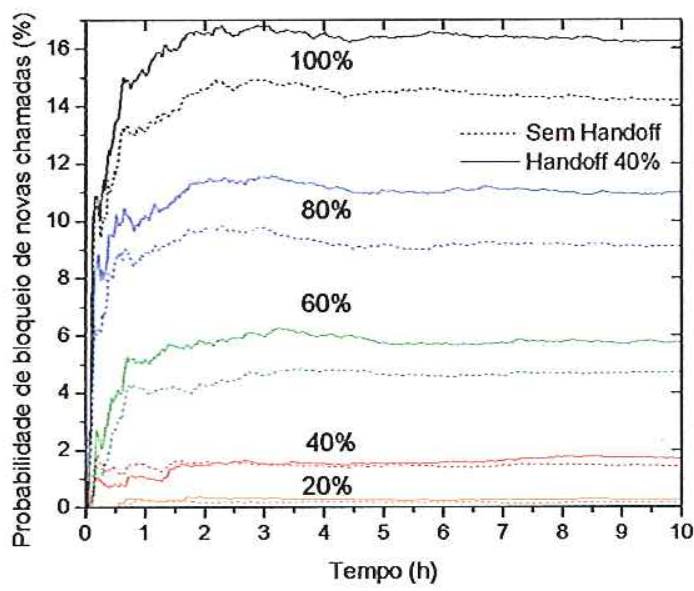

(b)

Figura 5.36: Algoritmo GALC com $40 \%$ de handoff. (a) Número de gerações para convergência em função do aumento percentual de tráfego; e (b) Probabilidade de bloqueio de novas requisições em função do tempo de operação do sistema.

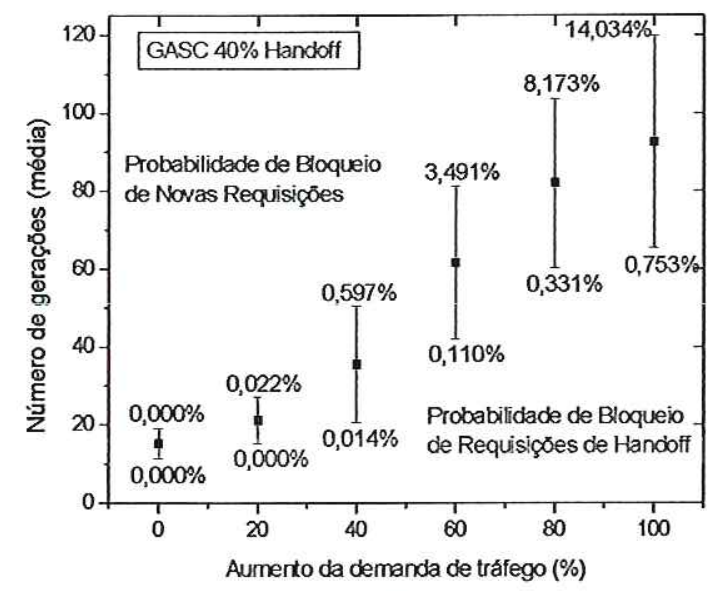

(a)

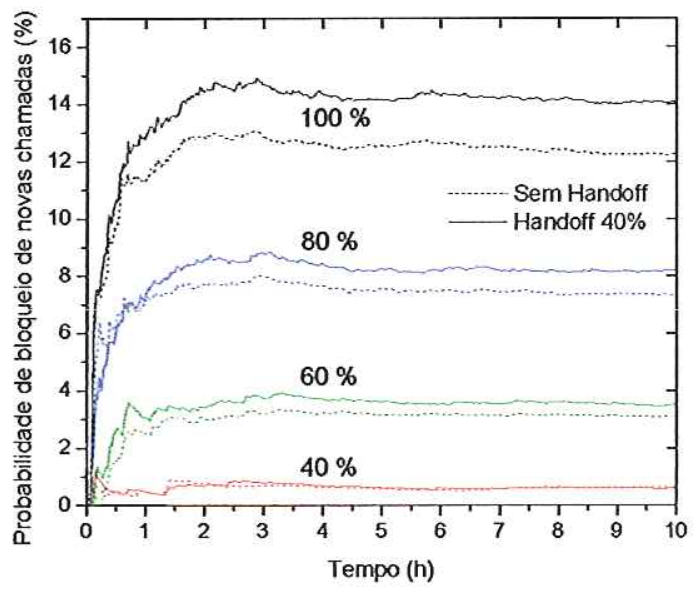

(b)

Figura 5.37: Algoritmo GASC com 40\% de handoff. (a) Número de gerações para convergência em função do aumento percentual de tráfego; e (b) Probabilidade de bloqueio de novas requisições em função do tempo de operação do sistema. 
A comparação entre os esquemas GALC e GASC para $20 \%$ e $40 \%$ de taxa de handoff é mostrada nas Figuras 5.38-5.40 e nas Tabelas 5.31-5.33. Elas relacionam a probabilidade de bloqueio de novas chamadas, handoff e número de gerações para convergência do algoritmo com aumento da carga do tráfego, respectivamente. Admitindo handoff no ambiente celular, o modelo GASC apresenta uma menor variação na probabilidade de bloqueio de novas requisições e, mesmo em condições de carga elevada, mantém a probabilidade de bloqueio de handoff próxima à obtida pelo método GALC (ver Figura 5.38). Os resultados para a taxa de handoff de $20 \%$ são similares e não foram apresentados na Figura 5.39 para não comprometer a visualização. O esquema GASC tem sempre mais canais atribuídos que o GALC, resultando em um maior número de solicitações de handoff. Entretanto, o desempenho do GASC é inferior ao do GALC somente para casos em que o sistema opera sob a condição de demanda do tráfego elevada. Uma diferença notável entre as duas estratégias é que o GASC procura alocar todas os canais, redistribuindo as chamadas atribuídas, enquanto o GALC procura alocar somente as novas solicitações. Para melhorar a compreensão da diferença entre eles, o número médio de gerações em função do aumento da carga do tráfego para esquemas GASC e GALC é mostrado na Figura 5.40. Neste caso, o esquema GASC garante melhor alocação de canais no menor intervalo de tempo do que o GALC, para o sistema operando sob a circunstância de demanda de tráfego leve a moderada. Em contraste, sob ocorrência de demanda de tráfego elevada não existem recursos disponíveis para o GALC alocar canais e as solicitações de chamada tendem a ser bloqueadas mais rapidamente do que no GASC.

Tabela 5.31: Probabilidade de bloqueio de novas chamadas para os esquemas GALC e GASC. Tráfego heterogêneo com média 91,83 chamadas por hora e taxas de handoff de 0,20 e $40 \%$.

\begin{tabular}{|c|c|c|c|c|c|c|}
\cline { 2 - 7 } \multicolumn{1}{c|}{} & \multicolumn{4}{c|}{ Probabilidade de Bloqueio de Novas Chamadas (\%) } \\
\hline Aumento de & \multicolumn{3}{|c|}{ GALC } & \multicolumn{3}{c|}{ GASC } \\
\cline { 2 - 7 } tráfego (\%) & $0 \%$ & $20 \%$ & $40 \%$ & $0 \%$ & $20 \%$ & $40 \%$ \\
\hline \hline 0 & 0,00221 & 0,00000 & 0,01105 & 0,00000 & 0,00000 & 0,00000 \\
20 & 0,18691 & 0,25539 & 0,23318 & 0,03146 & 0,01851 & 0,06292 \\
40 & 1,21230 & 1,72441 & 1,68173 & 0,62117 & 0,52633 & 0,70810 \\
60 & 4,30154 & 5,61816 & 6,07088 & 3,06798 & 3,16904 & 3,69376 \\
80 & 8,79354 & 10,50391 & 11,20818 & 7,31998 & 8,18315 & 8,35051 \\
100 & 13,52474 & 15,58864 & 16,32139 & 12,23022 & 13,76145 & 13,90082 \\
\hline
\end{tabular}




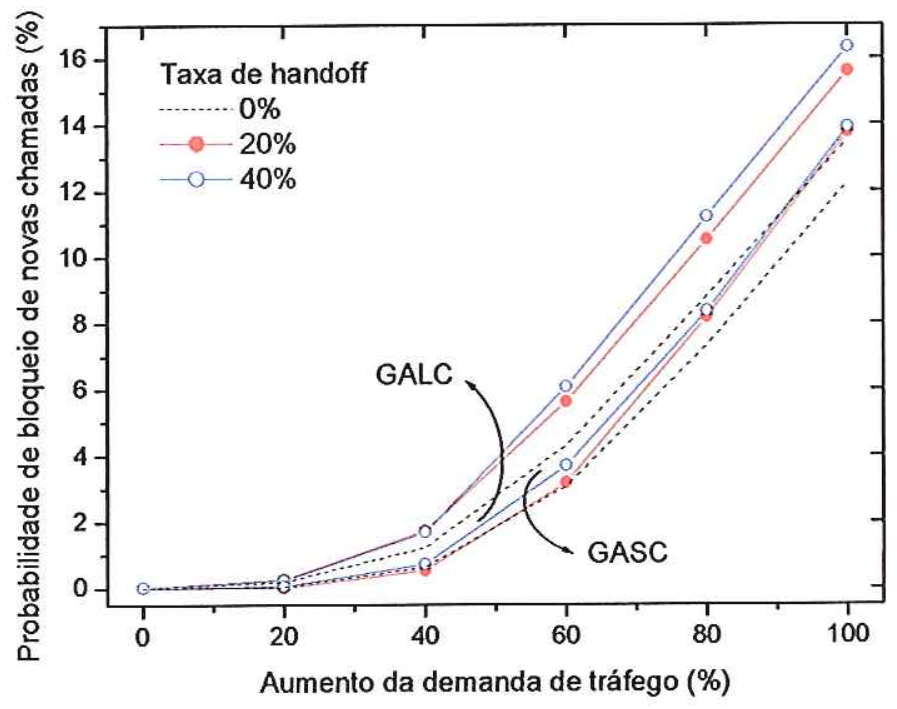

Figura 5.38: Probabilidade de bloqueio das novas chamadas em função da demanda de tráfego para os modelos GALC e GASC, considerando distribuição heterogênea de tráfego com média 91,83 chamadas por hora e taxas de handoff 0,20 e $40 \%$.

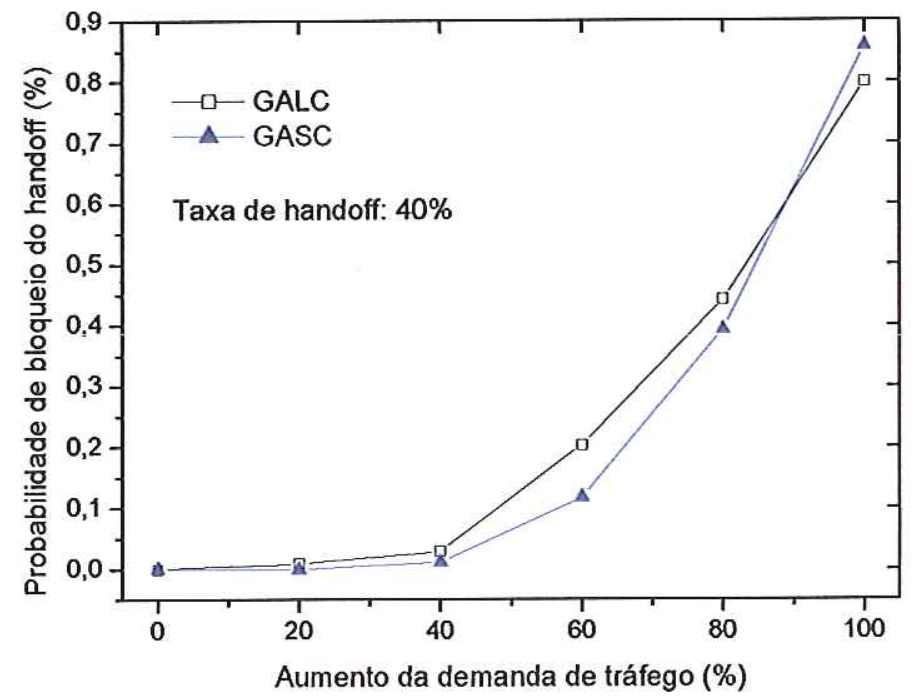

Figura 5.39: Probabilidade de bloqueio de handoff em função da demanda de tráfego para GALC e GASC, considerando distribuição heterogênea de tráfego com média 91,83 chamadas por hora e $40 \%$ de taxa de handoff. 
Tabela 5.32: Probabilidade de bloqueio de handoff para os esquemas GALC e GASC. Tráfego heterogêneo com média 91,83 chamadas por hora e taxas de handoff de 20 e $40 \%$.

\begin{tabular}{|c|c|c|c|c|}
\cline { 2 - 5 } \multicolumn{1}{c|}{} & \multicolumn{3}{c|}{ Probabilidade de Bloqueio de Handoff (\%) } \\
\hline Aumento de & \multicolumn{2}{c|}{ GALC } & \multicolumn{2}{c|}{ GASC } \\
\cline { 2 - 5 } tráfego (\%) & $20 \%$ & $40 \%$ & $20 \%$ & $40 \%$ \\
\hline \hline 0 & 0,00000 & 0,00000 & 0,00000 & 0,00000 \\
20 & 0,00435 & 0,00888 & 0,00000 & 0,00000 \\
40 & 0,01129 & 0,02880 & 0,03714 & 0,01139 \\
60 & 0,14100 & 0,20376 & 0,09098 & 0,01139 \\
80 & 0,39400 & 0,44228 & 0,48535 & 0,39256 \\
100 & 0,57273 & 0,88165 & 0,88165 & 0,85750 \\
\hline
\end{tabular}

Tabela 5.33: Média do número de gerações para os esquemas GALC e GASC. Tráfego heterogêneo com média 91,83 chamadas por hora e taxas de handoff de 0, 20 e 40\%.

\begin{tabular}{|c|c|c|c|c|c|c|}
\cline { 2 - 7 } \multicolumn{1}{c|}{} & \multicolumn{4}{c|}{ Média do Número de Gerações para Convergência do Algoritmo } \\
\cline { 2 - 7 } Aumento de & \multicolumn{3}{|c|}{ GALC } & \multicolumn{3}{c|}{ GASC } \\
tráfego (\%) & $0 \%$ & $20 \%$ & $40 \%$ & $0 \%$ & $20 \%$ & $40 \%$ \\
\hline \hline 0 & 22,3533 & 23,5200 & 24,4150 & 15,6467 & 15,8400 & 15,8400 \\
20 & 29,2117 & 32,0800 & 33,9283 & 20,0010 & 21,2116 & 21,3933 \\
40 & 45,8200 & 51,7967 & 59,1583 & 31,9983 & 35,1917 & 35,7533 \\
60 & 63,7583 & 72,4100 & 79,3483 & 51,1967 & 61,3567 & 61,5783 \\
80 & 72,8783 & 83,6016 & 94,2133 & 69,5350 & 81,7683 & 83,7367 \\
100 & 76,0217 & 88,9583 & 100,5416 & 76,9283 & 95,4183 & 93,0500 \\
\hline
\end{tabular}

A ocupação média dos canais, $\bar{C}_{\text {Ocup }}$, traduz a utilização dos canais nas células por meio da seguinte relação:

$$
\bar{C}_{\text {Ocup }}=\frac{\sum_{j=1}^{N} \sum_{i=1}^{N_{\text {Req }}^{(j)}} i \cdot 1 / \mu \cdot 1 / T}{M_{c e l}},
$$

na qual $N$ é o número de células, $N_{R e q}^{(j)}$ é o total de requisições na célula $j, M_{c e l}$ é o número de canais de rádio por célula e $T$ é o período de tempo avaliado. A ocupação média dos enlaces em função da demanda de tráfego oferecido no ambiente celular está apresentada na Figura 5.41 e na Tabela 5.34.

\subsubsection{Demanda de Tráfego com Variação Temporal}

Considerando as variações de tráfego que ocorrem durante um típico dia útil, conforme ilustra a Figura 5.42, o comportamento dinâmico do algoritmo genético foi avaliado 


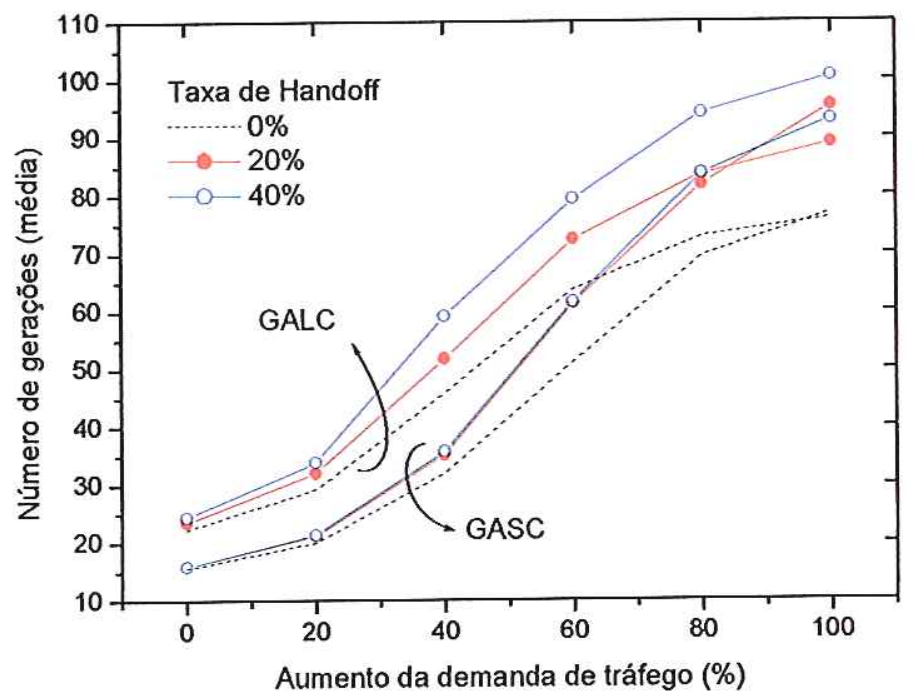

Figura 5.40: Número de gerações em função da demanda de tráfego para os algoritmos GALC e GASC, considerando distribuição heterogênea de tráfego com média 91,83 chamadas por hora e taxas de handoff 0,20 e $40 \%$.

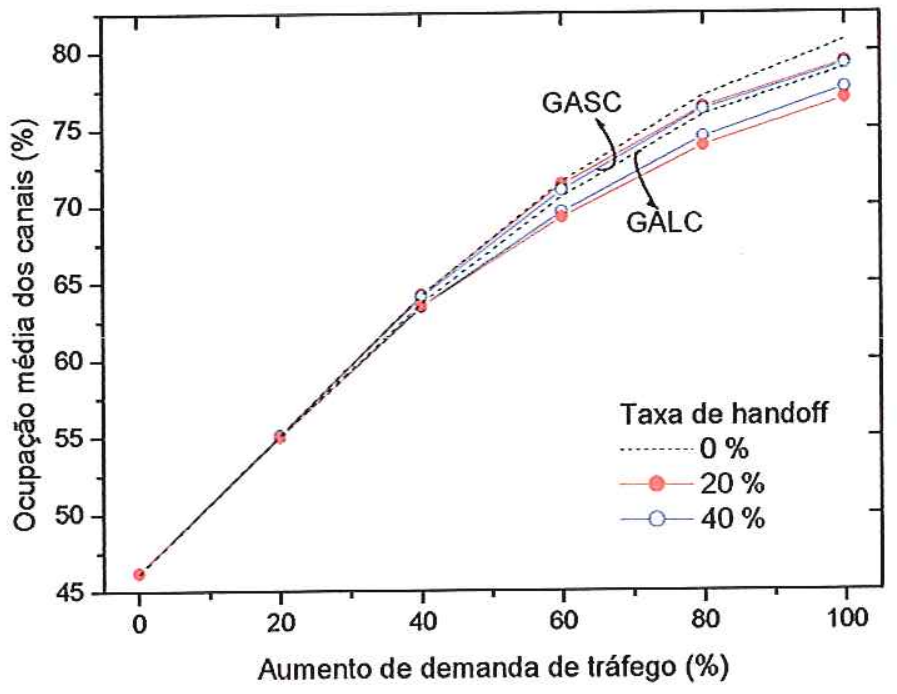

Figura 5.41: Ocupação média dos canais (\%) em função da demanda de tráfego para os modelos GALC e GASC, considerando distribuição heterogênea de tráfego com média 91,83 chamadas por hora e taxas de handoff 0, 20 e $40 \%$. 
Tabela 5.34: Ocupação média dos canais (\%) em função da demanda de tráfego para os modelos GALC e GASC.

\begin{tabular}{|c|c|c|c|c|c|c|}
\hline & \multicolumn{6}{|c|}{ Ocupação Média dos Canais (\%) $^{1}$} \\
\hline \multirow{2}{*}{$\begin{array}{l}\text { Aumento de } \\
\text { tráfego (\%) }\end{array}$} & \multicolumn{3}{|c|}{ GALC-Taxa de handoff } & \multicolumn{3}{|c|}{ GASC-Taxa de handoff } \\
\hline & $0 \%$ & $20 \%$ & $40 \%$ & $0 \%$ & $20 \%$ & $40 \%$ \\
\hline 0 & 46,1734 & 46,1744 & $4 \overline{46,1693}$ & 46,1744 & 46,1745 & 46,1745 \\
\hline 20 & 55,0357 & 54,9979 & 55,0102 & 55,1214 & 55,1285 & 55,1041 \\
\hline 40 & 63,6438 & 63,4459 & 63,4734 & 64,1551 & 64,2194 & 64,1020 \\
\hline 60 & 70,5561 & 69,5632 & 69,2296 & 71,5408 & 71,3684 & 70,9816 \\
\hline 80 & 75,8530 & 74,4306 & 73,8449 & 77,0846 & 76,3663 & 76,2224 \\
\hline 100 & 78,8826 & 77,5826 & 76,9092 & 80,6704 & 79,2735 & 79,1418 \\
\hline
\end{tabular}

(1) 75 indivíduos, 50 gerações, 70 canais.

utilizando a distribuição heterogênea de tráfego com média de 91,83 chamadas por hora, apresentada na Figura 5.30. Os resultados para o desempenho da probabilidade de bloqueio de novas chamadas e handoff para os modelos GASC e GALC estão apresentados nas Figuras 5.43 e 5.44. O GASC exibe melhor desempenho para novas chamadas em todas as situações. Nos dois intervalos de tempo com maior demanda (10-11 h e 16-17 h) o GASC apresenta probabilidades de bloqueio de novas requisições de $12,467 \%$ e $8,492 \%$, enquanto as apresentadas pelo GALC são $14,502 \%$ e $10,838 \%$, respectivamente. Entretanto, a intensidade de tráfego gerenciado pelo GASC é sempre maior que aquela do GALC e, para estes períodos, as probabilidades de bloqueio de handoff para o GASC são $0,875 \%$ e $0,6207 \%$ e para o GALC são 0,513\% e 0,279\%. Esta penalização é o custo pela redução obtida no bloqueio de novas requisições de 14,03\% e 21,65\%, nos períodos considerados. O número de gerações necessárias para a convergência dos modelos está apresentado na Figura 5.45. O modelo GASC apresenta maior velocidade de convergência para situações de carga leve a moderada. Entretanto, em situações com elevada demanda de tráfego o modelo GASC necessita de maior número de gerações. Enquanto o GALC aloca as novas requisições somente nos canais disponíveis, o GASC necessita explorar o espaço de busca com maior intensidade para determinar uma alocação ótima ou sub-ótima para todo o conjunto de solicitações, formado pelas já alocadas e novas requisições, obtendo, assim, resultados melhores que o GALC.

\subsubsection{Restrições Eletromagnéticas}

Os testes seguintes tratam de avaliar o impacto das restrições EMC sobre o desempenho do sistema. O valor $n$ associado às restrições EMC significa que os $(n-1)$ 


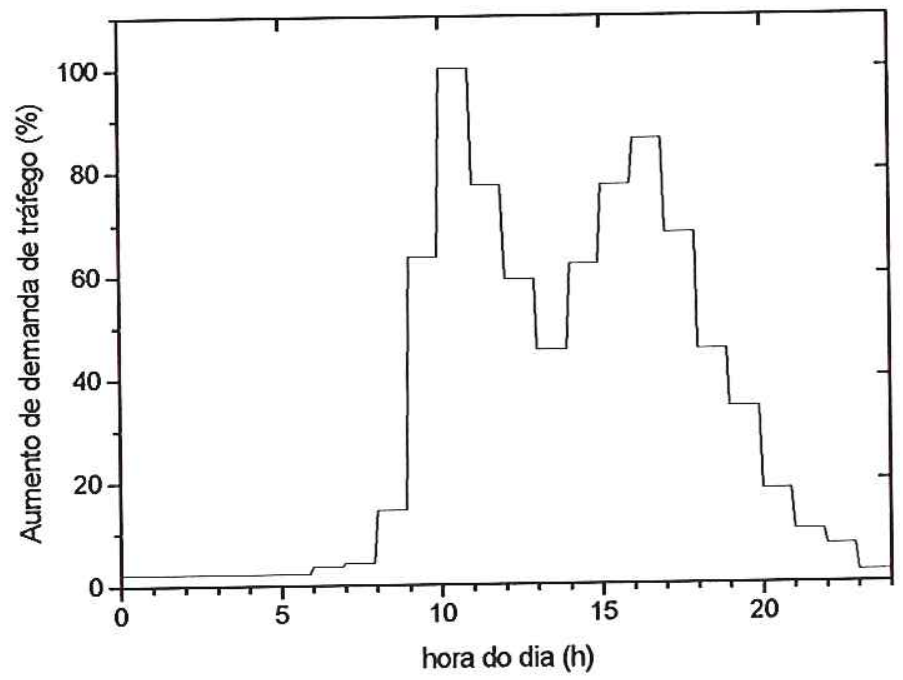

Figura 5.42: Padrão de tráfego de um dia útil típico [100], [101].

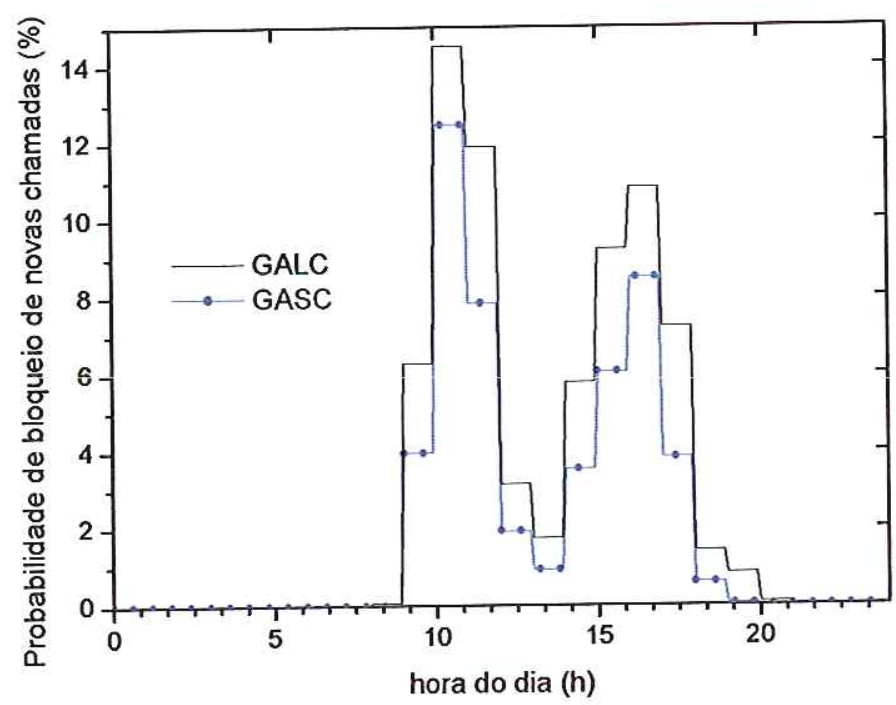

Figura 5.43: Probabilidade de bloqueio de novas chamadas dos algoritmos GALC e GASC considerando variação temporal do tráfego (Figura 5.42) e distribuição heterogênea de tráfego com média 91,83 chamadas por hora. 


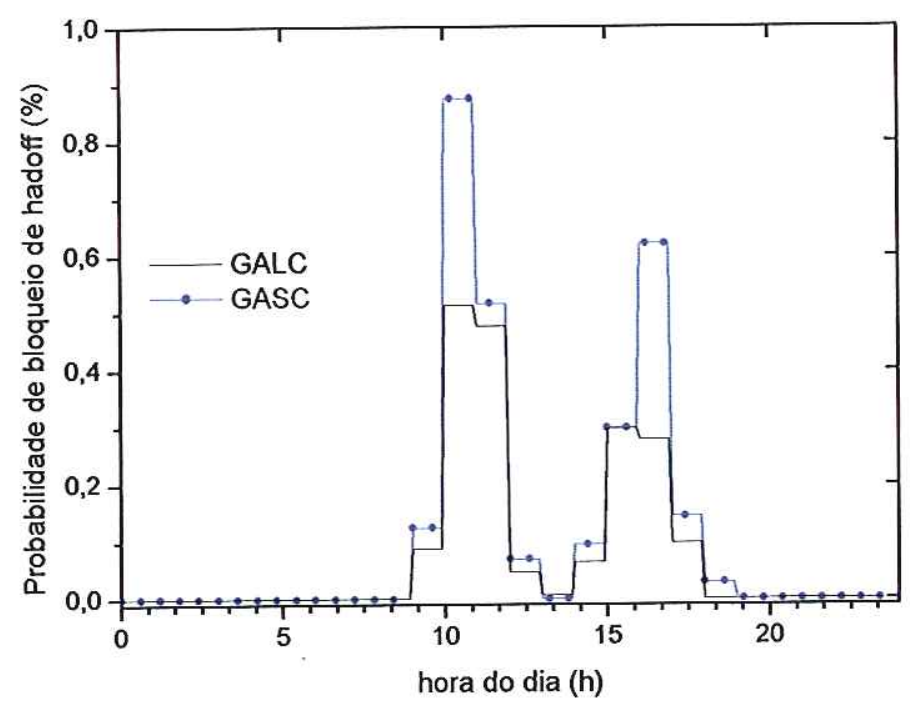

Figura 5.44: Probabilidade de bloqueio de handoff dos algoritmos GALC e GASC considerando variação temporal do tráfego (Figura 5.42) e distribuição heterogênea de tráfego com média 91,83 chamadas por hora.

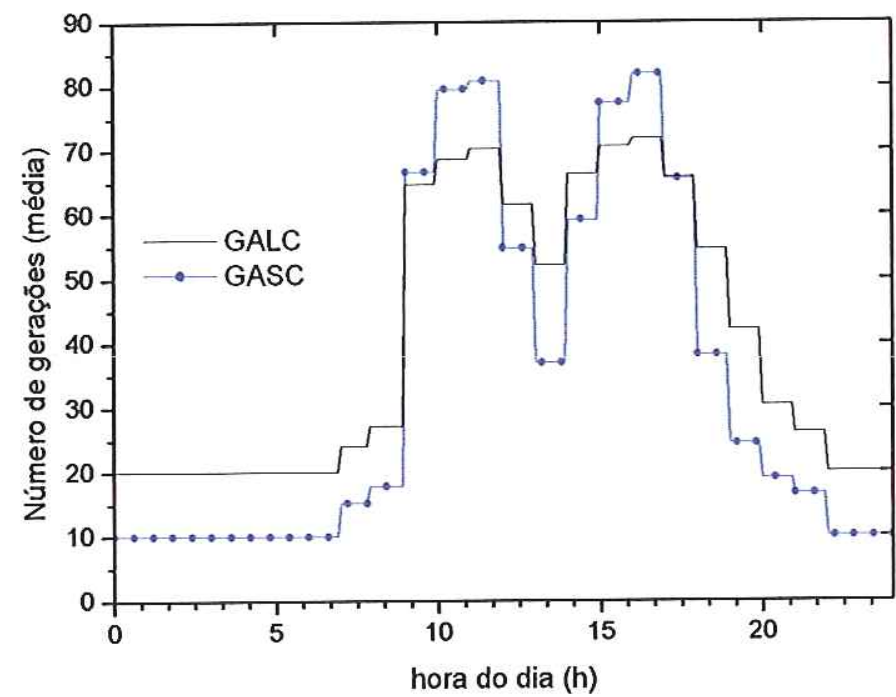

Figura 5.45: Número de gerações para convergência dos algoritmos GALC e GASC considerando variação temporal do tráfego (Figura 5.42) e distribuição heterogênea de tráfego com média 91,83 chamadas por hora. 
canais para ambos os lados esquerdo e direito do espectro não estão disponíveis para uso. Nos primeiros testes foi avaliado o impacto da restrição co-site e da inclusão da restrição canal adjacente, utilizando demanda de tráfego dinâmico com distribuição de tráfego heterogênea com média de solicitações de 91,83 chamadas por hora, conforme apresentado na Figura 5.30. Em seguida, foram realizados testes com EMC e taxa de handoff de $20 \%$. Os resultados numéricos mostram o impacto do CAC no desempenho do sistema. Quando o CSC limita somente os $(n-1)$ canais na própria célula, o ACC causa uma grande degradação no desempenho do sistema, pois torna indisponíveis os $(n-1)$ canais pertencentes à vizinhança da célula de referência.

\section{Restrição Eletromagnética Co-Site}

Considere o ambiente celular apresentado na Figura 5.30, sujeito às restrições cocanal, $c c c=1$, canal adjacente, $a c c=1$, e a diferentes valores de restrição co-site, $c s c \in\{1,2,3,4,5\}$. Os resultados obtidos para os modelos GALC e GASC em função do tempo estão apresentados nas Figuras 5.46-5.51, para as condições de aumento de demanda de tráfego $0,20,40,60,80$ e $100 \%$.

Tabela 5.35: Probabilidade de bloqueio para os modelos GALC e GASC em função da restrição co-site, parametrizada pelo aumento de demanda de tráfego.

\begin{tabular}{|c|c|c|c|c|c|}
\hline \multirow{2}{*}{$\begin{array}{c}\text { Aumento de } \\
\text { tráfego (\%) }\end{array}$} & \multicolumn{5}{|c|}{ GALC - Probabilidade de Bloqueio (\%) } \\
\cline { 2 - 6 } & $c s c=1$ & $c s c=2$ & $c s c=3$ & $c s c=4$ & $c s c=5$ \\
\hline \hline 0 & 0,00221 & 0,00884 & 0,21657 & 1,23754 & 3,48943 \\
20 & 0,18691 & 0,32941 & 1,12332 & 3,16456 & 6,94352 \\
40 & 1,41778 & 2,06265 & 3,38086 & 7,29911 & 11,91124 \\
60 & 4,69888 & 5,49356 & 7,58826 & 11,76796 & 17,41520 \\
80 & 9,08801 & 10,22294 & 12,56764 & 16,81165 & 23,69606 \\
100 & 14,17422 & 15,28001 & 18,02780 & 22,70295 & 29,82947 \\
\hline Aumento de & \multicolumn{6}{|c|}{ GASC - Probabilidade de Bloqueio $(\%)$} \\
\cline { 2 - 6 } tráfego (\%) & $c s c=1$ & $c s c=2$ & $c s c=3$ & $c s c=4$ & $c s c=5$ \\
\hline \hline 0 & 0,00000 & 0,00442 & 0,10829 & 0,73811 & 2,52812 \\
20 & 0,03146 & 0,18321 & 0,76060 & 2,48908 & 5,83870 \\
40 & 0,62591 & 1,18701 & 2,79920 & 6,00303 & 10,19315 \\
60 & 3,06798 & 4,77641 & 6,77004 & 10,78222 & 14,84009 \\
80 & 7,31998 & 10,11619 & 12,07440 & 16,10370 & 19,72320 \\
100 & 12,23022 & 15,48539 & 17,85683 & 20,88996 & 24,97446 \\
\hline
\end{tabular}

Os resultados obtidos para os modelos GALC e GASC em função da restrição cosite, parametrizada pelo aumento de demanda de tráfego, estão apresentados na Figura 5.52 e na Tabela 5.35. Os resultados demonstram que o modelo GASC apresenta 


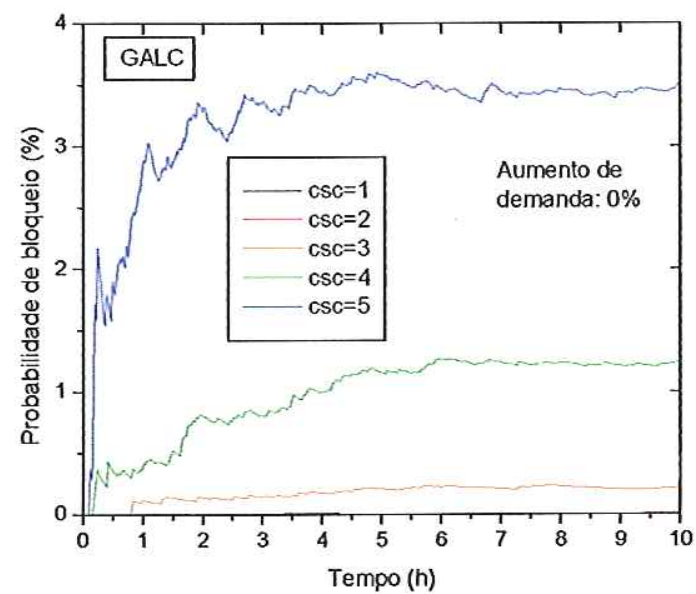

(a)

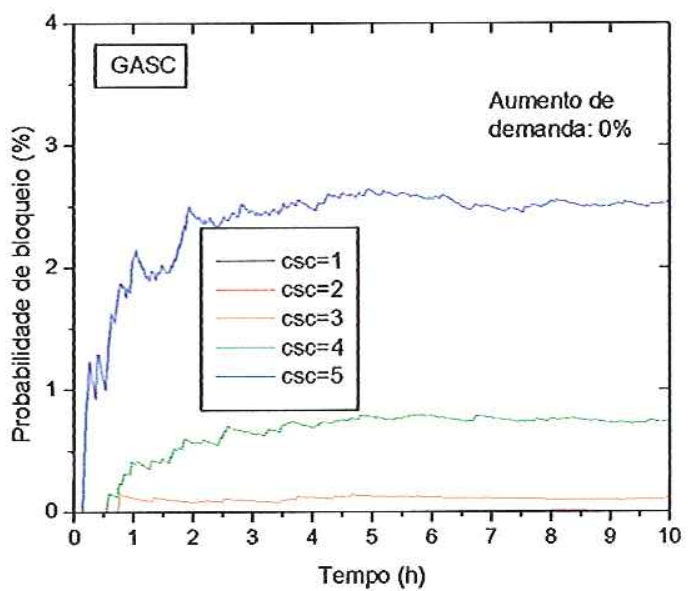

(b)

Figura 5.46: Probabilidade de bloqueio em função do tempo para restrição co-site, $c s c \in\{1,2,3,4,5\}$, considerando $0 \%$ de aumento na demanda de tráfego. Algoritmos: (a) GALC; e (b) GASC.

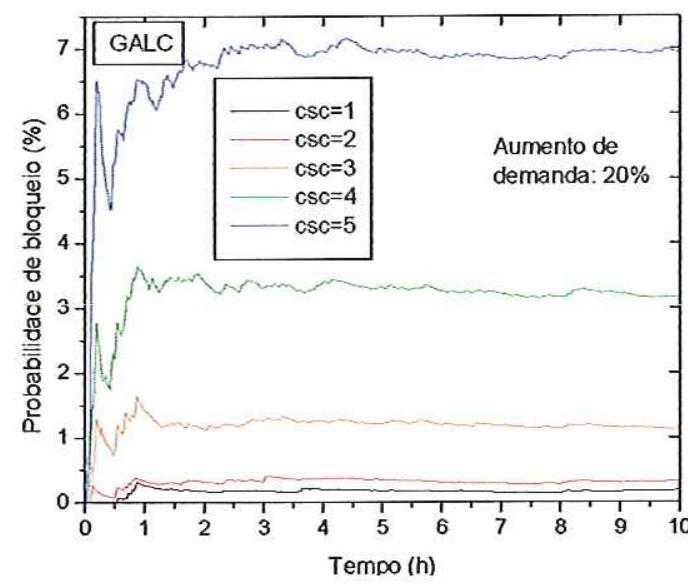

(a)

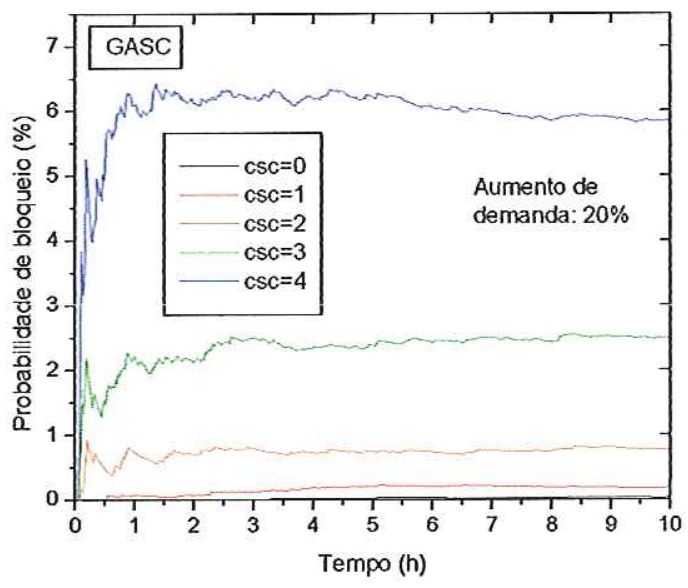

(b)

Figura 5.47: Probabilidade de bloqueio em função do tempo para restrição co-site, $c s c \in\{1,2,3,4,5\}$, considerando $20 \%$ de aumento na demanda de tráfego. Algoritmos: (a) GALC e (b) GASC. 


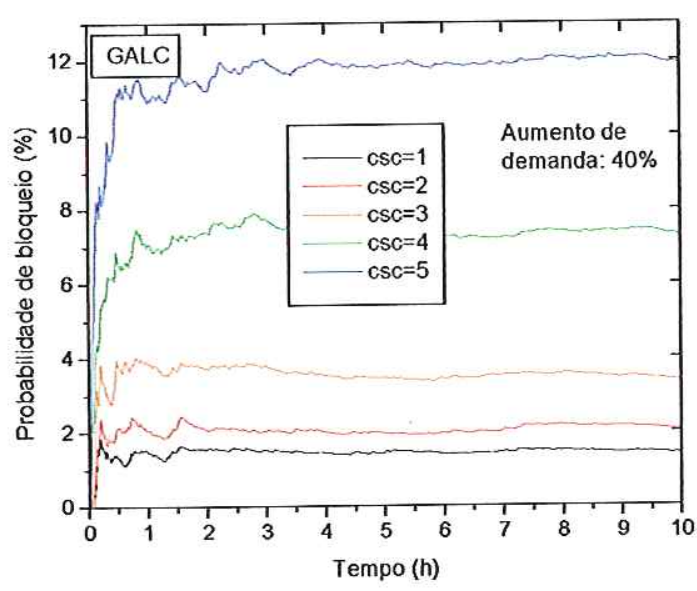

(a)

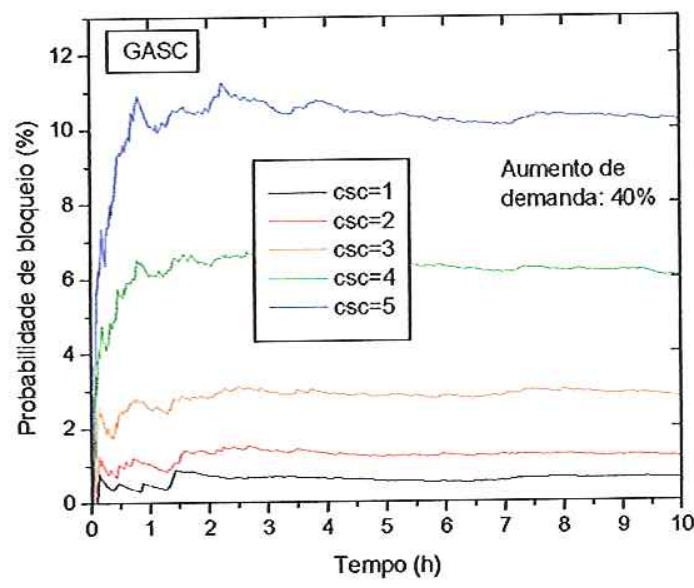

(b)

Figura 5.48: Probabilidade de bloqueio em função do tempo para restrição co-site, $c s c \in\{1,2,3,4,5\}$, considerando $40 \%$ de aumento na demanda de tráfego. Algoritmos: (a) GALC; e (b) GASC.

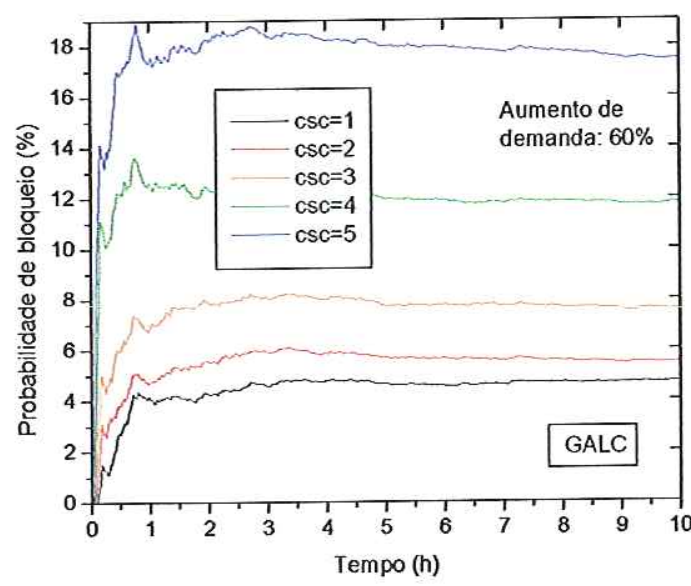

(a)

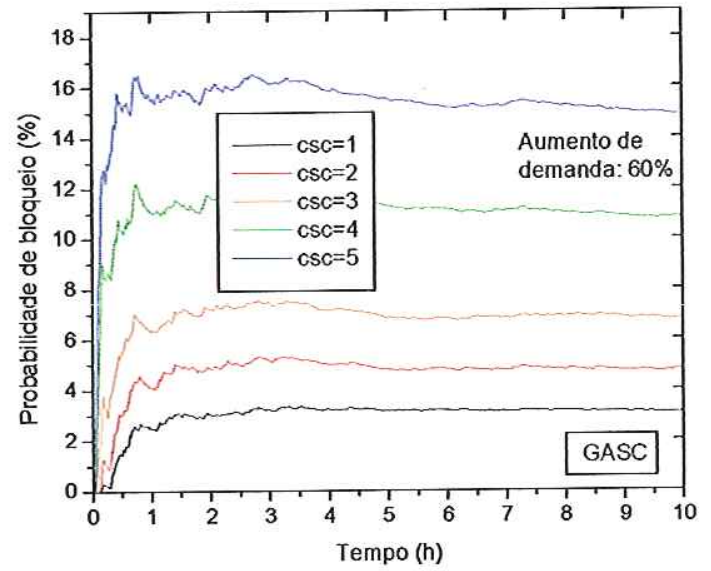

(b)

Figura 5.49: Probabilidade de bloqueio em função do tempo para restrição co-site, csc $\in\{1,2,3,4,5\}$, considerando $60 \%$ de aumento na demanda de tráfego. Algoritmos: (a) GALC e (b) GASC. 


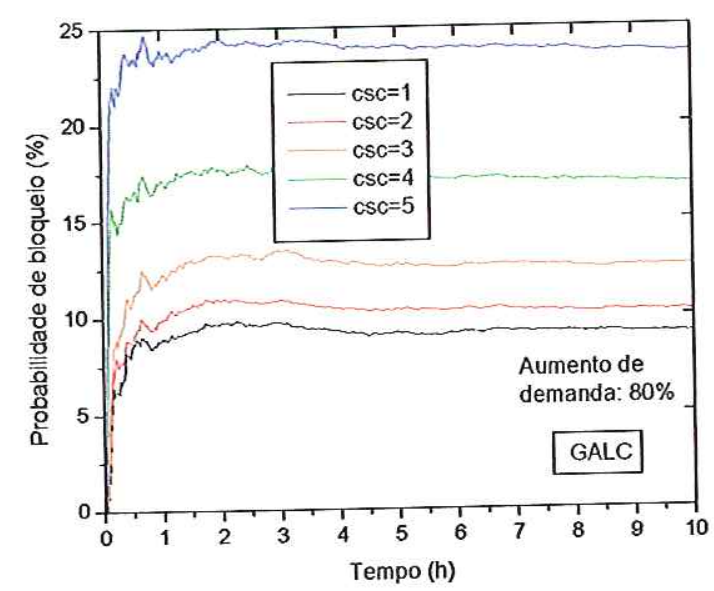

(a)

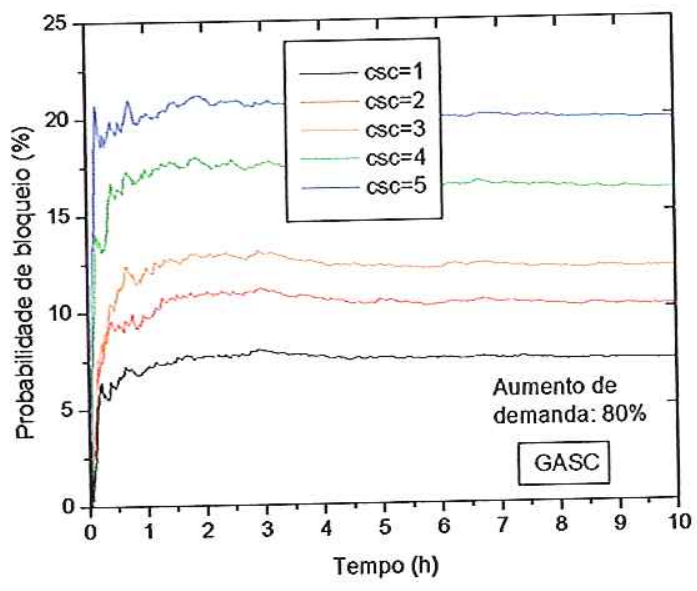

(b)

Figura 5.50: Probabilidade de bloqueio em função do tempo para restrição co-site, $c s c \in\{1,2,3,4,5\}$, considerando $80 \%$ de aumento na demanda de tráfego. Algoritmos: (a) GALC; e (b) GASC.

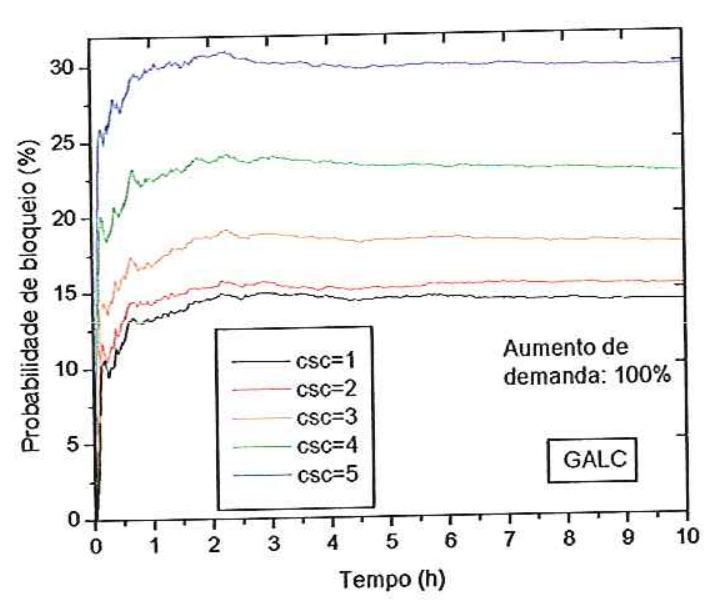

(a)

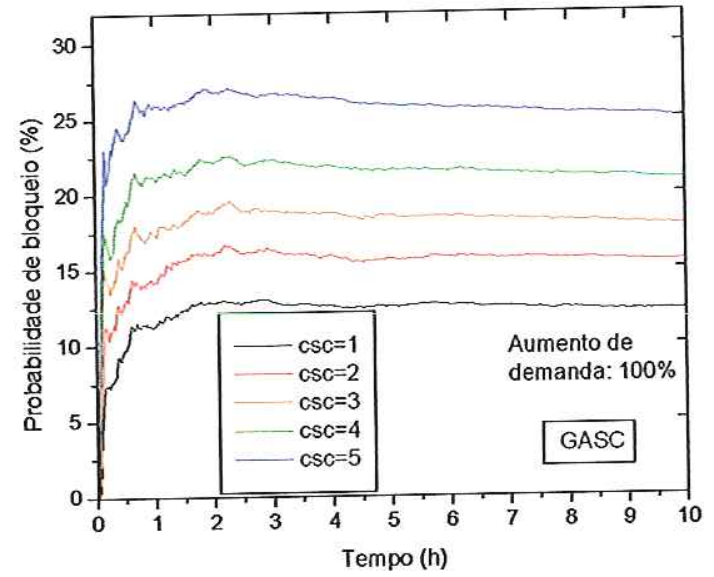

(b)

Figura 5.51: Probabilidade de bloqueio em função do tempo para restrição co-site, $\csc \in\{1,2,3,4,5\}$, considerando $100 \%$ de aumento na demanda de tráfego. Algoritmos: (a) GALC; e (b) GASC. 


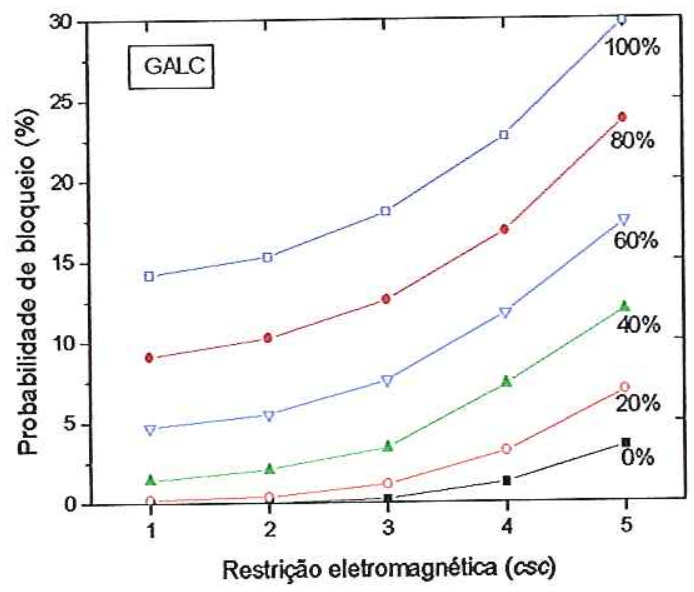

(a)

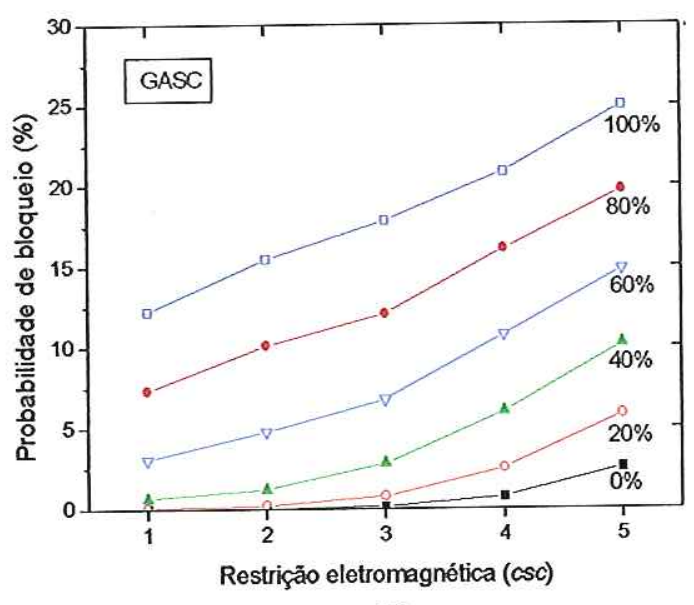

(b)

Figura 5.52: Probabilidade de bloqueio para os algoritmos GALC e GASC em função da restrição co-site, parametrizada pelo aumento de demanda de tráfego com média 91,83 chamadas por hora.

desempenho superior em todas as situações analisadas.

\section{Restriçāo Eletromagnética Canal Adjacente}

Considere o ambiente celular apresentado na Figura 5.30, sujeito às restrições cocanal, $c c c=1$, co-site, $c s c \in\{1,2,3,4,5\}$, e canal adjacente, acc $\in\{1,2,3\}$, tal que $c s c \geq a c c \geq c c c$. Os resultados obtidos para os modelos GALC e GASC em função do tempo estão apresentados nas Figuras 5.53-5.55, para as condições de aumento de demanda de tráfego 0,40 e $60 \%$.

Os resultados obtidos para os modelos GALC e GASC em função das três restrições eletromagnéticas, parametrizada pelo aumento de demanda de tráfego, estão apresentados nas Figuras 5.56 e 5.57 e na Tabela 5.36 .

No modelo GALC, para minimizar a probabilidade de bloqueio, foi imposto um critério de parada mais rigoroso (ver Figura 5.56 (a)). Entretanto, o algoritmo necessita de tempos de simulação extremamente longos, inviabilizando a utilização do algoritmo em tempo real. Como solução, pode ser permitida a convergência para pontos de ótimo local, conforme apresentado pelo modelo GASC (ver Figura 5.57 (a)). Observe que o GASC verifica a inexistência de recursos disponíveis e decide pelo bloqueio da requisição utilizando um número reduzido de gerações. 


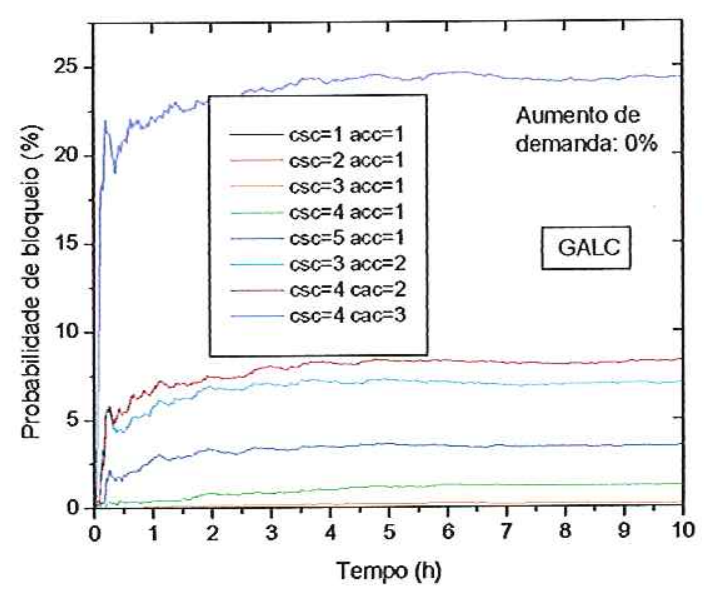

(a)

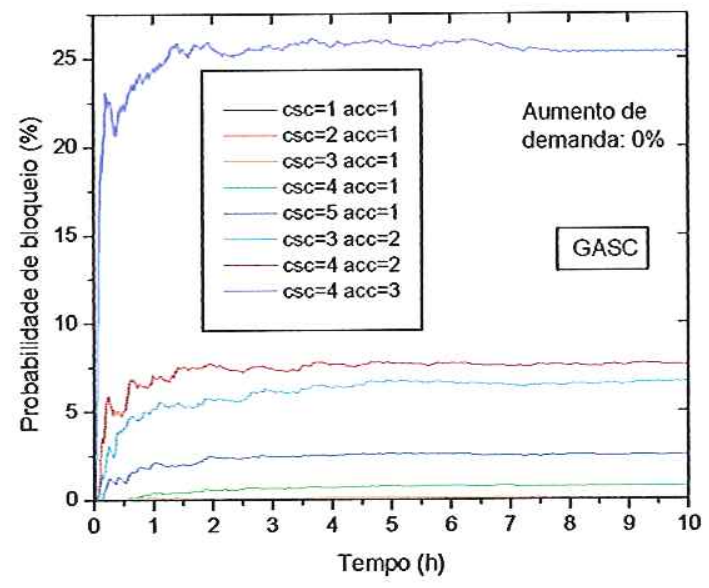

(b)

Figura 5.53: Probabilidade de bloqueio em função do tempo para diferentes restrições eletromagnéticas, considerando $0 \%$ de aumento na demanda de tráfego. Algoritmos: (a) GALC; e (b) GASC. No par (xy), $x$ representa a $C S C$ e $y$, a $A C C$.

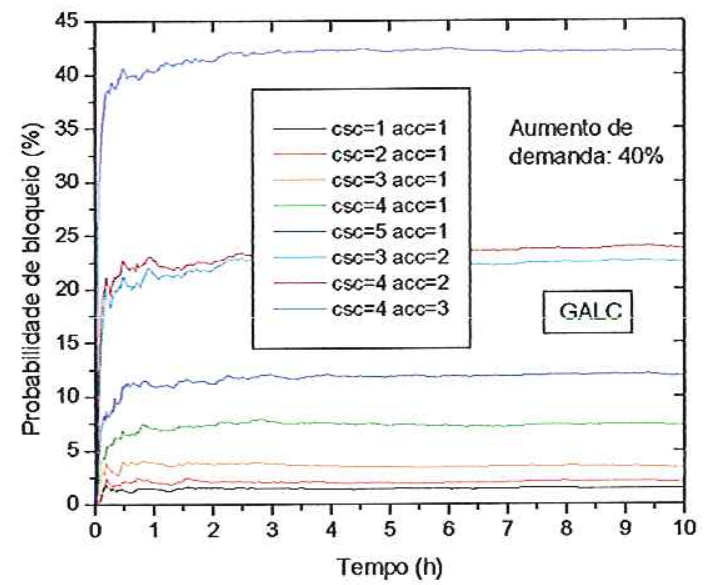

(a)

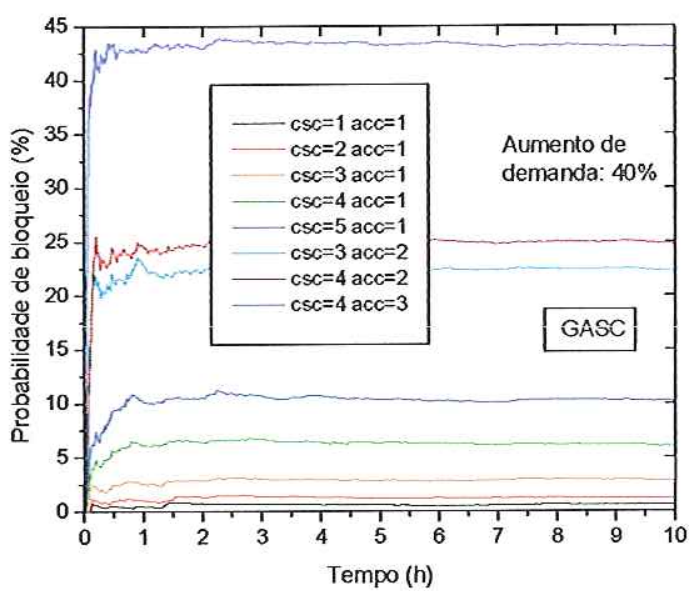

(b)

Figura 5.54: Probabilidade de bloqueio em função do tempo para diferentes restrições eletromagnéticas, considerando $40 \%$ de aumento na demanda de tráfego. Algoritmos: (a) GALC; e (b) GASC. No par (xy), $x$ representa a $C S C$ e $y$, a $A C C$. 


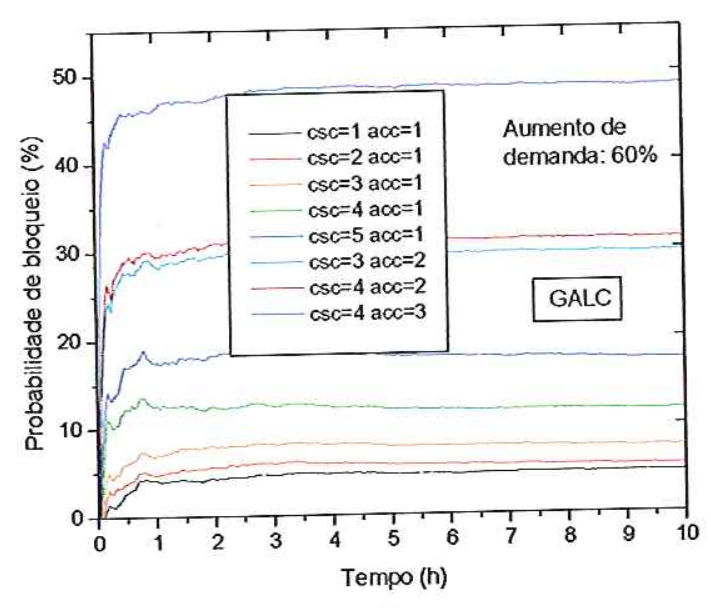

(a)

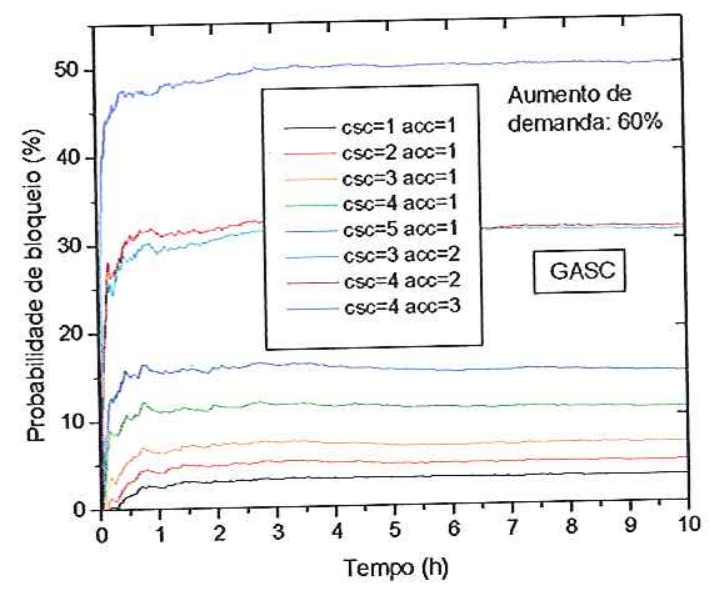

(b)

Figura 5.55: Probabilidade de bloqueio em função do tempo para diferentes restrições eletromagnéticas, considerando $60 \%$ de aumento na demanda de tráfego. Algoritmos: (a) GALC; e (b) GASC. No par ( $x y$ ), $x$ representa a $C S C$ e $y$, a $A C C$.

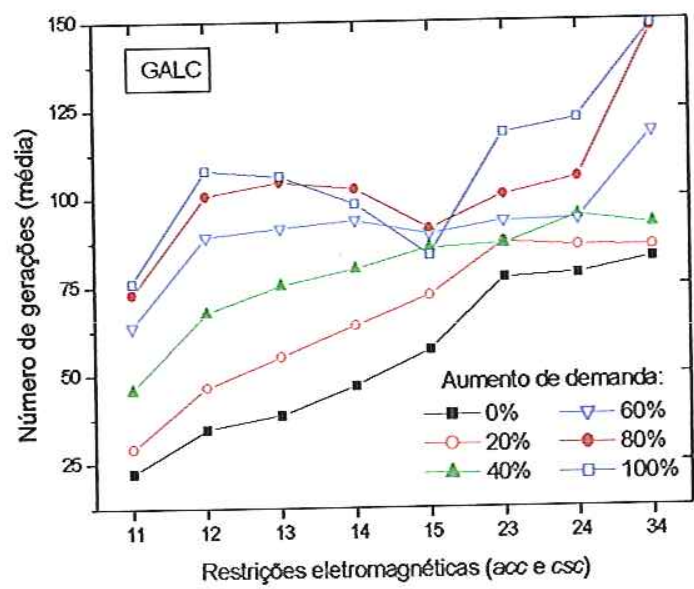

(a)

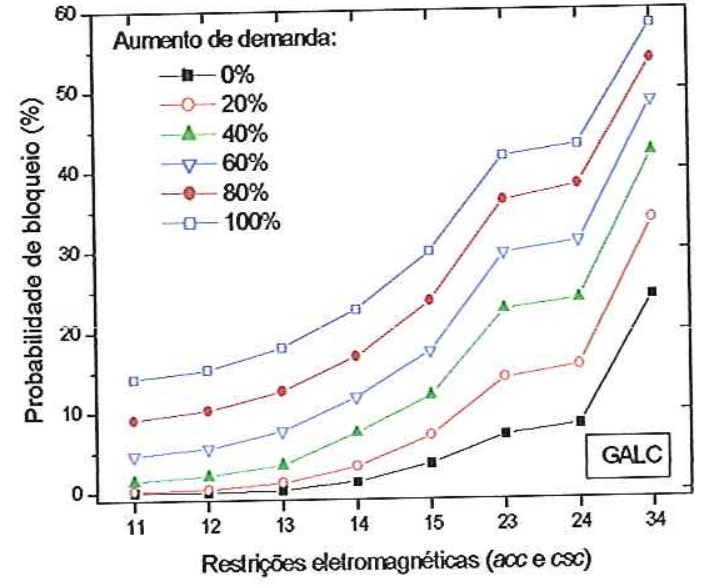

(b)

Figura 5.56: Algoritmo GALC: (a) Número de gerações; e (b) Probabilidade de bloqueio em função das restrições eletromagnéticas, considerando $0,20,40,80$ e $100 \%$ de aumento na demanda de tráfego. No par $(x y), x$ representa a $A C C$ e $y$, a $C S C$. 


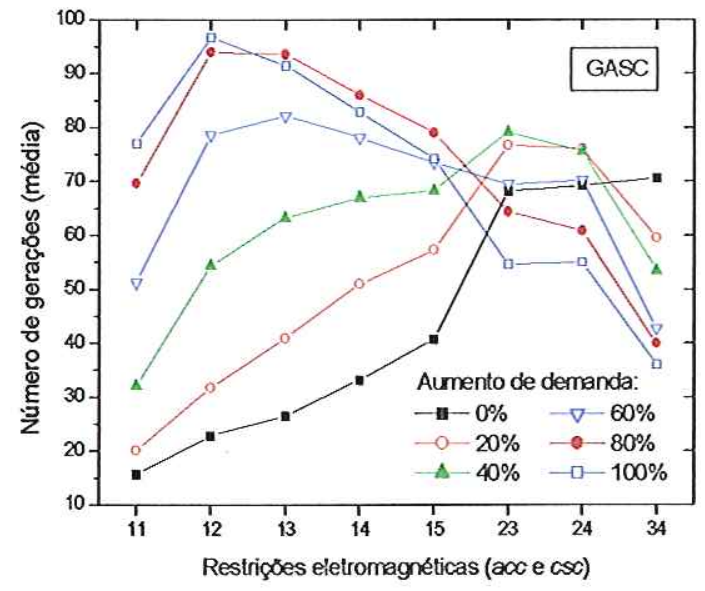

(a)

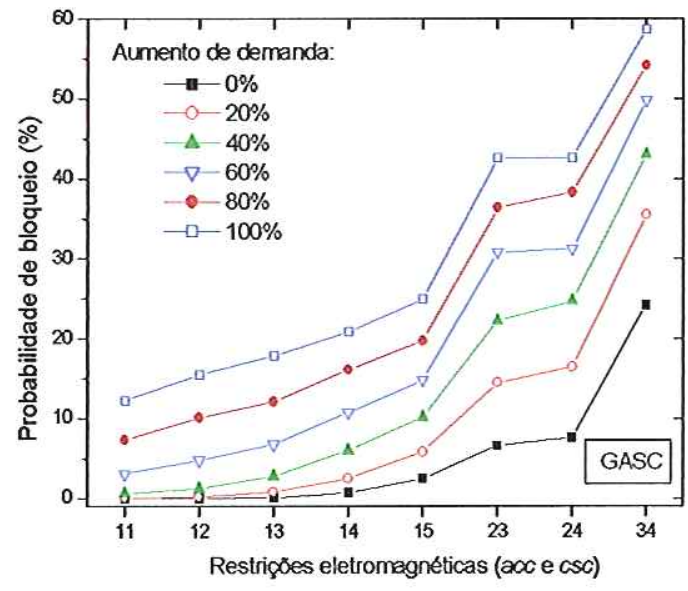

(b)

Figura 5.57: Algoritmo GALC: (a) Número de gerações; e (b) Probabilidade de bloqueio em função das restrições eletromagnéticas, considerando $0,20,40,80$ e $100 \%$ de aumento na demanda de tráfego. No par $(x y), x$ representa a $A C C$ e $y$, a $C S C$.

\subsubsection{Restrições Eletromagnéticas e Handoff}

Os próximos testes incluem o impacto das três restrições eletromagnéticas sobre a alocação de canais em um sistema celular operando com handoff. Em todos os exemplos foi considerada distribuição de tráfego heterogênea com média 91,83 chamadas por hora com $20 \%$ de taxa de handoff. O desempenho em termos da probabilidade de bloqueio para as novas chamadas e para o handoff está apresentado nas Figuras $5.58 \mathrm{e}$ 5.59 , e nas Tabelas 5.37 e 5.38, respectivamente. Os resultados numéricos mostram o impacto da ACC no desempenho do sistema. Quando a CSC limita somente os $(n-1)$ canais na própria célula, a ACC causa uma grande degradação no desempenho do sistema, pois torna indisponíveis os $(n-1)$ canais pertencentes à vizinhança da célula de referência. Considerando o desempenho do modelo para atendimento às novas solicitações, o GASC é superior ao GALC em todos os casos apresentados. A análise dos resultados numéricos apresentados na Figura 5.59 indica que a estratégia GASC exibe um desempenho ligeiramente melhor em relação ao handoff do que a estratégia GALC em condições de demanda de tráfego leve a moderado, caso a restrição canal adjacente seja unitária, $a c c=1$. Por exemplo, para $c s c=3 \mathrm{com} 20 \%$ de aumento de demanda de tráfego, a probabilidade de bloqueio de handoff para os dois modelos é $0,88 \%$. Para $60 \%$ de aumento de demanda de tráfego o bloqueio ao handoff para GALC é $0,18 \%$, enquanto para o esquema GASC é $0,33 \%$. Entretanto, considerando a restrição canal adjacente, $c c c=1, a c c=3, c s c=3$, e para $20 \%$ de aumento de demanda, os valores tornam-se $0,75 \%$ para o GASC e $0,92 \%$ para o GALC. Em $60 \%$ de aumento, os valores 
Tabela 5.36: Probabilidade de bloqueio dos algoritmos GALC e GASC em função das restrições canal adjacente e co-site, parametrizada pelo aumento de demanda de tráfego.

\begin{tabular}{|c|c|c|c|}
\hline \multirow{2}{*}{$\begin{array}{l}\text { Aumento de } \\
\text { tráfego (\%) }\end{array}$} & \multicolumn{3}{|c|}{ GALC — Probabilidade de Bloqueio (\%) } \\
\hline & $a c c=2, c s c=3$ & $a c c=2, c s c=4$ & $a c c=3, c s c=4$ \\
\hline 0 & 7,0053 & 8,2849 & 24,2730 \\
\hline 20 & 14,0813 & 15,5951 & 33,7700 \\
\hline 40 & 22,5643 & 23,8098 & 42,1034 \\
\hline 60 & 29,6137 & 31,0715 & 48,4687 \\
\hline 80 & 36,1986 & 38,0881 & 53,6348 \\
\hline 100 & 41,7343 & 43,0633 & 58,0824 \\
\hline Aumento de & \multicolumn{3}{|c|}{ GASC - Probabilidade de Bloqueio (\%) } \\
\hline tráfego $(\%)$ & $a c c=2, c s c=3$ & $a c c=2, c s c=4$ & $a c c=3, c s c=4$ \\
\hline 0 & 6,6584 & 7,5932 & 25,3342 \\
\hline 20 & 14,5032 & 16,4853 & 35,4967 \\
\hline 40 & 22,2687 & 24,7392 & 43,0420 \\
\hline 60 & 30,8514 & 31,2377 & 49,8144 \\
\hline 80 & 36,3937 & 38,2881 & 54,1501 \\
\hline 100 & 42,5914 & 42,6569 & 58,7097 \\
\hline
\end{tabular}

são $2,54 \%$ e 2,81\% para os modelos GASC e GALC, respectivamente. A média do número de gerações para convergência dos modelos em função do aumento da carga do tráfego para os casos analisados está apresentada na Figura 5.60.

Os resultados confirmam o grande impacto da $A C C$ no desempenho do sistema. Enquanto a $C S C$ limita apenas os canais na própria célula, a $A C C$ provoca uma grande degradação, visto que a alocação de um canal em uma célula torna indisponíveis $2 \times(a c c-1)$ canais pertencentes a cada uma das células vizinhas. A média do número de gerações necessárias para a convergência do algoritmo em função do aumento de demanda de tráfego está apresentada na Figura 5.60 e na Tabela 5.39, para os casos analisados.

O porcentual de ocupação média dos canais em função do aumento de demanda de tráfego para os algoritmos GASC e GALC está apresentado na Figura 5.61 e na Tabela 5.40, considerando as restrições EMC e taxa de handoff de $20 \%$.

\subsubsection{Falhas em Equipamentos}

Falhas em equipamentos durante o período normal de operação podem ocorrer nos sistemas de comunicações móveis. Uma típica falha de equipamento é tornar canais temporariamente indisponíveis. Um exemplo do impacto da falha de canal na proba- 


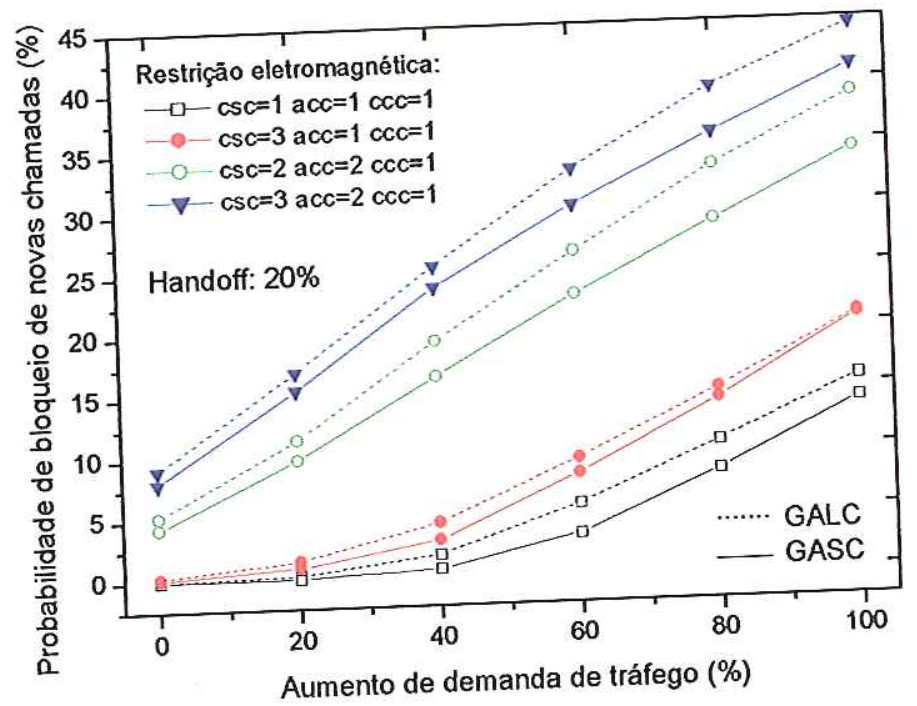

Figura 5.58: Probabilidade de bloqueio de novas chamadas em função do aumento de demanda de tráfego para os algoritmos GALC e GASC. Distribuição de tráfego heterogênea com média 91,83 chamadas por hora, $20 \%$ de taxa de handoff e incluindo restrições eletromagnéticas.

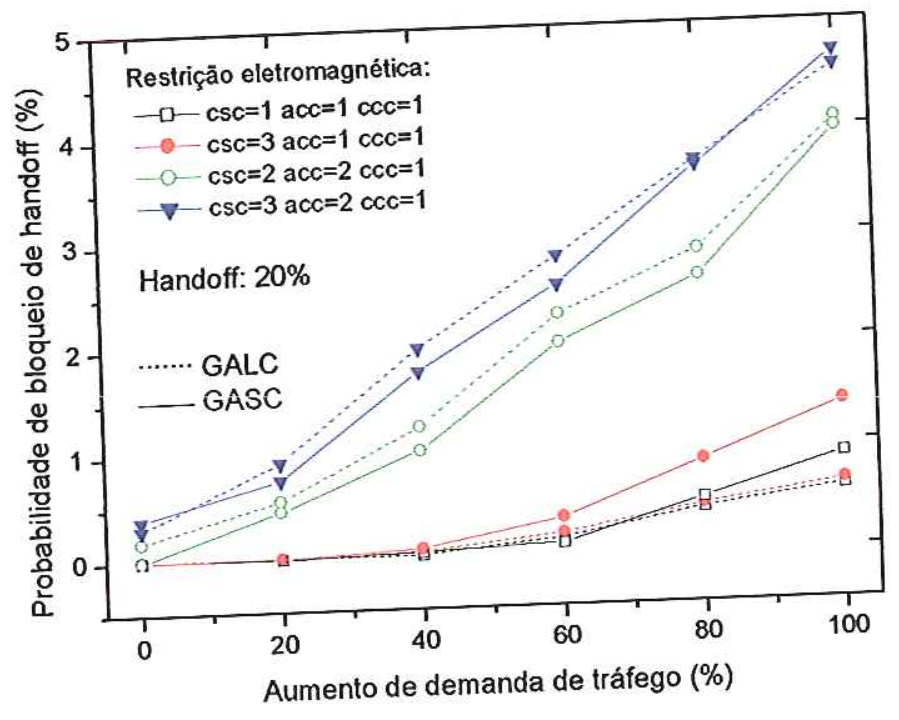

Figura 5.59: Probabilidade de bloqueio de handoff em função do aumento de demanda de tráfego para os algoritmos GALC e GASC. Distribuição de tráfego heterogênea com média 91,83 chamadas por hora, $20 \%$ de taxa de handoff e incluindo restrições eletromagnéticas. 


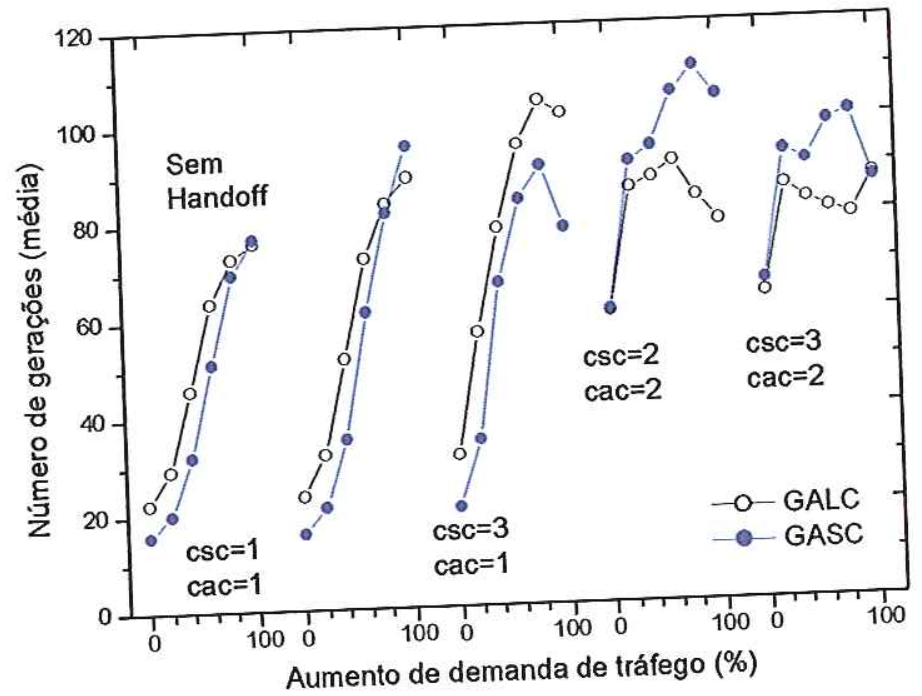

Figura 5.60: Numero de gerações em função do aumento de demanda de tráfego para os algoritmos GALC e GASC. Distribuição de tráfego heterogênea com média 91,83 chamadas por hora, $20 \%$ de taxa de handoff e incluindo restrições eletromagnéticas.

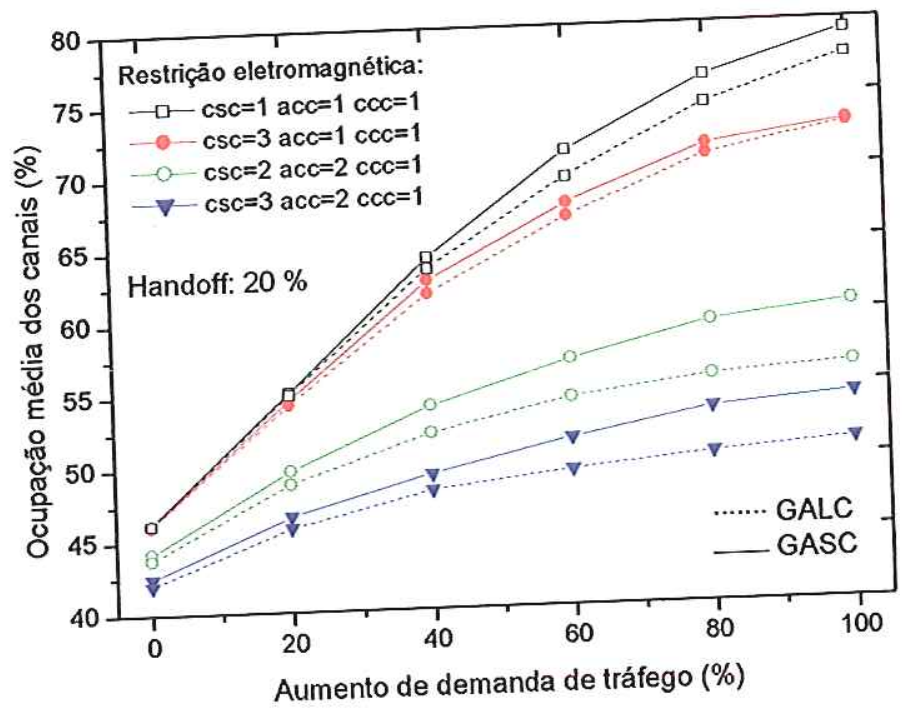

Figura 5.61: Ocupação média dos canais (\%) em função do aumento de demanda de tráfego para os algoritmos GALC e GASC, considerando as restrições eletromagnéticas e taxa de handoff de $20 \%$. 
Tabela 5.37: Probabilidade de bloqueio de novas chamadas (\%) dos algoritmos GALC e GASC. Tráfego heterogêneo com média 91,83 chamadas por hora, incluindo $20 \%$ de handoff e restrições eletromagnéticas.

\begin{tabular}{|c|c|c|c|c|c|c|c|c|}
\cline { 2 - 8 } \multicolumn{1}{c|}{} & \multicolumn{6}{c|}{ Probabilidade de Bloqueio de Novas Chamadas (\%) } \\
\hline \multirow{2}{*}{$\begin{array}{c}\text { Acres. } \\
\text { tráfego } \\
\text { (\%) }^{(1)}\end{array}$} & \multicolumn{3}{c|}{$c s c=1$} & \multicolumn{4}{c|}{$c s c=3$} & \multicolumn{3}{c|}{$c s c=2$} & \multicolumn{2}{c|}{$c s c=3$} \\
\cline { 2 - 9 } & GALC & GASC & GALC & GASC & GALC & GASC & GALC & GASC \\
\hline \hline 0 & 0,0000 & 0,0000 & 0,2784 & 0,1325 & 5,2573 & 4,2915 & 9,1025 & 8,0217 \\
20 & 0,2553 & 0,0185 & 1,4730 & 0,9290 & 11,4127 & 9,7762 & 16,9627 & 15,4933 \\
40 & 1,7244 & 0,5263 & 4,3560 & 2,9509 & 19,2640 & 16,3516 & 25,3777 & 23,6486 \\
60 & 5,6181 & 3,1690 & 9,3423 & 8,1060 & 26,3062 & 22,7520 & 33,0610 & 30,0855 \\
80 & 10,5039 & 8,1831 & 14,7933 & 13,9595 & 33,1079 & 28,6217 & 39,5212 & 35,7679 \\
100 & 15,5886 & 13,761 & 20,7500 & 20,6047 & 38,7434 & 34,2177 & 44,4344 & 41,0553 \\
\hline
\end{tabular}

(1) Tráfego heterogêneo média 91,83 chamadas por hora, taxa de handoff de $20 \%$.

bilidade de bloqueio para os esquemas GALC e GASC está apresentado nas Figuras 5.62-5.65. São consideradas duas distribuições de demanda de tráfego heterogêneo com médias 91,83 chamadas por hora (Figura 5.62 e Figura 5.64) e 106,53 chamadas por hora (Figura 5.63 e Figura 5.65), com aumento de tráfego de 80 e 60 por cento, respectivamente. Inicialmente, o sistema operava com 70 canais e durante o período de falha, das 10 às $15 \mathrm{~h}$, sete canais, escolhidos aleatoriamente, permaneceram temporariamente indisponíveis para uso em cada célula. Comparando os resultados mostrados na Tabela 5.41, os modelos de algoritmos de alocação de canal demonstram certo grau de robustez para situação de falha de canais e sugerem que são capazes de se adaptar às configurações do ambiente. Particularmente, as variações no esquema GALC foram menores do que aquelas do esquema GASC.

Para testar a utilidade do método adaptativo foi considerado um período de falha. O esquema GASC, com e sem o mecanismo adaptativo é comparado. Os resultados da probabilidade de bloqueio para novas chamadas e handoff estão apresentados nas Figuras 5.66 e 5.67, respectivamente. Foram consideradas duas distribuições de demanda de tráfego heterogêneo, médias 91,83 e 106,53 chamadas por hora, com aumento de tráfego de 80 e 60 por cento, respectivamente.

Antes da ocorrência da falha, o sistema adaptativo apresenta desempenho melhor do que o não-adaptativo. Por exemplo, às 10 horas as probabilidades de bloqueio para as distribuições de tráfego baixa e elevada são $7,73 \%$ e $13,62 \%$, visto que no esquema não-adaptativo são $10,25 \%$ e $15,76 \%$, respectivamente. No término do período da falha (às 15 horas), o sistema adaptativo apresenta probabilidades de bloqueio de 


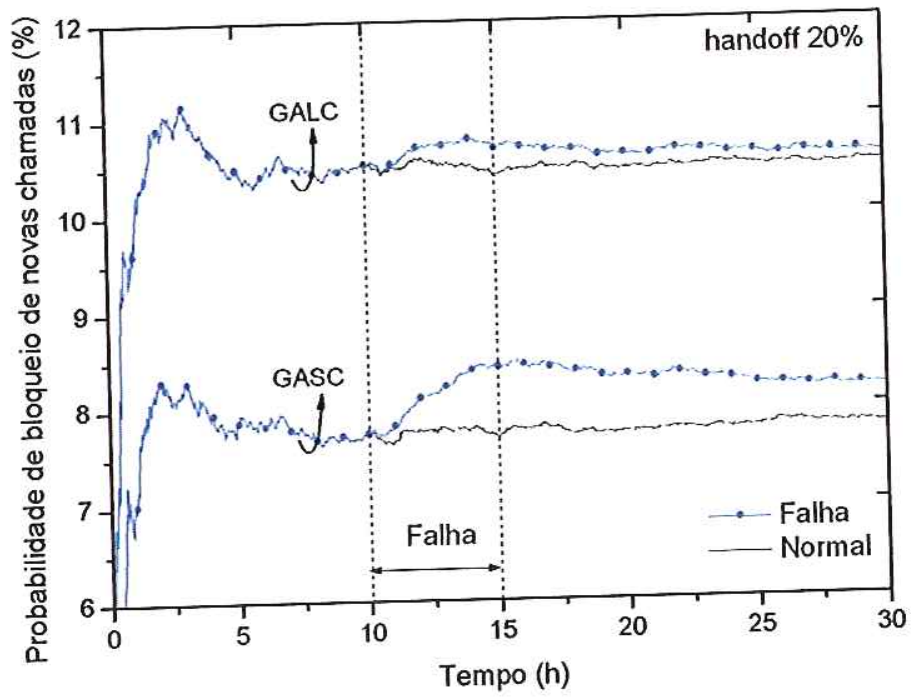

Figura 5.62: Robustez dos algoritmos GALC e GASC a falhas nos canais: operação normal e ocorrência de falha em 7 canais por célula entre 10 e $15 \mathrm{~h}$. Tráfego heterogêneo, média 91,83 chamadas por hora com $80 \%$ de acréscimo.

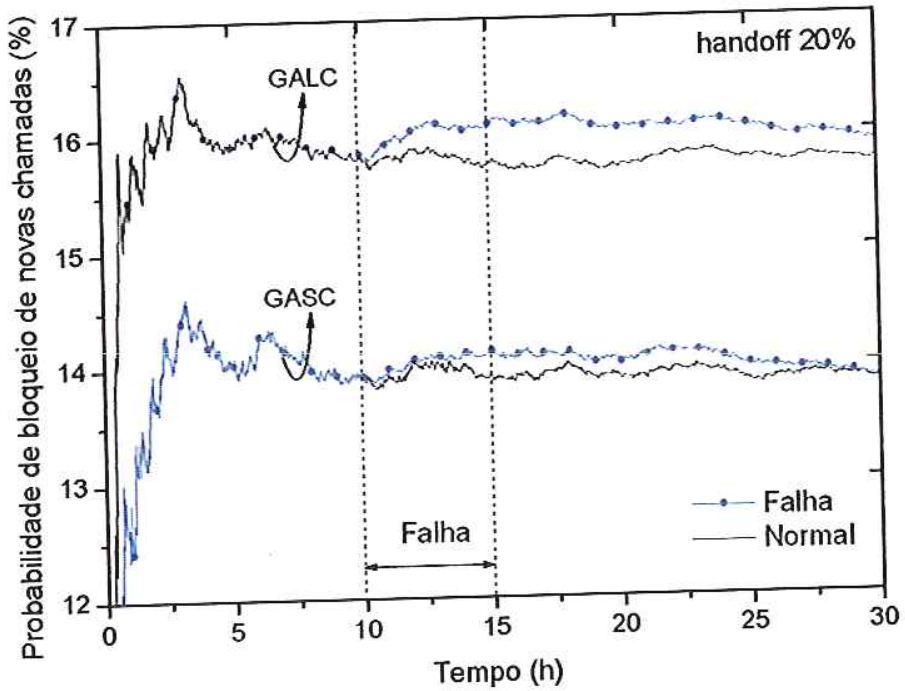

Figura 5.63: Robustez dos algoritmos GALC e GASC a falhas nos canais: operação normal e ocorrência de falha em 7 canais por célula entre 10 e $15 \mathrm{~h}$. Tráfego heterogêneo, média 106,53 chamadas por hora com $60 \%$ de acréscimo. 


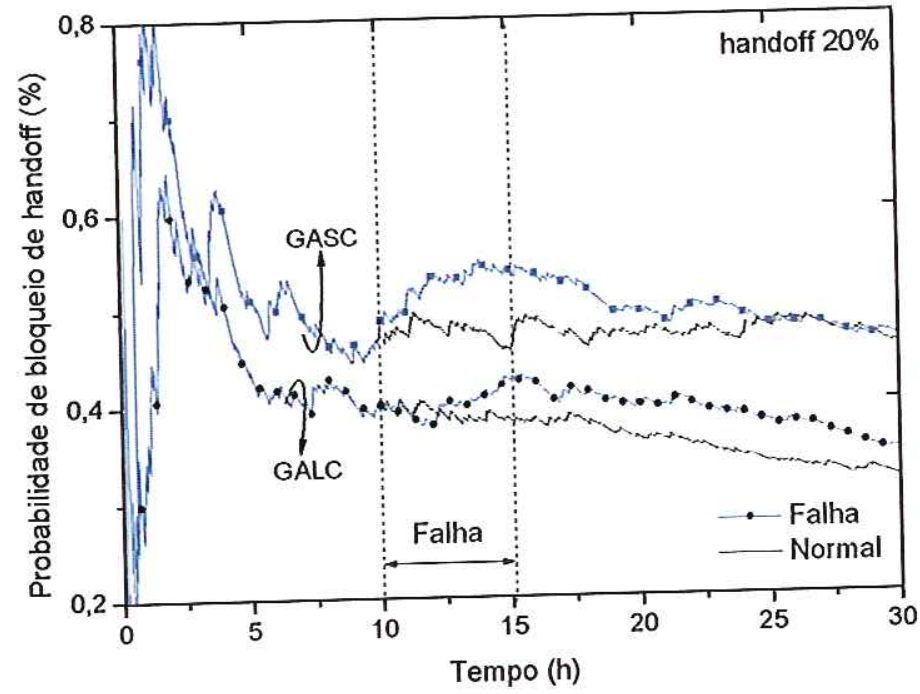

Figura 5.64: Probabilidade de bloqueio de handoff dos algoritmos GALC e GASC sob falhas em canais: operação normal e ocorrência de falha em 7 canais por célula entre 10 e 15 h. Tráfego heterogêneo, média 91,83 chamadas por hora com $80 \%$ de acréscimo.

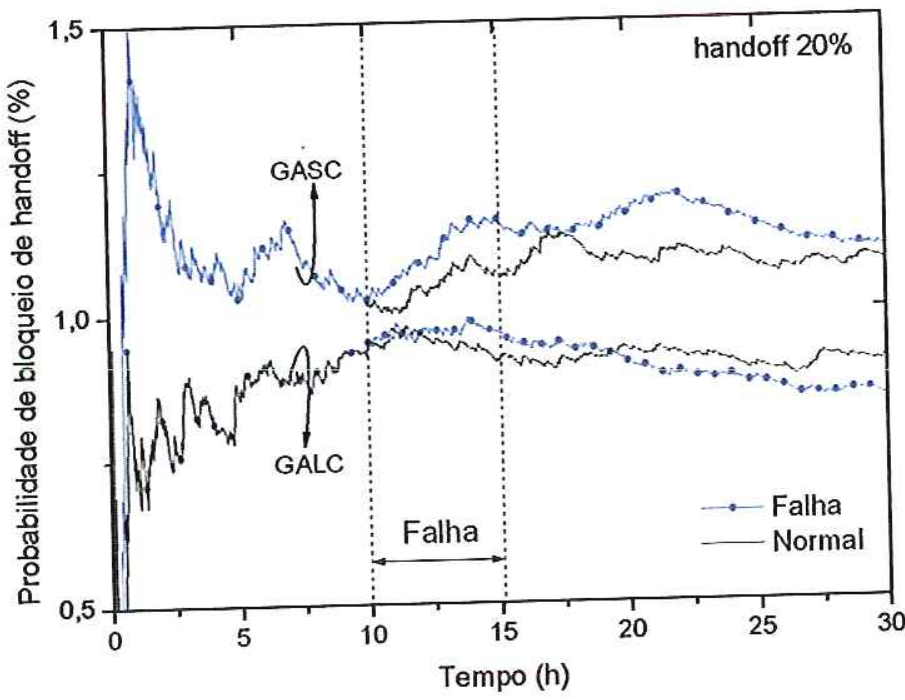

Figura 5.65: Probabilidade de bloqueio de handoff dos algoritmos GALC e GASC sob falhas em canais: operação normal e ocorrência de falha em 7 canais por célula entre 10 e 15 h. Tráfego heterogêneo, média 106,53 chamadas por hora com $60 \%$ de acréscimo. 


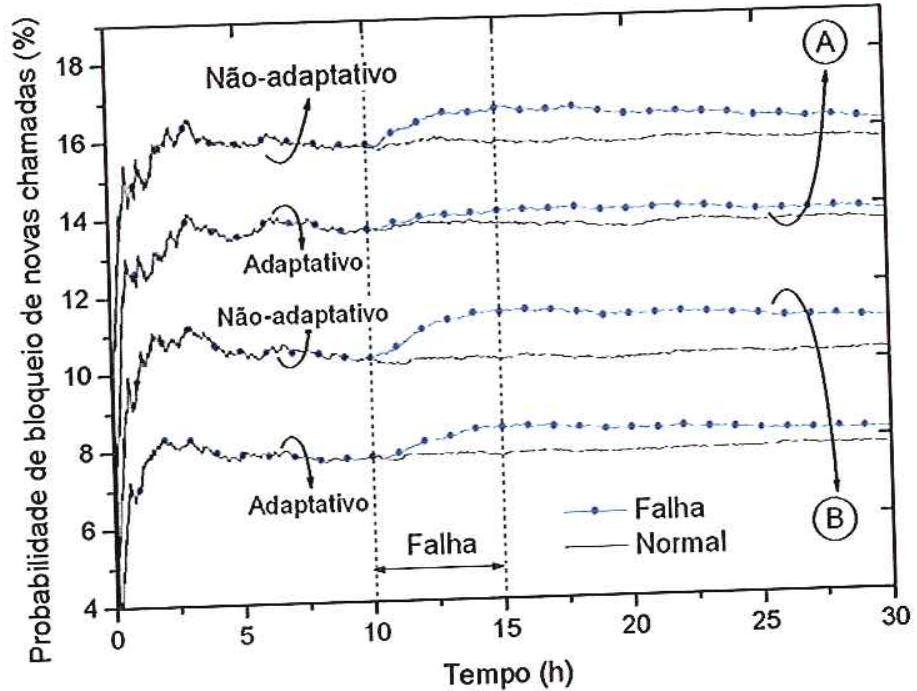

Figura 5.66: Robustez do algoritmo GASC a falhas em canais: operação normal e falhas em 7 canais no intervalo de 10 às $15 \mathrm{~h}$. Tráfego heterogêneo com médias: (A) 106,53 ; e (B) 91,83 chamadas por hora, com aumento de 60 e 80 por cento, respectivamente.

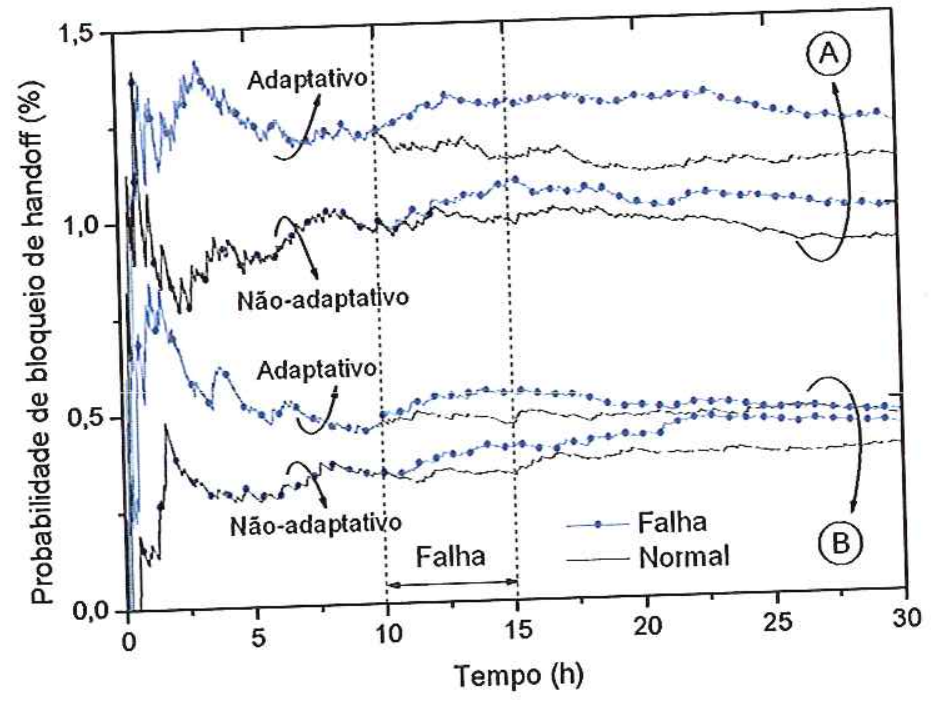

Figura 5.67: Robustez do algoritmo GASC a falhas em canais: operação normal e falhas em 7 canais no intervalo de 10 às $15 \mathrm{~h}$. Tráfego heterogêneo com médias: (A) 106,53 ; e (B) 91,83 chamadas por hora, com aumento de 60 e 80 por cento, respectivamente. 
Tabela 5.38: Probabilidade de bloqueio de handoff (\%) dos algoritmos GALC e GASC. Tráfego heterogêneo com média 91,83 chamadas por hora, incluindo $20 \%$ de handoff e restrições eletromagnéticas.

\begin{tabular}{|c|c|c|c|c|c|c|c|c|}
\cline { 2 - 8 } \multicolumn{1}{c|}{} & \multicolumn{6}{c|}{ Probabilidade de Bloqueio de Handoff (\%) } \\
\hline Acres. & \multicolumn{3}{c|}{$a c c=1$} & \multicolumn{4}{c|}{$a c c=2$} \\
\cline { 2 - 9 } tráfego & \multicolumn{3}{c|}{$c s c=1$} & \multicolumn{2}{c|}{$c s c=3$} & \multicolumn{2}{c|}{$c s c=2$} & \multicolumn{2}{c|}{$c s c=3$} \\
\cline { 2 - 9 }$(\%)^{(1)}$ & GALC & GASC & GALC & GASC & GALC & GASC & GALC & GASC \\
\hline \hline 0 & 0,0000 & 0,0000 & 0,0052 & 0,0000 & 0,1800 & 0,0000 & 0,2990 & 0,3915 \\
20 & 0,0043 & 0,0000 & 0,0088 & 0,0088 & 0,5547 & 0,4555 & 0,9207 & 0,7530 \\
40 & 0,0112 & 0,0371 & 0,0425 & 0,0687 & 1,2280 & 1,0035 & 1,9701 & 1,7523 \\
60 & 0,1410 & 0,0909 & 0,1799 & 0,3299 & 2,2609 & 1,9904 & 2,8150 & 2,5442 \\
80 & 0,3940 & 0,4853 & 0,4240 & 0,8444 & 2,8458 & 2,5912 & 3,6936 & 3,6411 \\
100 & 0,5727 & 0,8816 & 0,6205 & 1,3731 & 4,0557 & 3,9669 & 4,5599 & 4,6933 \\
\hline
\end{tabular}

(1) Tráfego heterogêneo média 91,83 chamadas por hora, taxa de handoff de $20 \%$.

Tabela 5.39: Numero de gerações para para os algoritmos GALC e GASC. Tráfego heterogêneo com média 91,83 chamadas por hora, incluindo $20 \%$ de taxa de handoff e restrições eletromagnéticas.

\begin{tabular}{|c|c|c|c|c|c|c|}
\hline \multirow{4}{*}{$\begin{array}{c}\text { Acres. } \\
\text { tráfego } \\
(\%)\end{array}$} & \multicolumn{6}{|c|}{ Número de Gerações para Convergência (média) } \\
\hline & \multicolumn{6}{|c|}{$a c c=1$} \\
\hline & \multicolumn{2}{|c|}{$c s c=1^{(1)}$} & \multicolumn{2}{|c|}{$c s c=1$} & \multicolumn{2}{|c|}{$c s c=3$} \\
\hline & GALC & GASC & GALC & GASC & GALC & GASC \\
\hline 0 & 22,35 & 15,64 & 23,52 & 15,84 & 31,27 & 20,48 \\
\hline 20 & 29,21 & 20,00 & 32,08 & 21,21 & 56,51 & 34,33 \\
\hline 40 & 45,82 & 31,99 & 51,79 & 35,19 & 78,01 & 66,69 \\
\hline 60 & 63,75 & 51,19 & 72,41 & 61,35 & 95,12 & 83,78 \\
\hline 80 & 72,87 & 69,53 & 83,60 & 81,76 & 104,09 & 90,58 \\
\hline 100 & 76,02 & 76,92 & 88,95 & 95,41 & 101,36 & 77,78 \\
\hline \multirow{3}{*}{$\begin{array}{c}\text { Acres. } \\
\text { tráfego } \\
(\%)\end{array}$} & \multicolumn{6}{|c|}{$a c c=2$} \\
\hline & \multicolumn{2}{|c|}{$c s c=2^{(1)}$} & \multicolumn{2}{|c|}{$c s c=2$} & \multicolumn{2}{|c|}{$c s c=3$} \\
\hline & GALC & GASC & GALC & GASC & GALC & GASC \\
\hline 0 & 56,97 & 40,66 & 60,27 & 60,57 & 63,43 & 66,01 \\
\hline 20 & 72,26 & 57,27 & 85,71 & 91,07 & 85,54 & 92,55 \\
\hline 40 & 85,79 & 68,26 & 87,73 & 94,13 & 82,55 & 90,49 \\
\hline 60 & 89,68 & 73,42 & 90,94 & 105,17 & 80,53 & 98,53 \\
\hline 80 & 91,16 & 78,93 & 83,70 & 110,38 & 79,16 & 100,35 \\
\hline 100 & 83,77 & 74,23 & 78,60 & 104,37 & 87,29 & 86,58 \\
\hline
\end{tabular}

(1) Sem handoff. 
Tabela 5.40: Ocupação média dos canais (\%) em função da demanda de tráfego para o algoritmo GASC, considerando restrições eletromagnéticas e taxa de handoff de $20 \%$.

\begin{tabular}{|c|c|c|c|c|c|c|}
\cline { 2 - 7 } \multicolumn{1}{c|}{} & \multicolumn{4}{c|}{ Ocupação Média dos Canais (\%) } \\
\cline { 2 - 7 } \multicolumn{1}{c|}{} & \multicolumn{3}{c|}{ GALC } & \multicolumn{3}{c|}{ GASC } \\
\hline Aumento de & $c s c=3$ & $c s c=2$ & $c s c=3$ & $c s c=3$ & $c s c=2$ & $c s c=3$ \\
tráfego (\%) & $a c c=1$ & $a c c=2$ & $a c c=2$ & $a c c=1$ & $a c c=2$ & $a c c=2$ \\
\hline \hline 0 & 46,0459 & 43,7469 & 41,9714 & 46,1132 & 44,1938 & 42,4714 \\
20 & 54,3408 & 48,8459 & 45,7857 & 54,6265 & 49,7510 & 46,5959 \\
40 & 61,7469 & 52,1224 & 48,1755 & 62,6540 & 54,0061 & 49,2949 \\
60 & 66,8183 & 54,3153 & 49,3367 & 67,7296 & 56,9479 & 51,5398 \\
80 & 70,8632 & 55,6316 & 50,2979 & 71,5602 & 59,3765 & 53,4306 \\
100 & 72,8388 & 56,3010 & 51,0704 & 72,9795 & 60,4887 & 54,2020 \\
\hline
\end{tabular}

(1) 75 indivíduos, 50 gerações, 70 canais, taxa de handoff de $20 \%$.

Tabela 5.41: Robustez dos algoritmos GALC e GASC a falhas nos canais: operação normal e ocorrência de falha em 7 canais por célula entre 10 e $15 \mathrm{~h}$.

\begin{tabular}{|c|c|c|c|c|c|c|}
\cline { 2 - 7 } \multicolumn{1}{c|}{} & \multicolumn{3}{c|}{ Probabilidade de Bloqueio de Novas Chamadas (\%) } \\
\cline { 2 - 7 } \multicolumn{1}{c|}{} & \multicolumn{3}{|c|}{ GALC } & \multicolumn{3}{c|}{ GASC } \\
\cline { 2 - 7 } \multicolumn{1}{c|}{} & $10 \mathrm{~h}$ & \multicolumn{2}{|c|}{$15 \mathrm{~h}$} & $10 \mathrm{~h}$ & \multicolumn{2}{c|}{$15 \mathrm{~h}$} \\
\hline \hline Tráfego & Normal & Normal & Falha & Normal & Normal & Falha \\
\hline$\Lambda_{1}$ & 10,5039 & 10,3981 & 10,6839 & 7,7389 & 7,6920 & 8,4239 \\
$\Lambda_{2}$ & 15,8098 & 15,7552 & 16,0888 & 13,9104 & 13,9109 & 14,1410 \\
\hline \multicolumn{5}{|c|}{ Probabilidade de Bloqueio de Handoff (\%) } \\
\cline { 2 - 7 } \multicolumn{1}{|c|}{ GALC } & \multicolumn{4}{c|}{ GASC } \\
\cline { 2 - 7 } & $10 \mathrm{~h}$ & \multicolumn{3}{c|}{$15 \mathrm{~h}$} & $10 \mathrm{~h}$ & \multicolumn{2}{c|}{$15 \mathrm{~h}$} \\
\hline \hline Tráfego & Normal & Normal & Falha & Normal & Normal & Falha \\
\hline \hline$\Lambda_{1}$ & 0,4009 & 0,3833 & 0,42336 & 0,4734 & 0,4563 & 0,5387 \\
$\Lambda_{2}$ & 0,9422 & 0,9157 & 0,96596 & 1,0188 & 1,0645 & 1,1587 \\
\hline
\end{tabular}

$\Lambda_{1}: 91,83$ chamadas por hora com acréscimo de $80 \%$.

$\Lambda_{2}: 106,53$ chamadas por hora com acréscimo de $60 \%$. 
Tabela 5.42: Robustez do algoritmo GASC adaptativo a falhas nos canais: operação normal e ocorrência de falha em 7 canais por célula entre 10 e $15 \mathrm{~h}$.

\begin{tabular}{|c|c|c|c|c|c|c|}
\hline & \multicolumn{6}{|c|}{ GASC - Probabilidade de Bloqueio de Novas Chamadas (\%) } \\
\hline & \multicolumn{3}{|c|}{ Não Adaptativo } & \multicolumn{3}{|c|}{ Adaptativo } \\
\hline & $10 \mathrm{~h}$ & \multicolumn{2}{|c|}{$15 \mathrm{~h}$} & $10 \mathrm{~h}$ & \multicolumn{2}{|c|}{$15 \mathrm{~h}$} \\
\hline Tráfego & Normal & Normal & Falha & Normal & Normal & Falha \\
\hline 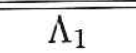 & 10,2524 & 10,1755 & 11,4076 & 7,7389 & 7,6920 & 8,4239 \\
\hline \multirow[t]{4}{*}{$\Lambda_{2}$} & 15,7604 & 15,8039 & 16,6553 & 13,6242 & 13,6949 & 14,0196 \\
\hline & \multicolumn{6}{|c|}{ GASC - Probabilidade de Bloqueio de Handoff (\%) } \\
\hline & \multicolumn{3}{|c|}{ Não Adaptativo } & \multicolumn{3}{|c|}{ Adaptativo } \\
\hline & $10 \mathrm{~h}$ & \multicolumn{2}{|c|}{$15 \mathrm{~h}$} & $10 \mathrm{~h}$ & \multicolumn{2}{|c|}{$15 \mathrm{~h}$} \\
\hline Tráfego & Normal & Normal & Falha & Normal & Normal & Falha \\
\hline$\Lambda_{1}$ & 0,3347 & 0,3262 & 0,3948 & 0,4734 & 0,4563 & 0,5387 \\
\hline$\Lambda_{2}$ & 0,9936 & 0,9866 & 1,0854 & 1,2298 & 1,1434 & 1,3020 \\
\hline
\end{tabular}

$\Lambda_{1}: 91,83$ chamadas por hora com acréscimo de $80 \%$.

$\Lambda_{2}: 106,53$ chamadas por hora com acréscimo de $60 \%$. 
$8,42 \%$ e $14,01 \%$ para tráfegos baixo e elevado, respectivamente. Os resultados representam um aumento de $9,51 \%$ e de $2,37 \%$ quando comparados à operação normal. Na mesma situação, no sistema não-adaptativo as probabilidades de bloqueio são 11,40\% e $16,65 \%$, representando um aumento de $12,10 \%$ e $5,38 \%$. Após o período da falha, o sistema adaptativo necessita de um período de tempo mais curto para se estabilizar. Os resultados evidenciam o potencial do comportamento dinâmico do algoritmo adaptativo. Ambos apresentam probabilidades de bloqueio de handoff similares. Antes da ocorrência da falha, às 10 horas, o sistema adaptativo apresenta probabilidades de bloqueio de $0,47 \%$ e $1,22 \%$, e o não-adaptativo, $0,33 \%$ e $0,99 \%$ para as demandas de tráfego baixa e elevada, respectivamente. No término do período de falha (às 15 horas) o esquema adaptativo apresenta probabilidades de bloqueio de $0,53 \%$ e de $1,30 \%$, enquanto o não-adaptativo apresenta $0,39 \%$ e $1,08 \%$ para as demandas de tráfego baixa e elevada, respectivamente.

\subsection{Rede Híbrida Brasileira Óptica e Via Satélite}

As redes de telecomunicações via satélite operam recebendo sinais de rádio transmitidos por uma estação terrestre e retransmitindo-os para uma outra estação terrestre. Geralmente, os satélites de comunicação operam a partir de órbita geoestacionária, uma órbita equatorial com um período de 24 horas, tal que o satélite esteja sempre na mesma posição em relação à superfície terrestre [168]. Devido à distância geoestacionária, $35.800 \mathrm{~km}$, uma comunicação via satélite acrescenta ao sinal um atraso de $250 \mathrm{~ms}$, aproximadamente. Este atraso pode comprometer a qualidade de ligações telefônicas ou sistemas de vídeo interativo. Por outro lado, as redes via satélite permitem acesso de regiões inacessíveis às redes de telecomunicações globais. São elas as regiões que tornam inviável o uso de cabos ou enlaces de microondas com várias estações. Dependendo do tipo de serviço, as estações terrestres podem ser instaladas rapidamente, tornando os satélites úteis para permitir comunicações em períodos limitados, como no caso de eventos especiais ou desastres [168].

Como hoje em dia as redes são interligadas, o algoritmo genético proposto gerencia simultaneamente a demanda de tráfego nas duas redes, óptica e via satélite, abordadas integradamente. A probabilidade de bloqueio é minimizada considerando características das duas redes. Os resultados numéricos indicam a aplicabilidade da abordagem proposta na gerência integrada de redes distintas, identificando rotas e dispositivos mais utilizados. 


\subsubsection{Requisitos da Rede Híbrida}

Nas simulações foi utilizada uma rede de telecomunicações via satélite cobrindo o território brasileiro, combinando rede óptica com rede via satélite, conforme ilustrado na Figura. 5.68. Em parte do território há somente estações terrestres da rede via satélite. É uma solução que apresenta melhor custo-benefício devido à extensão e presença de regiões isoladas das metrópoles. As principais regiões destas localidades estão equipadas com estações terrestres. A comunicação pode ser realizada entre as estações terrestres diretamente via satélite, ou entre qualquer nó da rede óptica por meio de estações terrestres localizadas em 5 capitais do país com nós roteadores destacados na Figura 5.68. No sentido contrário, estes nós roteadores permitem o acesso de tráfego de qualquer nó pertencente à rede óptica, a qualquer localidade servida por comunicação via satélite.

A rede óptica é formada por 44 nós roteadores e 56 enlaces e conecta-se à rede de satélite por meio de 5 estações terrestres estrategicamente localizadas. Os enlaces da rede óptica apresentam distribuição heterogênea de comprimentos de onda e dispõe de $W=4$ comprimentos de onda, exceto o anel formado pelos nós $21,22,29,30,31$ e 32 , que dispõem de $W=8$. A banda básica é de $2,5 \mathrm{Gbps}$, com taxa total de $10 \mathrm{Gbps}$. Em cada comprimento de onda podem ser agregadas até $g=4$ sub-bandas.

A rede de satélite é formada por 14 estações terrestres, das quais 5 estão interligadas à rede óptica. As estações são equipadas com transceptores digitais com 4 canais de 2,5 Gbps. Cada canal pode ser agregado em $g=4$ sub-bandas, com banda básica de 622 Mbps. A comunicação entre estações é realizada por meio de um enlace englobando um satélite geoestacionário.

Em relação à largura de faixa, enquanto a rede óptica pode apresentar transparência e extensa largura de faixa até $10 \mathrm{Gbps}$, os rádios digitais do satélite operam com taxa máxima total de 2,5 Gbps. As requisições para os nós das estações terrestres não podem exceder a taxa de transmissão máxima de 2,5 Gbps. Foram colocados à disposição 4 transceptores por estação terrestre, para os quais são permitidas taxas de transmissão múltiplas de $622 \mathrm{Mbps}$. Neste nosso estudo preliminar consideramos que o enlace via satélite satisfaz as condições mínimas de potência de sinal e relação sinal-ruído.

A distribuição de tráfego é dinâmica, heterogênea e proporcional ao número de habitantes das regiões atendidas pelos nós roteadores, $H_{j}$, conforme apresentado na Tabela 5.43. A probabilidade de um nó ser escolhido para oferecer tráfego à rede, $P_{o}$, é dada pelo percentual do número de habitantes da região em relação ao total de 
habitantes do país,

$$
P_{o}=\frac{H_{o}}{\sum_{n}^{N} H_{n}} .
$$

Definido o nó origem, a probabilidade de escolha de um nó destino, $P_{d}$, é determinada pelo percentual de habitantes remanescentes,

$$
P_{d}^{(j)}=\frac{H_{j}}{\sum_{n, H_{o}=0}^{N} H_{n}} .
$$

A análise dos resultados da rede híbrida de telecomunicações brasileira foi dividida em redes óptica e via satélite. Ainda, foi incluída uma subdivisão no sistema de comunicações via satélite, denominada rede auxiliar. A rede auxiliar é formada pelos enlaces via satélite entre as estações terrestres que estão ligadas à rede óptica. Na rede auxiliar, a taxa de transmissão é limitada a 2,5 Gbps e o sinal é afetado pelo atraso de propagação. Assim, o algoritmo RWA deverá oferecer tráfego a esta rede somente quando não existirem recursos disponíveis na rede óptica, ou em condição de falha em equipamentos ou perda de enlaces. Desta forma, a não ser excepcionalmente, o tráfego deve ser atendido por caminhos de menor atraso de propagação. No caso de caminhos envolvendo enlace via satélite, o atraso a que o sinal está sujeito está dentro do valor admissível.

\subsubsection{Resultados Numéricos}

A probabilidade de bloqueio para a rede nacional em função da demanda de tráfego está apresentada na Figura 5.69 (a). O desempenho para a rede equipada com roteadores com capacidade de agregação plena WGXC está apresentado na Figura 5.69 (b). A probabilidade de bloqueio para duas configurações de rede com agregação esparsa, realizada por meio de comutadores com agregação restrita WSXC e plena WGXC, está apresentada na Figura 5.70. Os resultados numéricos correspondentes estão exibidos na Tabela 5.44.

O desempenho em relação à probabilidade de bloqueio global é superior utilizando os modelos agregação de tráfego. Por exemplo, considerando uma demanda de tráfego oferecido de 4 ( $\times 5,3$ erlangs), as probabilidades de bloqueio para a arquitetura de rede óptica sem e com agregação são $6,77 \%$ e $0,47 \%$. Se o tráfego for 8 ( $\times 5,3$ erlangs), as probabilidades de bloqueio são $26,06 \%$ e $6,77 \%$, respectivamente. Estes resultados representam uma melhoria de $93 \%$ e $74 \%$ na probabilidade de bloqueio global da rede. Ainda, a configuração esparsa garante menor degradação no bloqueio global de solicitações com menor custo dos dispositivos de rede. Por exemplo, considerando as 


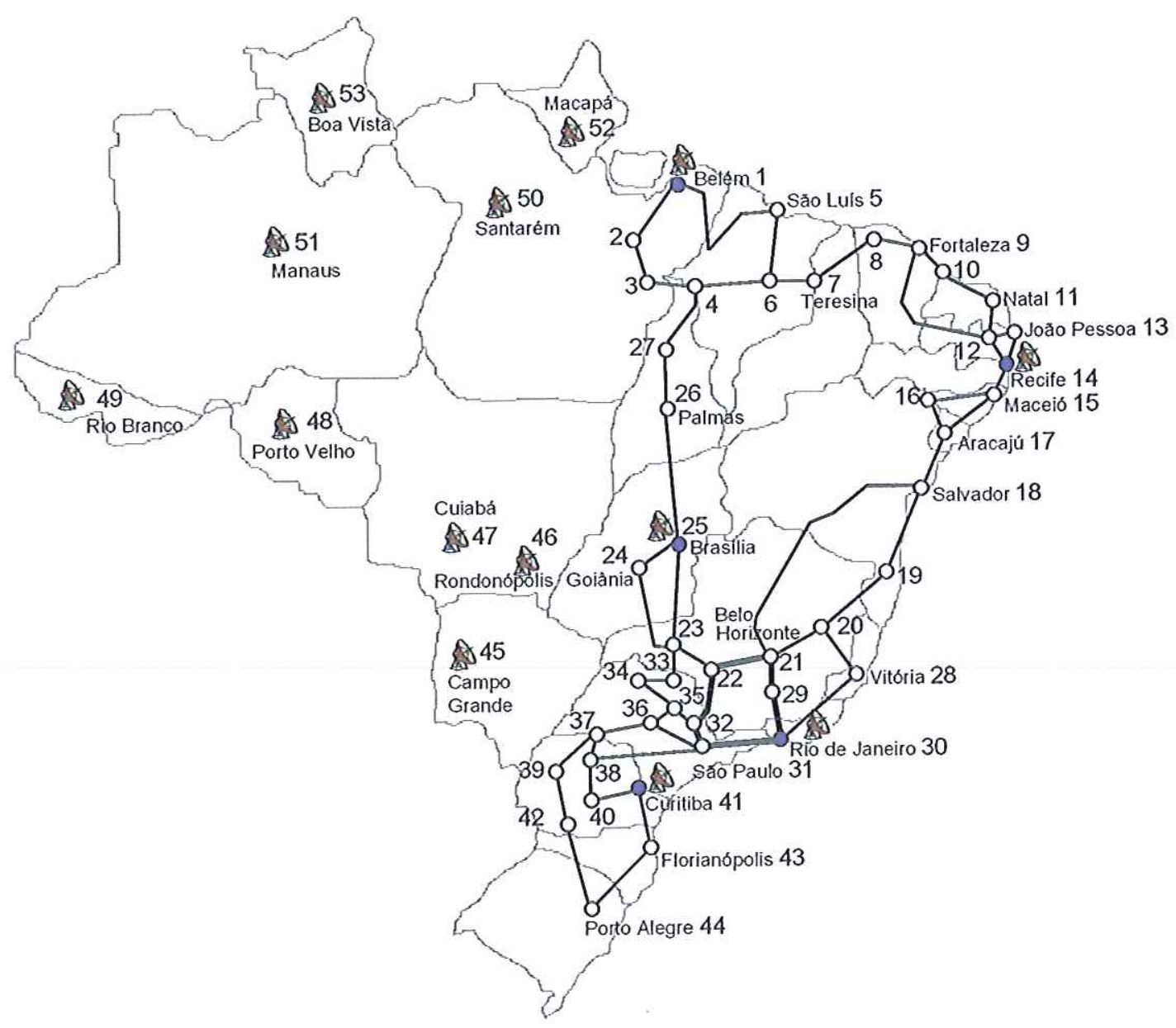

Figura 5.68: Rede híbrida brasileira formada por enlaces de fibra óptica e via satélite. Os nós roteadores em destaque são equipados com estações de comunicação por satélite. A rede optica dispõe de $W=4$ comprimentos de onda. Os enlaces em destaque possuem $W=8$ por causa da grande densidade populacional da região. Na rede via satélite há $C=4$ transceptores disponíveis. A agregação utilizada é $g=4$. 
duas configurações apresentadas, 9 WSXC + 6 WGXC e 12 WSXC + 9 WGXC, as probabilidades de bloqueio são $1,77 \%$ e $0,97 \%$ para 4 ( $\times 5,3$ erlangs), e $11,55 \%$ e $9,06 \%$ para 8 ( $\times 5,3$ erlangs). Em relação à rede sem agregação, estes resultados representam uma redução no número de requisições bloqueadas de $73 \%$ e $85 \%$ para 4 ( $\times 5,3$ erlangs) e $55 \%$ e $65 \%$ para 8 ( $\times 5,3$ erlangs), respectivamente.

A ocupação média dos enlaces em função da demanda de tráfego oferecido está apresentada nas Figuras 5.74 e 5.73 e na Tabela 5.46, obtida por meio de (5.3) para a rede óptica e (5.4) para a rede sem fio. Considerando uma demanda de tráfego oferecido de 4 (×5,3 erlangs), a arquitetura de rede óptica sem agregação, com agregação esparsa e com agregação plena apresentam ocupação média de $13,72 \%, 15,43 \%$ e 17,17\%, enquanto os valores para rede satélite são $3,69 \%, 3,15 \%$ e $3,08 \%$, respectivamente. Para uma demanda de tráfego de 8 (×5,3 erlangs), os valores para rede óptica são $19,76 \%$, $26,10 \%$ e $30,75 \%$ e para rede satélite são $8,75 \%, 6,75 \%$ e $6,07 \%$, respectivamente.

Ao se equipar a rede com nós com capacidade de agregação de tráfego o uso da rede auxiliar é reduzido, conforme mostrado nas Figuras 5.71 e 5.72 e na Tabela 5.45 . Considerando a rede sem agregação e uma demanda de tráfego de $8(\times 5,3$ erlangs), o tráfego médio por enlace oferecido à rede auxiliar é 0,34 erlangs. Equipando-se a rede com agregação plena o tráfego é reduzido para 0,005 erlangs. Respectivamente, a ocupação dos enlaces da rede auxiliar também é reduzida. Por exemplo, considerando uma demanda de tráfego de 4 ( $\times 5,3$ erlangs), a ocupação é reduzida de 1,75\% no caso de rede sem agregação, para $0,20 \%$ no caso de rede com agregação esparsa, e para $0,0069 \%$ no caso de rede com agregação plena. Se a demanda de tráfego for $8(\times 5,3$ erlangs), a redução é de $8,50 \%$ para $2,30 \%$ e $0,12 \%$ para rede com agregação espasa e plena, respectivamente.

O comprimento médio das rotas em função do tráfego total oferecido está apresentado na Figura 5.75 e na Tabela 5.47. Para demanda de tráfego reduzida as rotas do sistema são compostas em média por 5,79 enlaces. Com o aumento da demanda de tráfego a rede sem agregação não utiliza os recursos disponíveis de forma eficiente, apresenta maior acréscimo na probabilidade de bloqueio e redução na ocupação dos enlaces e no comprimento médio das rotas. Considerando uma demanda de tráfego de 5 ( $\times 5,3$ erlangs), a rede sem capacidade de agregação, com agregação esparsa e plena apresentam comprimento médio das rotas de 5,63, 6,13 e 7,10 enlaces, respectivamente. Para uma demanda de 10 ( $\times 5,3$ erlangs) os valores são 5,08, 5,95 e 7,09 enlaces, respectivamente.

O tempo médio para os modelos realizarem o atendimento às solicitações de comprimento de onda em função do tráfego total oferecido está apresentado na Figura 5.76 e na Tabela 5.48. Em cada período de tempo, o algoritmo verifica as novas requisições, determina a melhor rota e os respectivos comprimentos de onda para esta- 


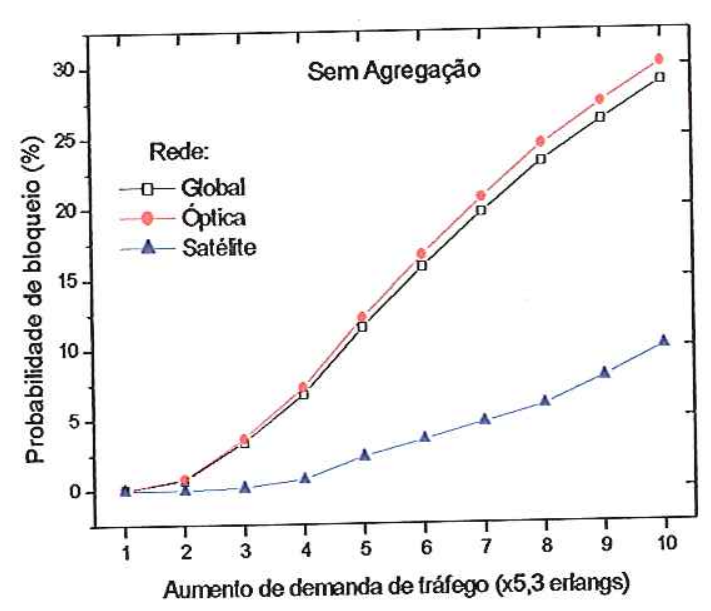

(a)

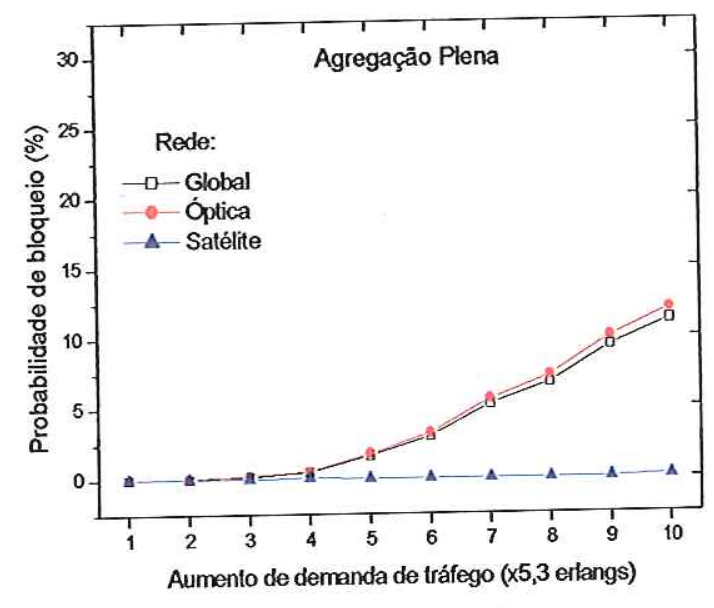

(b)

Figura 5.69: Probabilidade de bloqueio (\%) em função do aumento de demanda de tráfego para a rede híbrida brasileira. (a) Sem capacidade de agregação; e (b) utilizando comutadores com agregação plena WGXC.

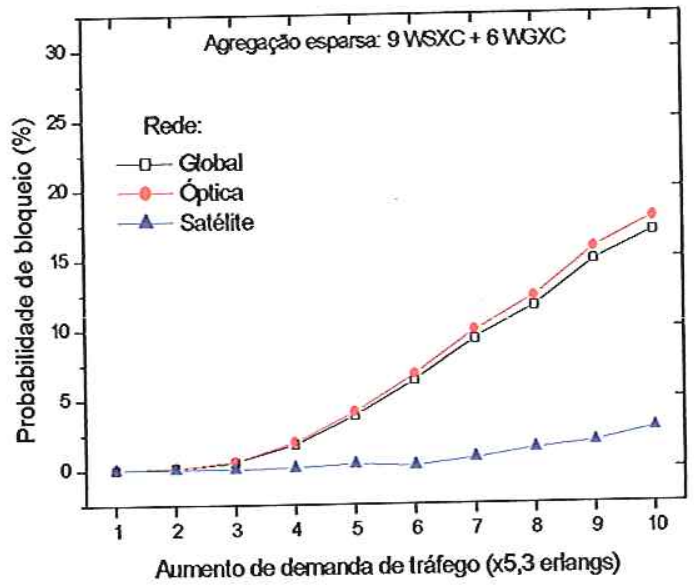

(a)

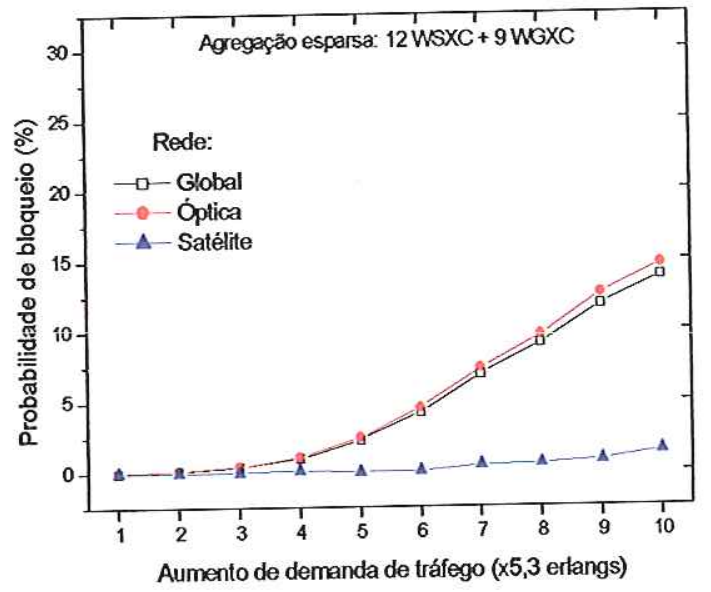

(b)

Figura 5.70: Probabilidade de bloqueio (\%) em função do aumento de demanda de tráfego para a rede brasileira utilizando agregação esparsa. (a) 9 WSXC e 6 WGXC; e (b) 12 WSXC e 9 WGXC. 


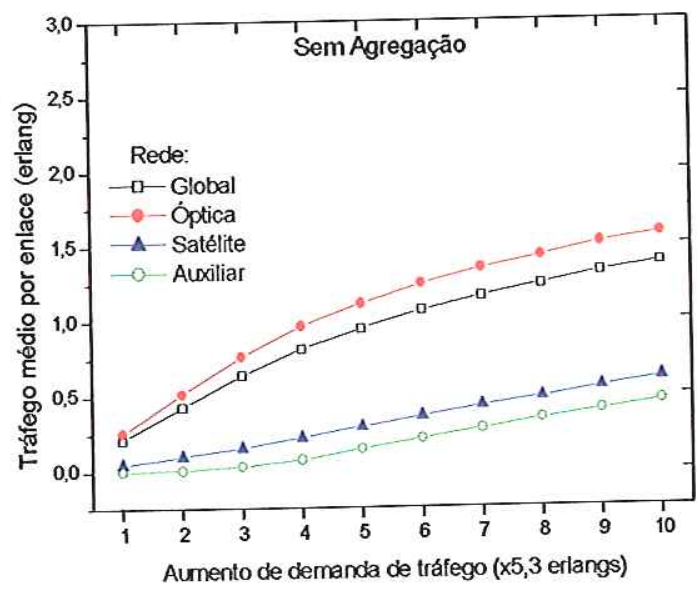

(a)

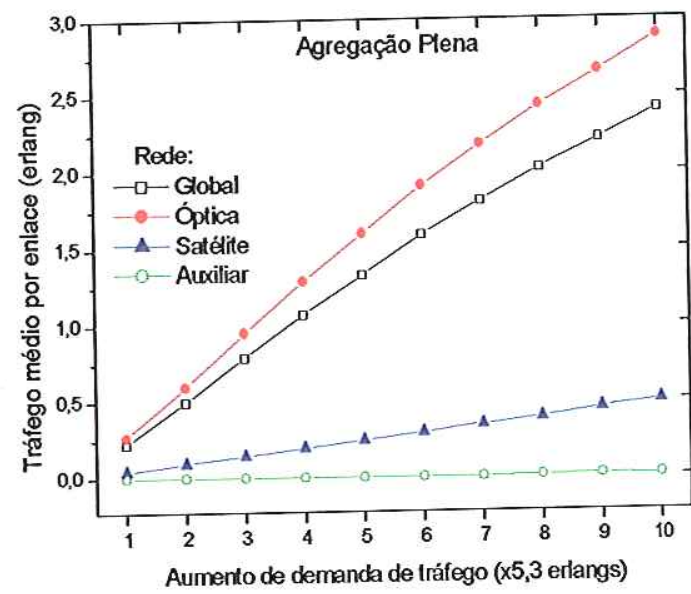

(b)

Figura 5.71: Tráfego médio por enlace (erlang) em função do aumento de demanda de tráfego para a rede híbrida brasileira. (a) Sem capacidade de agregação; e (b) utilizando comutadores com agregação plena WGXC.

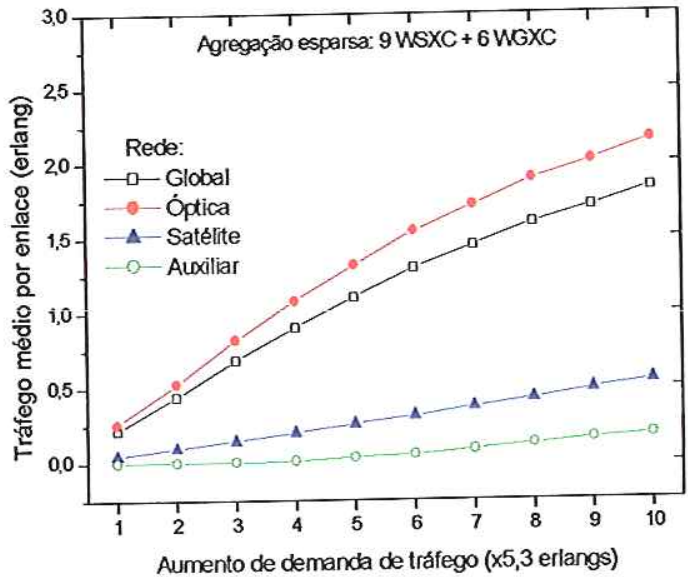

(a)

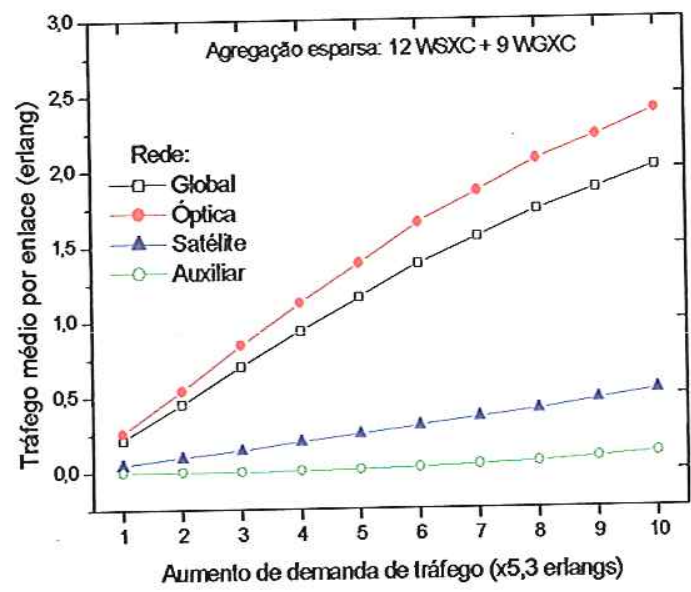

(b)

Figura 5.72: Tráfego médio por enlace (erlang) em função do aumento de demanda de tráfego para a rede híbrida brasileira utilizando agregação esparsa. (a) 9 WSXC e 6 WGXC; (b) 12 WSXC e 9 WGXC. 


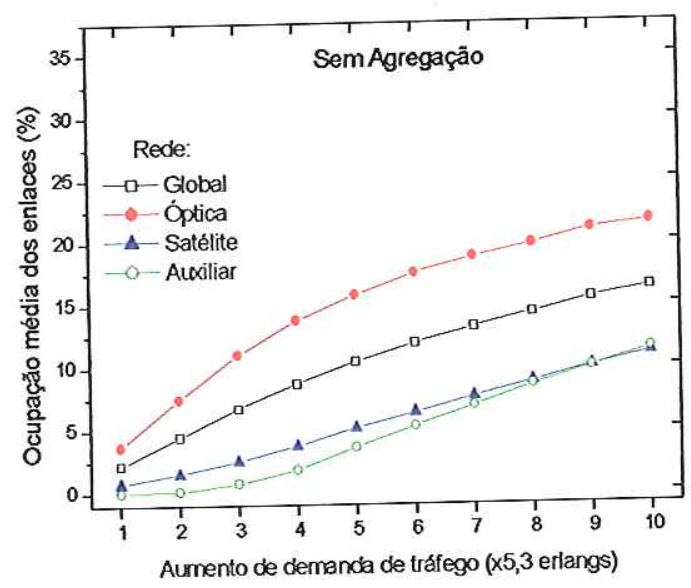

(a)

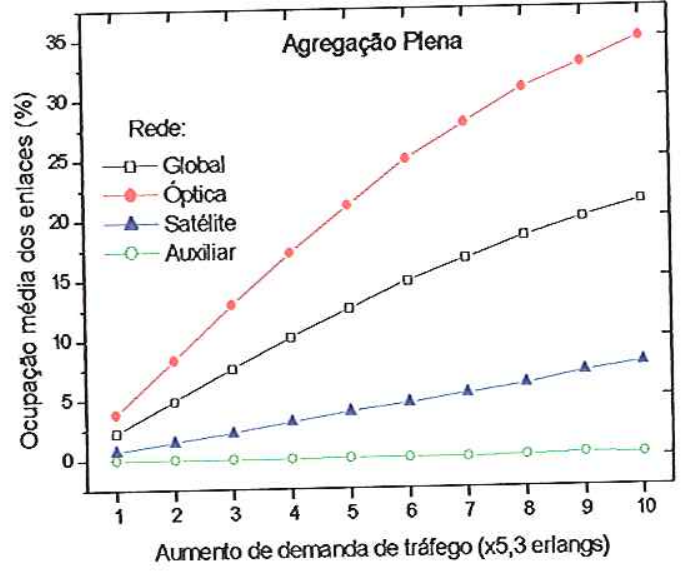

(b)

Figura 5.73: Ocupação média dos enlaces (\%) em função do aumento de demanda de tráfego para a rede híbrida brasileira. (a) sem capacidade de agregação; e (b) utilizando comutadores com agregação plena WGXC.

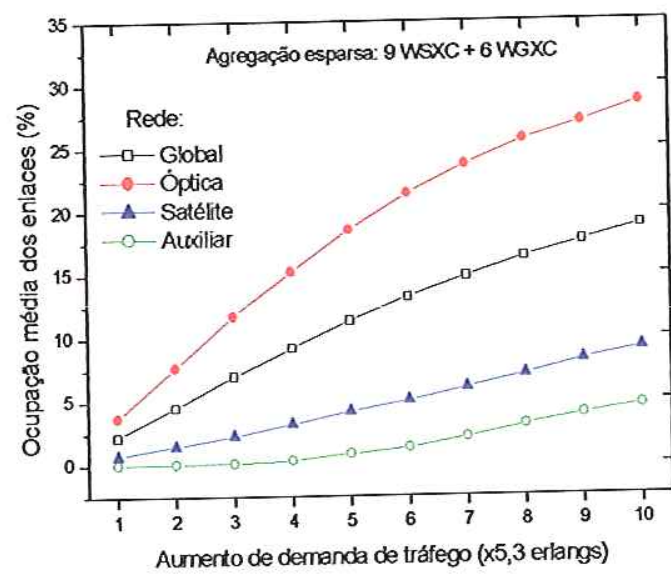

(a)

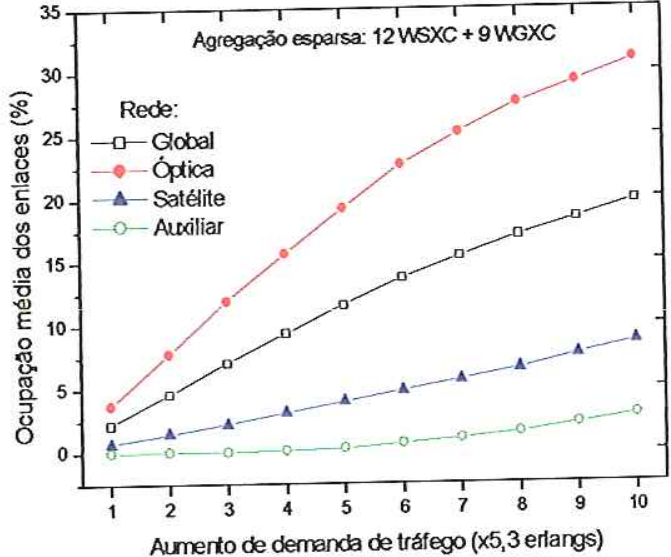

(b)

Figura 5.74: Ocupação média dos enlaces (\%) em função do aumento de demanda de tráfego para a rede híbrida brasileira utilizando agregação esparsa. (a) 9 WSXC e 6 WGXC; e (b) 12 WSXC e 9 WGXC. 


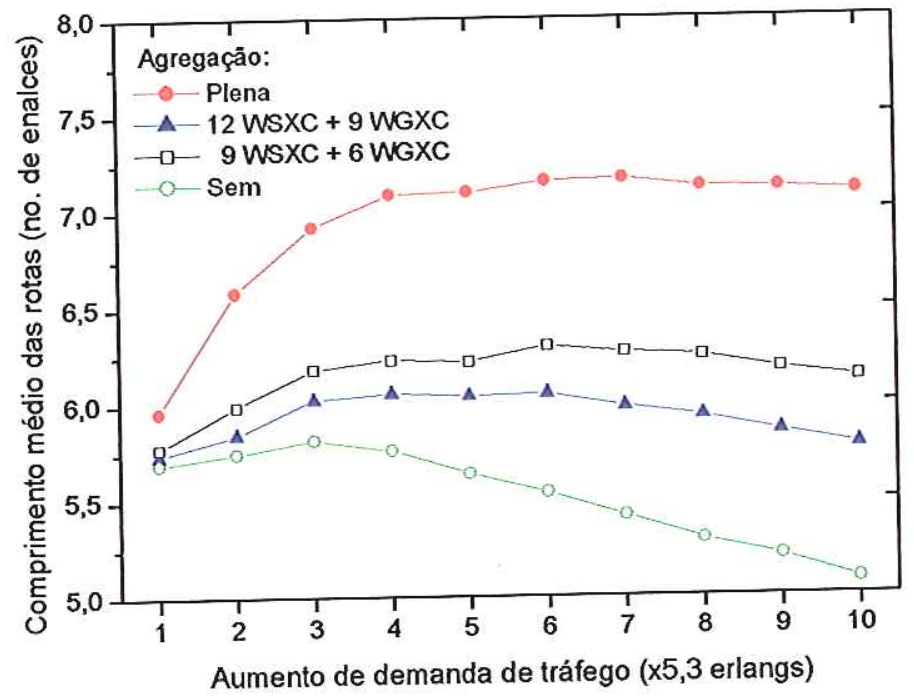

Figura 5.75: Comprimento médio das rotas (no. de enlaces) em função do aumento de demanda de tráfego para a rede híbrida brasileira com agregação plena, esparsa e sem agregação.

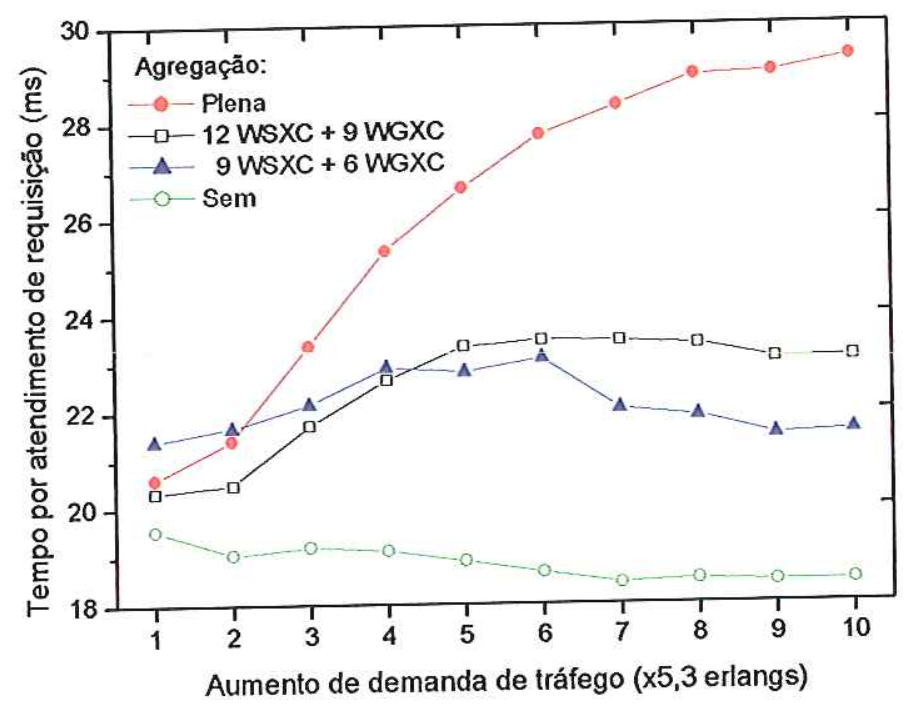

Figura 5.76: Tempo médio por atendimento de requisição (ms) em função do aumento de demanda de tráfego para a rede híbrida brasileira com agregação plena, esparsa e sem agregação. 
belecer a conexão. Os tempos de processamento obtidos com o AG são adequados. $\mathrm{Na}$ rede com agregação esparsa, o AG necessita em média de apenas 22,2 milissegundos para realizar o atendimento a uma nova requisição. Com agregação plena, o tempo necessário para o processamento é de apenas 26,1 milissegundos.

$\mathrm{O}$ algoritmo permite o gerenciamento integrado da rede híbrida brasileira identificando rotas e dispositivos mais utilizados. Na Tabela 5.49 estão apresentados o tráfego nos enlaces mais carregados para a rede utilizando agregação plena e as duas configurações de agregação esparsa, 9 WSXC e 6 WGXC; e 12 WSXC e 9 WGXC. Os resultados indicam o tráfego elevado entre as capitais mais densamente povoadas. Nestes casos, a demanda de tráfego foi atendida por meio de enlaces com 8 comprimentos de onda. Entretanto, os enlace entre os nós 17 e 18 (Aracajú-Salvador) e 25 e 26 (Brasília- Palmas) são os enlace mais densamente carregados, visto que possuem 4 comprimentos de onda. Caso se deseje ampliar a demanda da rede e manter os mesmos padrões de desempenho estes enlaces deverão ter a sua capacidade elevada. As chaves com capacidade de agregação de tráfego que apresentam maior percentual de uso estão apresentadas na Tabela 5.50. Na Tabela 5.51 estão apresentados o uso dos conversores de comprimento de onda. Observe que apenas os nós roteadores equipados com chaves WGXC realizam conversão. 
Tabela 5.43: Distribuição demográfica do Brasil (mil habitantes) servidos pelos nós roteadores.

\begin{tabular}{|c|c|c|c|c|c|}
\hline \multicolumn{6}{|c|}{ Número de mil habitantes servidos pelos nós roteadores ${ }^{(1)}$} \\
\hline Reg. Sudeste & 72412,41 & Nó & Reg. Norte & 12900,70 & Nó \\
\hline Baurú & 916,13 & 36 & Araguaína & 522,63 & 27 \\
\hline Belo Horizonte & 11189,52 & 21 & Belém & 4442,63 & 1 \\
\hline Campinas & 2809,85 & 32 & Boa Vista & 324,40 & 53 \\
\hline Gov. Valadares & 1235,31 & 20 & Macapá & 477,03 & 52 \\
\hline Juiz de Fora & 2283,34 & 29 & Manaus & 2812,56 & 51 \\
\hline P. de Caldas & 677,95 & 22 & Marabá & 582,88 & 3 \\
\hline Rib. Preto & 1463,55 & 33 & Palmas & 634,47 & 26 \\
\hline Rio de Janeiro & 14391,28 & 30 & Porto Velho & 1379,79 & 48 \\
\hline São Carlos & 559,42 & 35 & Rio Branco & 557,53 & 49 \\
\hline São J. R. Preto & 1039,20 & 34 & Santarém & 910,78 & 50 \\
\hline São Paulo & 30244,26 & 31 & Tucuruí & 256,02 & 2 \\
\hline Uberlândia & 2505,37 & 23 & & & \\
\hline \multirow{2}{*}{ Vitória } & \multirow[t]{2}{*}{3097,23} & \multirow[t]{2}{*}{28} & Reg. Nordeste & 47741,71 & Nó \\
\hline & & & Alagoas & 2678,28 & 15 \\
\hline Reg. C.-Oeste & 11636,73 & Nó & Aracajú & 1784,48 & 17 \\
\hline Brasília & 2051,15 & 25 & Camp. Grande & 1283,69 & 12 \\
\hline Campo Grande & 2078,00 & 45 & Caxias & 769,34 & 6 \\
\hline Cuiabá & 1910,54 & 47 & Delm. Golveia & 144,34 & 16 \\
\hline Goiânia & 5003,23 & 24 & Fortaleza & 6928,28 & 9 \\
\hline \multirow[t]{2}{*}{ Rondonópolis } & \multirow[t]{2}{*}{593,81} & \multirow[t]{2}{*}{46} & João Pessoa & 2160,13 & 13 \\
\hline & & & Mossoró & 641,13 & 10 \\
\hline Região Sul & 25107,62 & Nó & Natal & 2135,65 & 11 \\
\hline Curitiba & 6958,48 & 41 & Porto Franco & 92,70 & 4 \\
\hline Ponta Grossa & 1199,48 & 38 & Porto Seguro & 492,79 & 19 \\
\hline Pato Branco & 272,82 & 42 & Recife & 7918,34 & 14 \\
\hline Campo Mourao & 352,79 & 39 & Salvador & 12577,46 & 18 \\
\hline Cambará & 99,69 & 37 & São Luís & 4789,43 & 5 \\
\hline Guarapuava & 680,20 & 40 & Sobral & 502,38 & 8 \\
\hline Florianópolis & 5356,36 & 43 & Teresina & 2843,28 & 7 \\
\hline \multirow[t]{2}{*}{ Porto Alegre } & \multirow[t]{2}{*}{10187,80} & \multirow[t]{2}{*}{44} & & & \\
\hline & & & Brasil & \multicolumn{2}{|c|}{169799,17} \\
\hline
\end{tabular}

(1) Número de habitantes fonte Censo IBGE 2000. 
Tabela 5.44: Probabilidade de bloqueio (\%) em função do aumento de demanda de tráfego para a rede híbrida brasileira utilizando agregação plena, esparsa e sem agregação.

\begin{tabular}{|c|c|c|c|c|}
\hline \multirow{2}{*}{$\begin{array}{c}\text { Aumento } \\
\text { demanda } \\
\text { (x5,3 Erl) }\end{array}$} & \multicolumn{4}{|c|}{ Probabilidade de Bloqueio (\%) } \\
\cline { 2 - 5 } & Sem & 9 WS+6WG & 12 WS+9WG & Plena \\
\hline \hline 1 & 0,0528 & 0,0000 & 0,0000 & 0,0000 \\
2 & 0,7224 & 0,1051 & 0,1051 & 0,0263 \\
3 & 3,3884 & 0,5039 & 0,9755 & 0,1738 \\
4 & 6,7758 & 1,7741 & 0,9755 & 0,4779 \\
5 & 11,4963 & 3,8060 & 2,2815 & 1,6341 \\
6 & 15,7470 & 6,3075 & 4,2382 & 2,9802 \\
7 & 19,6085 & 9,2665 & 6,8885 & 5,2473 \\
8 & 23,2054 & 11,5571 & 9,0666 & 6,7748 \\
9 & 26,0611 & 14,8115 & 11,8249 & 9,3587 \\
10 & 28,8229 & 16,8699 & 13,8069 & 11,1911 \\
\hline \hline & \multicolumn{4}{|c|}{ Rede Óptica } \\
\hline (x5,3 Erl) & Sem & 9 WS+6WG & 12 WS+9WG & Plena \\
\hline \hline 1 & 0,0560 & 0,0000 & 0,0000 & 0,0000 \\
2 & 0,7686 & 0,1118 & 0,1118 & 0,0279 \\
3 & 3,6029 & 0,5372 & 0,4075 & 0,1852 \\
4 & 7,2019 & 1,8916 & 1,0369 & 0,5044 \\
5 & 12,129 & 4,0449 & 2,4381 & 1,7463 \\
6 & 16,5802 & 6,7219 & 4,5214 & 3,1826 \\
7 & 20,6397 & 9,8544 & 7,3321 & 5,6095 \\
8 & 24,4055 & 12,262 & 9,6578 & 7,2451 \\
9 & 27,3366 & 15,7195 & 12,6009 & 10,0114 \\
10 & 30,1008 & 17,8261 & 14,6491 & 11,9442 \\
\hline \hline & \multicolumn{4}{|c|}{ Rede Satélite } \\
\hline (x5,3 Erl) & Sem & 9 WS+6WG & $12 W S+9 W G$ & Plena \\
\hline \hline 1 & 0,0000 & 0,0000 & 0,0000 & 0,0000 \\
2 & 0,0000 & 0,0000 & 0,0000 & 0,0000 \\
3 & 0,1403 & 0,0000 & 0,0000 & 0,0000 \\
4 & 0,6993 & 0,0999 & 0,0999 & 0,0999 \\
5 & 2,2764 & 0,3252 & 0,0000 & 0,0000 \\
6 & 3,4789 & 0,2046 & 0,0682 & 0,0000 \\
7 & 4,6686 & 0,7493 & 0,4611 & 0,0000 \\
8 & 5,9178 & 1,4042 & 0,5517 & 0,0000 \\
9 & 7,8587 & 1,8543 & 0,7506 & 0,0442 \\
10 & 10,0408 & 2,8163 & 1,4286 & 0,1224 \\
\hline
\end{tabular}


Tabela 5.45: Tráfego médio por enlace (erlang) em função do aumento de demanda de tráfego para a rede híbrida brasileira utilizando agregação plena, esparsa e sem agregação.

\begin{tabular}{|c|c|c|c|c|}
\hline \multirow{2}{*}{$\begin{array}{c}\text { Aumento } \\
\text { demanda } \\
\text { (x5,3 Erl) }\end{array}$} & \multicolumn{4}{|c|}{ Tráfego Atendido (erlang) } \\
\cline { 2 - 5 } & Sem & 9 WS+6WG & 12 WS+9WG & Plena \\
\hline \hline 1 & 0,2555 & 0,2577 & 0,2595 & 0,2682 \\
2 & 0,5141 & 0,5270 & 0,5409 & 0,5972 \\
3 & 0,7637 & 0,8198 & 0,8430 & 0,9506 \\
4 & 0,9629 & 1,0774 & 1,1198 & 1,2877 \\
5 & 1,1126 & 1,3168 & 1,3818 & 1,5979 \\
6 & 1,2444 & 1,5439 & 1,6491 & 1,9109 \\
7 & 1,3440 & 1,7168 & 1,8556 & 2,1765 \\
8 & 1,4269 & 1,8933 & 2,0640 & 2,4325 \\
9 & 1,5136 & 2,0160 & 2,2203 & 2,6552 \\
10 & 1,5721 & 2,1549 & 2,3877 & 2,8817 \\
\hline \hline & \multicolumn{4}{|c|}{ Rede Satélite } \\
\hline (x5,3 Erl) & Sem & $9 \mathrm{WS}+6 \mathrm{WG}$ & $12 \mathrm{WS}+9 \mathrm{WG}$ & Plena \\
\hline \hline 1 & 0,0467 & 0,0467 & 0,0467 & 0,0467 \\
2 & 0,0982 & 0,0970 & 0,0970 & 0,0967 \\
3 & 0,1534 & 0,1444 & 0,1436 & 0,1435 \\
4 & 0,2189 & 0,1987 & 0,1966 & 0,1949 \\
5 & 0,2908 & 0,2545 & 0,2477 & 0,2441 \\
6 & 0,3593 & 0,3098 & 0,3012 & 0,2933 \\
7 & 0,4282 & 0,3699 & 0,3560 & 0,3437 \\
8 & 0,4860 & 0,4226 & 0,4028 & 0,3863 \\
9 & 0,5513 & 0,4898 & 0,4695 & 0,4480 \\
10 & 0,6094 & 0,5448 & 0,5273 & 0,4968 \\
\hline \hline & \multicolumn{4}{|c|}{ Rede Auxiliar } \\
\hline (x5,3 Erl) & Sem & 9 WS+6WG & $12 W S+9 W G$ & Plena \\
\hline \hline 1 & 0,0000 & 0,0000 & 0,0000 & 0,0000 \\
2 & 0,0042 & $8 \mathrm{E}-4$ & $8 \mathrm{E}-4$ & 0,0000 \\
3 & 0,0283 & 0,0028 & $6 \mathrm{E}-4$ & 0,0000 \\
4 & 0,0703 & 0,0108 & 0,0053 & $3 \mathrm{E}-4$ \\
5 & 0,1419 & 0,0311 & 0,0114 & $8 \mathrm{E}-4$ \\
6 & 0,2086 & 0,0506 & 0,0256 & $6 \mathrm{E}-4$ \\
7 & 0,2731 & 0,0839 & 0,0411 & $8 \mathrm{E}-4$ \\
8 & 0,3403 & 0,1225 & 0,0592 & 0,0050 \\
9 & 0,3964 & 0,1556 & 0,0869 & 0,0108 \\
10 & 0,4547 & 0,1819 & 0,1122 & 0,0078 \\
\hline
\end{tabular}


Tabela 5.46: Ocupação média dos enlaces (\%) em função do aumento de demanda de tráfego para a rede híbrida brasileira utilizando agregação plena, esparsa e sem agregação.

\begin{tabular}{|c|c|c|c|c|}
\hline \multirow{2}{*}{$\begin{array}{c}\text { Aumento } \\
\text { demanda } \\
\text { (x5,3 Erl) }\end{array}$} & \multicolumn{4}{|c|}{ Ocupação Média dos Enlaces (\%) } \\
\cline { 2 - 5 } & Sem & 9 WS+6WG & 12 WS+9WG & Plena \\
\hline \hline 1 & 3,6713 & 3,6992 & 3,7218 & 3,8309 \\
2 & 7,4405 & 7,6183 & 7,7619 & 8,2946 \\
3 & 10,9869 & 11,7121 & 11,9218 & 12,8962 \\
4 & 13,7209 & 15,2048 & 15,6653 & 17,1795 \\
5 & 15,7222 & 18,4980 & 19,2261 & 21,072 \\
6 & 17,4510 & 21,3595 & 22,6439 & 24,8941 \\
7 & 18,7421 & 23,6337 & 25,1861 & 27,8699 \\
8 & 19,7602 & 25,5952 & 27,5024 & 30,7511 \\
9 & 20,9470 & 26,9927 & 29,1603 & 32,7846 \\
10 & 21,5322 & 28,4907 & 30,9239 & 34,8515 \\
\hline \hline & \multicolumn{4}{|c|}{ Rede Satélite } \\
\hline (x5,3 Erl) & Sem & 9 WS+6WG & $12 W S+9 W G$ & Plena \\
\hline \hline 1 & 0,7161 & 0,7161 & 0,7161 & 0,7161 \\
2 & 1,5005 & 1,4707 & 1,4707 & 1,4633 \\
3 & 2,4640 & 2,2383 & 2,2160 & 2,2135 \\
4 & 3,6905 & 3,1752 & 3,1244 & 3,0810 \\
5 & 5,0955 & 4,1623 & 3,9906 & 3,8982 \\
6 & 6,3176 & 5,0112 & 4,7886 & 4,5846 \\
7 & 7,5459 & 6,0094 & 5,6467 & 5,3230 \\
8 & 8,7531 & 7,0474 & 6,5216 & 6,0789 \\
9 & 9,9399 & 8,1820 & 7,6383 & 7,0468 \\
10 & 11,0441 & 9,1152 & 8,5981 & 7,7765 \\
\hline \hline & \multicolumn{4}{|c|}{ Rede Auxiliar } \\
\hline (x5,3 Erl) & Sem & 9 WS+6WG & $12 W S+9 W G$ & Plena \\
\hline \hline 1 & 0,0000 & 0,0000 & 0,0000 & 0,0000 \\
2 & 0,1042 & 0,0208 & 0,0208 & 0,0000 \\
3 & 0,7083 & 0,0694 & 0,0139 & 0,0000 \\
4 & 1,7569 & 0,2708 & 0,1319 & 0,0069 \\
5 & 3,5486 & 0,7778 & 0,2847 & 0,0208 \\
6 & 5,2153 & 1,2639 & 0,6389 & 0,0139 \\
7 & 6,8264 & 2,0972 & 1,0278 & 0,0208 \\
8 & 8,5069 & 3,0625 & 1,4792 & 0,1250 \\
9 & 9,9097 & 3,8889 & 2,1736 & 0,2708 \\
10 & 11,3681 & 4,5486 & 2,8056 & 0,1944 \\
\hline
\end{tabular}


Tabela 5.47: Comprimento médio das rotas (no. de enlaces) em função do aumento de demanda de tráfego para a rede híbrida brasileira utilizando agregação plena, esparsa e sem agregação.

\begin{tabular}{|c|c|c|c|c|}
\hline Aumento & \multicolumn{4}{|c|}{ Comprimento Médio das Rotas (no. de enlaces) } \\
\hline demanda & \multicolumn{4}{|c|}{ Agregação } \\
\hline (x5,3 Erl) & Sem & 9WS+6WG & 12WS+9WG & Plena \\
\hline \hline 1 & 5,6932 & 5,7381 & 5,7781 & 5,9620 \\
2 & 5,7474 & 5,8457 & 5,9929 & 6,5842 \\
3 & 5,8165 & 6,0273 & 6,1817 & 6,9242 \\
4 & 5,7633 & 6,0584 & 6,2328 & 7,0902 \\
5 & 5,6393 & 6,0420 & 6,2208 & 7,1007 \\
6 & 5,5403 & 6,0543 & 6,2997 & 7,1552 \\
7 & 5,4171 & 5,9846 & 6,2678 & 7,1661 \\
8 & 5,2937 & 5,9342 & 6,2499 & 7,1228 \\
9 & 5,2076 & 5,8532 & 6,1815 & 7,1185 \\
10 & 5,0806 & 5,7794 & 6,1297 & 7,0976 \\
\hline
\end{tabular}

Tabela 5.48: Tempo por atendimento de requisição ( $\mathrm{ms}$ ) em função do aumento de demanda de tráfego para a rede híbrida brasileira utilizando agregação plena, esparsa e sem agregação.

\begin{tabular}{|c|c|c|c|c|}
\hline \multirow{2}{*}{$\begin{array}{c}\text { Aumento } \\
\text { demanda } \\
\text { (x5,3 Erl) }\end{array}$} & \multicolumn{4}{|c|}{ Tempo Médio por Atendimento de Requisição (ms) } \\
\cline { 2 - 5 } & Sem & 9 WS+6WG & 12WS+9WG & Plena \\
\hline \hline 1 & 19,5457 & 21,3946 & 20,3381 & 20,6022 \\
2 & 19,0464 & 21,6734 & 20,4913 & 21,4107 \\
3 & 19,2007 & 22,1546 & 21,7202 & 23,3709 \\
4 & 19,1162 & 22,9133 & 22,6514 & 25,3355 \\
5 & 18,8994 & 22,8151 & 23,3372 & 26,6263 \\
6 & 18,6535 & 23,0783 & 23,4687 & 27,7199 \\
7 & 18,4213 & 22,0312 & 23,4453 & 28,3205 \\
8 & 18,4914 & 21,8771 & 23,3747 & 28,9416 \\
9 & 18,4457 & 21,4814 & 23,0716 & 28,9980 \\
10 & 18,4612 & 21,5554 & 23,0895 & 29,3039 \\
\hline
\end{tabular}


Tabela 5.49: Tráfego nos enlaces mais carregados (erlang) na rede híbrida brasileira utilizando agregação plena e esparsa.

\begin{tabular}{|c|c|c|c|c|c|c|c|c|c|c|c|c|}
\hline \multirow[b]{4}{*}{ Ordem } & \multicolumn{12}{|c|}{ Tráfego nos Enlaces mais Carregados (erlang) } \\
\hline & \multicolumn{4}{|c|}{ Agregação Plena } & \multicolumn{4}{|c|}{ Agregação 12WS+9WG } & \multicolumn{4}{|c|}{ Agregacão 9WS+6WG } \\
\hline & \multicolumn{2}{|c|}{$5(\times 5,3 \mathrm{Erl})^{(1)}$} & \multicolumn{2}{|c|}{$10(\times 5,3 \mathrm{Erl})$} & \multicolumn{2}{|c|}{$5(\times 5,3 \mathrm{Erl})$} & \multicolumn{2}{|c|}{$10(\times 5,3 \mathrm{Erl})$} & \multicolumn{2}{|c|}{$5(\times 5,3 \mathrm{Erl})$} & \multicolumn{2}{|c|}{$10(\times 5,3 \mathrm{Erl})$} \\
\hline & O-D $\mathrm{D}^{(2)}$ & $\begin{array}{c}\text { tráfego } \\
\text { (Erl) }\end{array}$ & O-D & $\begin{array}{c}\text { tráfego } \\
\text { (Erl) }\end{array}$ & O-D & $\begin{array}{c}\text { tráfego } \\
\text { (Erl) }\end{array}$ & O-D & $\begin{array}{c}\text { tráfego } \\
\text { (Erl) }\end{array}$ & O-D & $\begin{array}{c}\text { tráfego } \\
\text { (Erl) }\end{array}$ & O-D & $\begin{array}{c}\text { tráfego } \\
\text { (Erl) }\end{array}$ \\
\hline 1 & $32-22$ & 3,543 & $31-32$ & $6,6,308$ & $32-22$ & 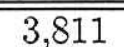 & $31-32$ & 6,538 & $32-22$ & 3,613 & $31-32$ & 6,206 \\
\hline 2 & $31-32$ & 3,511 & $32-22$ & 6,285 & $22-32$ & 3,663 & $32-22$ & 6,533 & $22-32$ & 3,536 & $32-22$ & 6,078 \\
\hline 3 & $22-32$ & 3,367 & $22-21$ & 6,142 & $31-32$ & 3,578 & $22-32$ & 6,176 & $31-32$ & 3,465 & $22-32$ & 5,833 \\
\hline 4 & $22-21$ & 3,265 & $22-32$ & 5,996 & $22-21$ & 3,347 & $32-31$ & 5,804 & $22-21$ & 3,260 & $32-31$ & 5,539 \\
\hline 5 & $32-31$ & 3,222 & $32-31$ & 5,885 & $32-31$ & 3,250 & $22-21$ & 5,786 & $32-31$ & 3,150 & $22-21$ & 5,529 \\
\hline 6 & $21-22$ & 3,011 & $21-22$ & 5,526 & $21-22$ & 3,110 & $21-22$ & 5,350 & $21-22$ & 3,124 & $21-22$ & 5,149 \\
\hline 7 & $18-17$ & 2,888 & $7-6$ & 5,233 & $18-17$ & 2,835 & $18-17$ & 4,572 & $18-17$ & 2,439 & $31-30$ & 4,246 \\
\hline 8 & $25-26$ & 2,824 & 8-7 & 5,178 & $17-15$ & 2,665 & $15-14$ & 4,346 & $17-18$ & 2,307 & $30-31$ & 4,015 \\
\hline 9 & $26-27$ & 2,799 & $9-8$ & 5,175 & $15-14$ & 2,632 & $17-18$ & 4,346 & $18-21$ & 2,303 & $23-22$ & 3,981 \\
\hline 10 & $27-4$ & 2,778 & $25-26$ & 4,985 & $17-18$ & 2,536 & $17-15$ & 4,293 & $23-22$ & 2,288 & $22-23$ & 3,869 \\
\hline 11 & $15-14$ & 2,775 & $27-4$ & 4,961 & $15-21$ & 2,358 & $31-30$ & 4,265 & $25-26$ & 2,268 & $25-26$ & 3,506 \\
\hline 12 & $7-6$ & 2,774 & $18-17$ & 4,881 & $17-18$ & 2,350 & $30-22$ & 4,119 & $17-15$ & 2,263 & $18-17$ & 3,471 \\
\hline
\end{tabular}

(1) Demanda de tráfego oferecido à rede híbrida brasileira.

(2) O-D representa os nós origem e destino do enlace, respectivamente. 
Tabela 5.50: Uso das chaves com capacidade de agregação de tráfego (\%) na rede híbrida brasileira utilizando agregação plena e esparsa.

\begin{tabular}{|c|c|c|c|c|c|c|c|c|c|c|c|c|}
\hline \multirow[b]{4}{*}{ Ordem } & \multicolumn{12}{|c|}{ Uso das Chaves com Capacidade de Agregação de Tráfego (\%) } \\
\hline & \multicolumn{4}{|c|}{ Agregação Plena WG } & \multicolumn{4}{|c|}{ Agregação 12WS+9WG } & \multicolumn{4}{|c|}{ Agregação 9WS+6WG } \\
\hline & \multicolumn{2}{|c|}{$5(\times 5,3 \mathrm{Erl})^{(1)}$} & \multicolumn{2}{|c|}{$10(\times 5,3 \mathrm{Erl})$} & \multicolumn{2}{|c|}{$5(\times 5,3 \mathrm{Erl})$} & \multicolumn{2}{|c|}{$10(\times 5,3 \mathrm{Erl})$} & \multicolumn{2}{|c|}{$5(\times 5,3 \mathrm{Erl})$} & \multicolumn{2}{|c|}{$10(\times 5,3 \mathrm{Erl})$} \\
\hline & Nó & Uso (\%) & Nó & Uso (\%) & Nó & Uso (\%) & Nó & Uso (\%) & Nó & Uso (\%) & No & Uso (\%) \\
\hline 1 & 22 & 9,150 & 22 & 8,832 & 31 & 14,655 & 31 & 14,203 & 31 & 19,508 & 31 & 18,484 \\
\hline 2 & 21 & 9,058 & 21 & 7,992 & 22 & 13,093 & 22 & 13,609 & 22 & 16,528 & 22 & 17,114 \\
\hline 3 & 32 & 6,611 & 32 & 6,936 & 21 & 11,504 & 21 & 10,786 & 21 & 13,573 & 21 & 13,473 \\
\hline 4 & 23 & 6,372 & 23 & 5,879 & 18 & 9,831 & 18 & 9,558 & 32 & 10,560 & 32 & 11,242 \\
\hline 5 & 25 & 5,612 & 25 & 5,591 & 32 & 8,514 & 32 & 8,895 & 18 & 7,109 & 23 & 7,752 \\
\hline 6 & 6 & 5,515 & 6 & 4,895 & 14 & 7,477 & 14 & 7,838 & 30 & 6,927 & 30 & 6,594 \\
\hline 7 & 36 & 5,138 & 36 & 4,725 & 25 & 5,874 & 23 & 6,083 & 23 & 6,809 & 25 & 6,571 \\
\hline 8 & 18 & 5,112 & 37 & 4,668 & 23 & 5,625 & 25 & 6,081 & 25 & 5,759 & 18 & 6,376 \\
\hline 9 & 37 & 4,638 & 4 & 4,303 & 30 & 5,024 & 6 & 5,245 & 14 & 4,044 & 41 & 3,720 \\
\hline 10 & 4 & 4,290 & 18 & 4,096 & 6 & 4,593 & 30 & 4,847 & 41 & 3,835 & 14 & 3,706 \\
\hline
\end{tabular}

(1) Demanda de tráfego oferecido à rede híbrida brasileira. 
Tabela 5.51: Uso dos conversores de comprimento de onda (\%) na rede híbrida brasileira utilizando agregação plena e esparsa.

\begin{tabular}{|c|c|c|c|c|c|c|c|c|c|c|c|c|}
\hline & \multicolumn{12}{|c|}{ Uso dos Conversores de Comprimento de Onda (\%) } \\
\hline & \multicolumn{4}{|c|}{ Agregação Plena WG } & \multicolumn{4}{|c|}{ Agregação 12WS+9WG } & \multicolumn{4}{|c|}{ Agregação 9WS+6WG } \\
\hline & \multicolumn{2}{|c|}{$5(\times 5,3 \mathrm{Erl})^{(1)}$} & \multicolumn{2}{|c|}{$10(\times 5,3 \mathrm{Erl})$} & \multicolumn{2}{|c|}{$5(\times 5,3 \mathrm{Erl})$} & \multicolumn{2}{|c|}{$10(\times 5,3 \mathrm{Erl})$} & \multicolumn{2}{|c|}{$5(\times 5,3 \mathrm{Erl})$} & \multicolumn{2}{|c|}{$10(\times 5,3 \mathrm{Erl})$} \\
\hline Ordem & Nó & Uso (\%) & Nó & Uso (\%) & Nó & Uso (\%) & Nó & Uso (\%) & Nó & Uso (\%) & No & Uso (\%) \\
\hline 1 & 31 & $9,9,309$ & 31 & $7,7,781$ & 22 & 21,110 & 22 & 20,901 & 22 & 27,551 & 22 & 26,816 \\
\hline 2 & 22 & 6,606 & 22 & 6,432 & 21 & 19,420 & 21 & 17,999 & 21 & 25,100 & 21 & 21,814 \\
\hline 3 & 21 & 6,500 & 23 & 6,062 & 32 & 14,419 & 32 & 15,688 & 32 & 17,973 & 32 & 20,216 \\
\hline 4 & 23 & 6,028 & 21 & 5,966 & 18 & 9,213 & 31 & 8,930 & 31 & 12,220 & 31 & 12,236 \\
\hline 5 & 25 & 5,763 & 25 & 5,930 & 31 & 8,780 & 23 & 8,650 & 23 & 10,899 & 23 & 10,982 \\
\hline 6 & 32 & 5,274 & 32 & 5,137 & 23 & 7,889 & 18 & 8,135 & 25 & 6,258 & 25 & 7,936 \\
\hline 7 & 6 & 4,850 & 6 & 4,944 & 14 & 6,725 & 25 & 6,646 & - & - & - & - \\
\hline 8 & 18 & 4,672 & 14 & 4,708 & 25 & 6,268 & 6 & 6,589 & - & - & - & - \\
\hline 9 & 14 & 4,523 & 18 & 4,451 & 6 & 6,177 & 14 & 6,462 & - & - & - & - \\
\hline 10 & 9 & 4,096 & 9 & 4,328 & - & - & - & - & - & - & - & - \\
\hline
\end{tabular}

(1) Demanda de tráfego oferecido à rede híbrida brasileira. 


\section{Capítulo 6}

\section{Conclusões}

\subsection{Problema}

O vertiginoso avanço tecnológico exibido pelo setor de telecomunicações nos últimos tempos tem exigido das redes o aumento, cada vez mais acentuado, das taxas de transmissão. Este aumento tem decorrido da necessidade das redes suportar aplicações que exigem faixa larga como internet e vídeo interativo. Também, o número de usuários tem crescido exponencialmente.

Por outro lado, a convencional expansão proporcional dos recursos físicos para atender à demanda é limitada pelo custo elevado e o gerenciamento eficaz dos recursos das redes passa a ser um dos alvos principais da pesquisa tecnológica. O problema de alocação de recursos em redes de telecomunicações tornou-se tema atual de inúmeras pesquisas e as soluções, uma necessidade imperiosa no corrente estágio de expansão e gerenciamento de redes.

A alocação dos recursos disponíveis para ampliar a eficiência e o roteamento do tráfego é característica comum às redes de telecomunicações, especialmente às redes óptica e de comunicação móvel celular. Desta forma, há similaridade entre as características das redes ópticas e comunicação móvel celular que permitem abordagem comum. São elas a engenharia de largura de faixa, via reuso de comprimentos de onda e reuso de freqüências, e as limitações dos dispositivos ópticos e as restrições eletromagnéticas. Neste contexto, a rede óptica deve estar provida de esquemas para gerenciar a largura de faixa, lidando com alocação de comprimentos de onda, características de dispositivos e agregação de tráfego. Equivalentemente, a rede de comunicação móvel celular deve lidar com largura de faixa reduzida, melhoria do esquema de reuso de frequiências, handoff e restrições eletromagnéticas. 


\subsection{Abordagem}

As abordagens utilizando AGs têm despertado enorme interesse na comunidade científica, em decorrência da simplicidade, funcionalidade e capacidade de generalização, apresentando resultados satisfatórios na solução de diferentes problemas com múltiplas variáveis em sistemas dinâmicos. As diferentes propostas para melhoria da eficiência dos algoritmos genéticos englobando estratégias de controle destacam-se como uma das mais importantes e promissoras áreas de pesquisa em computação evolucionária, pois permitem ao algoritmo o ajuste dos parâmetros tornando-o adaptável às condições dinâmicas impostas pelo sistema.

Este trabalho apresenta soluções para o problema de alocação de recursos e roteamento de tráfego (PARRT) em redes de telecomunicações baseado em algoritmos genéticos (AG). Os AGs demonstram ser eficientes em resolver problemas de alocação de recursos em ambientes dinâmicos, como o problema de roteamento e alocação de comprimento de onda (RWA - routing and wavelength assignment) em redes ópticas WDM e a alocação de canais (CAP - channel assignment problem) em sistemas de comunicação móvel celular. Os modelos elaborados permitem abordar todos os parâmetros e restrições do sistema e são aptos para gerenciar redes de telecomunicações. O objetivo dos algoritmos propostos é otimizar a alocação e o uso dos recursos disponíveis nas redes atendendo às restrições específicas de cada ambiente e reduzindo a probabilidade de bloqueio de solicitações de conexão.

Os parâmetros do AG otimizado para uso em alocação dinâmica de recursos foi obtido em termos de números de indivíduos, número de gerações, número de pontos de cruzamento, e controle adaptivo dos operadores genéticos em função da diversidade da população. O modelo ainda inclui: política elitista, mecanismo de seleção por truncamento, inserção de imigrantes e um reservatório para assistir a formáção da população inicial.

\subsubsection{Rede Óptica}

O algoritmo elaborado para a rede óptica WDM possui a capacidade de realizar o roteamento e a alocação de comprimentos de onda, gerenciar a largura de faixa, atender às características dos dispositivos de rede, otimizar a distribuição dos conversores de comprimentos de onda, agregar tráfego dinamicamente e realizar imparcialidade de capacidade de largura de faixa garantindo elevada qualidade de serviço. O modelo apresentado é dinâmico e soluciona o problema RWA baseado em informações atuais dos enlaces da rede.

O algoritmo determina o RWA por meio da rota com menor caminho, do comprimento de onda mais utilizado e do menor número de dispositivos de rede. Foram 
consideradas diferentes propriedades físicas das fibras e dos dispositivos ópticos, como: atenuação, dispersão e taxa de transmissão. Os conversores utilizados permitem conversão plena de comprimentos de onda e foram distribuídos nas redes pelo AG de forma otimizada.

\subsubsection{Rede Móvel Celular}

O modelo proposto para otimizar o uso de recursos na rede de comunicação móvel celular otimiza o esquema de reuso de freqüências, considera o handoff $\mathrm{e}$ atende às restrições eletromagnéticas. O algoritmo genético resolve o problema de alocação dinâmica de canais ajustando seus parâmetros às variações do ambiente, como falhas em canais. $\mathrm{O}$ modelo proposto considera distribuição de tráfego heterogênea, alocação dinâmica de canais, restrições eletromagnéticas e handoff.

\subsubsection{Rede Híbrida}

Para enfatizar a versatilidade do algoritmo proposto é apresentada a simulação de uma rede brasileira de comunicação óptica conectada a uma rede de comunicação via satélite. O AG proposto gerencia simultaneamente a demanda de tráfego nas duas redes, abordadas integradamente. Foi utilizada uma distribuição de tráfego dinâmica, heterogênea e proporcional ao número de habitantes das regiões atendidas pelos nós roteadores. Os resultados numéricos indicam a aplicabilidade da abordagem proposta na gerência integrada de redes distintas, identificando rotas e dispositivos mais utilizados. A probabilidade de bloqueio é minimizada considerando características das duas redes.

\subsection{Resultados}

Neste trabalho, são apresentadas duas figuras de méritos para avaliar o desempenho das redes de telecomunicações em função da demanda de tráfego oferecido à rede: a probabilidade de bloqueio e o uso dos recursos disponíveis. Os resultados estão apresentados em gráficos e os valores correspondentes estão ilustrados em tabelas. Ainda, são apresentadas tabelas ilustrando o tempo médio de simulação do algoritmo proposto para o atendimento às solicitações dos recursos.

\subsubsection{Rede Óptica}

Foram elaborados dois algoritmos baseados em AG para solucionar o problema de RWA. O primeiro utiliza roteamento fixo alternativo e o algoritimo deve alocar os comprimentos de onda às rotas previamente estabelecidas. No segundo, o roteamento 
e a alocação de comprimentos de onda são determinados simultaneamente e de forma dinâmica. Avaliados na rede NSFnet na qual foi otimizada a distribuição dos conversores de comprimento de onda na rede, os dois modelos apresentam resultados satisfatórios e superiores ao proposto por Vijayanand et al. [61] em termos de desempenho e flexibilidade. Por exemplo, para as demandas de tráfego de 70 e 80 erlangs, os resultados demonstram, respectivamente, uma redução do número de chamadas bloqueadas para o AG proposto de $33 \%$ e $18 \%$ em relação ao esquema de Vijayanand et al. [61].

$\mathrm{Na}$ rede italiana de faixa larga foram avaliados o impacto das restrições da camada física no desempenho da rede óptica. As restrições consideradas são a emissão espontânea amplificada (ASE- amplified spontaneous emission) e a dispersão por modo de polarização (PMD - polarization mode dispersion). O algoritmo proposto realiza o RWA sujeito às restrições da camada física, limita o número de amplificadores em cascata e reduz o número de conversões de comprimentos de onda, mantendo a qualidade de transmissão do sinal óptico. Ainda, determina a distribuição dos conversores, compensadores de PMD e amplificadores ópticos na rede.

Adicionalmente, foi incluído nos modelos a agregação de tráfego dinâmico e o controle de admissão de conexão. São utilizados dois tipos de nós de rede: seletivos em comprimento de onda (WSXC- wavelength selective crossconnect) e com agregação em comprimento de onda (WGXC- wavelength grooming crossconnect). O algoritmo proposto permite avaliar o desempenho da rede para diferentes configurações esparsas, otimizando a distribuição dos nós WSXC e WGXC. Por exemplo, equipando-se a rede italiana de faixa larga com chaves WSXC obtém-se uma melhoria na utilização dos recursos de 14,14\%, enquanto o uso das chaves WGXC, mais caras e complexas, possibilita uma melhoria de $30,06 \%$. O equilíbrio entre desempenho e custo dos equipamentos pode ser obtido por meio da distribuição esparsa das chaves WSXC e WGXC determinada pelo AG.

\subsubsection{Rede Móvel Celular}

Foram elaboradas duas estratégias utilizando algoritmos genéticos para otimização da alocação dinâmica de canais em um sistema de comunicações móveis. Na primeira abordagem, denominada GALC (genetic algorithm with locking channel), os canais previamente indicados são mantidos fixos durante todo o tempo de permanência da chamada. Na segunda, GASC (genetic algorithm with switching channel), as chamadas podem ser comutadas para diferentes canais durante o tempo de conexão. Os algoritmos foram extensivamente avaliados em um arranjo formado por 49 células e 70 canais disponíveis, considerando distribuições de tráfego uniforme e não-uniforme, em 
presença de handoff e sujeito às restrições de compatibilidade eletromagnética (EMC).

O objetivo dos algoritmos consiste em determinar uma solução otimizada para a alocação dos canais, sujeita às restrições EMC, minimizando a probabilidade de bloqueio global. Fundamentalmente, apresenta uma solução para o ambiente celular considerando simultaneamente o handoff e as restrições EMC. As restrições eletromagnéticas são a co-canal, canal adjacente e co-site.

Os modelos GALC e GASC foram comparados aos modelos FCA, DCA-Q e FCABDCL relatados na literatura. Os resultados demonstram a eficiência do AG proposto e destaca o modelo GASC como o melhor modelo estudado para resolver o CAP. Por exemplo, para duas distribuições homogêneas de tráfego de 7 e 8 erlangs os resultados demonstram redução no número de chamadas bloqueadas para o GASC em $37 \%$ e $17 \%$ em relação ao esquema FCA-BDCL [87].

Em destaque foi apresentado a influência do controle adaptivo no desempenho dos modelos. O controle adaptativo melhora o desempenho do modelo em termos de probabilidade de bloqueio e exige menor tempo de simulação. Antes da ocorrência da falha, o sistema adaptativo apresenta desempenho melhor do que o não-adaptativo. Por exemplo, considerando duas distribuições de demanda de tráfego heterogêneo com médias 91,83 e 106,53 chamadas por hora com aumento de tráfego de 80 e 60 por cento, respectivamente, o GASC adaptativo possibilita uma redução no número de chamadas bloqueadas de $24 \%$ e $13 \%$ em relação ao não-adaptativo.

\subsubsection{Rede Híbrida}

Foi apresentada a simulação de uma rede brasileira de comunicação óptica integrada a uma rede de comunicação via satélite, para enfatizar a versatilidade do algoritmo proposto. A rede óptica conecta-se a rede de satélite por meio de estações terrestres estrategicamente localizadas. Os enlaces da rede óptica apresentam distribuição heterogênea de comprimentos de onda. Cada comprimento de onda pode ser agregado em $g=4$ sub-bandas. A banda básica é de 2,5 Gbps, com taxa total de $10 \mathrm{Gbps}$. As estações terrestes são equipadas com transceptores digitais com 4 canais de 2,5 Gbps. Cada canal pode ser agregado em $g=4$ sub-bandas, com banda básica de $622 \mathrm{Mbps}$. A comunicação entre estações é realizada por meio de um enlace englobando um satélite geoestacionário. Foram utilizados dois tipos de nós de rede: WSXC e WGXC.

O desempenho da rede foi avaliado para rede com agregação plena, rede sem agregação e para duas configurações de agregação esparsa. O desempenho em relação à probabilidade de bloqueio global é superior utilizando os modelos agregação de tráfego. Por exemplo, em relação à rede sem agregação e considerando as demandas de tráfego de 4 e 8 ( $\times 5,3$ erlangs), a melhoria na probabilidade de bloqueio global da rede com 
agregação plena é de $93 \%$ e $74 \%$, respectivamente. Para as demandas consideradas, as configurações esparsas apresentam redução no número de requisições bloqueadas de $80 \%$ e $60 \%$, respectivamente.

Os resultados numéricos indicam a aplicabilidade da abordagem proposta na gerência integrada de redes distintas, identificando rotas e dispositivos mais utilizados. Por exemplo, no gerenciamento da rede híbrida brasileira caso se deseje aumentar a demanda de tráfego o AG elegeu os enlace entre os nós 17 e 18 (Aracajú-Salvador) e 25 e 26 (Brasília- Palmas) como os candidatos a uma futura ampliação de capacidade.

\subsection{Propostas para Trabalhos Futuros}

As revistas especializadas têm exibido quantidade crescente de artigos descrevendo alternativas para alocação otimizada de recursos em redes de telecomunicações.

A modelagem mais realista de componentes e sistemas, como comutadores ópticos (OXC), conversores de comprimento de onda e compensadores de dispersão, ainda não foi extensivamente investigada e pode ser ampliado com o uso dos algoritmos já desenvolvidos. O objetivo é avaliar e reduzir o impacto de suas limitações sobre o desempenho das redes. Como algumas restrições da camada física já foram abordadas neste trabalho, a incorporação aos algoritmos de outras limitações fica facilitada.

Outro tema que se destaca é o impacto da utilização de formatos diferentes de modulação e técnicas de processamento de sinais já utilizados em outros tipos de sistemas de comunicação para permitir a transmissão de sinais com taxas de 40 Gbps por meio da infra-estrutura instalada das redes ópticas que transportam taxas de 10 Gbps. Os formatos que estão sendo avaliados são o duobinário, M-PAM, SSB/VSB e DPSK, entre outros. A meta é melhorar a eficiência espectral limitada dos formatos NRZ e RZ, reduzir as penalidades associadas, permitindo ampliar significativamente as distâncias sem regeneração de enlaces de sistemas de $40 \mathrm{Gbps}$. Como os algoritmos desenvolvidos neste trabalho avaliam a probabilidade de bloqueio diante de restrições da camada física, eles poderiam ser ampliados para acomodar esquemas de avaliação do impacto destes formatos no desempenho das redes.

Por outro lado, há tendência de reduzir o número de camadas de protocolos que compõem as redes atuais para melhorar a eficiência. Destaca-se a redução para duas camadas, compondo a arquitetura IP sobre WDM. A padronização tende para a adoção da arquitetura GMPLS (generalized multiprotocol label switching). Para tanto, os protocolos de sinalização e roteamento devem se adaptar às funcionalidades da comutação óptica. Dentre eles, destacam-se o protocolo de roteamento OSPF-TE (open shortest path first-traffic engineering) e o protocolo de sinalização RSVP-TE (resource reservation protocol-traffic engineering). Um tema para pesquisa seria estudar a viabilidade 
de implementação destes protocolos com base em algoritmos genéticos.

Ainda no caso de redes ópticas, a implementação de esquemas de proteção contra falhas pode ser ampliada, bem como o de agregação de tráfego, para garantir qualidade de serviço.

Em relação às redes de comunicação sem fio, a alocação e gerenciamento de faixas de freqüências são temas para futuros trabalhos, dado o oferecimento crescente de serviços faixa larga e as emergentes redes sem fio de computadores.

O desenvolvimento de algoritmos para projeto e alocação de recursos em redes híbridas é outro tema de pesquisa que pode ser ampliado com os resultados preliminares obtidos neste trabalho. 


\section{Referências Bibliográficas}

[1] S. Dixit, Y. Guo e Z. Antoniou, "Resource management and quality of service in third-generation wireless networks", IEEE Communications Magazine, pp. 125-133, fevereiro de 2001.

[2] D. Ralph e I. Bonner, "3G and beyond- The applications generation", Third International Conference on $3 \mathrm{G}$ Mobile Communication Technologies, pp. 433438, maio de 2002.

[3] J.A. Village, K.P. Worral e D.L. Crawford, "3G shared infrastructure", Third International Conference on 3G Mobile Communication Technologies, pp. 10-16, maio de 2002.

[4] M. Diniz e J. Fernandes, "Provision of sufficient transmission capacity for broadband mobile multimedia: A new step toward $4 \mathrm{G}$ ", IEEE Communications Magazine, vol. 39, pp. 46-54, agosto de 2001.

[5] T. Cinkler, "Traffic and $\lambda$ Grooming", IEEE Network, vol. 17, no. 2, pp. 16-21, março/abril de 2003.

[6] F.T. Andrews, "The telephone network of the 1960s", IEEE Communications Magazine, vol. 40, no. 7, pp. 49-53, julho de 2000.

[7] Bell Labs "Networking", Technology Bell Labs Trends \&Developments, vol. 4, no. $2,2000$.

[8] M. Listanti, V. Eramo e R. Sabella, "Architectural and technological issues for future optical internet networks", IEEE Communications Magazine, vol. 38, no. 9, pp. 82-92, setembro de 2000.

[9] J.M.H. Elmirghani e H.T. Mouftah, "All-optical wavelength conversion: technologies and applications in DWDM networks", IEEE Communications Magazine, vol. 38, no. 3, pp. 86-92, março de 2000.

[10] M.S. Borella, J.P. Jue, D. Banerjee, B. Ramamurthy e B. Mukherjee, "Optical components for WDM lightwave networks", Proceedings of the IEEE, vol. 85, no. 8, pp. 1274-1307, agosto de 1997.

[11] J.M. Yates, M.P. Rumsewicz e J.P.R. Lacey, "Wavelength converters in dynamically-reconfigurable WDM networks", IEEE Communications Surveys, pp. 2-15, 1999. 
[12] A.E. Willner, "Mining the optical bandwidth for a terabit per second", IEEE Spectrum, pp. 32-41, abril de 1997.

[13] K. Fukuchi, T. Kasamatsu, M. Morie, R. Ohhira, T. Ito, K. Sekiya, D. Ogasahara e T. Ono, "10,92 Tb/s $(273 \times 40 \mathrm{~Gb} / \mathrm{s})$ triple-band/ultra-dense WDM optical-repeatered transmission experiment", IEEE Optical Fiber Communications OFC, pp. PD24-1-PD24-3, 2001.

[14] J.M.H. Elmirghani e H.T. Mouftah, "Technologies and architectures for scalable dynamic dense DWM networks", IEEE Communications Magazine, vol. 38, no. 2, pp. 58-66, fevereiro de 2000.

[15] C. Qiao, D. Datta, G. Ellinas, A. Gladish, E. Modiano e J. Hayes, "Guest editorial: WDM-based network architetures", IEEE Journal on Selected Areas in Communications, vol. 20, no. 1, pp. 1-3, janeiro de 2002.

[16] J. Strand, R. Doverspike e G. Li, "Importance of wavelength conversion in an optical network", Optical Networks Magazine, pp. 24-32, maio/junho de 2001.

[17] K. C. Lee e O. K. Li, "A wavelenght-convertible optical network", Journal of Lightwave Technology, vol. 11, no. 5/6, pp. 962-970, maio/junho de 1993.

[18] S. Wu, H. Pang, X. Sun e M. Zhang, "Wavelength conversion in WDM alloptical networks and analytical models", International Journal of Infrared and Millimeter Waves, vol. 21, no. 12, pp. 2055-2063, 2000.

[19] K.G. Ramakrishnan e M.A. Rodrigues, "Optimal routing in shortest-path data networks", Bell Labs Technical Journal, pp. 117-137, janeiro/junho de 2001.

[20] B. Chen e J. Wang, "Efficient routing and wavelength assignment for multicast in WDM networks", IEEE Journal on Selected Areas in Communications, pp. 97-109, vol. 20, no. 1, janeiro de 2002.

[21] H. Harai, M. Murata e H. Miyara, "Heuristic algorithm for allocation of wavelength convertible nodes and routing coordination in all-optical networks", Journal on Ligthwave Technology, vol. 17, no. 4, pp. 535-545, abril de 1999.

[22] L. Li e A. K. Somani, "Dynamic wavelength routing using congestion and neighborhood information", IEEE/ACM Transactions on Networking, vol. 7, no. 5, pp. 779-786, outubro de 1999.

[23] J. Yoo e S. Banerjee, "Design, analysis, and implementation of wavelengthrouted all-optical networks: routing and wavelength assignment approach" IEEE Communications Surveys, Broadband Networks area, vol. 1, no. 1, 1998. http://home.att.net/ sbanerjee/papers/YoBa97.pdf.

[24] M. Kovacevic e A. Acampora, "Benefits of wavelength translation in all-optical clear channel networks", IEEE Journal on Selected Areas in Communications, vol.14, no. 5, pp. 868-880, junho de 1996. 
[25] A. Birman, "Computing approximate blocking probabilities for a class of alloptical networks", IEEE Journal on Selected Areas in Communications, vol. 14, pp. 852-857, junho de 1996.

[26] A. Mokhtar e M. Azizoglu, "Adaptive wavelength routing in all-optical networks", IEEE/ACM Transactions on Networking, vol. 6, no. 2, pp. 197-206, abril de 1998.

[27] S. Ramamurthy e B. Mukherjee, "Fixed-alternate routing and wavelength conversion in wavelength-routed optical networks", Proceedings of IEEE GLOBECOM '98, Sydney, Australia, pp. 2295-2303, 1998.

[28] H. Harai, H. Miyahara e M. Murata, "Performance of alternate routing methods in all-optical switching networks", Proceedings of the IEEE INFOCOM '97, vol. 2, pp. 516-524, abril de 1997.

[29] D. Banerjee e B. Mukherjee, "Practical approaches for routing and wavelength assignment in all-optical wavelength-routed networks", IEEE Journal on Selected Areas in Communications, vol. 14, no. 5, pp. 903-908, junho de 1996.

×[30] B.M.E. Moret e H.D. Shapiro, Algorithms from P to NP: Design and Efficiency. The Benjamin/Cummings Publishing Company, Inc. CA, 1990, p. 576.

[31] A. Aggarwal, A.Bar-Noy, D. Coppersmith, R. Ramaswami, B. Schieber e M. Sudan, "Efficient routing and scheduling algorithms for optical networks", ACM/SIAM Symposium on Discrete Algorithms, pp. 412-423, janeiro de 1994.

[32] A. Aggarwal, A.Bar-Noy, D. Coppersmith, R. Ramaswami, B. Schieber e M. Sudan, "Efficient routing in optical networks", Journal of the ACM/JACM Association for Computing Machinery, vol. 43 , no. 6, pp. 973-1001, novembro de 1996.

[33] R.A. Barry e P. Humblet, "On the number of wavelengths and switches in alloptical networks", IEEE Transactions on Communications, vol. 42, no. 2/3/4, pp. 583-591, fevereiro/março/abril de 1994.

[34] Ramaswami e K.N. Sivarajan, "Design of logical topologies for wavelength routed optical networks", Proceedings of the IEEE INFOCOM '95, pp. 1316-1325, Boston, abril de 1995.

[35] S. Banerjee e C. Chen, "Design of wavelength-routed optical networks for packet switched traffic", Proceedings of IEEE ICC'96, pp.444-448, Dallas, junho de 1996.

[36] Ramaswami e K.N. Sivarajan, "Optimal routing and wavelength assignment in all-optical networks", Proceedings of the IEEE INFOCOM '94, pp. 970-979, Toronto, junho de 1994.

[37] D. Banerjee e B. Mukherjee, "Wavelength-routed optical networks: linear formulation, resource budgeting tradeoffs, and a reconfiguration study", IEEE Transactions on Networking, vol. 8, no. 5, pp. 598-607, outubro de 2000. 
[38] R.A. Barry e P. Humblet, "Models of blocking probability in all-optical networks with and without wavelengths changers", IEEE Journal on Selected Areas in Communications, vol. 14, no. 5, pp. 858-867, junho de 1996.

[39] B. Mukherjee, S. Ramamurthy, D. Banerjee e A. Mukherjee, "Some principles for designing a wide-area optical networks", Proceedings of IEEE INFOCOM '94, pp. 110-119, Toronto, junho de 1994.

[40] Z. Zhang e A.S. Acampora, "A heuristic wavelength assignment algorithm for multihop WDM networks with wavelength routing and wavelength re-use", IEEE Transactions on Communications, vol. 40, no. 7, pp. 1171-82, julho de 1992.

[41] A.E. Eiben e G. Rudolph, "Theory of evolutionary algorithms: a bird's eye view", Theoretical Computer Science, vol. 229, pp. 3-9, 1999.

[42] R.S. Sutton e A.G. Barto, Reinforcement Learning: An Introduction. MIT Press, Cambridge, MA, 1998, p. 432.

[43] D.E. Moriarty, A.C. Schultz e J. J. Grefenstette, "Evolutionary algorithms for reinforcement learning", Journal of Artificial Intelligence Research, vol. 11, pp. 241-276, setembro de 1999.

[44] L.P. Kaelbling, M.L. Littman e A.W. Moore, "Reinforcement learning: a survey", Journal of Artificial Intelligence Research, vol. 4, pp. 237-285, abril de 1996.

[45] S.S. Keerthi e B. Ravindran, "A tutorial survey of reinforcement learning", Sadhana, published by the Indian Academy of Sciences, vol.19, no. 6, pp. 851-889, 1994.

[46] L. Kanal e V. Kumar, Search in Artificial Intelligence. London, UK: SpringerVerlag, 1988, p. 482.

[47] D.M. Skapura, Building Neural Networks. ACM Press/Addison-Wesley Publishing Co. New York, NY, USA, 1996, p. 286.

X[48] K.F. Man, K.S. Tang e S. Kwong, "Genetic algorithms: concepts and designs", IEEE Transactions on Industrial Electronics, vol. 43, no. 5, pp. 519-534, outubro de 1996.

[49] H. Chou, G. Premkumar e C-H. Chu, "Genetic algorithms for communications network design-An empirical study of the factors that influence performance", IEEE Transactions on Evolutionary Computation, vol. 5, no. 3, pp. 236-249, junho de 2001.

[50] M.A.C. Lima, A.C. César e A.F.R. Araújo, "Optical network optimization with transmission impairments based on genetic algorithm", 2003 SBMO/IEEE MTT-S International Microwave and Optoelectronics Conference- IMOC 2003 Proceedings, vol. 1, pp. 361-365, Foz do Iguaçu, Brazil, setembro de 2003. 
[51] M.A.C. Lima, A. F.R. Araújo e A.C. César, "Dynamic channel assignment in mobile communications based on genetic algorithms", The 13th IEEE International Symposium on Personal, Indoor, Mobile Radio Communications, Lisboa, Portugal, setembro de 2002.

[52] M.A.C. Lima, A. F.R. Araújo e A.C. César, "Agregação dinâmica de tráfego em redes ópticas WDM sob impacto de ASE e PMD utilizando algoritmo genético", XXI Simpósio Brasileiro de Telecomunicações-SBT'04, pp. 1-6 (CDROM), Belém, PA, setembro de 2004.

[53] M.A.C. Lima, A. F.R. Araújo e A.C. César, "Agregação dinâmica de tráfego em redes ópticas WDM utilizando algoritmo genético", $11^{\circ}$ SBMO- Simpósio Brasileiro de Microondas e Optoeletrônica (MOMAG 2004), pp. 1-6 (CD-ROM), ISSN-1807-0809, São Paulo, SP, agosto de 2004.

[54] M.A.C. Lima, A. F.R. Araújo e A. C. César, "Dynamic channel assignment using genetic algorithms for mobile communications", X Simpósio Brasileiro de Microondas e Optoeletrônica-SBMO 2002, vol.1, pp.458-462, Recife, PE, agosto de 2002 .

[55] M.A.C. Lima, A. F.R. Araújo e A.C. César, "Alocação dinâmica de canais em sistemas de comunicações móveis utilizando algoritmos genéticos", XIX Simpósio Brasileiro de Telecomunicações- SBT' 2001, vol.1, pp.1-6 (CD-ROM), Fortaleza, CE, setembro de 2001.

[56] L.D.S. Alcantara, M.A.C. Lima, A.F.R. Araújo, A.C. César e B-H V. Borges, "Projeto de isolador óptico utilizando algoritmo genético", XX Simpósio Brasileiro de Telecomunicações-SBT'03, pp. 1-5 (CD-ROM), Rio de Janeiro, RJ, outubro de 2003.

[57] M.A.C. Lima, A.F.R. Araújo e A.C. César, "Roteamento e alocação de comprimentos de onda em redes ópticas usando algoritmo genético", XX Simpósio Brasileiro de Telecomunicações-SBT'03, pp.1-5 (CD-ROM), Rio de Janeiro, RJ, outubro de 2003.

[58] C. Rose e R.D. Yates, "Genetic algorithms and call admission to telecommunications networks", Computers and Operations Research, vol. 23, no. 5, pp. 485-499, 1996.

[59] C. Gazen e C. Ersoy, "Genetic algorithms for designing multihop lightwave network topologies", Artificial Intelligence in Engineering, vol. 13, pp. 211-221, 1996.

*60] D. Saha, M. D. Purkayastha e A. Mukherjee, "An approach to wide area WDM optical network design using genetic algorithm", Computer Communications, vol. 22 , no. 2, pp. 156-172, janeiro de 1999.

[61] C. Vijayanand, M. S. Kumar, K. R. Venugopal and P. S. Kumar, "Converter placement in all-optical networks using genetic algorithms", Computer Communications, vol. 23, pp. 1223-1234, 2000. 
×[62] D. Bisbal, I. Miguel, F. González, J. Blas, J.C. Aguado, P. Fernández, J. Durán, R. Durán, R.M. Lorenzo, E.J. Abril e M. López, "Dynamic routing and wavelength assignment in optical networks by means of genetic algorithms", Photonic Network Communications, vol. 7, no. 1, pp. 43-58 (16), 2004.

[63] J.H. Siregar, H. Takagi e Y. Zhang, "Optimal converter placement in optical networks by genetic algorithm", IEICE Transactions on Communication, vol.E85-B, no. 6, pp.1075-1082, junho de 2002 .

[64] S. Subramaniam, M. Azizoglu e A.K. Somani, "All-optical networks with sparse wavelength conversion", IEEE/ACM Transactions on Networking, vol. 4, no. 4, pp. 544-557, agosto de 1996.

[65] S. Subramaniam, M. Azizoglu e A.K. Somani, "On optimal converter placement in wavelength-routed networks", IEEE/ACM Transactions on Networking, vol. 7, no. 5, pp. 754-766, outubro de 1999.

[66] B. Ramamurthy e B. Mukherjee, "Wavelength conversion in WDM networking", IEEE Journal on Selected Areas in Communications, vol. 16, no. 7, pp. 10611073, setembro de 1998.

- [67] J. Strand, A.L. Chiu e R. Tkach, "Issues for routing in the optical layer", IEEE Communications Magazine, vol. 39, no. 2, pp. 81-87, fevereiro de 2001.

[68] R. Sabella, E. Iannone, M. Listanti, M. Berdusco e S. Binetti, "Impact of transmission performance on path routing in all-optical transport networks", Journal of Lightwave Technology, vol. 16, no. 11, pp. 1965-71, novembro de 1998.

[69] M. Ali, D.E.D. Cosaque e L. Tancevski, "Network optimization with transmission impairments-based routing", ECOC’01 Amsterdam, pp. 1-3 (CD-ROM), 2001.

[70] E. Karasan e E. Ayanaglu. "Effects of wavelength routing and selection algorithms on wavelength conversion gain in WDM optical networks", IEEE Transactions on Communications, vol. 6, no. 2, pp. 186-196, abril de 1998.

[71] A.F. Cerutti, R. Rajagopalan, M.R.X. de Barros e S.M. Rossi, "Impact of polarization mode dispersion in multi-hop and multi-rate WDM rings", Photonic Network Communications, vol.5, no.3, pp.259-271, 2003.

[72] I.E. Fonseca, R.C. Almeida Jr, M.R.N. Ribeiro e H. Waldman, "Greedy algorithm for reducing FWM impairments in dynamic optical networks", XX Simpósio Brasileiro de Telecomunicações-SBT'03, pp. 122-126 (CD-ROM), Rio de Janeiro, RJ, outubro de 2003.

[73] I.E. Fonseca, R.C. Almeida Jr, H. Waldman e M.R.N. Ribeiro, "CAC/RWA's for preserving optical QoS in dynamic optical networks", $11^{\circ}$ SBMO-Simpósio Brasileiro de Microondas e Optoeletrônica (MOMAG 2004), pp. 1-5 (CD-ROM), ISSN-1807-0809, São Paulo, SP, agosto de 2004. 
[74] R. Dutta e G.N. Rouskas, "Traffic grooming in WDM networks: past and future", IEEE Network, vol.16, no. 6, pp. 46-56, novembro/dezembro de 2002.

[75]) R. Parthiban, R. S. Tucker e C. Leckie, "Waveband grooming and IP aggregation in optical networks", Journal of Lightwave Technology, vol. 21, no. 11, pp. 24762488, novembro de 2003.

[76] N. Srinivas e C.S.R Murthy, "Design and dimensioning of a WDM mesh network to groom dynamically varying traffic", Photonic Network Communication, vol. 7, no. 2, pp. 179-191, março de 2004.

[77] K. Zhu, H. Zhu e B. Mukherjee, "Traffic engineering in multigranularity heterogeneous optical WDM mesh networks through dynamic traffic grooming", IEEE Network, vol.17, no. 2, pp. 8-15, março/abril de 2003.

[78] S. Thiagarajan e A.K. Somani, "Performance analysis of WDM optical networks with grooming capabilities", Proceedings SPIE Int. Symp. On Voice, Video, and Data Communication. -Terabit Optical Networking: Arch., Control, and Management, Boston, novembro de 2000.

479] S. Thiagarajan e A.K. Somani, "Capacity fairness of WDM networks with grooming capabilities", Optical Networks Magazine, pp. 24-32, maio/junho de 2001.

[80] K.-N. Chang e S. Kim, "Channel allocation in cellular radio networks", Computers and Operations Research, vol. 24, no. 9, pp. 849-860, setembro de 1997.

[81] R. Fantacci, "Performance evaluation of prioritized handoff schemes in mobile cellular networks", IEEE Transactions on Vehicular Technology, vol. 49, no. 2, pp. 485-493, março de 2000.

[82] L.O.-Guerreiro e A.H. Aghvami, "A prioritized handoff dynamic channel allocation strategy for PCS", IEEE Transactions on Vehicular Technology, vol. 48, no. 4, pp. 1203-1215, julho de 1999.

[83] A.A. Shinoda e M.D. Yacoub, "Combined techniques for channel allocation algorithms in mobile radio systems", IEE Proceedings of Communications, 144 (3), pp. 205-210, junho 1997.

[84] E. Del Re, R. Fantacci e G. Giambene, "Handover and dynamic channel allocation techniques in mobile cellular networks", IEEE Transactions on Vehicular Technology, vol. 44, no. 2, pp. 224-234, maio de 1995.

[85] S. Yamanaka, H. Kawano e Y. Takahashi, "Modeling and performance analysis of cellular networks with channel borrowing", IEICE Transactions on Communications, vol. E85-B, no. 5, pp. 929-937, 2002.

[86] Y. Xiao, C.L. Philip Chen e Y. Wang, "A near optimal call admission control with genetic algorithm for multimedia services in wireless/mobile networks", Proceedings of National Aerospace and Electronics Conference 2000 (NAECON), pp. 787-792, 2000. 
[87] M. Zhang e T.S.P. Yum, "Comparisons of channel-assignment strategies in cellular mobile telephone systems", IEEE Transactions on Vehicular Technology, vol. 38, no. 4, pp. 211-215, novembro de 1989.

[88] A.A. Bertossi, C.M. Pinotti e R.B. Tan, "Channel assignment with separation for interference avoidance in wireless networks", IEEE Transactions on Parallel and Distributed Systems, vol. 14, no. 3, março de 2003.

[89] S. Sakar e K.N. Sivarajan, "Channel assignment algorithms satisfying cochannel and adjacent channel reuse constraints in cellular mobile networks", IEEE Transactions on Vehicular Technology, vol. 51, no. 5, pp. 954-967, setembro de 2002.

[90] K.N. Sivarajan, R.J. McEliece e J.W. Ketchum, "Channel assignment in cellular radio" in Proceedings 39th IEEE Vehicular Technology Conference, Local, pp. 846-850, maio de 1989.

[91] N. Funabiki, T. Nakanishi, T. Yokohira, S. Tajima e T. Higashino, "A quasisolution state evolution algorithm for channel assignment problems", IEICE Transactions on Fundamentals, vol. E85-A, no.5, pp. 977-987, maio de 2002

[92] W.K. Lai e G.G. Coghill, "Channel assignment through evolutionary optimization", IEEE Transactions on Vehicular Technology, vol. 45, no. 1, pp. 91-96, fevereiro de 1996.

[93] Y. Ngo e V.O.K. Li, "Fixed channel assignment in cellular radio networks using a modified genetic algorithm", IEEE Transactions on Vehicular Technology, vol. 47, no. 1, pp.163-172, fevereiro de 1998.

[94] D. Beckmann e U. Killat, "A new strategy for the application of genetic algorithm to the channel-assignment problem", IEEE Transactions on Vehicular Technology, vol. 48, no. 4, pp. 1261-1269, novembro de 1989.

[95] Yener e C. Rose, "Genetic algorithms applied to cellular call admission: local policies", IEEE Transactions on Vehicular Technology, vol. 46, no. 1, pp. 72-79, fevereiro de 1997.

[96] F.J. Jaimes-Romero, D. Munoz-Rodriguez e S. Tekinay, "Channel assignment in cellular systems using genetic algorithms", in Proceedings of the IEEE Vehicular Technology Conference-VTC'96, Atlanta, GA, maio de 1996.

[97] C.Y. Lee, H.G. Kang e T. Park, "A dynamic sectorization of microcells for balanced traffics in CDMA: genetics algorithms approach", IEEE Transactions on Vehicular Technology, vol. 51, no. 1, pp. 63-72, janeiro de 2002.

[98] S. Tekinay e B. Jabbari, "A measurement based prioritization scheme for handovers in mobile cellular networks", IEEE Journal on Selected Areas in Communications, vol. 10, no. 8, pp 1343-1350, outubro de 1992. 
[99] S. Borst e P. Whiting, "Achievable performance of dynamic channel assignment schemes under varying reuse constraints", IEEE Transactions on Vehicular Technology, vol. 49, no. 4, pp. 1248-1254, julho de 2000.

[100] J. Nie e S. Haykin, "A Q-learning dynamic channel assignment technique for mobile communication systems", IEEE Transactions on Vehicular Technology, vol. 48 , no. 5, pp. 1676-1687, setembro de 1999.

[101] J. Nie e S. Haykin, "A dynamic channel assignment policy through Q-learning", IEEE Transactions on Neural Networks, vol. 10, no. 6, pp. 1443-1455, novembro de 1999.

[102] J. Zander, "Generalized re-use partitioning in cellular mobile radio", in Proceedings 43th IEEE Vehicular Technology Conference, pp. 181-184, maio de 1993.

[103] I. Katzela e M. Naghshineh, "Channel assignment schemes for cellular mobile telecommunication systems: A comprehensive survey", IEEE Personal Communications, pp. 10-31, junho de 1996.

[104] K.N. Sivarajan, R.J. McEliece e J.W. Ketchum, "Dynamic channel assignment in cellular radio", in Proceedings 40th Vehicular Technology Conference, pp. 631-637, 1990.

$\Varangle[105]$ D.E. Goldberg, Genetic Algorithms in Search, Optimization, and Machine Learning. Addison-Wesley Longman Publishing Co., Inc. Boston, MA, USA, 1989, p. 432.

[106] A. S. Tanenbaum, Computer Networks. Prentice Hall PTR, New Jersey, USA, 2002, ed. 4th, p. 891.

[107] J.W. Roberts, "Traffic Theory and the Internet", IEEE Communications Magazine, vol. 39, no. 1, pp. 94-99, janeiro de 2001.

X[108] L. Xu, H.G. Perros e G. Rouskas, "Techniques for optical packet and optical burst switching", IEEE Communications Magazine, vol. 38, no. 2, pp. 136-142, janeiro de 2001.

× [109] J.R. Boucher, Traffic System Design Handbook: Timesaving Telecommunication Traffic Tables and Programs. New York, IEEE Press, 1992, p. 200.

[110] D. Bayart, P. Baniel, A. Bergonzo, J.-Y. Boniort, P. Bousselet, L. Gasca, D. Hamoir, F. Leplingard, A. Le Sauze, P. Nouchi, F. Roy e P. Sillard, "Broadband optical fibre amplification over $17.7 \mathrm{THz}$ range", Electronics Letters, vol. 36, no. 18, pp. 1569-1571, agosto de 2000.

[111] S. Sudo, Optical Fiber Amplifiers: Materials, Devices and Applications. Artech House Optoelectronics Library, Inc. MA, 1997. 627 p.

[112] Web Proforum Tutorials, "Raman amplification design in WDM systems", The International Engineering Consortium, www.iec.org, último acesso em 16 de dezembro de 2004. 
[113] S. Banedee, A. Agarwal, D.E. Grosz, A. Kung, D.N. Maywar, M. Movassaghi e T.H. Wood, "Long-haul 64x40 Gbit/s DWDM transmission over commercial fibre types with large operating margins", IEEE Electronics Letters, vol. 39, no. 1, pp. 92-94, janeiro de 2003.

[114] K. Iga, Fundamentals of Laser Optics. Plenum Publishing Corporation. New York, 1994, p. 285.

[115] G.P. Agrawal, Semiconductor Lasers: Past, Present, and Future. American Institute of Physics. New York, 1995, p. 365.

[116] W.T. Tsang, Semiconductors and Semimetals. Lightwave Communications Technology. vol. 22 Part E Integrated Optoelectronics. Academic Press, Inc. Orlando, Flórida, 1985, p. 325.

[117] G.P. Agrawal, Fiber-Optic Communication Systems. Jonh Wiley \& Sons, Inc. New York, 1992, p. 445.

[118] D. Nesset, T. Kelly e D. Marcenac, "All-optical wavelength conversion using SOA nonlinearities", IEEE Communications Magazine, vol. 46, no. 1, pp. 56-61, dezembro de 1998.

[119] R. Handel, M.N. Huber e S. Schroder, ATM Networks. Concepts, Protocols, Applications. Addison-Wesley Publishing Company. University Press Cambrige, Gran Britain, 2.ed., 1995, p. 287.

[120] C.A. Siller jr e M. Shafi, SONET SDH. A Sourcebook of Synchronous Networking. IEEE communication Society. IEEE Press, New York, 1996, p.391.

[121] D.J. Bishop, C.R. Giles e G.P. Austin, "The Lucent lambda router: MEMS technology of the future here today", IEEE Communications Magazine, vol. 40, no. 3, pp. 75-79, março de 2002.

[122] P.B. Chu, S-S. Lee e S. Park, "MEMS: the path to large optical crossconnects", IEEE Communications Magazine, vol. 40, no. 3, pp. 80-87, março de 2002.

[123] P.D. Dobbelaere, K. Falta, L. Fa e S. Gloeckner, "Digital MEMS for optical switching", IEEE Communications Magazine, vol. 40, no. 3, pp. 88-95, março de 2002 .

X [124] S. Banerjee, V. Jain e S. Shah, "Regular multihop logical topologies for lightwave networks", IEEE Communications Surveys, pp. 2-18, First Quarter 1999.

[125] G. Xiao e Y. Leung, "Algorithms for allocating wavelength converters in alloptical networks", IEEE/ACM Transactions on Networking, vol. 7, no. 4, pp. 545-557, agosto de 1999.

[126] W.C.Y. Lee, Mobile Communications Design Fundamentals. John Wiley \& Sons, Inc. 1993, p. 372. 
[127] I. Rechenberg, Evolutionstrategie: Optimierung technischer Systeme nach Prinzipien der biologischen Evolution. Stuttgart: Fromman-Holzboog, 2.ed., 1993.

[128] L.J. Fogel , A.J. Owens e M.J. Walsh, "Artificial Intelligence Through Simulated Evolution", John Wiley, New York, 1966, p. 170.

\& [129] J.H. Holland, Adaptation in Natural and Artificial Systems. Cambridge, MA: The MIT Press. 1992, p. 211.

$\vdash$ [130] C. Munteanu e V. Lazarescu, "Global search using a new evolutionary framework: The Adaptive reservoir genetic algorithm", Complexity International, vol. 5, julho de 1998. http://journal-ci.csse.monash.edu.au/ci/vol05/munteanu/.

[131] C. Darwin, On the Origin of Species by Means of Natural Selection. Jonh Murray, 1859 , p. 516.

† [132] J.R. Koza, Genetic Programming: on the Programming of Computers by Means of Natural Selection. Cambridge, Mass.: MIT Press, 1992, p. 819.

[133] K.A. De Jong, "An analysis of the behavior of a class of genetic adaptive systems", Doctoral dissertation, University of Michigan, 1975. Dissertation Abstracts International, vol. 36, no. 10, 5140B, University Microfilms no. 76-9381.

[134] D.E. Goldberg, K. Deb e J.H. Clark, "Genetic algorithms, noise, and the sizing populations", Complex Systems, vol. 6, no. 19, pp. 333-362, 1992.

[135] J.J. Grefenstette, "Optimization of control parameters for genetic algorithms", IEEE Transaction on Systems, Man and Cybernetics, vol.16, no.1, pp.122-128, janeiro/fevereiro de 1986 .

[136] J.D. Schaffer, R.A. Caruana, L.J. Eshelman, e R. Das, "A study of control parameters affecting online performance of genetic algorithms for function optimization", Proceedings of the Third International Conference on Genetic Algorithms, San Mateo, CA: Morgan Kaufmann, pp. 51-60, 1989.

[137] J. Hesser, R. Manner e O.Stucky, "Optimization of steiner trees using genetic algorithms", Proceedings of Third International Conference in Genetic Algorithms, pp. 231-236, junho de 1992.

[138] Z. Michalewicz, Genetic Algorithms + Data Structures = Evolution Programs. Berlin: Springer-Verlag, 2.ed., 1994, p. 340.

[139] J.E. Baker, "Reducing bias and inefficiency in the selection algorithm", Proceedings of the Second International Conference on Genetic Algorithms and their Application, Hillsdale, New Jersey, USA: Lawrence Erlbaum Associates, pp. 14-21, 1987.

[140] D.E. Goldberg e K. Deb, "A comparative analysis of selection schemes used in genetic algorithms", Foundations of Genetic Algorithms. San Mateo, California, USA: Morgan Kaufmann Publishers, pp. 69-93, 1991. 
[141] H. Muhlenbein e D. Schlierkamp-Voosen, "Predictive models for the breeder genetic algorithm: I. Continuous parameter optimization", Evolutionary Computation. MIT Press, vol. 1, no. 1, pp. 25-49, Spring 1993.

[142] R. Salomon, "Re-evaluating genetic algorithm performance under coordinate rotation of benchmark functions. A survey of some theoretical and practical aspects of genetic algorithms", Elsevier Science BioSystems, vol. 39, no. 3, pp263-278, 1996.

[143] K.A. De Jong and W.M. Spears, "An analysis of the interacting roles of population size and crossover in genetic algorithms", Proceedings of the First International Conference on Parallel Problem Solving from Nature, H.P. Schwefel and R. Manner (eds.), Berlin: Springer-Verlag, pp. 38-47, 1990.

[144] K.A. De Jong e W.M. Spears, "A formal analysis of the role of multi-point crossover in genetic algorithms", Annals of Mathematics and Artificial Intelligence, vol. 5, no. 1, 1992.

[145] W.M. Spears, "Crossover or Mutation?", in Whitley (ed.), Foundations of Genetic Algorithms-2. San Mateo, CA: Morgan Kaufmann Publishers, pp. 221-237, 1992.

[146] W.M. Spears, "Adapting crossover in a genetic algorithm", in Richard K. Belew and Lashon B. Booker (ed.). Proceedings of the 4th International Conference on Genetic Algorithms (ICGA'91), pp. 166-173, junho de 1991.

[147] T. Bäck, "Optimal mutation rates in genetic search", Proceedings of the fifth International Conference on Genetic Algorithms, in S. Forrest (ed.), pp. 2-8, 1993.

[148] P.J. Angeline, "Adaptive and self-adaptive evolutionary computation", in Palaniswami M., Attikiouzel Y., Marks R.J., Fogel D., and Fukuda T., editors, Computational Intelligence: A Dynamic System Perspective,IEEE Press, pp. 152-161, 1995.

[149] A.E. Eiben, R. Hinterding e Z. Michalewicz, "Parameter control in evolutionary algorithms", IEEE Transactions on Evolutionary Computation, vol. 3, no. 2, pp. 124-141, julho de 1999.

[150] R. Hinterding, Z. Michalewicz, e A.E. Eiben, "Adaptation in evolutionary computation: A survey", in Proceedings of the 4th IEEE Conference on Evolutionary Computation, pp. 65-69, abril de 1997.

[151] J.J. Grefenstette, "Genetic algorithms for changing environments", Parallel Problem Solving from Nature, 2. Amsterdam: North Holland, pp. 137-144, 1992.

[152] T. Bäck e Hans-Paul Schwefel, "Evolutionary computation: An overview", Proceedings of the third IEEE Conference on Evolutionary Computation 1996, IEEE Press, Piscataway NJ, pp. 20-29, 1996. 
[153] T. Bäck, "On the behavior of evolutionary algorithms in dynamic environments", Proceedings of the 5th IEEE International Conference on Evolutionary Computation - ICEC, pp. 446-451, 1998.

[154] N. Saravanan, D.B. Fogel e K.M. Nelson, "A comparison of methods for selfadaptation in evolutionary algorithms", Elsevier Science BioSystems, vol. 36, no. 2, pp. 157-166, 1995.

[155] T. Bäck, "Self-adaptation in genetic algorithms", In Francisco J. Varela and Paul Bourgine (ed.). Towards a Practice of Autonomous Systems: Proceedings of the First European Conference on Artificial Life, Cambridge, MA, MIT Press. pp. 263-271, 1992.

[156] X. Yao, G. Lin e Y. Liu, "An analysis of evolutionary algorithms based on neighborhood and step sizes", Proceedings 6th International Conference on Evolutionary Programming, pp. 297-307, abril de 1997.

[157] K.Chellapilla "Combining mutation operators in evolutionary programming", IEEE Transactions on Evolutionary Computation, vol. 2, no. 3, pp. 91-96, setembro de 1998.

[158] J. Lis e M. Lis, "Self-adapting parallel genetic algorithm with the dynamic mutation probability, crossover rate and population size", in Proceedings 1st Polish National Conference on Evolutionary Computation, pp. 324-329, 1996.

[159] S. Tongchim e P. Chongstitvatana, "Parallel genetic algorithm with parameter adaptation", Information Processing Letters, vol. 82, no. 1, pp. 47-54, 2002.

[160] W.M. Spears e K.A. De Jong "An analysis of multipoint crossover", Proceedings Workshop of the Foundations of Genetic Algorithms, ed. Morgan-Kauffmann, pp. 301-315. 1991.

[161] X. Chu, B. Li e I. Chlamtac, "Wavelength converter placement under different RWA algorithms in Wavelength-routed all-optical networks", IEEE/ACM Transactions on Networking, vol. 51, no. 4, pp. 607-617, abril de 2003.

[162] I. Chlamtac, A. Ganz e G. Karmi, "Lightpath communications: an approach to high bandwidth optical WAN's", IEEE Transactions on Communications, vol. 40, no. 7, pp. 1171-1182, julho de 1992.

[163] V.R. Konda e T.Y. Chow, "Algorithm for traffic grooming in optical networks to minimize the number of transceivers", Proceedings of the IEEE Workshop High Perf. Switching and Routing, pp. 218-21, maio de 2001.

† [164] R. Barr and R.A. Patterson, "Grooming telecommunications networks", Optical Networks Magazine, pp. 20-23, maio/junho de 2001.

[165] O. Gerstel e R. Ramaswami, "Cost-effective traffic grooming in WDM rings", IEEE/ACM Transactions on Networking, vol. 8, no. 5, pp. 618-630, outubro de 2000 . 
[166] R. Berry e E. Modiano, "Reducing electronic multiplexing costs in SONET/WDM rings with dynamically changing traffic", IEEE Journal on Selected Areas in Communications, vol. 18, no. 10, pp. 1961-71, outubro de 2000.

[167] D.Bertsimas e J.N. Tsitsiklis, Introduction to Linear Optimization. Athena Scientific. Massachusetts, 1997, p. 587.

[168] R.J. Horrocks e R.W.A. Scarr, Future Trends in Telecommunications. J. Wiley \& Sons, 1996, p. 452. 


\section{Apêndice A}

\section{Algoritmos para Coordenação de Roteamento em Redes Ópticas}

Dois algoritmos denominados descent e sequential para coordenação de roteamento em redes ópticas são utilizados por Harai et al. [21]. O procedimento dos algoritmos pode ser assim resumido:

Para as duas aproximações, iniciar o conjunto de rotas associando uma única rota a todo par origem-destino. Um conjunto de rotas primárias, $R_{a}^{(1)}$, está apresentado na Tabela 4.1. A rota alternativa é escolhida no conjunto $\left\{R_{a} ; i=1,2, \ldots, n_{a}\right\}$. Um conjunto de rotas alternativas, $R_{a}^{(2)}$, está apresentada na Tabela 4.2;

(a) Algoritmo sequential-para todos os pares origem-destino: Remover a rota atravessando o enlace mais carregado. O enlace mais carregado pode ser determinado por meio de $\alpha_{j}$ (4.19). Para todo par $a$ satisfazendo $R_{a} \in \Re_{j}$, encontrar as rotas canditadas $R_{a}^{(i)}\left(j \notin R_{a}^{(i)}\right)$ que não utilizam o enlace $j$. Para cada uma das rotas, calcule a soma do tráfego em todos os enlaces da rota $R_{a}^{(i)}$. A soma é calculada por $\sum_{k \in R_{a}^{(i)}} \alpha_{k}$. Encontrar a rota $R$ que minimiza o somatório sujeito à restrição $\alpha_{j}-e_{a} L_{a}>\alpha_{k}, k \in R_{a}^{(i)}$. A restrição indica que a rota alternativa não é apropriada quando a taxa de chegada de cada enlace na rota $R$ é maior que a do enlace $j$ atual;

(b) Algoritmo descent-substituir heuristicamente uma rota do par origem-destino até que o desempenho seja melhorado. $O$ ganho pode ser avaliado pela diferença entre a probabilidade de bloqueio (4.14) obtida pela rota atual $R_{a}$ e pela nova rota $R_{a}^{(i)}$. Para evitar infinitas iterações, o algoritmo é parado após um número suficiente de iterações. 


\section{Apêndice B}

\section{Problema de Estabelecimento Estático de Caminhos Ópticos}

Teorema 3 Estabelecimento estático de caminhos ópticos (SLE- static lightpath establishment) é NP-completo [162].

Prova. Primeiro, é demonstrado que resolvendo o problema de um grafo de $n$ coloração pode também resolver o SLE. Seja um grafo não-direcionado $G_{L}\left(V_{L}, E_{L}\right)$ com um nó $i \in V_{L}$ para todo caminho óptico em $L$. Dois vértices $i, j \in V_{L}$ possuem uma aresta de interconexão $e \in E_{L}$ se os respectivos caminhos ópticos possuem, no mínimo, um enlace em comum. Colorir $V_{L}$ com $n$ ou menos cores assim que nenhum par de vértices adjacentes possua a mesma cor. Assim, uma alocação de comprimentos de onda em $W$, poderia ser determinada, para qual nenhum par de caminhos ópticos em um mesmo enlace compartilha o mesmo comprimento de onda. Determinando um colorimento factível poderia também determinar uma alocação de comprimentos de onda factível, resolvendo o problema SLE.

Para completar a prova, demonstra-se que resolvendo SLE também se pode resolver o problema de grafos de $n$-coloração, sugerindo que determinar uma solução polinomial para o SLE é improvável. Isto será demonstrado descrevendo um algoritmo polinomial em tempo que representa qualquer problema de coloração de grafo em uma rede e um apropriado conjunto de demanda. Dado um grafo $G_{C}\left(V_{C}, E_{C}\right)$, traduz-se a coloração de $G_{C}$ no seguinte problema de estabelecimento de caminhos ópticos:

1) gerar um nó $v_{i}^{o}$ para todo nó $i \in V_{c}$;

2) para toda aresta $e=i \rightarrow j \in E_{C}$ :

a) gerar quatro novos nós $x, y, v_{i}^{k}, v_{j}^{l}$ e arestas direcionadas $v_{i}^{k-1} \rightarrow x, v_{j}^{l-1} \rightarrow x$, $x \rightarrow y, y \rightarrow v_{i}^{k}, x \rightarrow v_{j}^{l}$;

b) fixar a marca $i$ nas arestas direcionadas de/para $v_{i}$ 's, e $x \rightarrow y$; Repetir similarmente para a marca $j$.

A designação de um nó no novo grafo $v_{i}^{k}$ corresponde à $k$ - ésima replicação do nó correspondente ao nó $i$ na rede original, $k=0 \ldots d(i)$, na qual $d(i)$ é o grau nodal de $i$. A construção é exemplificada por um grafo de quatro nós. A Figura B.1 (a) mostra um grafo para o qual deve ser resolvido o problema de $n$-coloração. A Figura B.1 (b) ilustra a transformação em rede; os números dos enlaces são as marcas. O conjunto 


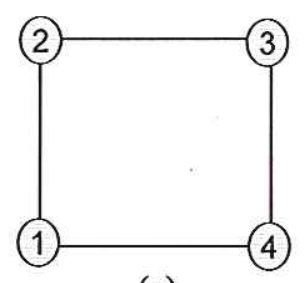

(a)

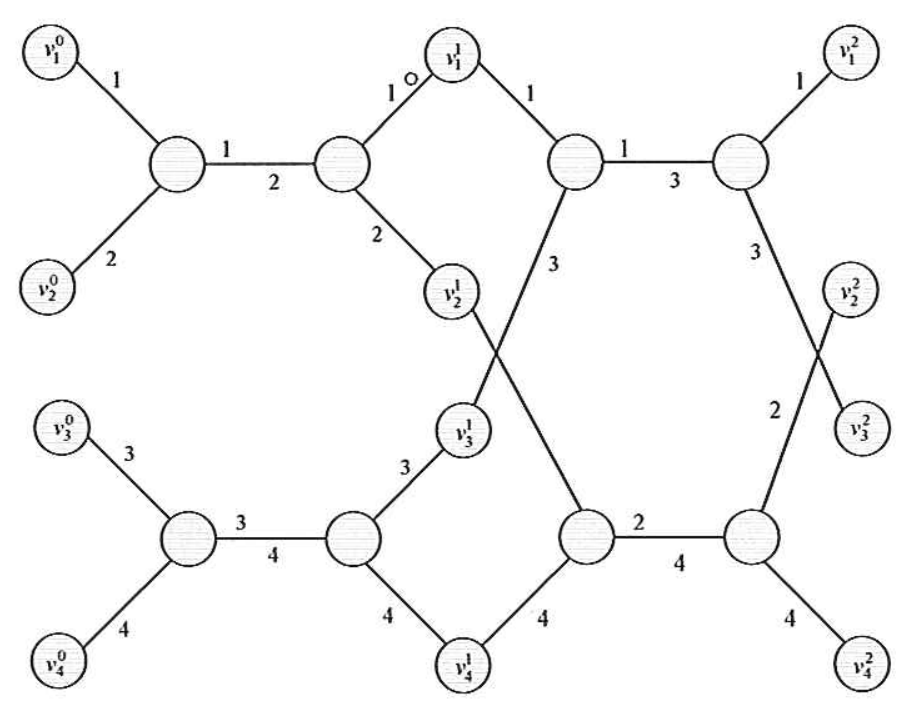

(b)

Figura B.1: (a) Grafo para o problema de $n$-coloração; (b) Translação para SLE [162].

de demanda dos caminhos ópticos $L$ é definido pelos $\left|V_{c}\right|$ caminhos ópticos, nos quais o caminho óptico $i$ requer o uso de todos os enlaces com a marca $i$. A complexidade do algoritmo é $O\left(\left|E_{c}\right|\right)$.

Lema 4 A solução para o SLE com n comprimentos de onda implica em que o número cromático de $G_{C}$ seja menor ou igual a $n$.

Prova. O Lema parte da construção. Se caminhos ópticos podem ser estabelecidos, então existe uma função determinando um comprimento de onda para cada caminho óptico, na qual não são alocados o mesmo comprimento de onda para caminhos ópticos compartilhando um mesmo enlace. Desde que dois caminhos ópticos compartilhem um enlace, se e somente se os respectivos nós em $V_{C}$ forem adjacentes, isto implica em existência de uma função determinando uma cor para cada nó em $V_{C}$, onde não será determinada a mesma cor para dois nós adjacentes .

Na definição da nomenclatura, a identificação $\mathrm{P}$ representa o conjunto de problemas que podem ser resolvidos deterministicamente por algoritmos de complexidade polinomial. Esta é a classe dos problemas tratáveis. Um problema que não possui algoritmo polinomial, certamente é intratável. Neste caso, as soluções exatas podem 
somente ser encontradas quando o tamanho do problema é pequeno ou com o uso de aproximações ou heurísticas em problemas maiores. A classe NP representa o conjunto de problemas que podem ser resolvidos, não-deterministicamente, por algoritmos de complexidade polinomial. A classe NP-completo representa o conjunto de problemas NP com a propriedade adicional de que a existência de um algoritmo polinomial e determinístico que o resolva torna-o um problema $\mathrm{P}$. 


\section{Apêndice C}

\section{Problema de Alocação de Comprimentos de Onda em Redes com Conversores}

Definição 5 Problema de alocação de comprimentos de onda com conversores (CWAconvertible wavelength assignment problem) [17].

Sejam dados a rede $G(N, L)$, o conjunto de comprimentos de onda, $W$, e o número de conversores em cada nó, $k(i), \forall i \in N$. Seja $S$ o conjunto de requisições de conexão no qual cada conexão possui o conhecimento da rota. É possível encontrar uma solução especificando os canais da rota atendendo as restrições de largura de banda e conversão?

Condição 6 CWA é um problema NP-completo.

Prova. Para demonstrar que o CWA é NP-completo será apresentado quão NPdifícil (NP-hard) é o problema. A prova consiste em demonstrar que a solução para o problema CWA não é mais fácil que para o problema de alocação de comprimento de onda, WA. Segundo o Teorema 1 Apêndice B, o WA é um caso particular de CWA no qual o número de conversores em cada nó é limitado a zero, $k(i)=0, \forall i \in N$. Mas, o WA é NP-completo. Assim, o CWA deve ser NP-completo devido à versão restrita WA ser NP-completo.

Condição 7 O Algoritmo de roteamento é um algoritmo polinomial em tempo.

Prova. Em cada iteração, o cálculo do roteamento deveria ser limitado pela complexidade da transformação do grafo, do roteamento, da conexão e desconexão. Transformação em grafos necessita de $O(|L||W|)$ e $O\left(|L|^{2}|W|^{2}\right.$ ) operações (cada operação pode ser uma multiplicação, adição ou comparação) para gerar os vértices e as arestas, respectivamente, sendo limitado por $O\left(\left.p N\right|^{4}|W|^{2}\right)$. Utilizando o algoritmo de Dijkstra para determinar o roteamento, serão necessárias $O\left(|V|^{2}\right) \equiv O\left(|L|^{2}|W|^{2}\right)$ operações, limitadas por $O\left(|N|^{4}|W|^{2}\right)$. A conexão e desconexão de uma chamada necessitam de $O(|E|)$ para processar os vértices dos canais e os vértices das conversões, limitado 
C. Problema de Alocação de Comprimentos de Onda em Redes com Conversores

por $O\left(|L|^{2}|W|^{2}\right) \equiv O\left(|N|^{4}|W|^{2}\right)$. Assim, o procedimento completo é limitado por $O\left(|N|^{4}|W|^{2}\right)$ operações. Logo, o algoritmo de roteamento é um algoritmo polinomial em tempo. 